\title{
Factors impacting on the adoption and operation of corporate governance reform in Australian state government departments
}

\author{
Paul Ramage \\ BA (SocSci) M.Bus (GovtBusMgt)
}

A thesis submitted in fulfilment of the requirements of the degree of Doctor of Philosophy

Centre for International Corporate Governance Research

Victoria University

2009 


\begin{abstract}
Corporate governance reforms are increasingly common in public sector organisations. Despite the scope of recent and ongoing public sector change, the processes used to adopt and operate public sector corporate governance reform are not clearly documented. In some cases there is evidence of reform failure.
\end{abstract}

This study sought to identify and describe the variables associated with corporate governance change in Australian state government departments, particularly the factors that impact on the adoption and operation of reform. Concepts associated with scientific management (rational/technocratic influences) and organisational culture (political/cultural influences), and their impact on change, were combined to produce a framework that was tested in two phases.

Phase one focused on the collection of qualitative data relating to corporate governance reform in the Victorian Department of Human Services. The second phase involved the collection of quantitative data from chief executives and senior executives in all Australian state government departments. The qualitative data collected in phase one was used to validate the conceptual framework which was then further tested using quantitative methods during phase two.

Phase one and two findings were consistent with the conceptual model. In particular, a factor analysis of phase two results identified the adoption of change being influenced by leadership capability; external improvement drivers; internal improvement drivers; organisational politics; the capacity of an organisation to interpret knowledge; and changes in an 
organisation's operating environment. The operation of reform was influenced by continuity of leadership; actions taken to embed change and build supportive attitudes to change; management of organisational politics; and the capacity of an organisation to understand change.

The immediate implication of this research is the definition of a new model to manage corporate governance change. The rational/scientific and political/cultural factors identified by this project provide an integrated approach that can be drawn upon by change actors. It acknowledges the significance of the rational/scientific and political/cultural factors that come into play during corporate governance reform.

This study has filled a gap relating to how public sector organisations go about making corporate governance changes and provides customised and practical recommendations for future corporate governance reforms in Australian state government departments. These include giving priority to corporate governance reform training (the research found that only around one in two senior officers had been trained in corporate governance reform) and further strengthening organisational leadership (leadership was identified as a critical factor at both the adoption and operation stages of corporate governance reform).

This research provides new insight into understanding corporate governance change in an Australian public sector context and provides a model to more effectively manage future reform. 


\section{DECLARATION}

I, Paul Ramage, declare that the $\mathrm{PhD}$ thesis entitled "factors impacting on the adoption and operation of corporate governance reform in Australian state government departments" is no more than 100,000 words in length including quotes and exclusive of tables, figures, appendices, bibliography, references and footnotes. This thesis contains no material that has been submitted previously, in whole or in part, for the award of any other academic degree or diploma. Except where otherwise indicated, this thesis is my own work.

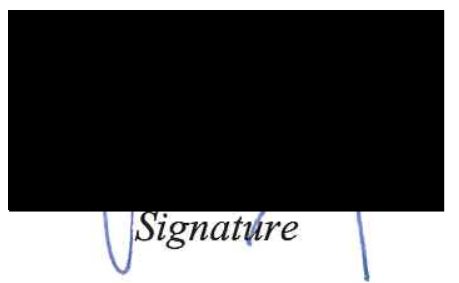

$$
23 / 2 / 09
$$




\section{ACKNOWLEDGEMENTS}

This research took place over four years and in conducting the project, the assistance of a number of people was critical to its successful completion.

I would like to acknowledge and thank Professor Anona Armstrong, my research supervisor, for her guidance, expertise, encouragement and support. I also received valuable contributions from my co-supervisor, Mr Peter Demediuk, at key stages of the project.

I am grateful to my employer, the Department of Human Services, who provided the support and flexibility necessary to conduct this research on a part time, but ongoing, basis.

I also extend my sincere thanks to the former Secretary and senior officers in the Department of Human Services (Victoria), along with the chief executives and senior officers in the other Australian state government departments who participated in the research, and who generously gave their time.

Finally, I would like to thank my wife, Shannon, for her support and understanding over the past four years and my parents, for the encouragement that started me on my academic journey. 
TABLE OF CONTENTS

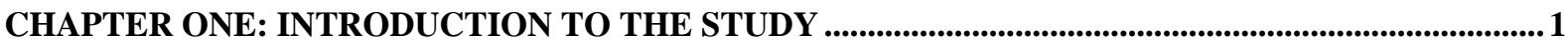

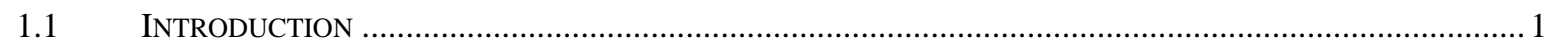

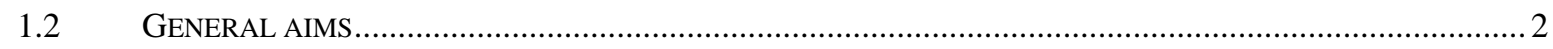

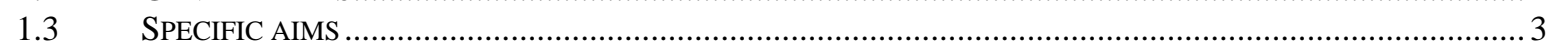

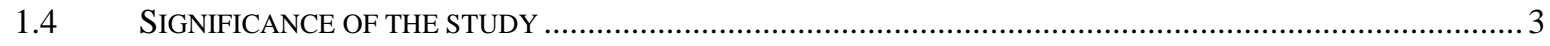

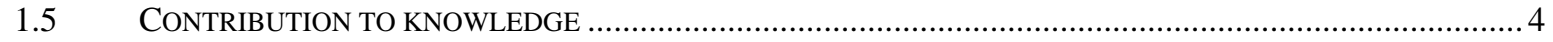

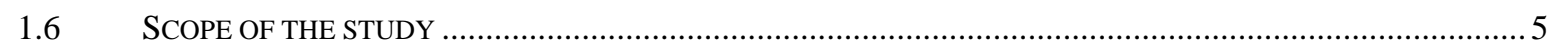

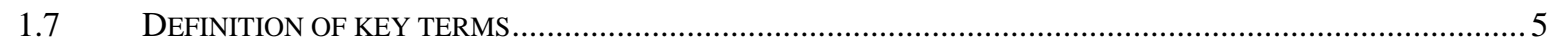

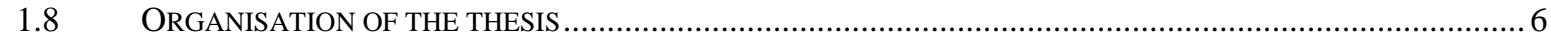

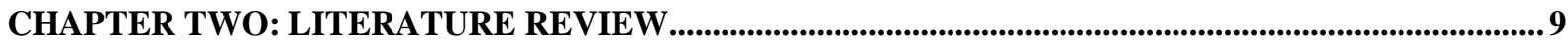

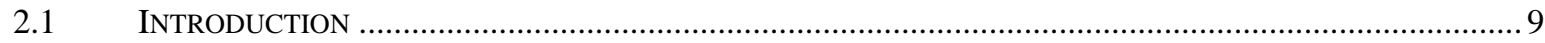

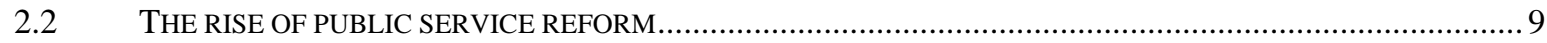

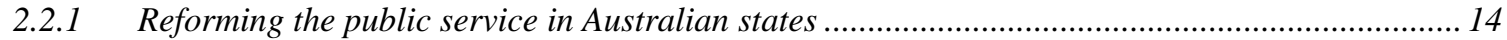

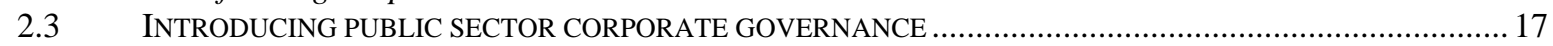

2.3.1 NPM reforms and public sector corporate governance improvement........................................ 17

2.3.2 Other drivers of public sector corporate governance reform ................................................... 19

2.3.3 Defining 'public sector corporate governance'....................................................................2 21

2.3.4 How public service reforms shape corporate governance arrangements.....................................24

2.3.5 What is 'effective corporate governance'? ...........................................................................25

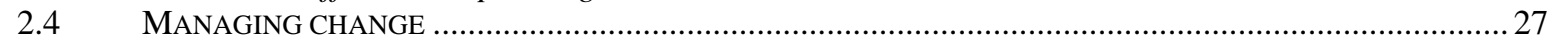

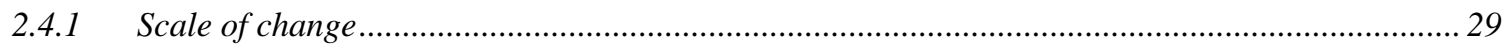

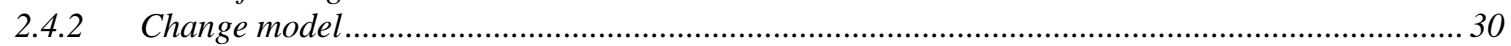

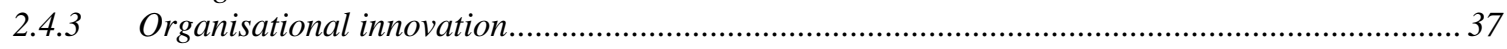

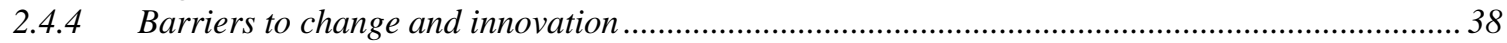

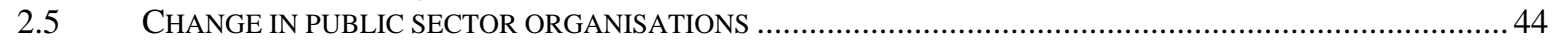

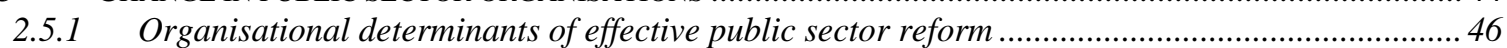

2.5.2 A framework to categorise organisational change factors .......................................................50

CHAPTER THREE: THEORETICAL FRAMEWORK AND RESEARCH QUESTIONS ......................54

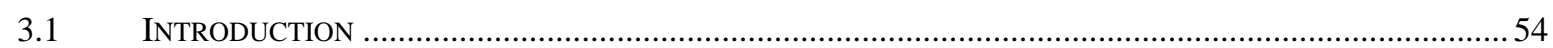

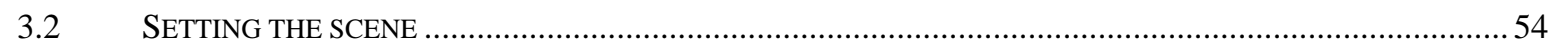

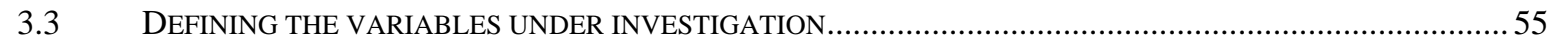

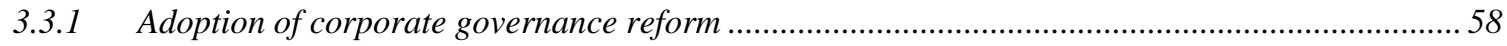

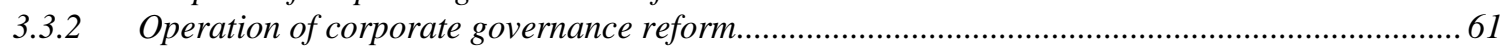

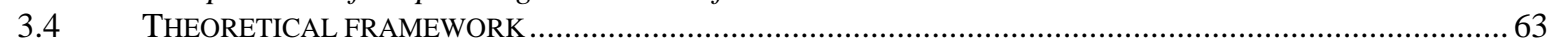

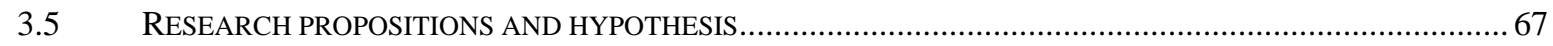

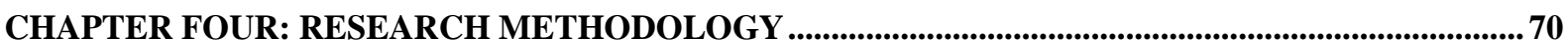

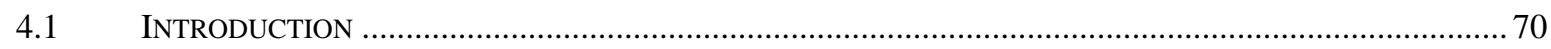

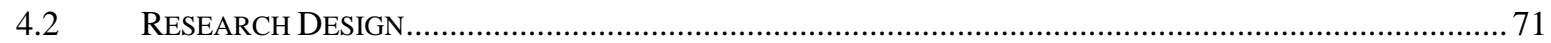

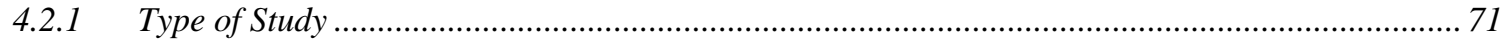

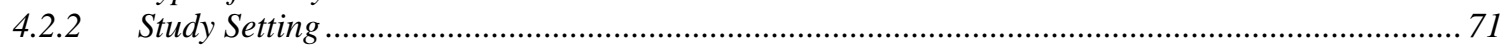

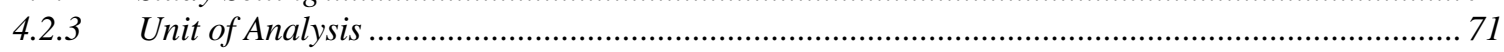

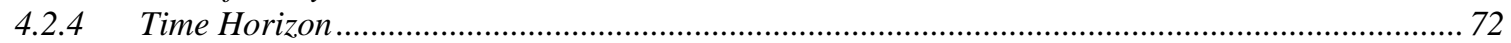

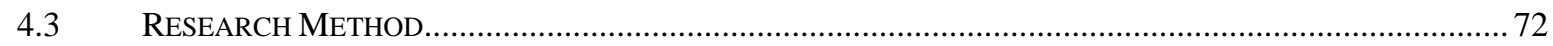

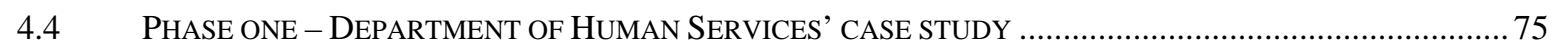

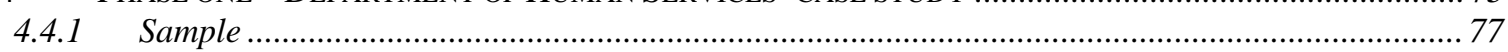

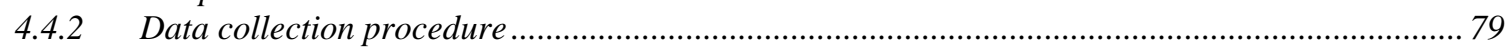

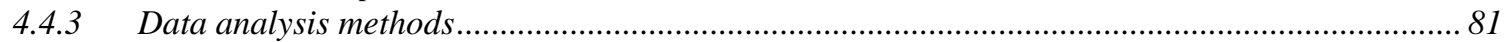

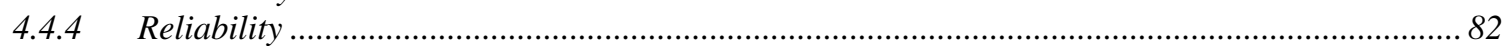

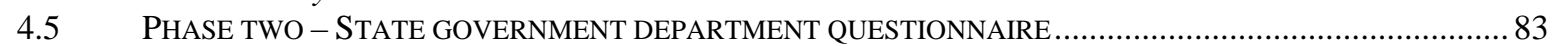

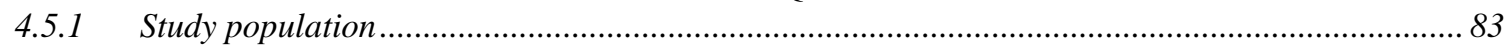

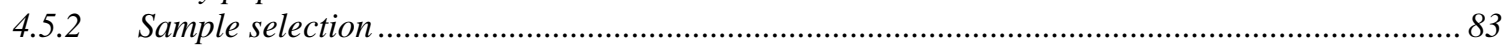

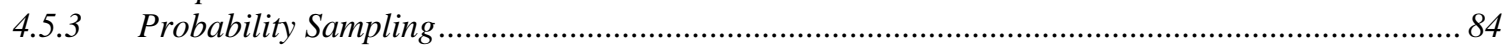

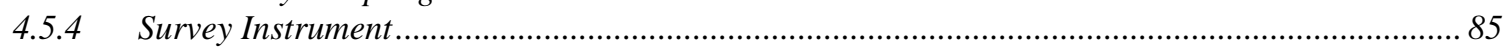

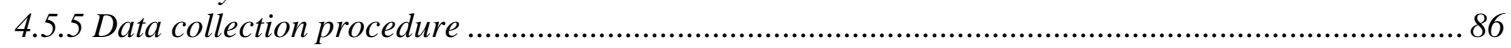




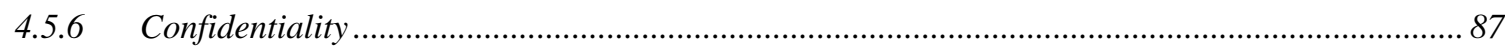

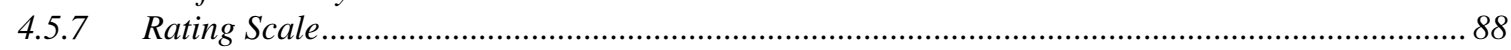

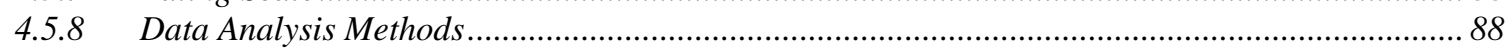

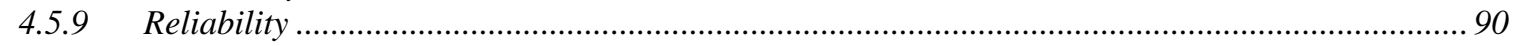

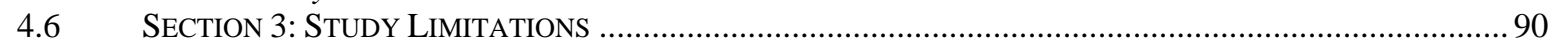

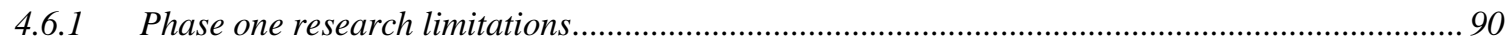

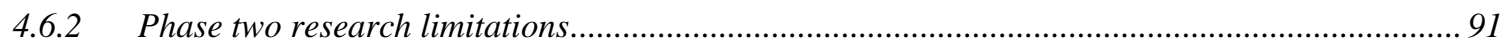

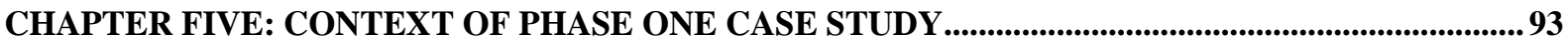

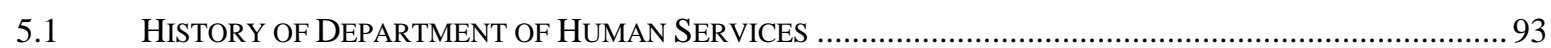

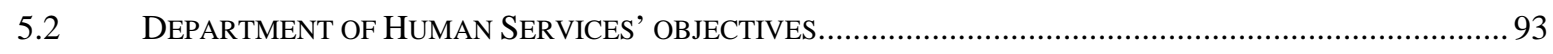

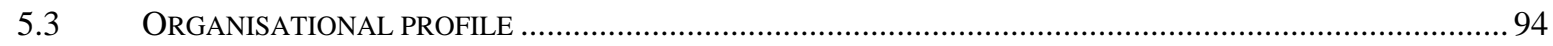

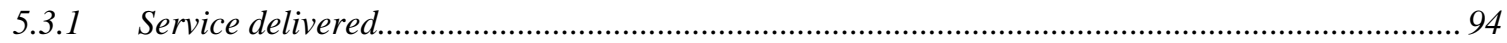

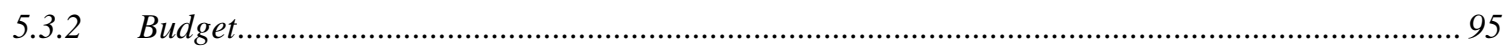

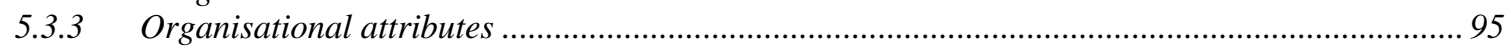

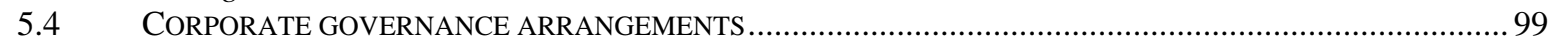

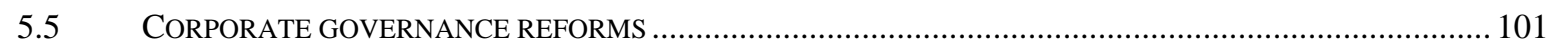

5.5.1 Project-based approach to strategic issue management ........................................................ 101

5.5.2 Creation of geographic-based health divisions ................................................................... 102

5.5.3 A strategic approach to risk management ........................................................................... 102

5.5.4 Establishment of an Office for Children ............................................................................... 103

5.5.5 Amalgamation of Northern and Western Metropolitan regions .............................................. 104

5.5.6 'Joining up' decision making in the Health portfolio .............................................................. 104

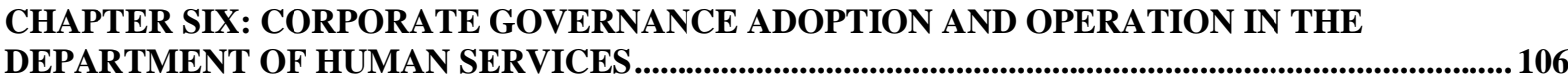

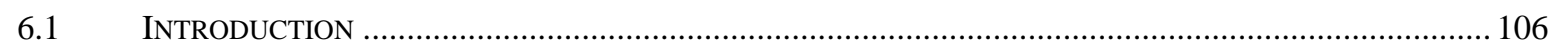

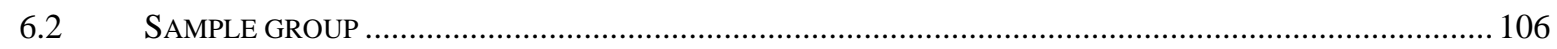

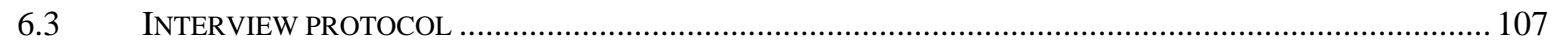

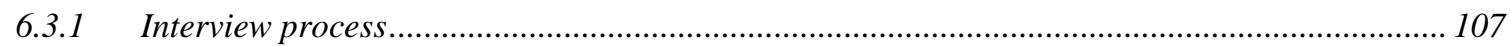

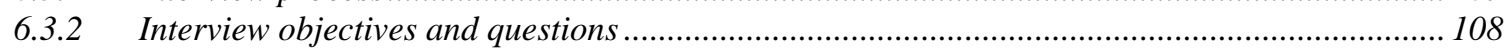

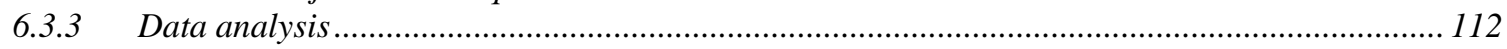

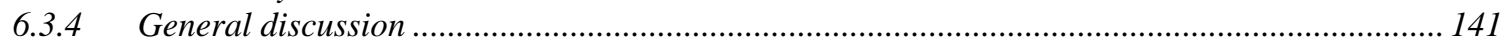

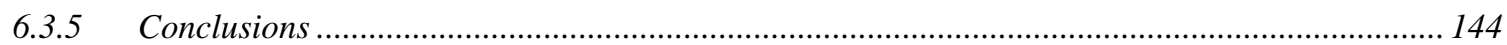

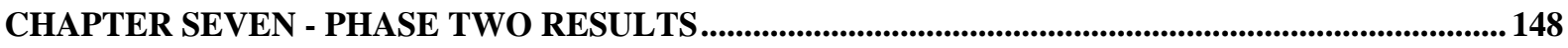

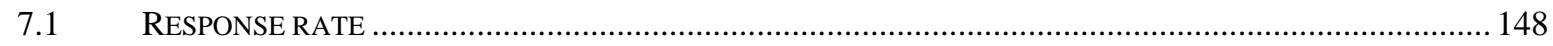

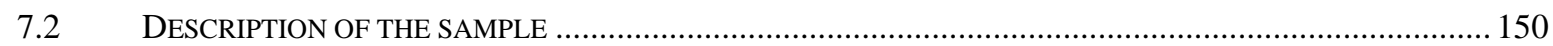

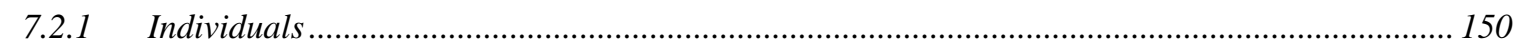

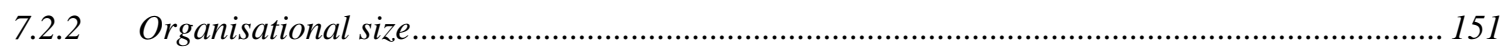

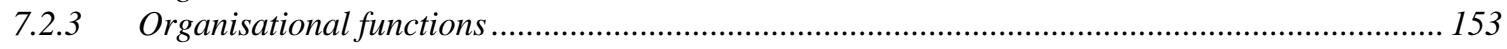

7.3 CHARACTERISTICS OF CORPORATE CORPORATE GOVERNANCE ADOPTION IN DEPARTMENTS ............. 156

7.3.1 Rational/scientific factors impacting on reform adoption ...................................................... 157

7.3.2 Political/cultural factors impacting on reform adoption ....................................................... 161

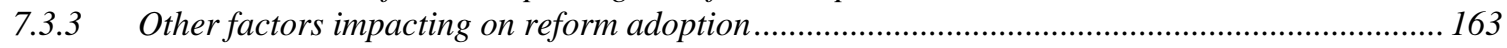

7.3.4 Most important factors impacting on reform adoption........................................................... 164

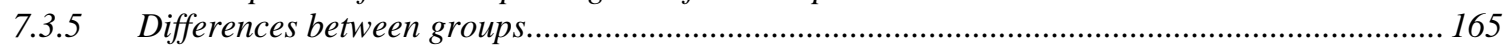

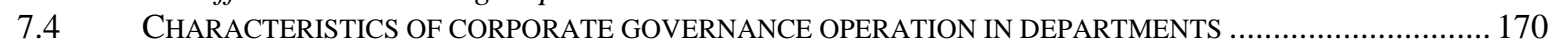

7.4.1 Rational/scientific factors impacting on reform operation ................................................... 171

7.4.2 Political/cultural factors impacting on reform operation...................................................... 175

7.4.3 Other factors impacting on reform operation................................................................... 178

7.4.4 Most important factors impacting on reform operation ....................................................... 179

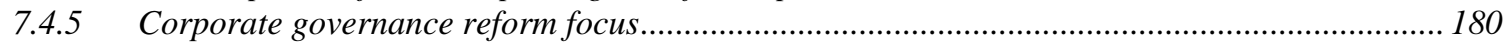

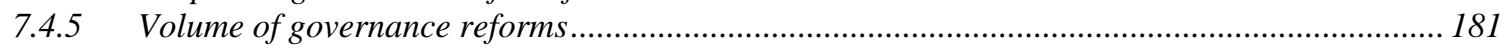

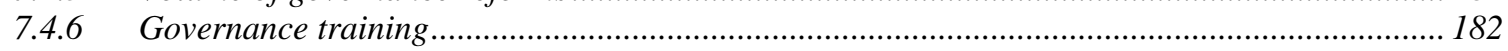

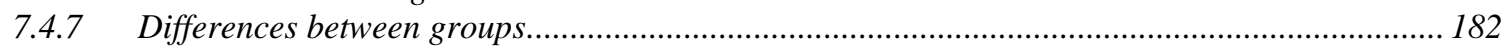

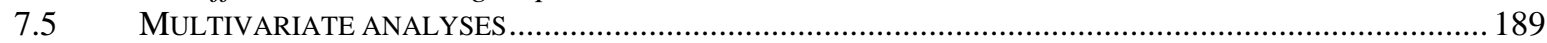

7.5.1 Factor analysis - adoption of corporate governance reform ................................................... 190

7.5.2 Factor analysis - operation of corporate governance reform................................................... 195

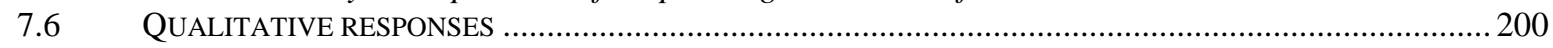

7.6.1 Open-ended question one: adoption of corporate governance reform ......................................200

7.6.2 Open-ended question two: operation of corporate governance reform......................................... 205

7.6.3 Open-ended question three: future corporate governance reforms........................................... 208 


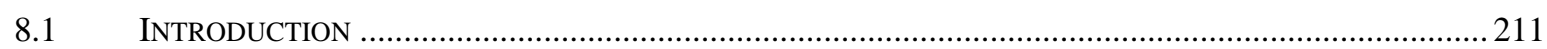

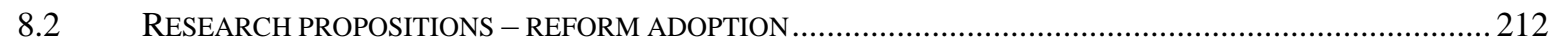

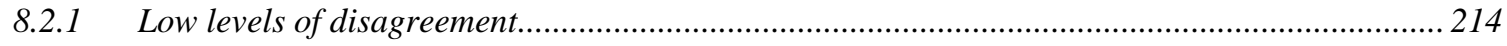

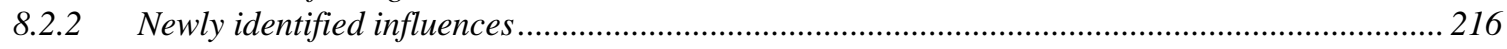

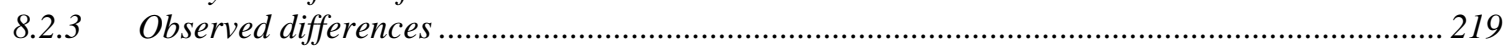

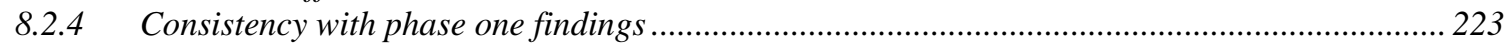

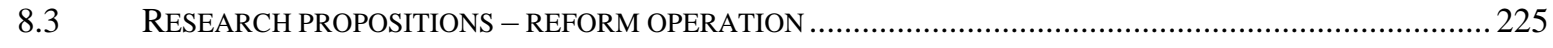

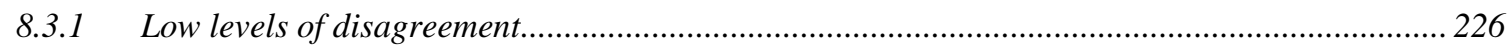

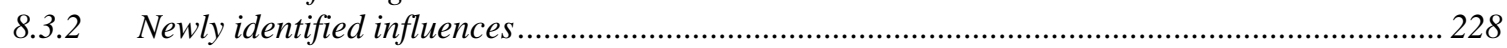

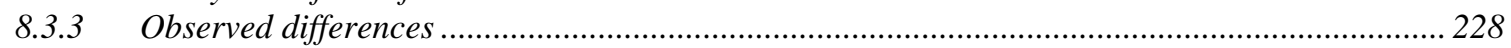

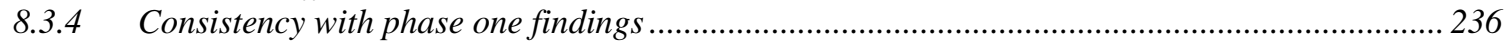

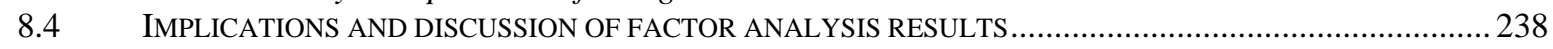

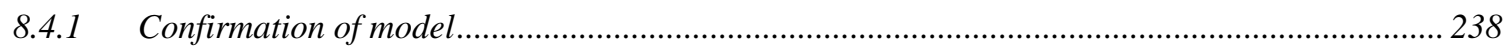

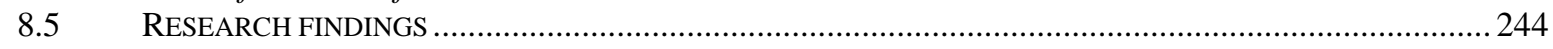

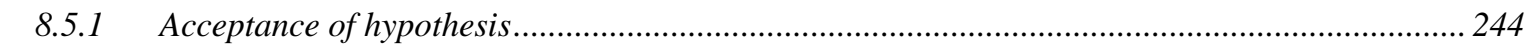

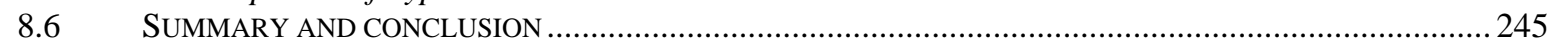

CHAPTER NINE - CONCLUSIONS, RECOMMENDATIONS AND IMPLICATIONS .......................2246

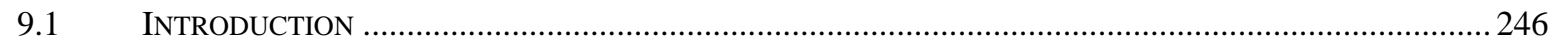

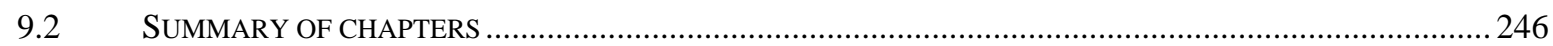

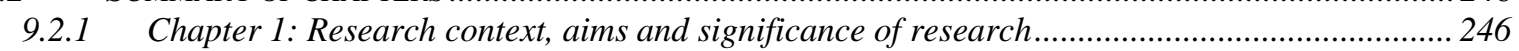

9.2.2 Chapter 2: literature review .............................................................................................. 247

9.2.3 Chapter 3: Theoretical framework and research questions .................................................. 249

9.2.4 Chapter 4: Research methodology ....................................................................................... 250

9.2.5 Chapter 5: Context of phase one case study (Department of Human Services cases study) ....... 252

9.2.6 Chapter 6: Phase one results and discussion (Department of Human Services).......................... 253

9.2.7 Chapter 7: Phase two results (government department survey)............................................. 254

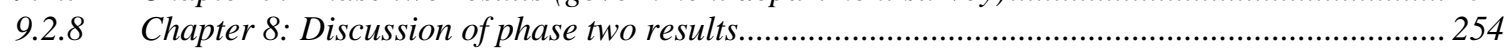

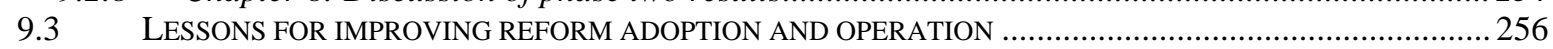

9.3.1 Improving the success of reform adoption............................................................................. 256

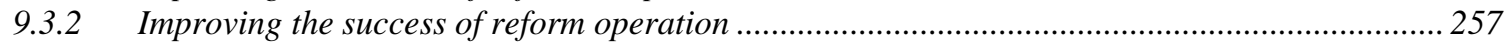

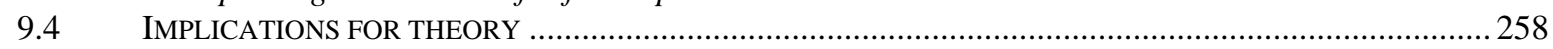

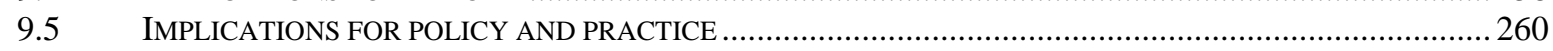

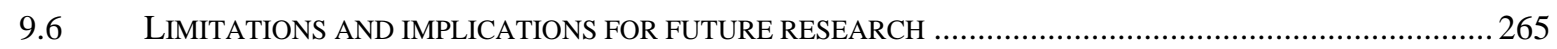

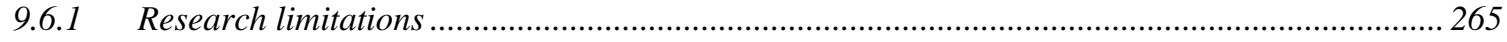

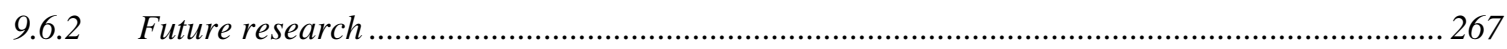

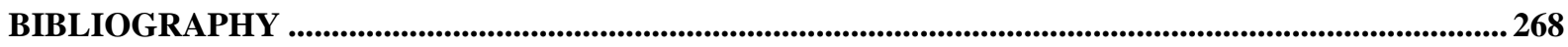

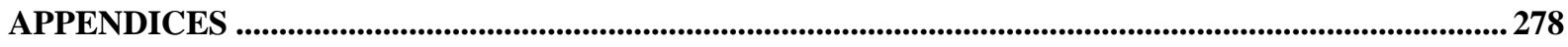

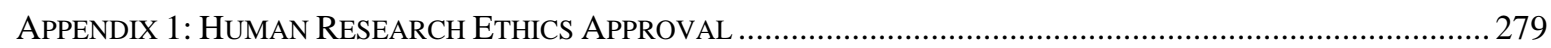

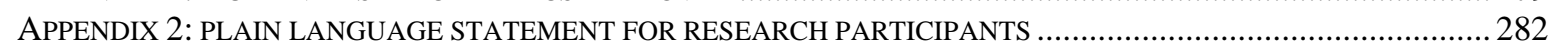

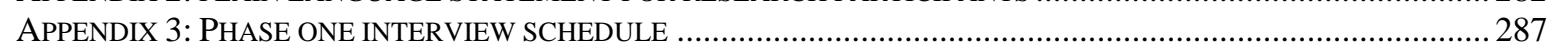

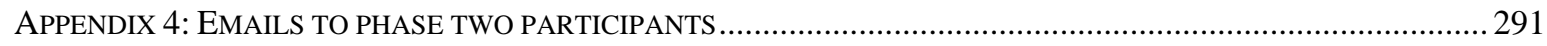

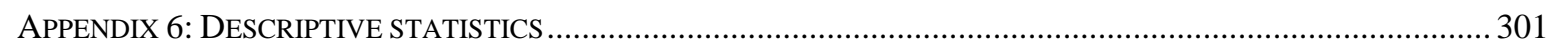




\section{LIST OF TABLES}

TABLE 1: PUBLIC BUREAUCRACY CORPORATE GOVERNANCE TYPES …......................................................... 18

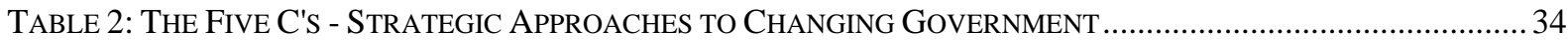

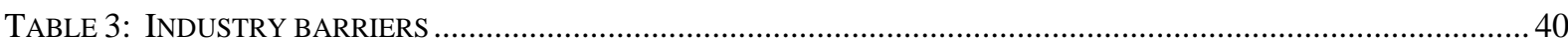

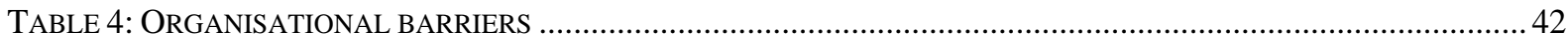

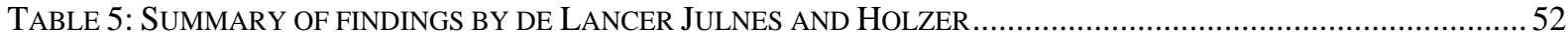

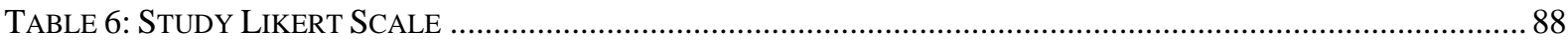

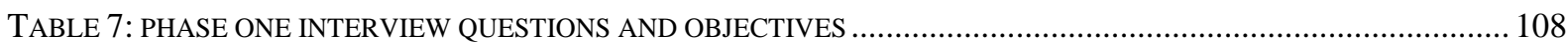

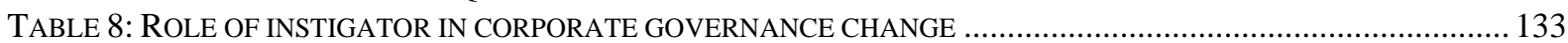

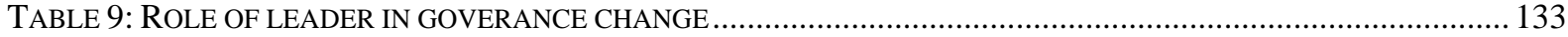

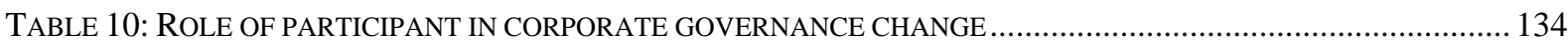

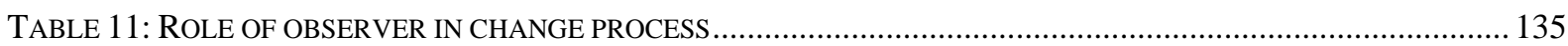

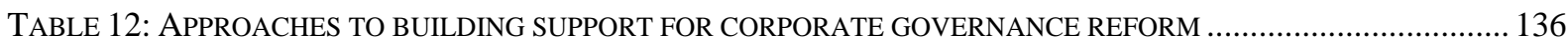

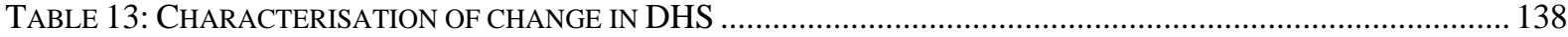

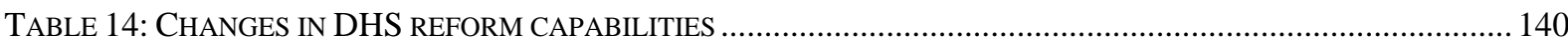

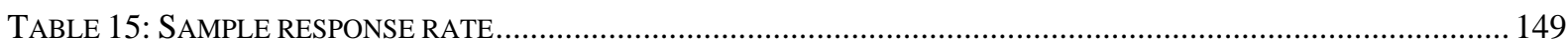

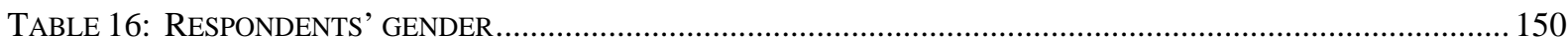

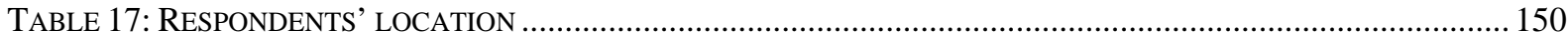

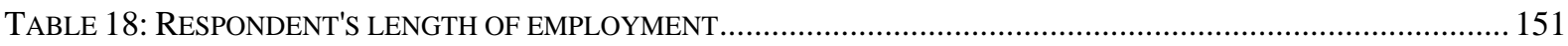

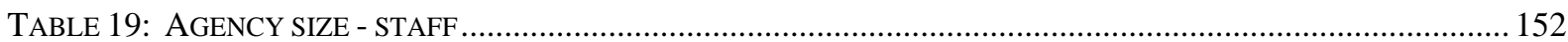

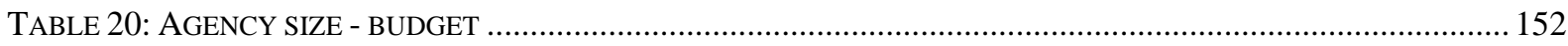

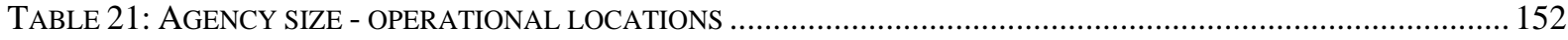

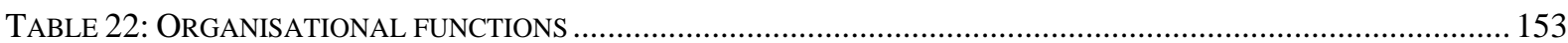

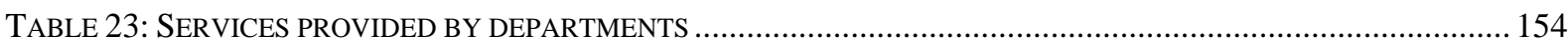

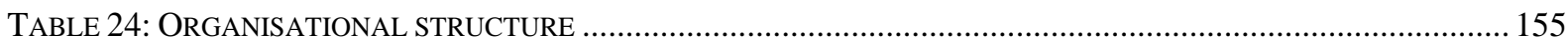

TABLE 25: FREQUENCY DISTRIBUTIONS OF RESPONSES TO RATIONAL/SCIENTIFIC FACTORS IMPACTING ON REFORM

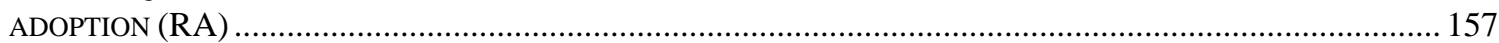

TABLE 26: FREQUENCY DISTRIBUTION OF RESPONSES TO POLITICAL/CULTURAL FACTORS IMPACTING ON REFORM ADOPTION (PA).

TABLE 27: CORPORATE GOVERNANCE ADOPTION INFLUENCES - LIKERT SCORE (AVERAGE) ............................... 165

TABLE 28: FREQUENCY DISTRIBUTION OF RESPONSES TO RATIONAL/SCIENTIFIC FACTORS IMPACTING ON REFORM OPERATION (RO)

TABLE 29: FREQUENCY DISTRIBUTION OF RESPONSES TO POLITICAL/CULTURAL FACTORS IMPACTING ON REFORM OPERATION

TABLE 30: CORPORATE GOVERNANCE OPERATION INFLUENCES - LIKERT SCORES (AVERAGE) ...........................180

TABLE 31: GOVERNANCE REFORMS UNDERTAKEN DURING EMPLOYMENT OF RESPONDENT................................ 181

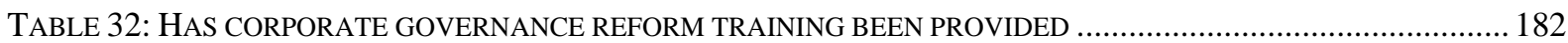

TABLE 33: KMO AND BARTLETT'S TEST - CORPORATE GOVERNANCE ADOPTION........................................... 190

TABLE 34: TOTAL VARIANCE EXPLAINED - CORPORATE GOVERNANCE ADOPTION ............................................. 191

TABLE 35: FACTOR PATTERN MATRIX - CORPORATE GOVERNANCE ADOPTION................................................... 192

TABLE 36: RELIABILITY STATISTICS - CORPORATE GOVERNANCE REFORM ADOPTION........................................ 194

TABLE 37: KMO AND BARTLETT'S TEST: CORPORATE GOVERNANCE OPERATION ............................................ 195

TABLE 38: TOTAL VARIANCE EXPLAINED - CORPORATE GOVERNANCE REFORM OPERATION................................196

TABLE 39: FACTOR PATTERN MATRIX - CORPORATE GOVERNANCE REFORM OPERATION .....................................197

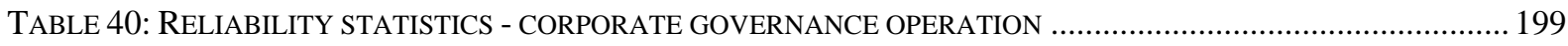

TABLE 41: SUMMARY OF RESEARCH PROPOSITIONS AND RESULTS - REFORM ADOPTION ................................213

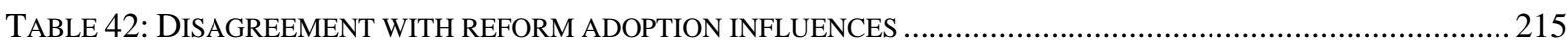

TABLE 43: IMPLICATIONS OF REFORM ADOPTION OBSERVED DIFFERENCES RELATING TO SUCCESSFUL ADOPTION OF REFORM

TABLE 44: IMPLICATIONS OF REFORM ADOPTION OBSERVED DIFFERENCES RELATING TO ORGANISATIONAL

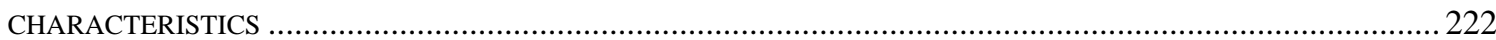

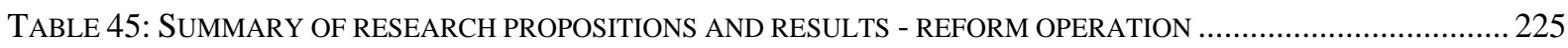

TABLE 46: DISAGREEMENT WITH REFORM OPERATION INFLUENCES .............................................................222

TABLE 47: IMPLICATIONS OF OBSERVED DIFFERENCES RELATING TO REFORM SUCCESS AND REFORM OPERATION

TABLE 48: IMPLICATIONS OF OBSERVED DIFFERENCES RELATING TO ORGANISATIONAL CHARACTERISTICS AND REFORM OPERATION

TABLE 49: IMPLICATIONS OF OBSERVED DIFFERENCES RELATING TO OTHER CHARACTERISTICS AND REFORM OPERATION

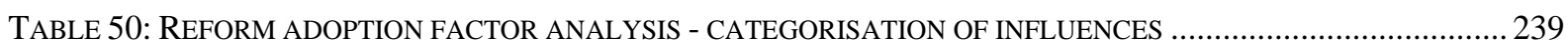

TABLE 51: REFORM OPERATION FACTOR ANALYSIS - CATEGORISATION OF INFLUENCES.....................................239 


\section{LIST OF FIGURES}

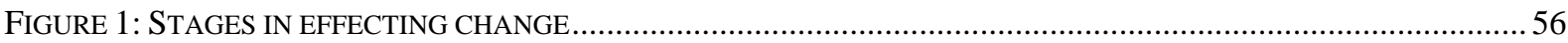

FIGURE 2: RATIONAL/SCIENTIFIC AND POLITICAL/CULTURAL INFLUENCE MATRIX ................................................64

FIGURE 3: RELATIONSHIP BETWEEN RATIONAL/TECHNOCRATIC AND POLITICAL/CULTURAL FACTORS ....................66

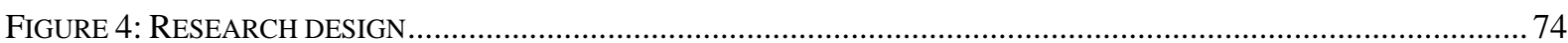

FigURE 5: DEPARTMENT OF HUMAN SERVICES ORGANISATIONAL STRUCTURE (APRIL 2008)..............................97

FIGURE 6: DEPARTMENT OF HUMAN SERVICES CORPORATE GOVERNANCE ARRANGEMENTS.................................. 99

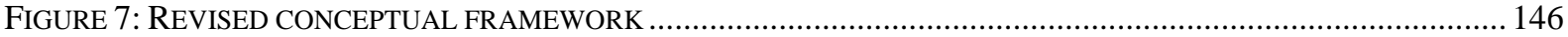

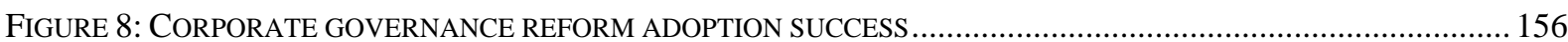

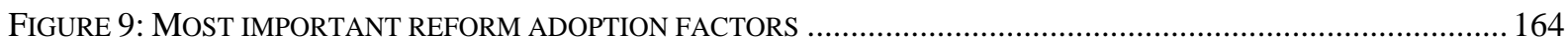

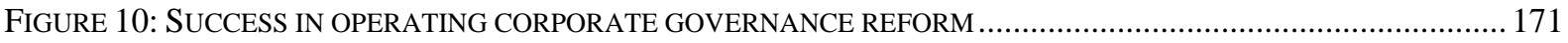

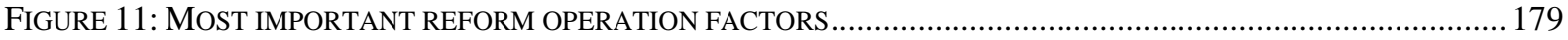

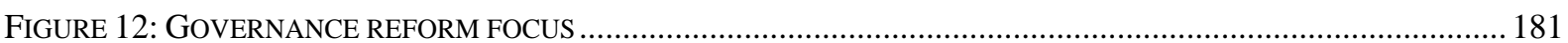

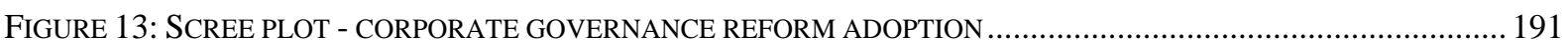

FIGURE 14: SCREE PLOT - CORPORATE GOVERNANCE REFORM OPERATION ......................................................... 195

FIGURE 15: A NEW MODEL TO MANAGE THE ADOPTION OF CORPORATE GOVERNANCE REFORM ............................2262

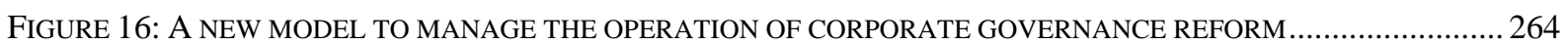




\section{Chapter one: Introduction to the study}

\subsection{Introduction}

The public service in Australia, like those in most other OECD countries, is very different in size, structure and operating processes from what it was in the 1970s (Prasser, 2004). While there is considerable debate about the outcome of this reform, the concept of 'New Public Management' (NPM) has been identified as the common driver of these changes (Armstrong, 1998; Barrett, 2003; Mark Considine \& Lewis, 1999; Dent, Chandler, \& Barry, 2004; Halligan, 2002; Hoggett, 1996; Pollitt, 2003).

The literature describes a cluster of ideas and practices (including managerialism and marketisation) that comprise NPM. It is a 'slippery label' (Manning, 2000) that describes a management culture with a primary focus on accountability (Kloot, 1999) that, at its, core seeks to use private-sector and business approaches in the public sector (Denhardt \& Denhardt, 2000).

As these approaches have increasingly penetrated the public service, governments have progressively sought to ground public management, organisational structures and culture within the corporate governance framework of the private sector (Halligan, 2002). While the strength of any causal relationship between NPM and efforts to develop public sector corporate governance is contested, it is clear that over the last decade Australian government agencies have put in place many corporate governance reforms (Barrett, 2003). Contemporary research has focused on the form taken by these changes (Mark Considine \& Lewis, 1999). 
Little attention has, however, been given to the way these structural changes have been implemented and the literature has not considered in any detail how the reforms impact on the role of 'ordinary officials' (Considine 1999). There is also a dearth of documented case studies of corporate governance improvements in the public sector (Edwards, 2002), with little information available about the evaluation of public sector reforms (Mir \& Rahaman, 2006) . Consequently, little is known about how these reforms, once implemented, impact on organisational control structures and decisionmaking processes. Implementation and ongoing management deficiencies are however, beginning to become apparent: 'too often elements are not linked......the different elements need to be coordinated in order to achieve better performance' (Barrett 2003 p11).

An improved understanding of issues affecting implementation and operation of corporate governance changes is required to inform and guide future public sector corporate governance reform.

\subsection{General aims}

It is proposed to document the factors impacting on the adoption and operation of corporate governance reform in Australian state government departments.

These factors will be analysed to determine internal and external influences and then categorised according to their characteristics. It is intended that this categorisation will contribute to the development of a model to guide future public sector corporate governance reform. 


\subsection{Specific aims}

The study intends to identify and describe variables associated with corporate governance reform in Australian state government departments, particularly the factors that impact on the adoption and operation of reform. Its specific aims are to:

- determine how the Victorian Department of Human Services adopts and operates corporate governance reform;

- identify why particular arrangements and processes are used to adopt and operate corporate governance reform, including the identification of internal and external influences;

- explore the nature of internal and external influences and the impact these have on reform;

- categorise influencing factors according to their characteristics;

- demonstrate the applicability of this categorisation to public sector corporate governance reform in other Australian state government departments; and

- develop a model for implementation of public sector corporate governance reform.

\subsection{Significance of the study}

Although there is an extensive literature on public sector corporate governance reform and similarly change management practice, no study has fully investigated the relationship between corporate governance reform and determinants of effective change. In particular, there is no consistent analytical framework applicable to the factors impacting on the success or otherwise of public sector corporate governance reform. 
Government agencies do not have access to private sector measures that readily assess the effectiveness of corporate governance reform, such as Share Value Added (Frumkin, 2003). Nor is determining the effectiveness of management changes straightforward or simple (Pollitt, 2003).

In addition, despite the scope of recent and ongoing public sector change, the processes used to implement and operate public sector corporate governance reform are not clearly documented. In some cases there is evidence of corporate governance reform failure. Poor coordination of corporate governance initiatives, inadequate definition of roles and responsibilities, insufficient transparency in decision making and the potential for conflict of interests are examples of common implementation issues facing public sector managers.

\subsection{Contribution to knowledge}

This project extends the knowledge of corporate governance reform in the Australian public sector by exploring the range of factors impacting on the adoption and operation of corporate governance change. In particular, the project groups identified issues as rational/scientific adoption factors, rational/scientific operation factors, political/cultural adoption factors and political/cultural operation factors.

The study contributes to knowledge because:

- it is the first study to explore factors impacting on corporate governance reform in Australian state government departments

- it is also the first study that seeks to categorise these factors and analyse them according to their characteristics 


\subsection{Scope of the study}

This study is focused on corporate governance reform in Australian state government departments. It seeks to examine the factors influencing the process of reform in these organisations. It is not intended to review or analyse the components or nature of the reforms undertaken.

\subsection{Definition of key terms}

\section{Term}

Adoption (of reform)

Chief Executive Officers

Corporate governance

Interest group

Leadership

New Public Management

\section{Definition}

To formally take up

Persons appointed by Government to be responsible for managing a public sector department; they are accountable officers for achieving organisational outcomes

The structures and processes for decision-making, accountability, control and behaviour at the top of organisations (Standards Australia 2004)

An organised collection of people who seek to influence decision-making

A set of behaviors by individuals in the context of the group or organization to which they belong consisting of actions such as setting group goals, moving the group toward its goals, improving the quality of interactions among the members, building cohesiveness of the group, and making resources available to the group (Conger, 2005)

A group of principles aimed at changing the public sector in three areas: (1) from hierarchical to economically based structures, (2) from regulative to economically based structures and (3) from legally 


\section{Term}

Operation (of reform)

Organisational Culture

Political/cultural influences

Rational/scientific influences

Reform

State government department

\section{Definition}

based to economically based values (Maor, 1999)

Performance of a practical work or of something involving the practical application of principles or processes

"The pattern of basis assumptions that a given group invented, discovered or developed in learning to cope with its problems of external adaption and internal integration, and that have worked well enough to be considered valid, and therefore, to be taught to new members as the correct way to perceive, think and feel in relation to these problems” (Schien, 1984) Actions based on the management of organisational culture, interest groups and attitudes to things such as innovation

Actions based on technically-based management approaches (Hammond, 1996)

To put or change into an improved form or condition A structure of executive government that is established under relevant public sector management legislation and reflects the portfolio responsibilities of Ministers

\subsection{Organisation of the thesis}

This thesis is organised into nine chapters, which are briefly described below.

Chapter two reviews the literature on public sector reform, with particular reference to changes associated with corporate governance improvement. It also provides information about the nature of change and innovation in public sector organisations, including impediments to successful reform. 
Chapter three establishes the conceptual framework for the study which is based around notions of rational/scientific and political/cultural influences.

Chapter four sets out the research design and methodology for the project. It discusses the overall research approach, data collection methods, formulation of questionnaires and procedures for data analysis. It proposes the collection of data in two phases. The first phase is focused on the collection of qualitative data in the Victorian Department of Human Services. The second phase involves the collection of quantitative data from chief executive officers and senior executive officers in all Australian state government departments. This research is primarily a quantitative study with substantial qualitative inputs. Frequency tests and cross tabulations are proposed using SPSS to determine the significance of certain variables over others. A factor analysis is also put forward as the appropriate statistical test to ascertain correlations between variables.

Chapter five outlines the context of the phase one research. It provides information about the history of the Department of Human Services, organisational profile, existing corporate governance arrangements and a brief background of major corporate governance reforms undertaken in that organisation.

Chapter six presents the results and analysis of the phase one research (Department of Human Services case study). It includes modifications to the conceptual framework identified as a result of phase one findings.

Chapter seven presents the results of phase two investigations (state government department survey). It provides information about the characteristics of the sample, 
characteristics of the adoption of reform in departments and characteristics of the operation of reform in departments.

Chapter eight discusses the results gathered from phase two investigations and compares these to phase one results. This chapter also presents findings as they relate to the conceptual framework including findings in response to the research propositions and research hypothesis.

Chapter nine presents the conclusions and recommendations. It also highlights the implications of the study for future research and for practitioners. The limitations of the study are also outlined in this chapter. 


\section{Chapter two: Literature review}

\subsection{Introduction}

This chapter sets the theoretical context within which the study was undertaken. There are three sections to this chapter. The first deals with public sector reforms, the second relates to the emergence of public sector corporate governance, including a discussion of the concept of effective corporate governance and the third outlines the management of change and innovation in public sector organisations.

\subsection{The rise of public service reform}

Public sectors around the world have become more like the private, with the language and management approaches the same in many respects (Halligan, 2002). Fiscal crises in most OECD countries during the 1980s triggered many public sector reforms (Bovaird \& Loffler, 2003) and Governments embraced reform as they sought to do things better and with fewer resources (Armstrong 1998).

The concept of NPM has been identified as the core of these reform efforts (Di Francesco, 2001). Much of what constitutes NPM is borrowed from private sector managerial approaches, themselves rooted in a long tradition founded on Scientific Management and Human Relations approaches (Dent et al., 2004).

Commentators have identified a range of features that characterise NPM. Common features include greater disaggregation of public sector organisations into separately managed units; adoption of measurable standards of performance; enhanced competition through the introduction of market and quasi-market functions; use of 
private sector managerial techniques; greater hands on management through the decentralisation of management authority; stress on greater discipline in resource use (often in the form of cost cutting) (Hood, 1991; Pollitt, 2003). The use of pre-set output measures to give greater emphasis to output rather than input controls (Dent et al., 2004), and greater emphasis on quality (Pollitt 2003) have also been put forward.

According to Osborne and Gaebler (Osborne \& Gaebler, 1992) NPM, as applied in the United States, can be seen as a revolutionary restructuring - an "American Perestroika". Like the Soviet version, they contend that this restructuring was driven largely by governments who, under great fiscal pressure, introduced market forces into monopolistic government enterprises. They identified 10 principles that distinguish this new '"entrepreneurial" form of government. These included separating policy development from service delivery, focusing on outcomes rather than inputs, treating clients as customers, decentralising authority by removing hierarchy and minimising bureaucracy by focusing on market mechanisms. Collectively these principles represented a major shift away from traditional public management approaches.

Amongst these various definitions of NPM characteristics and principles, a distinction has historically been drawn between the management and market dimensions of NPM (Schick, 1996) for example the introduction of private sector management techniques is a management reform while the creation of enhanced competition through the introduction of market and quasi market function operates as a market reform. Australia concentrated on management reforms during the 1980s but increasing accepted and introduced market-oriented reform in the 1990s (Halligan, 2002). 
Management reforms are drawn from the management literature while market reforms are based on economic theory (Halligan, 2002). Behind these two categories lie differing theories of how individuals and organisations behave, these theories not always sitting together comfortably (Pollitt, 2003). Market reforms involve a view of individuals as essentially selfish utility maximisers resulting in a low trust vision of organisations where controls must be tightly maintained to prevent individuals feathering their own nests (Pollitt 2003). This compares to the more optimistic model put forward by management theory which presumes individuals can be bound to organisational objectives by good leadership and a supportive organisational culture (Pollitt 2003).

In contrast to those commentators who see NPM as an integrated package of reform comprised of clearly defined market and management elements, others argue that NPM is, in practice, not a unified set of practices but rather a theme which has clear distinctions across sectors (Dent et al., 2004). Others go further and suggest that 'real reform' which seeks to make major changes to overcome public service inadequacies is rarer than some suggest (Prasser, 2004).

In order to better understand NPM it is suggested that we need to know what it is opposed to (Pollitt 2003). That is to say, NPM is a programme of reform and consequently it begins with a dissatisfaction with the status quo. A dissatisfaction that has meant changes to the underlying political, executive and operational spheres of government (Armstrong 1998). Most literature identifies the status quo prior to NPM as 'bureaucracy’. Bureaucracy is pictured as a dinosaur; too big, slow moving, insensitive, insufficiently adaptable with its large size demanding a huge and continuous supply of resources (Pollitt 2003). 
Considine tracks changes to the public bureaucracy status quo, including the decline of NPM, through a model that describes four images of bureaucracy (Considine 1999). It is argued that each describes a specific stage in public sector reform:

1. Procedural bureaucracy - use of a recognised system of universal rules to coordinate activities. These rules are supported by professional training and by specific experience with each local system of protocols and accepted practices. By the end of the 1970s many governments found these systems inadequate and unable to meet demands for faster service delivery and greater case-sensitive action.

2. Corporate bureaucracy - a planned synthesis of government objectives and resource allocation. Attempts were made to control all public administration through the use of strategic planning activity such as Management by Objectives (MBO) and zero-base budgeting. It became apparent however, that corporate bureaucracy required strong operational links between shifting political priorities, decision making and resource allocation. Most organisations did not develop these links.

3. Market bureaucracy - structured the internal elements of public organisations into actual or quasi markets and real or hypothetical tests of consumer demand. These elements of competition sought to reduce the cost of public administration by allowing markets to determine the most effective means to a defined end. Weaker levels of accountability characterised this model.

4. Network bureaucracy - developed in response to a view that market bureaucracies did not mobilise support, share information, invest in developing organisational capacities or focus on the individual needs of suppliers and 
clients. The network bureaucracy is characterised by high levels of collaboration between officials and other stakeholders and non-hierarchical systems of control and coordination.

Put more simply, the pre-reform public sector can be likened to one built upon vertically integrated organisational forms in which the vast majority of functions were performed in house (Hoggett, 1996). Reforms have sought to out-place many of these functions and to distance government from the process of service provision (Hoggett 1996). As a consequence, Hoggett argues, quite radical forms of horizontal integrated production have emerged. In particular, central controls (from agencies such as Premier and Cabinet and Treasury) are increasingly stronger rather than weaker. Other examples include centralisation in the sense of national regulation overtaking individual State jurisdictions. This results in a phenomenon of simultaneous centralisation and decentralisation (Hoggett 1996). This apparent contradiction is regarded by many as a distinctive element of the pubic sector post-bureaucratic reform (Hoggett 1996).

It is useful to observe at this point that public sector restructuring has not been a smooth movement from bureaucratic to post bureaucratic forms of control and many commentators note that there has not been a single coordinated move to some presumed post bureaucratic end point (Hoggett, 1996). For example, while NPM is now seen as having run its course in most developed countries (Dunleavy, Margetts, Bastow, \& Tinkler, 2005), some NPM practices are extensively institutionalised and NPM is itself gaining influence in countries such as Japan and India (Laking \& Norman, 2007).

The recent emergence of network bureaucracy, also sometimes described as digitial-era governance, is partly a reaction against the weaknesses of NPM (particularly in terms of 
service coordination), but also a reflection of opportunities offered by new technology to support more ‘agile’ government (Dunleavy et al., 2005). Indeed, public sector development is frequently subsumed under a range of other policy agendas such as economic management, industrial relations and national security (Prasser, 2004).

\subsubsection{Reforming the public service in Australian states}

The election of the Kennett government in Victoria in October 1992 resulted in a sweeping public sector reform program. This consisted of a major restructuring of government expenditure, as well as the introduction of a broad based strategy for increasing productivity levels. In essence this program was comprised of initiatives focused on 'downsizing', extensive privatisation, contracting out and increasing state taxes and charges (Teicher \& Van Gramberg, 1998). The principles underlying many of these reforms were (Armstrong, 1998)

- Clear accountability for results

- Empowering consumers of public services

- Minimising government bureaucracy

- Preference for market mechanisms in the provision of market services

- Professional and business like management of public agencies

Drawing heavily on the concept of entrepreneurialism as espoused by Osborne and Gaebler, the Victorian reforms were aimed at privatising state owned assets and transferring the operation of many services to the private sector. This included the replacement of traditional government employment with a private sector model (Teicher and van Gramberg 1998). The Victorian government reduced the number of 
government departments to eight and the state public sector by 61,000 people within four years (Armstrong, 1998). A similar reduction in the number of government departments and agencies occurred in South Australia during 1997 (Halligan 2001).

Supporting many of the changes introduced by Victoria, was the National Competition Policy (National Competition Council, 1998). Designed as a strategy to create a competitive market between the public and private sectors in the provision of goods and services to the public (Halligan, 2002), NCP was adopted by the heads of Australia's federal, state and territory governments in 1994. This policy placed new requirements on states and territories to converge (Halligan 2001).

Embracing the principles set out in the 1993 Himler Report ((National Competition Council, 1998) on competition, the purpose of the NCP was to 'accelerate and broaden progress on microeconomic reform to support higher rates of economic and employment growth’ (National Competition Council, 1998). The subsequent Competition Policy Reform Act (Cwlth) 1995, and supporting legislation in each state, required all public sector business activities to operate according to competitive practices and rules that apply in the public sector.

NCP focused on five broad areas, several with significant implications for public sector management:

1. infrastructure monopolies

2. public monopolies

3. monopolistic conduct

4. legislated restrictions on competition 


\section{5. competitive neutrality}

The broad focus of the NCP reforms was to free up domestic markets for goods and services from barriers to competition, and in particular remove complicated and duplicated procedures and administrative processes.

The NCP included provision for federal payments to states linked to their progress in implementing reforms. This led to the reform of government enterprises through the separation of regulatory and commercial activities and the separation of natural monopolies from activities that could be made competitive (James, 2005). NCP continued the drive to make public organisations more like private sector firms.

Public sector changes that resulted form NCP included (Clark \& Corbett, 1999):

- a shift in the ethos and culture of the public services with agencies being driven by imperatives and incentives similar to the private sector

- major structural changes including the break up of integrated public utilities into separate competing businesses

- greater emphasis on contract management and a separation of core business and community service obligations

- liberalisation of employment practices including greater flexibility of employment conditions focused on contractualisation

Reforms in Australian states have also been characterised by an emphasis on outcomes, rather that inputs (McCann, 2001). This has involved building a 'performance culture' with subsequent changes to accountability (News Ltd 2007), removal of central controls 
over finance, improved performance information and the use of this information to develop and operate performance based pay systems (McCann 2001).

\subsection{Introducing public sector corporate governance}

\subsubsection{NPM reforms and public sector corporate governance improvement}

The replacement of the traditional bureaucratic status quo has required extensive changes to the way public sectors are organised and controlled. As Australian governments have sought new ways of undertaking their functions (Moon, 1999) a process of organisational change has accompanied the public sector managerial revolution (Parker \& Bradley, 2000). A strong connection can be made between discussions about downsizing and accountability (Frumkin, 2003) as these changes to public service systems, administrative structures and processes are essentially issues of corporate governance (Standards Australia, 2004b).

The literature on corporate governance offers many definitions and public sector corporate governance has become a catch all phrase, usually contrasted with traditional images of government bureaucracy and rigid decision making (Moon 1999). There is however, general acknowledgement that public sector corporate governance is different from public management (Bovaird \& Loffler, 2003; Uhrig, 2003). In particular, not all practices of public sector management are part of public sector corporate governance and not all aspects of public sector corporate governance are part of public sector management. Bovaird and Loffler (2003) draw a distinction between public governance and public management on the basis that public management is an approach that uses managerial techniques to deliver improved value for money, while public sector 
corporate governance relates to organisational decision making and control

mechanisms . The literature provides many examples of this including the application of technology to sustain new work practices; a key aspect of public management but relatively removed from issues of corporate governance.

While the realms of public management and public sector corporate governance are separate they remain interconnected (Bovaird \& Loffler, 2003). For example, as set out earlier the types of bureaucracy identified by Considine (1999) describe not only changes in the nature of public management but also changes in the way public sector organisations are governed, particularly in terms of how they are controlled (refer table 1)

Table 1: Public bureaucracy corporate governance types

\begin{tabular}{lllll}
\hline & Source of & Form of & Primary & Service \\
& rationality & control & virtue & delivery focus \\
\hline Procedural & Law & Rules & Reliable & Universal \\
bureaucracy & & & & treatments \\
\hline Corporate & Management & Plans & Goal driven & Target groups \\
bureaucracy & & & & \\
\hline Market & Competition & Contracts & Cost driven & Price \\
bureaucracy & & & & \\
\hline Network & Culture & Co-production & Flexible & Client \\
bureaucracy & & & & \\
\hline
\end{tabular}

Source: Considine 1999, p 468

Although there is an inter-connection between NPM and corporate governance , particularly because corporate governance reforms frequently follow broader NPM 
reforms, there is also a level of incompatibility between NPM and corporate governance concepts. Some scholars argue that NPM contains inherent weaknesses brought about by its mainly intra-organisational focus, obsession with objectives, focus on results and contradiction between competition and steering (Bovaird \& Loffler, 2003).

However, as NPM reforms have created a public sector increasingly like the private sector, the concept of corporate governance in the public sector has emerged as a dominant idea (Halligan, 2002), particularly due to the relationship between accountability and increasing efficiency through downsizing and reorganisation (Frumkin, 2003). It is increasingly recognised that appropriate corporate governance arrangements are an important element in public sector corporate success (Barrett, 2003).

As a consequence, rather than there being a clear and separate movement from an 'old' public management paradigm to NPM and then onto a new concept of public sector corporate governance, most OECD countries retain strong elements of all three paradigms and it is not clear if or when there will be a transition to a 'unitary' approach (Bovaird \& Loffler, 2003; Dunleavy et al., 2005).

\subsubsection{Other drivers of public sector corporate governance reform}

Pressure to improve public sector corporate governance has emerged from sources other than NPM-led reforms. By the end of the $20^{\text {th }}$ century, NPM initiatives were claimed not to be delivering the outcomes that communities demanded (Denhardt \& Denhardt, 2000). Issues associated with the environment, access to services, and quality of life also emerged. The response of many governments to these pressures has focused on 
improving the coordination of government decision making and the integration of services to address them (Bovaird \& Loffler, 2003). This includes a concern for the governance of public policy and the corporate governance of public sector organisations (Bovaird \& Loffler, 2003).

Governments have also found themselves in uncharted waters as they are increasingly forced to be more participatory in policy decision making (Edwards, 2002). As the role of government changes to be a facilitator of outsourced services (Edwards, 2002) and attempts are made to restore public confidence in the underlying principles of good corporate governance, integrity, openness and accountability (Sendt, 2001a), corporate governance-based responses have been increasingly adopted by governments. For example, issues associated with the Queensland health system in 2005 which began with criminal investigations associated with surgeon Dr Jayant Patel, and involved the resignation of the State's health minister (The Age, 2005), resulted in major changes to the health department's corporate governance arrangements. These included changes to the role of central office functions and devolving decision making arrangements to a more local level (Queensland Government, 2005).

These responses tend to emphasise (Bovaird \& Loffler, 2003):

- Importance of wicked problems that cut across neat service delivery lines;

- Need to tackle wicked problems co-operatively, particularly through multi-party action;

- Need for agreed 'rules of the game' to guide multi-party actions in order to build trust (effectively extending corporate governance into public management); and 
- Importance of certain characteristics which should be embedded in all interactions, including transparency, integrity, honesty and fairness.

\subsubsection{Defining 'public sector corporate governance'}

An increased global focus on the importance of good corporate governance means that there has been a rapid growth in the number of guidelines and principles relating to corporate governance in the public sector, the latest being the AS8000 series of Corporate Governance Standards. The World Bank advocates the importance of corporate governance because there is a strong causal relationship between good corporate governance and better outcomes, such as lower infant mortality and higher literacy (Sendt, 2001b). The International Federation of Accountants also contends that effective corporate governance is essential for building confidence in public sector entities, which is in itself necessary if the organisations are to be effective in meeting their goals (International Federation of Accountants, 2000).

Widely used corporate governance guidelines in the public sector include those prepared by the Australian National Audit Office (ANAO), (Australian National Audit Office, 1997) the NSW Audit Office (NSW Audit Office, 1998) and the Municipal Association of Victoria (Municipal Association of Victoria, 2004). Among the most influential international guidelines are those proposed by the OECD, which provided the basis for the development of the Australian Standards (Standards Australia, 2004b). There is however, no single model of corporate governance. Corporate governance processes and practices must match the needs of particular jurisdictions and organisations (Standards Australia, 2004b) with the purpose of many of the guidelines being to ensure an appropriate balance between freedom to manage, accountability and 
the legitimate interests of the different stakeholders (International Federation of Accountants 2000).

There are however, some fundamental and common principles related to corporate governance. These are centred around the fact that corporate governance is essentially concerned with the structures and processes for decision-making, accountability, control and behaviour at the top of organisations (Standards Australia, 2004a, 2004b). The Public Accounts and Estimates Committee of the Parliament of Victoria extends this definition by noting that corporate governance relates not only to these structures and processes but also an agency’s purpose, values, culture, stakeholders (including employees) and mode of operation (Public Accounts and Estimates Committee, 2002). Others such as Bovaird (Bovaird \& Loffler, 2003) and Murdoch (Murdoch \& Abram, 1998) further consider corporate governance in the public sector to mean the ways in which stakeholders interact with each other in order to influence the outcomes of public policies.

Caution is required when defining corporate governance to avoid it being used as a catch all phrase primarily, particularly where its use involves more traditional notions of public sector administration (Moon, 1999). In particular, there is an important difference between concepts of 'government' and 'governance'. Government is the institution itself, where governance is a broader concept (Hughes, 2003) associated with regimes based on manageralism and contracts rather than the direct performance of government tasks and bureaucracy (Moon, 1999). Good corporate governance tries to do more than achieve the efficient management of economic and financial resources; it is also focused on strengthening the institutions of civil society by making government more open, accountable and responsive (Minogue, Polidano, \& D, 1998). 
Despite different legal boundaries, the concept of corporate governance as applied in public sector agencies essentially reflects the same principles used by their private sector counterparts. It is commonly assumed that private sector forms of corporate governance can be readily adapted to improve government policy and implementation activities (Edwards 2002), although a number of key difference have been identified (Australian Standards 2004). Kearnes (Kearnes, 1996) identifies similarities in accountabilities but notes that the public and private sectors are completely unlike in how they are situated in larger political economic life. Ultimately, the private sector does not have the roles and responsibilities of government policy and is not required to the protect the public interest (Edwards, 2002).

ANAO observes that the public sector corporate governance must also 'satisfy a more complex range of political, economic and social objectives and operate according to a quite different set of external constraints and influences’. Private sector organisations are accountable once a year; public agencies are accountable every day (Cameron 2003). Furthermore, in the public sector, the corporate governance process is frequently as important as the services ultimately provided to the public (Standards Australia, 2004a).

With globalisation, corporate governance is becoming more diffuse and with an increasing number of players governments no longer have a monopoly over corporate governance issues (Hughes 2003). 


\subsubsection{How public service reforms shape corporate governance arrangements}

By their nature, public organisations follow a 'vortex-sporadic' decision-making process involving more turbulence, more shifting participation by a greater diversity of internal and external interests and more delay (Rainey, 2003).

Recent analysis of developments in both public and private sectors have pointed to the emergence of ‘post-bureaucratic’ or ‘post-modern’ organisational forms (Clegg, 1990; Heydebrand, 1989; Hoggett, 1996). Clegg identifies that the boundary between the organisation and its environment, and therefore the distinction of being on the inside or outside of the organisation, has begun to collapse as traditional public bureaucracies make increasing use of profit centres, internal markets, transfer pricing and other market mechanisms. Heydebrand considers that the post-bureaucratic form is small and located in sub-units of larger organisations: its object typically being service or information provision with its division of labour informal and flexible and its managerial structure functionally decentralised and participative.

Hoggett however warns that there is a danger on focusing on just what is new in organisations rather than identifying how organisations are adopting many 'trappings' of the postmodern form while continuing to utilise old techniques (Hoggett 1996). Hoggett identifies three common elements in emerging organisational structures (Hoggett 1996):

- A pronounced shift towards the creation of operationally decentralised units with a simultaneous attempt to increase centralised control over strategy and policy; 
- Competition has become the dominant method of coordinating the activities of decentralised units; and

- Substantial development of performance management and monitoring processes.

In addition to these changes, efforts to improve horizontal coordination across public sector agencies, both within an organisation and across government, have been a feature of recent public sector corporate governance reforms in Australia (Halligan, 2007b)

\subsubsection{What is 'effective corporate governance'?}

Government agencies do not have access to private sector measures that readily assess the effectiveness of corporate governance reforms, such as Share Value Added (Frumkin 2003). Nor is determining the effectiveness of management changes straightforward or simple (Pollitt, 2003). Despite nearly a decade of reform in this area, little research has reached beyond the case study stage in defining the impact of reform on services, clients and organisations (Considine 1999) and a major factor impeding the definition of 'effective’ public sector corporate governance is the dearth of documented studies on good corporate governance practices, especially how they could work in the public sector (Edwards 2002). In particular, there is limited information about the evaluation of reform adoption in the public sector (Mir \& Rahaman, 2006).

Uhrig (2003) in a review of the corporate governance of Commonwealth statutory authorities and office holders notes that the question of what constitutes good corporate governance is less meaningful than the question of whether corporate governance is present and is the most appropriate for the organisation. Uhrig (2003) does however 
consider that a well-governed organisation is one that clearly understands what is to be achieved and operates in a supportive, encouraging and accountable environment.

Nevertheless, several potential, more tangible, measures of corporate governance reform value have been identified and include (Frumkin, 2003):

- Improved services through enhanced coordination.

- Increased efficiency.

- Lower costs to taxpayer.

- Increased accountability to the public.

Other commentators contend that the meaning of effective corporate governance is highly context-dependent and should be negotiated and agreed by stakeholders (Bovaird \& Loffler, 2003) particularly as 'good' corporate governance is about behaviour judged against an agreed framework (Cameron, 2003). Good corporate governance extends beyond sound financial management and includes transparency of policy development and decision-making processes, probity, integrity of decisions and actions of government, and a recognition that better practice enhances effective outcomes (Cameron 2003).

The evaluation of public sector reform is complex. Despite NPM's emphasis on clear targets, many if not most reforms have occurred with only a very general idea of what is to be achieved, with little attempt to assess the transitional costs and vague attempts to track and measure the purported gains (Pollitt 2003). Only monitoring and evaluation of implementation will provide the evidence required to assess the effectiveness of corporate governance change (Standards Australia, 2004a). 
Specific limitations associated with the evaluation of corporate governance reforms include (Pollitt 2003):

- original objectives of reform only being vaguely specified making it hard to know what to study;

- limited baseline data as no proper analysis of relevant parameters performed prior to reform (reformers are anxious to reform not study the status quo);

- reform consisting of simultaneous changes thus making it difficult to identify which element(s) have been most successful;

- the size and shape of organisations subject to reform are so altered that a before and after comparison is no longer possible; and

- the costs of reform were not measured.

This is not to say public sector reforms have not produced results. Reform outcomes include substantial savings in administrative costs, improvement to processing methods and evidence of cultural shifts (shifts in attitudes and values) (Pollitt 2003).

\subsection{Managing change}

Change in organisations has moved from being a mere topic of casual interest to one of major importance (McNish, 2002) and there is an established literature relating to organisational change. In particular, the literature stems from the dynamic and changing environment facing most organisations (Robbins, Millett, Cacioppe, \& Waters-Marsh, 2001). 
The change management literature resounds with terms such as transformation, reinvention and reengineering , leading to a bewildering array of understandings and approaches to change (Stewart \& Kringas, 2003). In addition, innovation is identified as a special kind of change, one that involves applying a new idea to initiating or improving a product, process or service (Robbins et al., 2001). Many writers have focused on the subjects of change and innovation, including Lewin (1947; 1951), Pettigrew, (1992) Kanter (1993), Kotter (1995) and Stickland (1998; 1998).

During the past 50 years many change management techniques have been proposed. Lewin (1951) identified a three-step process of unfreezing, changing and refreezing. Over the last 20 years, the idea of managing change has also emerged through commercial programs such as total quality management (TQM) and business process reengineering (BPR) where drives for improved efficiency highlight imperatives for changing organisational attributes, such as decision making and resource allocation processes.

The many types, levels and degrees of change complicate the discussion of the change process (Rainey, 2003). There are however, at least two ways to analyse and understand the varied approaches to organisational change:

1. the scale of change; and

2. the approach to change (change management model). 


\subsubsection{Scale of change}

Lindbloom (1959; 1959) differentiated between branch and root change. Branch change involves 'successive limited comparisons that continually build out of the current situation, step by step and by small degrees' whereas root change is a 'comprehensive approach starting from fundamentals each time' (Lindbloom 1959, 79). Grenier (1974)makes a similar distinction, contrasting evolutionary and revolutionary change. Evolutionary change is defined as the modest adjustments necessary for maintaining growth under the same overall pattern of management, while revolutionary change consists of serious upheavals and abandonment of past management practices involving finding a new set of organisational practices that will become the basis for managing the next period of evolutionary growth (Greiner, 1974).

Revolutionary change alters the very nature of the organisation and often emerges as a response to significant technological and environmental change (Robbins \& Barnwell, 2002). Evolutionary change describes minor changes incorporated into existing operational structures such as introducing a new software program (Robbins \& Barnwell, 2002). Most change is evolutionary change although revolutionary and evolutionary changes are not self contained categories: they are end points on a continuum (Robbins \& Barnwell, 2002).

Tichy (1983) argues that most approaches to organisational change have concentrated on one of three primary dimensions: the political, technical or cultural. According to Tichy, strategic change involves moving beyond these more fragmented approaches by coordinating changes in these three dimensions in order to effect large-scale transformations in an organisation (Rainey, 2003). 


\subsubsection{Change model}

Collins (1998) identifies two basic types of change model. The first, loosely called the 'rational model', emphasises the importance of planning, problem solving and execution while the second, more sociological in approach explores 'changing' rather than change and emphasises the uniqueness and contextual richness of each situation (Stewart \& Kringas, 2003).

The rational approach underlies a managerialist focus around change (Kotter, 1995) and is broadly aligned to the notions of planned change and behaviourist change.

Tsoukas (2005b) identifies the basic tenets of this model to include change being episodic and that it occurs in successive states; that objects exists in a natural state of stasis from which they move after external force is applied to them and to which they return (as proposed by Lewin); and that in organisations the object undergoing change is typically human behaviour and culture. Central to the rational model is the idea that the forces through which change is effected are managerial requests, orders and commands (including rewards and punishments), stemming from the authority relationship managers possess in organisational hierarchies. When, having applied force, objects fail to move, or do not sufficiently move, ways must be found to overcome their resistance, typically through applying stronger force. Looking through the lense of the rational change model, change is viewed as 'other-directional', that is to say others need to change and the change agent is there to make sure they do (Tsoukas, 2005).

Rational model literature is often abstract and process based, and it focuses on change management in the private sector (Stewart \& Kringas, 2003). The rational approach has three main criticisms (McNish, 2002): 
1. it assumes that the various parties in the organisation can come to some common consensus;

2. it assumes that change is suited to all organisations in all circumstances; and

3. the model was specifically created for organisations that operated in environments that were particularly stable and predicable.

The notion that an organisation is 'frozen' waiting for a change agent to 'unfreeze' it has also been criticised (Tsoukas, 2005).

In contrast to the rational model, the more sociological-based approach, often referred to as the cognitivist model, argues that the study of behaviour is insufficient to account for change - while we may observe people behaving differently over time, the important question is why? (Tsoukas, 2005). "Contrary to the behaviourist perspective which treats managers as black boxes, the cognitive science perspective delves into the working of the black boxes. Managers do not mainly act according to habit, instincts or environmental determinants, their behaviour is active and intentional (Stubbard \& Ramaprasad, 1990).

This approach is an ongoing process of constant learning, experimentation and risk taking (McNish, 2002). A range of change management approaches can be included within this cognitivist approach including Soft System Methodology (SSM) (White, 2000), Future Search (Weisbord \& Janoff, 1995), Search Conferences (Emery \& Purser, 1996) and Team syntegrity (Beer, 1995). 
Closely related to these sociological change models is institutional theory (Brunsson \& Olsen, 1993; Czarniawska \& Sevon, 1996; Powell \& Di Maggio, 1991). Institutional theory holds that many aspects of organisational structure, policies and procedures result from what society holds as acceptable practice and that organisational behaviour is considered to be ingrained in the broader system of interrelated economic, institutional and ecological influences (Di Maggio \& Powell, 1991). As a consequence, many of the rules in individuals organisations are seen as part of a society’s wider rule system (Brunsson \& Olsen, 1993). This portrays organisations as creatures of their institutional context and as a result, the initiative for change is often directed by expectations and requirements external to an entity (Brunsson \& Olsen, 1993).

Powell and Di Maggio (1991) reject rational-actor models and instead turn toward cognitive and cultural explanations for organisational behaviour. In particular, the customs and habits within an organisation are seen as establishing an agreement among employees around a recurring routine. Such routines eventually attain a rule-like status that become resistant to change (Zucker, 1983). Institutional theory has generated valuable insights into the causes of changes in the features of organisations and how organisations secure legitimacy by conforming with the norms of their environments, namely the societies in which they operate (Zucker, 1983).

Key criticisms of cognitivist models include (McNish, 2002):

1. the approach is not clear cut and orderly, but involves a number of interdependencies; and

2. the role of the manager changes and becomes one of a facilitator rather than a doer. 
Organisational development also emerged as a change model in its own right during the 1960s and 1970s (White, 2000). Largely based on the human relations orientation in organisational studies and the group dynamics movement, it draws on various elements of social science and organisational behaviour, such as theories of motivation, leadership and systems (Rainey, 2003).

Many organisational development concepts have filtered into the broader management literature, such as culture and leadership (Beer, 1995). Organisational development maintains that an organisation is an open system, that interacts with its environment. For this reason, an organisation must adapt to environmental changes (Beer, 1995). If not, it will eventually fail (Robbins et al., 2001)

Within the public sector context, Osborne and Plastrik (1997) have identified a model focused on transforming bureaucracies into entrepreneurial systems and organisations. This ‘five Cs' approach involves using 'key leverage points to make fundamental changes that ripple throughout government, changing everything else (Osborne \& Plastrik, 1997).

The model is comprised of the following: 
Table 2: The Five C's - Strategic Approaches to Changing Government

\begin{tabular}{|c|c|c|}
\hline Level & Strategy & Approaches \\
\hline Purpose & Core strategy & $\begin{array}{l}\text { Clarity of purpose } \\
\text { Clarity of role } \\
\text { Clarity of direction }\end{array}$ \\
\hline Incentives & Consequences strategy & $\begin{array}{l}\text { Managed competition } \\
\text { Enterprise management } \\
\text { Performance management }\end{array}$ \\
\hline Accountability & Customer strategy & $\begin{array}{l}\text { Customer choices } \\
\text { Competition choice } \\
\text { Customer quality assurance }\end{array}$ \\
\hline Power & Control strategy & $\begin{array}{l}\text { Organisational } \\
\text { empowerment } \\
\text { Employee empowerment } \\
\text { Community empowerment }\end{array}$ \\
\hline Culture & Culture strategy & $\begin{array}{l}\text { Breaking habits } \\
\text { Touching hearts } \\
\text { Winning minds }\end{array}$ \\
\hline
\end{tabular}

Source: Osborne and Plastrik 1997, p 39

Under the first of these areas, the Core Strategy, Osborne and Plastrik discuss focussing on the essential purpose of an organisation. This involves critically examining all functions undertaken by government in order to determine which ones are essential to the core goals of the entity. Steps to uncouple 'steering' (the policy-making and evaluation functions of an organization) from 'rowing' (the program and services 
delivery function) are also part of Core Strategy, along with ensuring services are delivered to the right target markets and are meeting their needs.

The second area is the Consequences Strategy, which introduces the notion of making managers and employees responsible for the consequences associated with their actions. Consequences are seen as incentives (or disincentives) for bringing about certain behaviours. Approaches to introducing Consequences Strategy include corporatisation (turning public sector activity into a profit seeking venture), managed competition (allowing the public sector to compete with the private sector) and performance evaluation (including performance pay and bonuses).

The third area is the Customer Strategy, which is centred on the customers and stakeholders of government departments and agencies. Three basic approaches are outlined. The first approach is to establish a choice between being served by the public or private sector. The second strategy is to introduce a competitive choice, that is to say the public can choose a provider with the public funding for that service going to the chosen provider. The third approach is based on implementing customer quality assurance processes.

The fourth area is the Control Strategy, which is concerned with decision making within a government organization. The approaches associated with this strategy are include empowering organizations, empowering employees, and empowering communities The last strategic approach examines the cultural makeup of government organisations. Using the US city of Hampton ('the most livable city in Virginia') as a case study, Osborne and Plastrik advance three Cultural Strategy approaches. These are changing 
day-to-day habits (including job rotation and meeting customers), winning hearts (including investing in the workforce and creating new workplace symbols) and winning minds (including benchmarking performance and building a shared vision).

Osborne and Plastrik point out that the simplest method to bring strategies together in a coherent and complementary way is to use a tool that brings two or three strategies into play at once (Downes, 1998). They call such instruments meta-tools and include performance measurement (uses both core and consequences strategies) and total quality management (uses customer, control and culture strategies).

The five C’s approach highlights many of the difficulties confronting public sector change. In particular, this includes change being a generally time consuming process, often due to lack of incentives, leadership, and willingness to change on the part of public service employees. As a result, public organisational systems are presented under the five C's model as complex, adaptive systems that live, grow and change over time.

Osborne and Plastrik’s model has been criticised by those that believe obstacles, particularly in large organisations, are consistent, potent and not highly amenable to change (Downes, 1998). The model, built with the aid of case studies, also focuses only on the success of reforms and pays relatively little attention to failed initiatives. A discussion of obstacles to change is set out in more detail below. 


\subsubsection{Organisational innovation}

The term innovation is used to refer to the process through which new ideas, objects and practices are created, developed or reinvented (Slappendel, 1996). Change is not the same thing as innovation as not all changes are innovative although all innovations do represent change (Robbins et al., 2001). The understanding of innovative behaviour in organisations however, remains relatively undeveloped as the results of much organisational innovation research have been inconclusive, inconsistent and characterised by low levels of explanation (Wade 1994).

Studies of innovation have also focused on different levels of analysis. Much of the early literature focused on the adoption of new ideas and practices (individualist centred), with more recent research focusing on organisational innovation (structurally centred) (Slappendel 1996).

This has lead to a number of models of innovation including individualist (individuals create innovation); structuralist (structural characteristics create innovation); and interactive processes (innovation is produced by interaction of structural and individual influences) (Slappendel 1996).

Although these models are often cited, some commentators have observed that there is no one model of innovation (Wade 1994). In particular, many models appear to hold under different conditions indicating that the variables themselves appear to be more important than any single theory of innovation. Research also indicates that innovation, and change more generally, does not appear to obey the linear phased plan of a change model or consultant (Beer, 1995). In particular, it does not occur in single episodes or 
management interventions. Rather it occurs as part of a continuous process, often outside the control of a single person or function.

Innovation is however frequently characterised as taking three forms (Robbins et al., 2001):

1. technological: encompassing the use of new tools, techniques, devices and systems to produce changes in products and services

2. administrative: encompassing changes in structure or administrative processes

3. product: encompassing design, development, production and marketing of new services and products

Some senior public sector practitioners caution against considering innovation as only those 'sparky ideas' that can lead to a reshaping of services overnight (Moran, 2004). Other types of innovation, based on the experience of front line staff, which results in the gradual improvement in day to day service delivery should not be ignored.

\subsubsection{Barriers to change and innovation}

The change management literature defines a range of broad factors that impact on change within organisations. One of the most documented findings from studies of individuals and organisational behaviour is that organisations and their members resist change (Robbins et al., 2001).

Formidable barriers can act to obstruct efforts to change the way an organisation's strategic decisions are made and routine operations conducted (Post \& Altman, 1994). Various studies have identified factors that act as barriers to change, or when reversed, 
actively promote organisational change (Kotter, 1995; O'Toole, 1986; Robertson \& Seneviratne, 1995; Stewart \& Kringas, 2003; Tsoukas, 2005; White, 2000).

Significant organisation resistance factors include:

1. Self interest - individual buy-in is affected to the degree that the interests of individuals are met. People must see ways they will benefit from the change in order to buy-in and support it (Trader-Leigh, 2002), particularly as changes in organisational patterns may threaten the expertise of specialised groups (Robbins 2001). Change will also be affected by perceptions of job security and social status in the organisation (Trader-Leigh 2002). Success may depend on whether potential advantages can be demonstrated or made visible (Rainey 2003).

2. Redistributive factor - changing policy and funding strategies redistributes resources, power and changes institutional relationships (Trader-Leigh, 2002). This can threaten established resource allocations affecting groups in organisations that control sizable resources (Robbins 2001).

3. Destabilisation effect - destabilisation can occur when the system shifts to a new way of operating for which staff have not been trained (Trader-Leigh, 2002). This can then activate built-in mechanisms that produce stability, acting as a counterbalance to reform efforts (Robbins 2001):

4. Culture compatibility - new approaches often conflict with continuing bureaucratic structures (Trader-Leigh, 2002). Group norms often act as a 
constraint on change (Robbins 2001) as custom inhibits change (TraderLeigh, 2002). Smaller-scale changes can also be nullified by the preservation of broader systems and work practices (Robbins 2001). The concept from institutional theory known as 'decoupling', or the separation of reform drivers from what the staff of an organisation see as necessary to maintain effective internal operations (Brunsson \& Olsen, 1993), is relevant here. In particular, decoupling involves an organisation attempting to influence drives for reform by altering their 'structures, processes and ideologies’ (Brunsson \& Olsen, 1993).

5. Political effect - significant change upsets the balance of power among groups and affects individuals and groups relative positions of power and control (Trader-Leigh, 2002). Often with change, there are a number of anxieties that arise. These usually revolve around the fear of change, dealing with uncertainty and bringing about commitment to change during a period of flux (White, 2000). In these cases, success will often be determined by how innovation is related to various influential persons or groups that can block or initiate innovation (Rainey 2003). For example, the introduction of changes such as participative decision making or self managed work teams may threaten traditional authority holders such as middle manager (Robbins 2001).

Post and Altman (1994) identify similar factors, although they consider change influences within a framework that categorises factors into industry and organisational barriers.

Table 3: Industry barriers 


\begin{tabular}{|c|c|c|}
\hline Barrier type & Description & $\begin{array}{l}\text { Means of overcoming } \\
\text { barrier }\end{array}$ \\
\hline Capital costs & $\begin{array}{l}\text { Funds for major and minor } \\
\text { improvements, expected } \\
\text { rate of return }\end{array}$ & $\begin{array}{l}\text { Market innovations eg } \\
\text { 'green' products to fund } \\
\text { environmental } \\
\text { improvements }\end{array}$ \\
\hline Community concerns & $\begin{array}{l}\text { Perception of risks } \\
\text { associated with the } \\
\text { business }\end{array}$ & $\begin{array}{l}\text { Risk communication. } \\
\text { Community advisory } \\
\text { councils. Community } \\
\text { initiatives }\end{array}$ \\
\hline Regulatory constraints & $\begin{array}{l}\text { Regulations, standards, } \\
\text { operating permits }\end{array}$ & Voluntary action programs \\
\hline Information & $\begin{array}{l}\text { Difficulty of collecting } \\
\text { appropriate data, } \\
\text { measurement problems }\end{array}$ & $\begin{array}{l}\text { Industry alliances, } \\
\text { performance measurement }\end{array}$ \\
\hline Technical knowledge & $\begin{array}{l}\text { Physical, chemical and } \\
\text { biological uncertainty. } \\
\text { Inability to eliminate some } \\
\text { risks or effects }\end{array}$ & Joint research/development \\
\hline
\end{tabular}

Source: adapted from Post and Altman 1994, p 68

Industry barriers include those related to capital costs, community concerns, regulatory constraints, information and technical knowledge. These represent special or unique features of the business activity in which the organisation engages. 
Table 4: Organisational barriers

\begin{tabular}{|l|l|l|}
\hline Barrier type & Description & Means of overcoming barrier \\
\hline Attitudes of & Disengagement, parochial & Information sharing, teams, \\
\hline Top management & Detached, uncaring, lack of & Peer pressure/action, \\
\hline Quality of & understanding & articulation of change drivers \\
communication & 'Distance' between top & Communication treated as a \\
management's espoused & critical business process, create \\
commitment and action & 'champions' at all levels \\
\hline heritage (past & throughout the organisation & \\
\hline practice) & Standard operating procedures, & Prospective outlook, strategic \\
\hline
\end{tabular}

Source: adapted from Post and Altman 1994, p 68

Organisational barriers include attitudes of personnel, top management, the quality of communication and administrative heritage. These represent barriers which affect an organisation's capacity to deal with any form of change.

The literature dealing with constraints and pressures acting on the change management process outside the control of managers stresses the role of an organisation's environment in setting the parameters of change .

Change fatigue can also become a real issue, particularly when an agency encounters unforseen reverses and continuity of leadership attention is seen as critical in sustaining momentum, particularly where the change programs strike difficulties . However, the effect of leadership is almost impossible to isolate from other factors influencing 
change, such as attention to communication, an appropriate change model and sufficient resources (Stewart \& Kringas, 2003).

There is also a tendency to blame employee resistance for failure of implementation when often the reality is that management has been unwilling or unable to explain the purpose of change(s) and what it will mean for employees. It is often assumed that there are correct solutions to organisational problems that only the reformers know about, and that any resistance to these are irrational and reactionary (Brunsson \& Olsen, 1993). The alternative interpretation offered by institutional theorists is that reformees also want their organisations to function more effectively, however, they often have more insight into how to achieve this than the reformers.

Stewart and Kringas conclude that successful change seems to depend on a number of factors:

1. an appropriate change model

2. effective leadership

3. sufficient resources

4. attention to communication

Change also 'changes' as it diffuses through an organisation, or as it is imposed. Accordingly, to fully understand how change occurs within an organisation comparing attitudes toward change between different levels of an organisation is an effective way of tapping into not only the success of implementation but also the dynamics of the process itself (Stewart \& Kringas, 2003). 


\subsection{Change in public sector organisations}

While there is an extensive literature on implementing public policy measures, there are fewer studies of change in administrative settings with a focus on implementation .

Literature regarding traditional differences between the public and private sectors suggest that the basic characteristics of public organisations may impede the success of planned change interventions (Robertson \& Seneviratne, 1995). Criticisms of public service bureaucracies, particularly larger ones, indicate that they are frequently slow and cumbersome, inefficient and ineffective, unresponsive and unaccountable and unable to deal with fast-paced change creatively and innovatively (Downes, 1998).

The traditional perspective has also been that key differences between private and public sectors have important implications for the likelihood of successfully implementing a program of planned change (Robertson \& Seneviratne, 1995).

Because private sector organisations are driven primarily by market or consumer preferences, organisational effectiveness is more readily measured in terms of efficiency and profitability. As a result, change activity can be implemented and assessed using these narrow criteria as the primary basis for evaluating their success, possibly making it easier for these change efforts to be successful (Robertson \& Seneviratne, 1995).

Managing change is not however, the preserve of the private sector and the increasing turbulence within public sector environments has seen change management approaches become integral to management in the public and voluntary sectors (White, 2000). Public sector organisations are now also expected to exhibit many features of the private sector, including some scope for entrepreneurialsim (White, 2000). 
Detailed analyses of the distinctions between public and private organisations confirms that the two sectors are not as distinct as suggested (Perry \& Rainey, 1988). Instead, organisations can be viewed as a continuum with any given organisation characterised as more or less 'public', with some organisations falling near the end points of this continuum (Robertson \& Seneviratne, 1995).

Despite the diminishing distinctions between public and private sectors, several unique barriers to change in the public sector have been identified. These include the fact that public sector organisations have multiple, sometimes conflicting, missions and few face the consequence of poor or mediocre performance (Osborne \& Plastrik, 1997). Compared to private organisations, many public sector entities are also subject to a greater range of rules, regulations and procedures (Rainey, 1983). Multiple actors in the change process also have access to multiple authorities, thus presenting a complex array of possible supporters or resistors for change (Rainey, 2003).

The highly political nature of the public arena can increase the difficulty in attaining leadership support for a change process. In particular, public organisations are often characterised by complex command linkages that must address competing identifications and priorities (Robertson \& Seneviratne, 1995). This frequently involves spending more time lobbying for an intervention in the public sector than in a private organisation (Robertson \& Seneviratne, 1995).

It has also been argued that many public sector programmes appear to reflect more a concern to collect 'trophies' than to engage in effective change management programs, largely a reflection of the skills of the personnel managing the change process. 


\subsubsection{Organisational determinants of effective public sector reform}

Studies of change within public organisations have however identified the following as important factors capable of impeding successful change:

\section{Fragmented control processes}

Most agencies that have undergone corporate governance reform have detailed strategic plans, mission statements and formal planning procedures in place, but most do not have an operational link between decision making, resource allocation and formal planning processes (Considine 1999). In particular, there is often little alignment between government outcomes, agency strategic planning and divisional business planning (Barrett 2003).

Reformed decision making processes of many public sector agencies also fail to account for the rapid shifts in priorities that individual Ministers often need to make (Considine 1999)

\section{Increased centralisation}

Whilst operational managers may be given real control over resources necessary to do the job, the centre increasingly retains control over strategic issues such as overall allocation of resources and the framework of financial and personnel rules within which devolution over operational matters is allowed to occur (Hoggett 1996). This can act to limit the ability to initiate and control change processes. 


\section{No cultural change}

Many changes in the public sector have largely failed as they occur as symbolic and rhetorical actions towards which the majority of staff are highly cynical (Hoggett 1996). Consequently, there is often little success in engaging and wining the support of staff as they see a large gap between rhetoric and reality (Barrett 2003).

Changes in public sector organisations have also often been pursued with relatively little empirical understanding of organisational culture in the public sector (Parker \& Bradley, 2000). From a management perspective, a lack of understanding of culture in the public sector is a concern because research on organisational culture indicates that culture is central to the change process and the attainment of strategic objectives (Parker \& Bradley, 2000).

The essence of an organisation's culture is found at two levels (Beer, 1995). Firstly, in the entity's embedded, pre-conscious basic assumptions about human nature and the nature of the world. Secondly, culture manifests itself as values (beliefs about how things ought to be done) which are testable only by social consensus.

There is a significant body of literature that draws attention to the difficulty of changing organisational culture on the ground that culture is deeply ingrained in the underlying norms and values or an organisation and cannot be imposed from above (Molinsky, 1999; Parker \& Bradley, 2000; Turner, 1986).

Cultural change in some organisations is particularly important as it has been suggested that a culture that is limited to conformance or compliance does not promote innovative behaviour or high-level performance (Standards Australia, 2004a). 


\section{Staff training and development}

It is not enough to simply define the elements of change, it is necessary to ensure that they are effectively integrated and understood and applied throughout the organisation (Barrett 2003). For example, the implementation of information systems requires not only training of staff responsible for entering data but also training for those responsible for accessing, interpreting, managing and applying this information (Barrett, 2003; Halligan, 2002). This includes improving the ability for Ministers to understand and use information in decision making (Halligan, 2002).

\section{Effective working relationships}

Nearly all recent public sector reforms have required the efforts of two or more agencies/parties/levels of government. This makes the development of effective working relationships an important element in implementing an effective corporate governance framework (Barrett 2003). Similarly, studies of accountability have tended to neglect the need to manage often interdependent programs within independent organisational units (Barrett 2003)

\section{Politicalisation of the public service}

The recent history of state government departments in Australia has been one of steady politicialisation (Halligan, 2001). Ministers have searched for new ways to exert their control over the public service including dismissing department heads that do not satisfy Ministerial expectations and imposing new coordination systems (Halligan, 2001).

The introduction of many of these public service reforms have threatened the concept of a professional and apolitical public service (Sendt, 2001a) and raised difficult tensions 
with Westminister principles of governing (Halligan, 2001). In addition, ministerial staff have frequently taken over roles previously undertaken by public servants, as well as becoming routinely involved in departmental processes (Halligan, 2002).

\section{Hierarchical nature of public sector organisations}

Consistent with recent reforms, research into Queensland public sector agencies by Parker and Bradley expected to find the traditional model of public administration no longer the dominant element of those organisation’s cultural frameworks. Contrary to what was expected, the majority of agencies were dominated by a hierarchical model of organisational culture (Parker \& Bradley, 2000).

Recent research has also indicated that public sector organisations are fundamentally different from private sector organisations on a number of dimensions, including the diversity of their goals, access to resources and the nature of organisational constraints (Parker \& Bradley, 2000). Public sector agencies are affected by prevailing political ideologies and do not perform in an equivalent manner to the production of goods or services in the private sector (Considine, 1990; Pollitt, 1990). Limited research has also focused on the different values and motives of public sector employees (Parker \& Bradley, 2000). This suggests that public sector workers are more altruistic than private sector employees and have a commitment to social development and the pursuit of the public interest (Parker \& Bradley, 2000).

Corporate governance is challenged in the public service by complex structures often involving an elaborate set of relationships between Parliament, Ministers (and their advisors), Boards and CEOs; intervention by Ministers, other parts of government, or the political process. Unclear or conflicting economic objectives and community 
service obligations; the selection process for board members - which might give rise to divided loyalties on the part of the appointee; and direct appointment of Chairs and CEOs by, or on, the advice of Ministers, also complicate public sector corporate governance (Cameron 2003).

\subsubsection{A framework to categorise organisational change factors}

To assist the categorisation of factors impacting on the implementation of organisational change, in particular the NPM focus on performance measurement, de Lancer Julnes and Holzer (2001) have formulated a framework comprising two parts:

- Rational/technocratic

- Political/cultural

The rational/technocratic category relates to the notion of 'scientific management' and the ability to bring rational, technically based actions to the management of organisations. It is based on the premise that problems are rationally and logically identified and that reason will always provide the solution to uncertainty. This involves the use of a well-ordered approach to finding the best solution to an issue, with a sound scientific analysis of all alternatives before a solution is selected. Rational factors include the availability and commitment of resources, technical knowledge of management techniques and externally-imposed requirements. Rational/technocratic factors exclude issues associated with tradition, custom and habit.

Supplementing rational/technocratic factors are political and cultural influences. These include the interests of internal groups (such as perceptions held by middle managers), 
interests of external groups and internal 'norms' and attitudes to thing such as innovation. Organisational change is frequently characterised as an intensely political activity despite the assumption by many that treat change as a deductive rational process (Robbins 2002). Politics suggest that the impetus for change is more likely to come from outside change agents, while power struggles within the organisation will largely determine the speed and quantity of change (Robbins 2001). The inclusion of nonrational factors recognises the influences of oneself and others in decision making (we are not just 'rational machines') and acknowledges that these comprise an integral part of what it is to be a rational human being in community with other independent humans (Hammond, 1996). People within organisations react constantly to political signals and criticisms as well as to new staff (Brunsson \& Olsen, 1993). Political/cultural factors draw on past experiences in preference to pure rationality.

A key difference between political/cultural influences as opposed to rational/scientific influences is its focus on human judgement and the use of intuition (which is generally unconscious, concerned with experience and fairly much reliant on probabilities). This is in contrast to rational/scientific influences (which are generally conscious, based in logic and subject to analysis and precision).

It is important to note that the study by de Lancer Julnes and Holzer (2001) found that the implementation of NPM performance measurement initiatives was not a single event but rather an ongoing process influenced by these rational/technocratic and political/cultural factors. The study by de Lancer Julnes and Holzer sought to establish that two sets of factors affect the adoption and successful implementation of performance measurement in public sector organisations. These two sets of factors, one from a rational/technocratic framework and the other from a political/cultural 
perspective, describe the methodology needed to implement measurement and the political climate that allows it to happen.

In particular, de Lancer Julnes and Holzer's study revealed that the mix of factors found in the successful adoption of a performance measurement policy is different from those found in its successful implementation. Table 5: Summary of findings by de Lancer Julnes and Holzer sets out the results of this research.

Table 5: Summary of findings by de Lancer Julnes and Holzer

\begin{tabular}{|l|l|l|}
\hline & Adoption & Implementation \\
\hline Rational/technocratic & External requirements & Resources \\
& Internal requirements & Information \\
& Gesources & \\
\hline Political/cultural & Information & \\
& Internal interest groups & External interest groups \\
& & Percent unionised \\
\hline
\end{tabular}

The keys to performance measurement adoption are the rational factors of dedicated resources, trained and informed staff, consensus on what is trying to be achieved, and an internally driven requirement to use performance measurement. The one political or cultural factor important to adoption is a strong motivated internal group that will take on the task of promoting performance measurement. If top management is not committed to the effort, de Lancer Julnes and Holzer found that the policy is not likely to be adopted. 
During implementation, however, the key factors were found to be primarily political or cultural in nature. These included the continued support of external interest groups, such as elected officials and the public, the potential negative influence of unions in implementing performance measures and the likelihood that organisational with positive attitudes to risk taking would actively use performance measurement systems. These issues are taken up in the following chapter.

This chapter has provided an outline of public sector corporate governance reform in Australia, described the concept of corporate governance within a public sector context and highlighted the drivers of corporate governance change. Previous research about the categorisation of factors impacting on organisational change was also described. The next chapter uses this information to build a conceptual framework. 


\section{Chapter three: Theoretical framework and research questions}

\subsection{Introduction}

This chapter sets out the theoretical framework for empirical research in this thesis.

Section 3.2 describes the scene for this research. Section 3.3 defines the variables under investigation in the study. Section 3.4 describes the research framework and section 3.5 identifies the research propositions and questions, which form the basis for this investigation.

\subsection{Setting the scene}

Corporate governance change is a common feature of public sector reform. Reforms associated with new public management, and more recently drives to increase community participation in government decision making and to employ more 'place based' responses to local issues, have all involved changes to the way public sector organisations are organised and controlled (Halligan, 2002).

Citizens are better informed and demand more responsive services. In response to these pressures public sector organisations are expected to develop complex, multi-faceted policy in increasingly contested environments and to do this with fewer resources (Armstrong, 1998).

The reformed public sector has set about meeting this expectation in many ways. Public sector organisations now undertake business planning, emphasise service flexibility and responsiveness, seek stakeholder involvement in service planning and decision-making 
and promote competition (Barrett, 2003). Governments are also exploring new ways of delivering services, including business-community partnerships where companies and community organisations are supported to work together on projects to benefit the community.

These new ways of working have resulted in differing levels of corporate governance change. Some have involved major alterations to accountability mechanisms and the transparency of decision-making. Other more subtle changes include establishing frameworks to ensure consideration of ethical issues in decision making.

Despite the scope of recent and ongoing public sector change, the processes used to implement and operate public sector corporate governance reform are not clearly documented (Mark Considine \& Lewis, 1999; Edwards, 2002; Mir \& Rahaman, 2006) . In some cases there is evidence of corporate governance reform failure. Poor coordination of corporate governance initiatives, inadequate definition of roles and responsibilities, insufficient transparency in decision making and the potential for conflict of interests are examples of common implementation issues facing public sector managers.

\subsection{Defining the variables under investigation}

Variables investigated in this study are associated with two distinct stages of corporate governance reform: adoption and operation.

Corporate governance adoption and operation stages are distinguished by several characteristics. Adoption reflects the capacity of an organisation to interpret knowledge 
about corporate governance while operation reflects the capacity of an organisation to act upon that knowledge. Consequently, operation is related to 'action'.
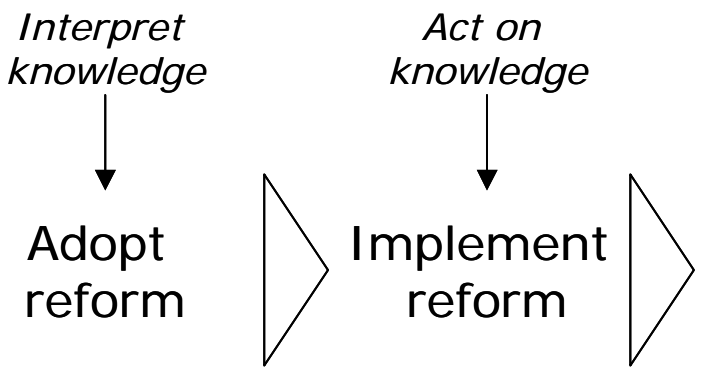

Proposed state

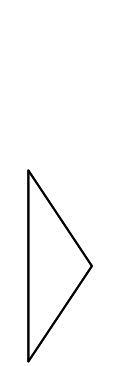

Figure 1: Stages in effecting change

Adapted from Joint Information Systems Committee (Northumbria University, 2007)

Closely allied to these characteristics is the notion that adoption is in many ways 'symbolic' and operation is 'real'. That is to say, adoption requires an organisation to agree on a policy setting while operation requires the organisation to put that policy into effect.

Variables within the stages of adoption and operation can be further categorised as either rational/scientific or political/cultural.

Rational/scientific factors are associated with scientific fact-finding methods to identify the right way to perform a task - a statement of hypothesis, collection of data, identification of alternatives, testing and then selection of action based on test results.

Rational/scientific factors are closely aligned with the Scientific Management school of thought, primarily represented by Taylorism, and its belief that by careful investigation of work, organisational practices can be refined and made more efficient (Wren, 2005). Taylor's approach was based on the notion of a single 'best way', determined after 
examining all the steps involved in a task, measuring the most efficient, and, most importantly, setting this method out as a set of procedures (Kanigel, 1997).

By rationalising an organisation with precise systems and instructions, employees are able to maximise their productivity. This systematisation of work methods involves the scientific analysis of all alternatives before a solution is identified. Rational/scientific factors are based on the premise that work-related tasks can be rationally examined and problems logically solved.

Political/cultural factors recognise that the culture of organisations is an important part of work along with the impact human behaviour has on decision making (Langan, 1979). Organisational culture is an amalgamation of the values and behaviour of the people in an organisation. It reflects the way people within an organisation relate to one another and how they work together to get things done (Deal \& Kennedy, 1982). In many ways, political/cultural factors go to the democratic

Culture is exhibited in the implicit rules and behaviour of an organisation where, even though the rules are not formally written down, employees know what is expected of them. Organisational culture can be a positive or negative attribute. A positive culture can prevent staff from becoming dissatisfied, help motivate staff and create positive perceptions by others. A negative culture has the opposite effect, that is to say it can demotivate staff and significantly contribute to dissatisfaction levels within the organisation. Negative culture can promote conflict, avoidance of responsibility and promote people playing politics to gain influence. 
The culture of an organisation is difficult to document, although it is less difficult to sense. For example, the culture of a large multi national corporation is quite different from that of a local community health service, or a family business. Culture is made up of the values and norms of the people that work in an organisation and are taught to new members as the correct way to perceive, think and feel (Schien, 1984). These values and norms effect organisational behaviour, strategies, image and services (Hatch, 1997). Previous studies about organisational culture, such as that conducted into change within a number of Queensland public sector agencies (Parker \& Bradley, 2000), have found that culture is difficult to change, particularly as a result of the limited understanding of change managers about the strong role culture plays in an organisation.

Rational/scientific and political/cultural factors recognise the existence of both a formal organisation with its rules, orders and plans simultaneously with an informal organisation comprised of complex human interaction, behaviour and expectations.

\subsubsection{Adoption of corporate governance reform}

\section{Rational/scientific factors}

Rational/scientific factors that influence the adoption of corporate governance reforms (RA) reflect formal methods and constraints affecting change.

These include drivers for change, such as externally imposed (central government) requirements for improved accountability or internally-led endeavours to improve efficiency. The need to improve service planning and delivery through enhanced coordination can also drive the adoption of corporate governance reform. These drivers 
are generally based on rational, fact-based arguments such as poor past performance or an emerging requirement for improved productivity.

The ability for state government departments to adopt change will also be affected by rational/scientific factors. These include the availability of resources (recurrent and capital) needed to implement and operate the reform. Regulatory requirements also play a role as these may either require a department to function in certain ways or constrain it from altering the status quo.

A key rational/scientific factor in the adoption of corporate governance reform is the level of corporate governance knowledge within departments and the skills needed to interpret and apply this knowledge to the organisation's context. The existing decisionmaking processes used within a department will also affect the adoption of corporate governance reform. A department with highly centralised controls will be better placed to adopt organisation-wide reform than a department with devolved controls.

\section{Political/cultural factors}

Acting in concert with rational/scientific factors are a range of political/cultural factors. These include the influence of interest groups (both internal and external) who may either support or oppose the adoption of corporate governance reform by a department. The influence of central government agencies over and above their formal responsibilities is a key political/cultural factor, and includes the ability of these agencies to influence the Premier and Treasurer who in turn may influence the Minister responsible for the department. 
The re-distributive effect corporate governance change will have on power and institutional relationships is also important. This political/cultural factor provides the motivation for many interest groups to either support or oppose corporate governance changes.

Corporate governance reform does not occur within an organisational vacuum. Changes are identified and proposed at the same time as other service delivery issues are occurring. Departments, particularly line departments, are responsible for maintaining service delivery at constant levels. There is limited scope for services to be disrupted by the introduction of new operating methods or procedures. For this reason, corporate governance change is often balanced with other organisational priorities. This can lead to a trade off between priorities resulting in the scaling down, or even non-adoption, of reform.

Given the role government department's play in managing and delivering services for citizens, community support (or concern) can also act as a political/cultural factor. For example, community support for greater department accountability may influence Government and departmental chief executives to adopt corporate governance changes. Community support is identified separately from interest groups as commonly held community views are generally broader than those held by constituent issue or population specific interest groups. 


\subsubsection{Operation of corporate governance reform}

\section{Rational/scientific factors}

Once reform has been adopted by a department, a range of further rational/scientific factors will affect its introduction and operation.

The attributes of the reform, including its scale, will significantly affect the ability of an organisation to operate it. Organisation wide change requires more effort to operate than a smaller scale reform (Robbins \& Barnwell, 2002). Accordingly, resource availability, both financial and non-financial, will also impact on how change is operated.

As was the case with reform adoption, the level of corporate governance knowledge and skills within on organisation will play a key role in operating corporate governance change. Knowledge about how to implement and successfully operate corporate governance reform along with the necessary skills to apply this knowledge are needed.

Once a decision to adopt reform has been made, then the communication of that decision (including the reasons for the change) will be an important factor in determining if the change will be subsequently implemented and operated. Information sharing processes that provide affected parties with knowledge of the decision and the steps necessary to implement it play a key role.

The dissemination of information is often affected in government departments by the hierarchical nature of public sector organisations. Information does not always reach 
the staff responsible for implementing change in a timely way. This impacts on the initial stages of implementation and can also impact on long term operation of the reform if insufficient information is provided.

Organisational control processes play a role in the operation of reform. A department with centralised control will be better placed to enforce the operation of a change than a department with devolved controls.

A further rational/scientific factor that impacts on the operation of corporate governance reform are time constraints. A change that is quickly implemented, without adequate understanding of the issues involved or its implications, will generally not operate as effectively as a change that is implemented following adequate research and consultation.

\section{Political/cultural factors}

Political/cultural support for corporate governance change both within and outside an organisation will shape how adoption occurs. The influences of internal and external interest groups again play a role.

In particular, the level of organisation support for change will be important. This support will be influenced by factors such as attitudes to innovation, managerial fear of losing control and the agenda of interest groups. These factors are affected by the culture of an organisation and its administrative history.

Competition with other priorities will influence the operation of corporate governance change. For example, depending on other priorities within the department, costs 
associated with implementation may be unaffordable, so are reduced, with a resulting loss of resources for operation. The number of actors in the change process will also influence how change in introduced, and consequently how it is operated.

Other political/cultural factors include the inherent nature of organisations to seek stability in response to change, potentially leading to a different outcome than was expected, and the continuity of leadership during the change process (Robbins 2001; Trader-Leigh 2002). Given the scale and scope of public sector change in the last decade, it is possible that change fatigue will also impact on the implementation and operation of corporate governance change (Garside, 1998). An organisation that has experienced extensive and ongoing change may be less likely or able to embrace the purpose of corporate governance change than an organisation that only has experienced mild, or no, change.

\subsection{Theoretical framework}

In this thesis, the framework developed by de Lancer and Holzer has been extended to produce a more comprehensive catagorisation of influences (see Figure 2:

Rational/Scientific and Political/Cultural Influence Matrix).

The framework developed by de Lancer Julnes and Holzer identified two categories of influences. This study has taken these categories and further developed them to produce a matrix that identifies a range of specific factors that may be encountered during the adoption and operation phases of reform. The framework has also been extended by including details of the expected relationship between the factors. 


\section{Adoption}

- External requirement for improved accountability

- External requirement for improved efficiency

- Internal drive to improve services through enhanced coordination

- Recurrent and capital costs including availability of resources

- Regulatory constraints

- Organisational knowledge and skills

- Organisational decision-making processes including increasing centralisation of control

\section{Operation}

- Reform attributes

- Organisational knowledge and skills

- Communication and information sharing processes

- Availability of resources

- Organisational control processes

- Time constraints

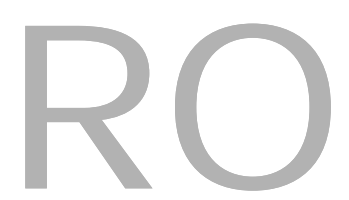

- Organisational support/culture

- agenda of interest groups

- attitudes to innovation

- attitude to why reform implemented

- managerial fear of losing control

- Administrative heritage

- Hierarchical nature of public sector organisations (or RO)

- Change fatigue

- Stability seeking responses to change

- Continuity of leadership

- Number of actors in change process

Figure 2: Rational/Scientific and Political/Cultural Influence Matrix

This new model identifies the factors impacting on the adoption and operation of corporate governance reforms according to the categories of rational/scientific and political/cultural influences described earlier. These influences are titled as: 
Rational/scientific adoption factors

Rational/scientific operation factors

Political/cultural adoption factors

Political/cultural operation factors
RA

RO

PA

PO

RA factors include a range of influences. They include the requirements for improved accountability and efficiency (Frumkin 2003; Sendt 2001), both frequently advanced by central agencies and regulators as reasons for organisational change (Scott, 2003). The drive from within an organisation to improve its services though enhanced coordination is also included (Bovaird and Loffler 2003), along with the impact existing decision making processes have on change adoption (Robbins 2001). The cost of change (both recurrent and capital) is also included as a RA factor, reflecting the potential constraint an organisation's budget has on decision making (Post and Altman 1994). The requirement of regulators, such as the Auditor General, may also constrain change so it similarly has been included. Lastly, the level of knowledge and skill within an organisation will have an important impact on decisions to adopt change (Post and Altman 1994).

PA factors include those issues relating to the influence on an organisation of interest groups, both internal and external, along with the concerns the community more generally may have about a proposed reform (Bovaird and Loffler 2003; Post and Altman 1994). The competition between other priorities in the decision making process (Trader-Leigh 2002) and the effect a change may have on relationships within the organisation (Robbins 2001; White 2000) are also included as PA factors. 
RO factors include the attributes of reform, organisational knowledge and skills, communication and information sharing processes (Stewart and Kringas 2003), availability of resources, organisational control processes and time constraints (Post and Altman 1994).

PO factors include organisational support and culture (including attitudes to innovation), administrative heritage (Post and Altman 1994), change fatigue (Stewart and Kringas 2003), stability seeking responses to change (Robbins 2001), continuity of leadership (Stewart and Kringas 2003) and the number of actors in the change process (Robertson and Seneviratne 1995).

The relationship between the factors affecting the adoption and operation of reform is complex. However, by placing the separate stages of adoption and operation into the context of rational/technocratic and political/cultural influences it is possible to predict the relationship as set out in Figure 3: Relationship between rational/technocratic and political/cultural factors.

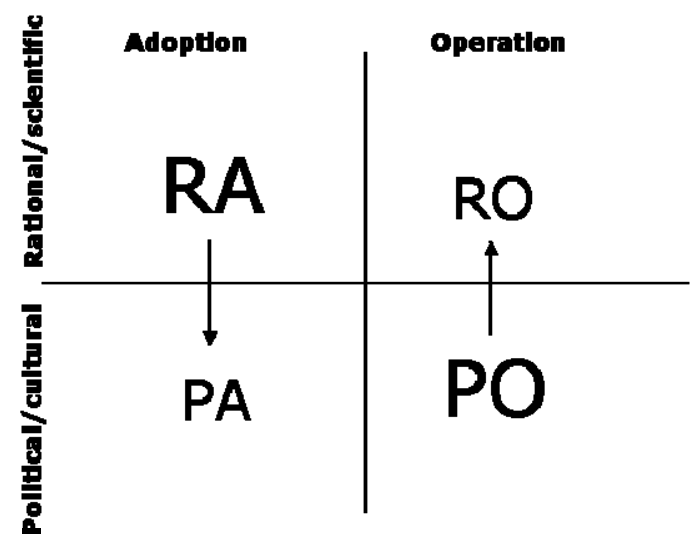

Figure 3: Relationship between rational/technocratic and political/cultural factors 
This change model relating to reform adoption and operation outlines the primary role rational factors play in the adoption phase of corporate governance reform and the prominent nature of political/cultural factors in their ongoing operation.

RA factors are expected to influence PA factors as the primary motivation in the adoption phase of reform. Corporate governance change is primarily shaped by rational/scientific influences, such as a drive to improve accountability, transparency or ethical decision making. This contrasts to the operation phase of reform where the primary motivation of the organisation is frequently driven from political/cultural sources, such as organisational culture and the administrative heritage of an organisation.

\subsection{Research propositions and hypothesis}

This study intends to identify and describe variables associated with corporate governance reform in Australian state government departments, particularly the factors that impact on the adoption and operation of reform. Its specific aims are to:

- determine how the Victorian Department of Human Services adopts and operates corporate governance reform;

- identify why particular arrangements and processes are used to adopt and operate corporate governance reform, including the identification of internal and external influences;

- explore the nature of internal and external influences and the impact these have on reform;

- categorise influencing factors according to their characteristics; 
- demonstrate the applicability of this categorisation to public sector corporate governance reform in other Australian state government departments; and

- develop a model for implementation of public sector corporate governance reform.

Based on the model outlined in Figure 3, it is proposed that:

1. Rational/technocratic factors will have a positive impact on the adoption of corporate governance reform

1.1. In particular, the factors that will have a positive relationship with the adoption of corporate governance reforms include:

1.1.1. External (central agency) requirements for improved accountability

1.1.2. External (central agency) requirements for increased efficiency

1.1.3. Internal drive to improve services through enhanced coordination

1.1.4. Availability of resources

1.1.5. Organisational control processes.

2. Political/cultural factors that will have a positive relationship with the operation of corporate governance reform include:

2.1. In particular, the following factors will impact on the ongoing operation of corporate governance reform

2.1.1. Organisational culture (including attitudes toward innovation; structural inertia)

2.1.2. Number of actors in change process

2.1.3. Change fatigue

2.1.4. Hierarchical nature of public sector. 
Accordingly, the following hypothesis were tested in this research:

Hypothesis $1\left(\mathrm{H}_{1}\right)$ - that in relation to the corporate governance reform, the adoption of reform will be positively related to factors that include:

$\mathrm{H}_{1} \mathrm{a} \quad$ External (central agency) requirements for improved accountability

$\mathrm{H}_{1} \mathrm{~b} \quad$ External (central agency) requirements for increased efficiency

$\mathrm{H}_{1} \mathrm{C}$ Internal drive to improve services through enhanced coordination

$\mathrm{H}_{1} \mathrm{~d} \quad$ Availability of resources

$\mathrm{H}_{1} \mathrm{e} \quad$ Organisational control processes

Hypothesis $2\left(\mathrm{H}_{2}\right)$ - that in relation to corporate governance reform, the operation of reform will be positively related to factors that include:

$\mathrm{H}_{2} \mathrm{a} \quad$ Organisational culture (including impact of reform on power and institutional relationships)

$\mathrm{H}_{2} \mathrm{~b} \quad$ Number of actors in change process

$\mathrm{H}_{2} \mathrm{C}$ Change fatigue

$\mathrm{H}_{2} \mathrm{~d} \quad$ Hierarchical nature of public sector 


\section{Chapter four: Research methodology}

\subsection{Introduction}

This chapter describes the methodology used to collect and analyse the research data that leads to answering the research questions. It contains the justification for the type of methodology chosen.

The chapter is organised into three major sections. Section 1 sets out research design issues, including type of study and unit of analysis. Section 2 describes research method issues, including study sample, survey tool and data collection procedures for phase one and phase two research stages. Section 3 identifies potential study limitations.

The student researcher was (is currently) employed as the Department of Human Services' Corporate Planning Manager and accessed qualitative and quantitative data required for phase one research as a component of this function. 


\subsection{Research Design}

Using the research design model provided by Cavana, Delahaye and Sekaran (2001), this study is described as follows.

\subsubsection{Type of Study}

The study is exploratory in nature and is intended to investigate the variables that influence corporate governance reform in Australian state government departments. The goal of the study is to determine how the various factors impact on the adoption and operation of corporate governance reform. In particular, the study aims to determine the relationship between the factors during the adoption and operation phases of corporate governance reform.

\subsubsection{Study Setting}

This study was a field study as factors were examined in the natural environment. There was minimal researcher interference.

\subsubsection{Unit of Analysis}

The unit of analysis for this project was Australian state government departments. Data for analysis was collected by formal, semi-structured interviews and questionnaire. A detailed discussion of these tools is set out below. 


\subsubsection{Time Horizon}

The study was cross-sectional with phase one data collected between October 2006 and November 2006. Phase two data was collected between November 2007 and December 2007.

\subsection{Research Method}

The first step was a literature search using Academic Search Premier, Blackwell Synergy, Business Search Complete, Emerald Fulltext, Expanded Academic ASAP, Ingenta and Sage Premier databases, available on Victoria University Library’s website. Journals accessed via these databases included Public Administration Review, Journal of Public Policy, Australian Journal of Public Administration, Academy of Management Review, International Journal of Public Sector Management, Harvard Business Review and the Journal of Organisational Change Management. This literature search informed the development of the conceptual framework.

In addition, various websites relevant to the topic of research were also referred to for publications. The sites searched included those of the Public Accounts and Estimates Committee of the Parliament of Victoria, Australian National Audit Office, Audit Office of NSW, Victorian Auditor General's Office, Office of the Auditor General for Western Australia, World Bank, Organisation for Economic Development and Cooperation (OECD), Department of Prime Minister and Cabinet and the various central agencies of Australian state governments. 
In order to obtain detailed information about corporate governance reform, data were collected in two phases. Phase one comprised of a case study with a focus on the Victorian Department of Human Services. Phase two comprised the collection of data from other Australian state government departments by a questionnaire.

Both qualitative and quantitative research methodologies were used to collect different types of information so that a better understanding of factors impacting on corporate governance reform might be obtained.

Figure 1 sets out an overview of the research design. 


\section{Research topic}

Factors impacting on the adoption and operation of corporate governance reform in Australian state government departments
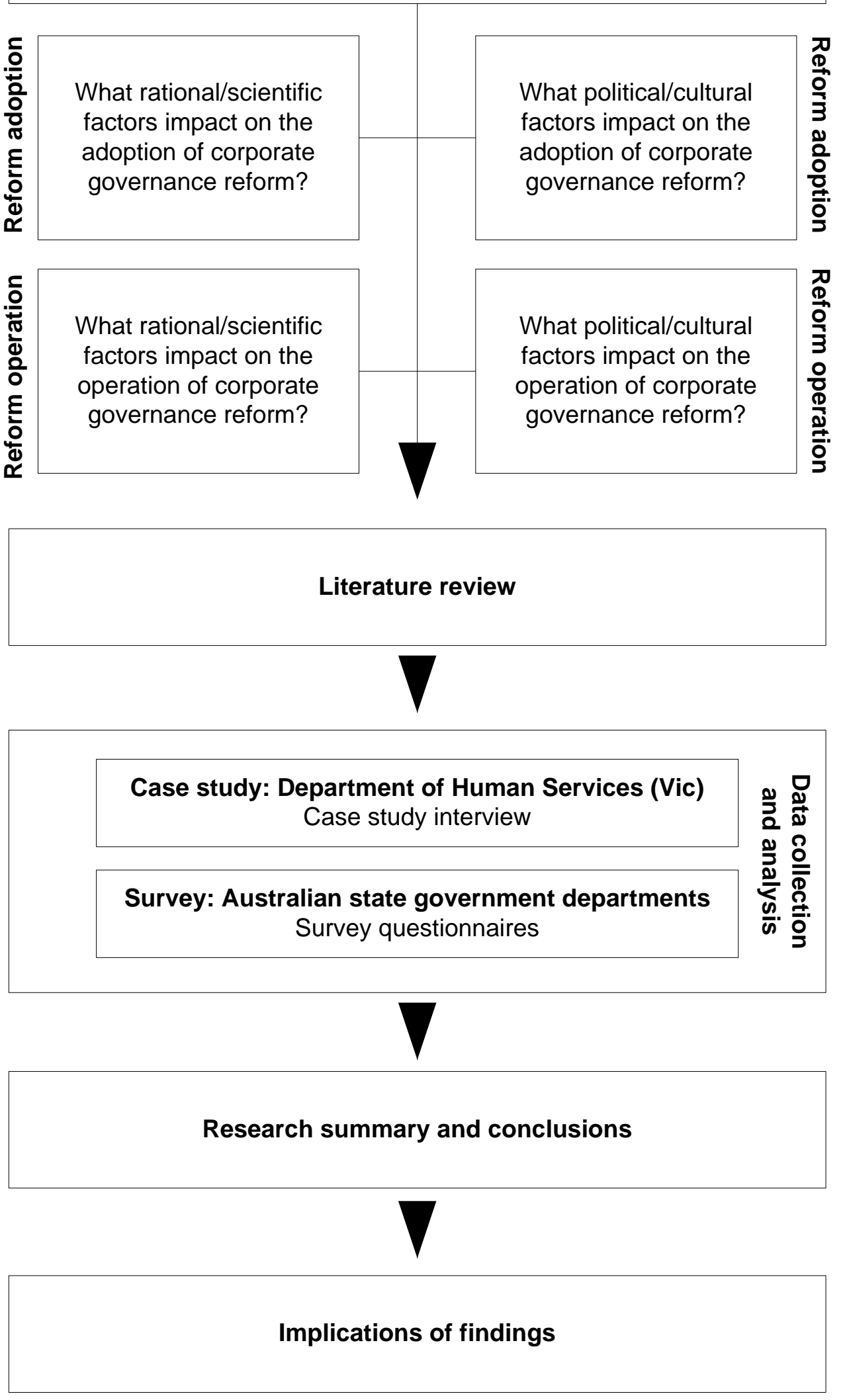

Figure 4: Research design 


\subsection{Phase one - Department of Human Services' case study}

Phase one was investigated using a case study approach.

Case studies provide the means by which a phenomenon can be studied with consideration of the context in which it occurs (Yin 1994). The study of organisational culture and its effects on organisational change is particularly suited to case studies as context is critical to understanding people's behaviours and interaction. In choosing a case study for phase 1 of this research, the researcher sought to contribute to the limited number of documented case studies that have addressed corporate governance reform and improvement in the public sector (Edwards 2002).

The appropriateness of qualitative methods for answering research questions raised in this study is strongly supported in the literature:

"Only qualitative methods are sensitive enough to allow the detailed analysis of change. In organisational research organisational dynamics and change are major areas of interest. With quantitative methods we may be able to assess that a change has occurred over time but we cannot say how (what processes were involved) or why (in terms of circumstances and stakeholders).” (Cassell, 1994)

A case study involves a study of an example - a case - of the phenomenon being researched (Ticehurst \& Veal, 2000). When using a case study approach, the researcher systematically gathers in-depth information on a single entity using a variety of data gathering methods (Cavana, Delahaye, \& Sekaran, 2001). The aim is to seek to understand the phenomenon by studying single examples. In particular, a case study seeks to determine the factors, and relationships among factors, that have resulted in the 
current behaviour or status of the subject of the study. In other words, the purpose of a case study is to determine why not just what (Gay \& Diehl, 1992).

Case studies are particularly well suited to new research areas or research areas for which existing theory seems inadequate (Eisenhardt, 1989). In relatively less know areas, such as the subject of this study, where there is less experience and theory available to serve as a guide, it is considered that an intensive study of a selected example is a useful method of gaining insight (Ghauri, Gronhaug, \& Kristianslund, 1995). There is also a consensus amongst researchers that a single case is appropriate for exploratory study where it serves as a first step to a later, more comprehensive, study (Yin, 2003).

Case studies secure information from multiple sources and allow evidence to be verified therefore avoiding missing data (Cooper \& Schindler, 1998). As most case studies are done through a review of existing historical material and records plus interviews, the case study method is quite similar to historical review, but it is different in the sense that there is a possibility of direct observation and interaction (Ghauri et al., 1995).

Case studies provide a greater emphasis on a full contextual analysis of fewer events or condition and their interrelations (Cooper \& Schindler, 1998). Given their emphasis on detail, case studies provide a valuable insight for problem solving, evaluation and strategy and provide for an indepth exploration of processes within an organisation (Hartley, 1994). 
Methodological issues associated with a case study include a researcher seldom being able to follow a pre-planned procedure or timetable (Ghauri et al., 1995) and the number of cases to be studied, along with the scope of the cases, are subject to modification.

It is often asserted that case studies are an easy research method, but this is a misconception (Ghauri et al., 1995). In fact, data collection is often much more demanding than surveys or other similar quantitative methods. A case study requires a researcher to collect data personally and unlike surveys, where data collection is more routinized, the researcher has to be skilled in the dynamics of a case needs to be able take advantage of opportunities offered during the data collection (Ghauri et al., 1995). Researchers must be able to ask relevant questions while also having the capabilities to listen and interpret the answers.

The major problems with case studies are possible observer bias, that is to say the researcher sees what he or she wants, and lack of generalisability (Gay \& Diehl, 1992). In addition the reliance on qualitative data makes support or rejection of a hypothesis more difficult (Cooper \& Schindler, 1998).

\subsubsection{Sample}

During the case study phase of the research (phase one), information was gathered from staff within the Department of Human Services with responsibility and/or involvement with corporate governance reform.

The phase one sample was a stratified selective sample comprising senior executives (including the department's Secretary) responsible for the overall adoption and 
operation of corporate governance reform (stratum 1); and executive officers responsible for implementing and operating elements of corporate governance reform (stratum 2).

The strata reflects the differing roles and responsibilities taken during the reform process.

- Strata A interviews - 8 subjects (representing the Department of Human Services' senior Executive group)

- Strata B interviews -20 subjects (representing senior managers responsible for implementing reforms)

Selective sampling was used to determine participants from each strata. Strauss (Strauss, 1987) describes selective sampling as an appropriate tool to choose a particular group of participants based on a reasonable, established set of dimensions determined in advance of the study's commencement

In this study, strata B participants were chosen based on their representation of the following dimensions:

- Involvement in key corporate governance reforms (see Chapter six Research Context for more information about the key corporate governance reforms adopted and implemented in the Department of Human Services))

- Males and females 


\subsubsection{Data collection procedure}

The prime source of data for the Phase one case study was through formal, semi structured interviews.

To gain informants, informal contact was made with staff at senior management levels to determine the likelihood of willingness to participate in the study. Formal contact was then made and that person invited to participate. Interviews for Strata A and B informants were then arranged. At the commencement of each interview, an explanation of the research was provided, permission was sought to record proceedings and participants were asked to sign a consent form agreeing to participate in the study. Each interview was the written up using the recording and from interview notes and other documents.

Each interview was comprised of 10 questions.

Question one invited participants to identify the key drivers associated with corporate governance reform in the Department of Human Services. Possible drivers included externally imposed requirements for improved accountability; internally led endeavours to improve decision making; poor organisational performance; and requirements for productivity improvement.

Question two asked participants to identify the impact (if any) the following factors had on the adoption of corporate governance reform: availability of resources; corporate governance knowledge and skills; decision making processes; influence of interest groups; and competing organisational priorities. 
Question three asked participants to comment on the impact (if any) the following factors had on reform operation: attributes of reform; availability of resources; corporate governance knowledge and skills; organisational control processes.

Question four focused on the culture of organisations and invited participants to details their experience in managing cultural change while adopting/implementing corporate governance change.

Question five invited participants to reflect on the role of communication in adopting/implementing corporate governance change.

Question six sought details of corporate governance reform failure. In particular, participants were asked to identify potential reasons for any failure such as low organisational support levels, poor implementation planning, inadequate resourcing; or unforseen consequences of reform.

Question seven sought to assess the participant's view on the department's readiness to accept any form of change, not just corporate governance reform.

Question eight asked participants to identify their role in past corporate governance reforms (instigator, participant, observer)

Question nine invited participants to detail their experience in building support for corporate governance change (participants were asked to relate this experience to building support amongst their peers, subordinates and superiors).

Question ten asked participants if they believe the department's ability to adopt/operate corporate governance reform has improved over time.

See Appendix 3 for details of the interview schedule. 
One on one semi structured interviews were used to collect data from Strata A and Strata B participants. The decision to use this method of data collection recognised their role as instigators, and in some cases both instigators and recipients of change. For this reason it was important to gain their perceptions of what changes they were seeking to implement and the nature of the influences that affected that change.

Semi-structured interviews were considered the most suitable method to achieve this as they allowed for the main topics and general themes to be targeted through specific questions while allowing the freedom to pursue other relevant issues as they arose (Maykut and Morehouse 1994).

Interviews were recorded and then transcribed. All data was studied to formulate response categories for coding. This coding maintained confidentiality and was used to assist in the interpretation of responses.

\subsubsection{Data analysis methods}

Data collection commenced with textual analysis of publications relating to corporate governance change within the department, such as annual reports. This analysis informed the focus and conduct of the stratified interviews. Both these sources of qualitative data then guided the development of the quantitative survey tool.

Qualitative data was analysed using NVivo software. This permitted the coding of information and the identification of themes. Coding was based on categories such as the driver of reform, factors impacting on adoption, factors impacting on operation and role of participant in reform, 
Data was also standardised through the use of matrices to enable comparison of responses. This analysis was useful in enhancing the generalisability of results and also deepening the understanding and explanation of results (Miles \& Huberman, 1994).

\subsubsection{Reliability}

To ensure reliability, the interview protocol was strictly adhered to. All interviews were digitally recorded. The data and name of interviewees were recorded and a numbering system was used to catalogue each interview.

A researcher’s diary was also maintained to record interview summaries as well as noting general observations. 


\subsection{Phase two - State government department questionnaire}

The phase one case study was used to inform the development of the survey

questionnaire. This questionnaire was then distributed via email to senior officers responsible for corporate governance change in each Australian state government department.

\subsubsection{Study population}

The population for the study comprised senior managers and change management staff of Australian state government departments.

At the time this study commenced data collection (November 2007), there were ninety seven state government departments in Australia.

\subsubsection{Sample selection}

The phase 2 sample was a purposive judgement sample and focused on staff within each organisation responsible for corporate governance functions.

Precautions were taken to choose samples who were experts and had in-depth knowledge of corporate governance reform adoption and operation to ensure that their answers provided evidence of the actual situation.

Chief Executive Officers comprised stratum 1 of the sample. These officers hold primary responsibility for corporate governance arrangements and are considered to 
hold both experience and knowledge of corporate governance reform in their organisations.

Senior executives and managers with corporate governance reform responsibilities comprised stratum 2 of the sample. These officers were identified from relevant state government senior staff directories. These directories were cross referenced against organisational arrangements details available from departmental websites to ensure these people continued to hold corporate governance reform responsibilities and were the most appropriate stratum 2 contact point in the organisation.

In several cases the survey invitation email elicited a reply advising of a more appropriate contact. A subsequent initiation was then sent to this person. These people were included in stratum 2. In most cases these respondents received the invitation where stratum 1 or another stratum 2 invitees considered this person the most appropriate officer to complete the survey based on their knowledge, experience or expertise.

\subsubsection{Probability Sampling}

All state governments departments were invited to participate (approximately 97 organisations as at November 2007). 


\subsubsection{Survey Instrument}

The questionnaire consisted of four parts (see Appendix 5).

Part one of the questionnaire related to general background information about the respondent and the organisation they worked for. It comprised ten questions including demographic information about organisation size, location and the respondent's position within the agency. This section also sought information about the length of the respondent's employment.

Part two of the questionnaire related to factors that influenced the operation of corporate governance reform within the agency. It comprised three groups of questions related to.

- Group one focused on rational/scientific (RA) factors. These questions investigated the extent to which rational/scientific factors influenced the adoption of corporate governance reform.

- Group two focused on political/cultural (PA) factors. These questions investigated the extent to which political/cultural factors influenced the adoption of corporate governance reform.

- Question three asked respondents to identify the most important factor impacting on the adoption of reform.

Part three of the questionnaire focused on the ongoing operation of corporate governance reform. It comprised three groups of questions.

- Group one focused on rational/scientific (RO) factors. These questions investigated the extent to which rational/scientific factors influenced the operation of corporate governance reform. 
- Group two focused on political/cultural (PO) factors. These questions investigated the extent to which political/cultural factors influenced the operation of corporate governance reform.

- Question three asked respondents to identify the most important factor impacting on the adoption of reform.

Part four of the questionnaire focused on collecting other information related to corporate governance reform. It comprised six questions:

- Open ended questions about factors impacting on the adoption and operation of corporate governance reform and suggestions for future reform

- .Questions about the number of reforms experienced by the respondent, the focus of reform in the respondent's organisation and whether the respondent had received training related to corporate governance reform

\subsubsection{Data collection procedure}

The data source for Phase two was a formal questionnaire distributed via email. The researcher sent an email to all state government departments in Australia to invite them to complete the questionnaire (see Appendix 4). The email also contained a link to the plain language statement about the research project.

Email contact details were based on the identification of both the agency's chief executive officer and a senior officer responsible for the management of corporate governance processes. This information was obtained via respective State Government directories and departmental internet sites. In instances where this information was not 
readily available, contact details were sought by telephone contact with the office of the chief executive of the respective agency.

The email explained the details of the study and asked that questionnaires be completed within two weeks. Reminder emails were sent to survey invitees seven and two days before the final response date. Several further emails were sent to invitees who had not responded, or only partially responded, by the final response date.

\subsubsection{Confidentiality}

Ensuring the confidentiality of the data was important not only to retain privacy of the respondents, but to ensure that the respondents provided accurate and honest responses to the questions

Prior to conducting the study, the proposal was submitted to Victoria University's Human Research Ethics Committee. The application addressed issues of privacy and confidentiality, management of potential risk and the information to be provided to participants. Data was aggregated and no individual responses were reported, ensuring confidentiality.

The questionnaire was anonymous.

HREC approval for research phases one and two is set out in Appendix 1. 


\subsubsection{Rating Scale}

A Likert Scale was used as the basis for the closed questions in both questionnaires.

This scale examined how strongly subjects agreed or disagreed with the statements on a five-point scale. A Likert Scale has an odd total of response points and the midpoint is either neutral or a passing level (Cavana, Delahaye and Sekaran 2001).

The following anchor points were used in this study:

\begin{tabular}{|c|c|c|c|c|}
\hline Strongly disagree & Disagree & Neither agree or disagree & Agree & Strongly Agree \\
\hline 1 & 2 & 3 & 4 & 5 \\
\hline
\end{tabular}

Table 6: Study Likert Scale

\subsubsection{Data Analysis Methods}

Four specific sets of data were collated from the sample population:

1. General information, including organisational and respondent demographics (Part one of the survey)

2. Perceptions about issues affecting adoption of corporate governance reform in Australian state government departments (Part two of the survey)

3. Perceptions about issues affecting the operation of corporate governance reform in Australian state government departments (Part three of the survey)

4. Other information about corporate governance reform, including responses to open ended questions (Part four of the survey). 
The Statistical Package for the Social Sciences (SPSS) was used to record and analyse data. Frequency distribution was used to summarise the responses to each question. Cross-tabulations were performed for each question along with Chi-square $\left(\mathrm{x}^{2}\right)$ testing for independence.

More information about data analysis calculation processes is set out in chapter seven phase two results.

To assist in the interpretation of results, where appropriate 'strongly disagree' and ‘disagree’ responses were coded as ‘disagree’ and where appropriate ‘strongly agree’ and 'agree' responses were coded as 'agree'. Blank responses were omitted from the calculation of results. This was considered the most appropriate way to handle missing data and to enhance the validity of the study (Cavana, Delahaye and Sekaran 2001).

To meet minimum cell count requirements for Chi-square testing, categories within some variables were also collapsed as required.

\section{Multivariate analysis}

Factor analysis, a form of multivariate analysis, was undertaken to explore correlations between variables. Multivariate analysis of variance, often referred to as MANOVA, is a generalisation of the usual univariate analysis of variance, ANOVA. The new aspect of MANOVA compared to ANOVA, is that instead of comparing $k$ group means for only one dependent variable, $k$ group means for $p$ dependent variables can be compared simultaneously (Ghauri et al., 1995) 
To perform one MANOVA is in most cases a more powerful procedure that conducting $p$ univariate ANOVAs. Group differences that are not revealed using several ANOVAs may be found using MANOVA. The reason is that MANOVA takes into account the correlations between the dependent variables. Interpretation of results may also be more meaningful using MANOVA (Ghauri et al., 1995)

\subsubsection{Reliability}

Responses were tested for reliability using Cronbach’s coefficient alpha. This is the most popular test of inter-item consistency reliability (Cavana et al., 2001). The Crohnbach's alpha is a measure of the intercorrelations between the various indicators used to capture the underlying construct (Ghauri et al., 1995). Inter-item consistency reliability is a test of the consistency of respondents' answers to all the items in a measure. To the degree that items are independent measures of the same concept, they will be correlated with on another. (Cavana et al., 2001).

\subsection{Section 3: Study Limitations}

The limitations associated with the phase one and phase two components of this research are set out below.

\subsubsection{Phase one research limitations}

Limitation associated with qualitative data include: 
- The apparent simplicity of qualitative data may mask its complexity, requiring high levels of care and self-awareness on behalf of the researcher (Miles \& Huberman, 1994).

- Reliance on qualitative data makes acceptance, or rejection, of hypotheses difficult (Cooper \& Schindler, 1998). This research was not significantly affected by this limitation as the intention of phase one was only to validate the conceptual model for testing during phase two.

- Qualitative data is frequently maligned as 'scientifically worthless' because they do not meet minimal requirements for comparison (Cooper \& Schindler, 1998). Again, qualitative research in this project was used to validate concepts rather enable scientific comparison.

- Risk of collecting too much information. This can result in more 'noise' than information. A large amount of information was collected during phase one interviews and in summarising and coding this information some detail may have been lost. To minimise this risk, where possible direct quotes have been used in the presentation of results.

- Time consuming. Compared to quantitative research, qualitative research can be significantly more time consuming.

\subsubsection{Phase two research limitations}

Surveys are a widely used technique for gathering data from large populations. They provide a quick, inexpensive and accurate means of assessing information about a population. Despite these advantages, surveys also have limitations. In particular, nonresponse rates can restrict the effectiveness of surveys. Few surveys have a 100\% response rate and it is hard to know whether a non-respondent has refused to participate 
or is just indifferent (Zikmund 1997). Reasons for not responding to the survey invitation include respondents considering themselves ill equipped or unable to find time. People who do respond may hold strong views on the question asked relative to those who did not respond. This view may then be overrepresented (Czaja \& Blair, 1996).

Other problems encountered when using surveys include deliberate falsification, unconscious misrepresentation and response bias (Zikmund 1997). The investigator is also prevented from learning the respondent's motivation for answering questions and respondents may be limited from providing free expression of opinions due to instrument design (Orlich 1978).

After consideration of survey advantages and disadvantages, it was considered a survey was the most effective and efficient means to collect data for Phase two of this study.

The mixed method approach employed in this research is also considered to respond at least partially to each of the limitations identified. 


\section{Chapter five: Context of Phase one case study}

\subsection{History of Department of Human Services}

The Department of Human Services was created in April 1996 by combining agencies responsible for housing, youth affairs and health and community services. It is the largest of the Victorian 'mega' departments (Department of Human Services (Victoria),

2007b). It includes the responsibilities of the Ministers for Health, Mental Health, Community Services and Housing (Department of Human Services (Victoria), 2007a). At the time the phase one research was conducted the department also included the responsibilities of the Minister for Children (these function were transferred to a newly created Department of Education and Early Childhood Development in August 2007).

\subsection{Department of Human Services' objectives}

The mission of the department is to enhance and protect the health and wellbeing of all Victorians, emphasising vulnerable groups and those most in need (Department of Human Services (Victoria), 2007a).

The organisation has six objectives that support this mission:

1. Building sustainable, well managed and efficient human services.

2. Providing timely and accessible human services.

3. Improving human service safety and quality.

4. Promoting least intrusive and earliest effective care.

5. Strengthening the capacity of individuals, families and communities. 
6. Reducing inequality be improving health and wellbeing, particularly for disadvantaged people and communities.

\subsection{Organisational profile}

\subsubsection{Service delivered}

The principal responsibilities of the Department of Human Services include funding and/or delivering the following types of services:

- Health care services, including mental health services, through public hospitals, community health services and ambulance services.

- Residential and rehabilitation care for older persons, including assistance to enable older people to live independently.

- Accommodation and support services for people with disabilities.

- Statutory responsibilities to vulnerable children and young people in relation to child protection and youth justice.

- Health promotion and protection, including public health services and emergency management.

- Alcohol and drug prevention and treatment services.

- Concessions to low income groups to improve the affordability of essential services. 


\subsubsection{Budget}

In 2007-08 the department's total expenditure was approximately $\$ 13$ billion. This represented around 38 percent of total Victorian government expenditure on services (Department of Human Services (Victoria), 2007a). The department also owns and controls assets valued in excess of \$22 billion (Unpublished - Department of Human Services, 2007a). These include assets such as hospitals, community residential units and juvenile justice facilities.

\subsubsection{Organisational attributes}

\section{Structure}

The department operates a hybrid of divisional and functional structures. It includes groupings of positions according to their main functional or specialised area (functional structure) as well as groupings according to similarities of products and geography (divisional structure) (refer Figure 5: Department of Human Services Organisational Structure (April 2008).

Major organisational units in the department include (Department of Human Services (Victoria), 2007b):

- Metropolitan Health and Aged Care Services Division, responsible for metropolitan health and aged care services and program responsibility for acute health, sub-acute health and ambulance services.

- Rural and Regional Health and Aged Care Services Division, responsible for rural and regional health and aged care services and program responsibility for aged care services, primary and community health and public health services. 
- Mental Health and Drugs Division, responsible for mental health and drug treatment services.

- Children, Youth \& Families Division, responsible for child protection and placement support, family and parenting support, sexual assault and family violence, youth and youth justice services and state concessions.

- Disability Services Division, provides and funds services for people with intellectual, physical, sensory and neurological disabilities and acquired brain injury

- Housing and Community Building Division, provides affordable and adequate housing assistance to those most in need of housing assistance.

- Five rural and three metropolitan regions responsible for working collaboratively with agencies to plan and deliver local services. 
Secretary

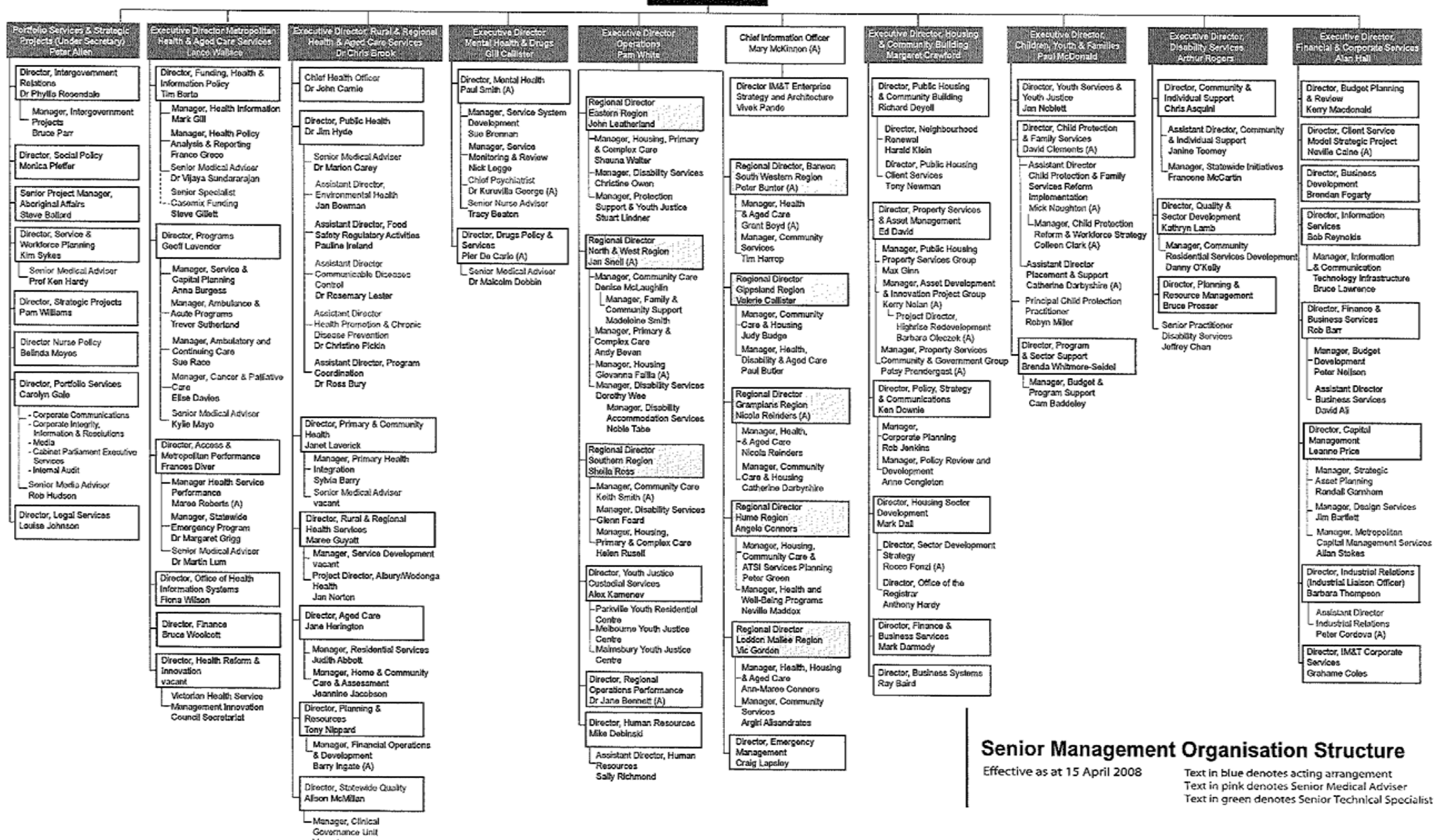

Figure 5: Department of Human Services Organisational Structure (April 2008) 


\section{Staffing}

The Department of Human Services directly employs around 11,500 people. These staff cover a range of workforce sectors, job classifications and geographic work locations. Approximately seventy seven percent of staff are located in the department's eight regions (Department of Human Services (Victoria), 2007a).

The department also funds organisations such as hospitals and community service agencies that collectively employ in excess of 90,000 people (Department of Human Services (Victoria), 2007a). Nearly eighty percent of the department's budget is spent on services provides by these partner agencies (Department of Human Services (Victoria), 2007a).

\section{Organisational climate}

The department conducts a biennial assessment of staff satisfaction with their work and working environments. The most recent employee climate survey was conducted in 2007. The results indicated employees were (Unpublished - Department of Human Services, 2007b):

- Committed

- Diverse

- Values drive

- Held high expectations of workplace, organisation and self

- Seventy five percent of employees saw a future for themselves in the department

- Eighty percent of employees would recommend working for the organisation 


\subsection{Corporate governance arrangements}

The structures for corporate governance in the Department of Human Services are set out in the department's annual report (Department of Human Services (Victoria), 2007b) (see Figure 6: Department of Human Services corporate governance arrangements for an outline of these arrangements).

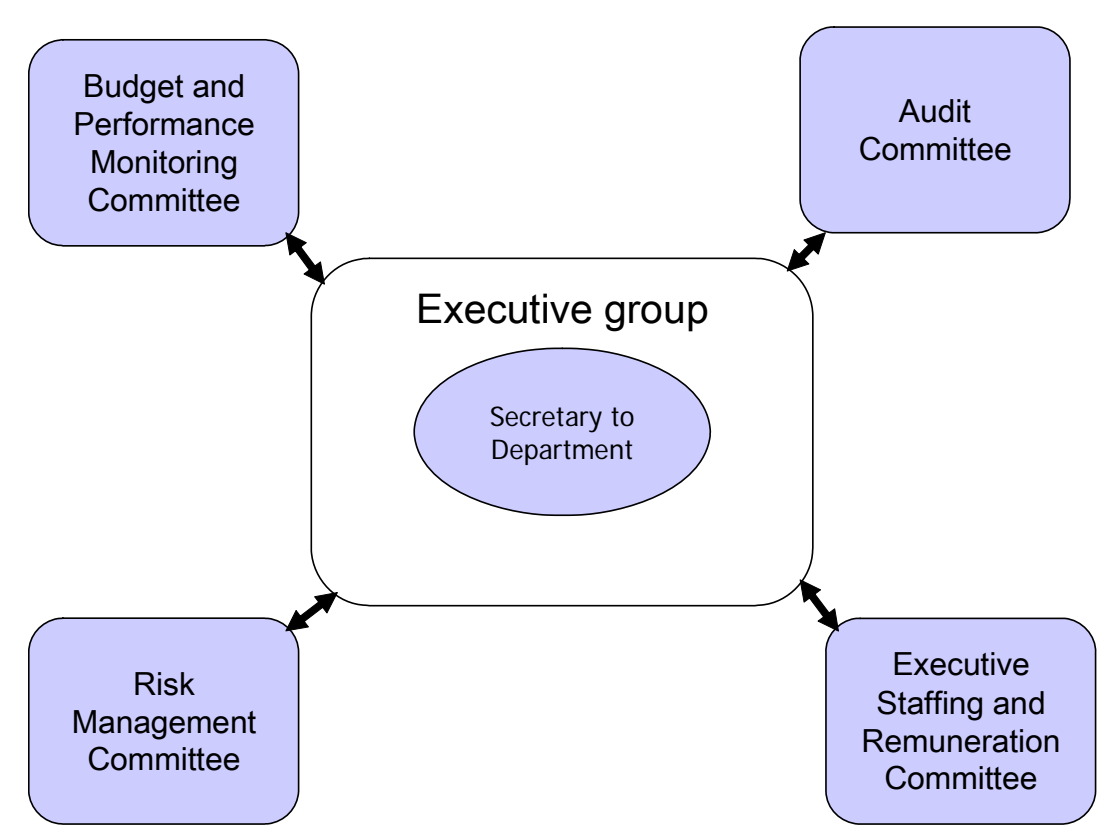

Figure 6: Department of Human Services corporate governance arrangements

The Secretary, as head of the department, is identified as responsible to the human services ministers for the overall management of the department. The Secretary and the department's executive directors collectively operate as the organisation's executive decision making body. They meet weekly to collectively manage issues across the 
department. Executive Directors report directly to the Secretary and are individually responsible for performance of their division (Department of Human Services (Victoria), 2007b).

A series of committees provide corporate governance support to the Secretary and Executive group (Department of Human Services (Victoria), 2007b):

- The Department’s Budget and Performance Monitoring Committee makes recommendations to the Executive group on long term budget strategy for the portfolio

- The Audit Committee assists the Secretary in reviewing the effectiveness of the department's internal controls, reliability of financial reporting and compliance with applicable regulation

- The Risk Management Committee is responsible for monitoring and reporting on major risks and risk management performance.

- The Executive Staffing and Remuneration Committee provides an independent approach to setting executive remuneration, including the classification of roles.

The department's corporate governance committees are also supported by a quarterly performance reporting process that focuses on key performance indicators and strategic targets (Department of Human Services (Victoria), 2007b). 


\subsection{Corporate governance reforms}

Recent major reforms undertaken in the department that involve corporate governance changes include, but are not limited to:

\subsubsection{Project-based approach to strategic issue management}

During 2001 a process to use 'strategic projects' to address key strategic issues facing the department and requiring high levels of cross organisational coordination was established (Unpublished - Department of Human Services, 2001b). This involved employing a rigorous project management methodology to ensure the on-time delivery of project goals.

Issues identified as potential strategic projects included those that:

- Addressed issues of high social, environmental, financial to, and priority for, the community, ministers and/or the department

- Prepared for future changes in the environment

- Ensured maximum savings and/or high materiality

- Addressed an issue which the department has committed to resolve.

- Addressed a cross-divisional issue or a single divisional issue that would benefit from focussed effort and corporate attention and oversight.

These projects required assignment of responsibility for the management of the projects. An existing division responsible for policy development was given management of these 
projects and renamed Strategic Projects Division. Key changes included leadership changes, reallocation of resources across the new divisional structure and the development of new protocols for project identification and cross department coordination.

\subsubsection{Creation of geographic-based health divisions}

Also during 2001 separate metropolitan health and aged care and rural and regional health and aged care divisions were created. These replaced organisational units previously focused on hospital care (Acute Care Division) and community based care (Aged, Community and Mental Health Division). Each new division was given responsibility for integrating the health and aged care services delivered in its geographic area (Unpublished

- Department of Human Services, 2001a). These divisions were also given statewide policy and program responsibilities for specific areas of services. For example, this included the Metropolitan division being given responsibility for Mental Health policy and program direction and the Rural and Regional division being given responsibility for Aged Care policy and program direction.

Key changes included leadership changes and reallocation of resources across the new divisional structure.

\subsubsection{A strategic approach to risk management}

In 2002 the Department's Executive established a strategic project to introduce a department-wide risk management program. This recognised the difficulty the department 
was experiencing in adequately managing the risks inherent in the large and diverse range of services it funded and delivered. A risk management committee was subsequently established to oversee the development of the program. The framework that was developed identified new policies and practices for systematic risk management. Key changes included the establishment of new processes and accountabilities for the identification, analysis, evaluation and treatment of key risks (Department of Human Services (Victoria), 2004).

\subsubsection{Establishment of an Office for Children}

In 2004 the Government announced the establishment of a new Office for Children.

The objectives of the revised arrangements for child-related functions were to (Unpublished - Department of Human Services, 2005b):

- Focus on improving outcomes for children through research, policy development and outcomes monitoring, coordinate the effort of all departments and collaborating with local and national Governments.

- Deliver existing children's services in a more integrated way, placing greater emphasis on the early years and continuing to protect the most vulnerable children.

- Strengthen the department's attention to strategic planning, better informed investment and quality of children's services delivery through sector development, quality frameworks and performance monitoring.

To achieve these objectives a number of structural changes occurred, including the transfer of functions and changed reporting arrangements. 
Note: as a result of machinery of government changes in August 2007, functions associated with the Office for Children have now been transferred to the Department of Education and Early Childhood Development.

\subsubsection{Amalgamation of Northern and Western Metropolitan regions}

The Department's North and West Metropolitan Region was formed in March 2004 with the amalgamation of the former Northern and Western Metropolitan regions. Following the announcement of the 2003-04 State Budget, the Department of Human Services was required to achieve a savings target of \$36.4 million for the 2003-04 financial year (Department of Treasury and Finance (Victoria), 2003). The major savings initiative that was proposed to meet this target was the amalgamation of the Western and Northern Metropolitan regions (Unpublished - Department of Human Services, 2005a). Key changes that occurred as part of the amalgamation included changes in regional leadership, changed reporting arrangements and changes to resource levels.

\subsection{6 'Joining up' decision making in the Health portfolio}

The Department's Executive group traditionally met on a weekly basis to discuss the management of organisational issues. During 2006 in recognition of increased government interest in health-related issues associated with the National Reform Agenda (Council of Australian Governments (COAG), 2006) and to address coordination issues associated with multiple health divisions (Unpublished - Department of Human Services, 2001a), a 
separate weekly meeting exclusively related to health issues was established. The Health Executive is a sub group of the full Executive group, and is focused on health topics.

The Health Executive comprises the following members:

- Secretary

- Under Secretary, Portfolio Services and Strategic Projects

- Executive Director, Regional and Rural Health and Aged Care Services

- Executive Director, Metropolitan Health and Aged Care Services

- Executive Director, Mental Health and Drugs

- Executive Director, Financial and Corporate Services

- Executive Director, Operations

Key changes that occurred as part of the amalgamation included changes in protocols for cross departmental coordination. 


\section{Chapter six: Corporate governance adoption and operation in the Department of Human Services}

\subsection{Introduction}

The focus for this research stage was corporate governance reform in the Victorian Department of Human Services. By undertaking this case study a more appropriate and sensitive data collection instrument for the stage 2 survey was established.

The case study took the form of a series of semi-structured interviews with senior executives (Stratum 1) and senior and middle managers (Stratum 2). The structure and content of the questions used in the interviews sought to validate the terminology and concepts that would be later used in the survey questionnaire to be distributed to corporate governance reform leaders in state government departments across Australia.

\subsection{Sample group}

The purposive judgement sample was comprised of two strata. Stratum one consisted of eight people making up the department's senior leadership group and included the department's Secretary, Under Secretary and Executive Directors (one Executive Director chose not to participate in the study).

The stratum 1 sample consisted of five men and three women. The functions managed by stratum 1 participants ranged in size from approximately 549 directly employed staff to 
116 directly employed staff. Resources managed by stratum 1 participants ranged from \$6.07 billion to \$1.04 billion.

Stratum 2 sample consisted of eight people and included four men and four women.

\subsection{Interview protocol}

\subsubsection{Interview process}

The researcher first made contact with participants by email. Participants were given an overview of the project, the objective of the interview and invited to participate. A copy of a plain language statement for research participants was also attached (refer Appendix 2). All but one person in Strata 1 agreed to participate. All people in Strata 2 agreed to participate.

Following agreement to participate, an interview time was arranged and a confirmation email sent to each participant. This confirmation email included an advance copy of the interview questions (refer to Table 7: phase one interview questions and objectives) and examples of recent corporate governance reforms implemented within the department to assist participant interview preparation.

At each interview, permission to record responses was sought from participants. Transcripts of each individual interview were then produced. For the purposes of this study, each transcript was then coded using Nvivo software to allow thematic analysis. Codes related to: 
- Drivers of change

- Adoption factors

- Operation factors

- Organisational culture

- Reform failure

- DHS acceptance of change

- Role of subject in reform

- Approaches to building support for reform

- Examples of DHS corporate governance reforms

Direct quotes are used to support the narrative throughout this paper.

\subsubsection{Interview objectives and questions}

Table 7: phase one interview questions and objectives

\begin{tabular}{|c|c|}
\hline Interview objective & Questions \\
\hline $\begin{array}{l}\text { Test the contextual relevance of } \\
\text { public sector reform drivers. }\end{array}$ & $\begin{array}{l}\text { Question } 1 \\
\text { What do you consider have been the key drivers of corporate } \\
\text { governance reform in the department over the past 5-10 years? } \\
\text { 1. Externally imposed requirement for improved (or changed) } \\
\text { 2. Internally-led endeavours to improve decision making } \\
\text { 3. Poor performance } \\
\text { 4. Productivity requirements } \\
\text { 5. Other }\end{array}$ \\
\hline
\end{tabular}




\begin{tabular}{|c|c|}
\hline Interview objective & Questions \\
\hline $\begin{array}{l}\text { Test the research propositions } \\
\text { associated with the specific } \\
\text { factors that impact on the } \\
\text { adoption and operation of } \\
\text { corporate governance reform. }\end{array}$ & $\begin{array}{l}\text { Question } 2 \\
\text { What impact, if any, do you consider the following had on reform } \\
\text { adoption in DHS } \\
\text { 1. Availability of resources } \\
\text { 2. Corporate governance knowledge and skills } \\
\text { 3. Decision making processes } \\
\text { 4. Influence of interest groups } \\
\text { 5. Competing organisational priorities } \\
\text { 6. Other (please specify) } \\
\text { Question } 3 \\
\text { What impact, if any, do you consider the following had on reform } \\
\text { operation in DHS? } \\
\text { 5. Organisational control processes } \\
\text { 6. Other (please specify) } \\
\text { 3. Attributes of reform } \\
\text { 4. Corporate governance knowledge and skills }\end{array}$ \\
\hline $\begin{array}{l}\text { Gauge the role and importance of } \\
\text { organisational culture in } \\
\text { corporate governance reform } \\
\text { processes }\end{array}$ & $\begin{array}{l}\text { Question } 4 \\
\text { 1. How would you describe the culture of DHS? } \\
\text { 2. In your experience, is organisational culture a significant issue } \\
\text { in adopting and operating corporate governance reform? }\end{array}$ \\
\hline
\end{tabular}




\begin{tabular}{|c|c|}
\hline Interview objective & Questions \\
\hline $\begin{array}{l}\text { Gauge the role and importance of } \\
\text { communication in corporate } \\
\text { governance change processes }\end{array}$ & $\begin{array}{l}\text { Question } 5 \\
\text { What role do you think DHS communication processes play in the } \\
\text { adoption and operation of corporate governance change? }\end{array}$ \\
\hline $\begin{array}{l}\text { Determine impediments to } \\
\text { governance reform, including } \\
\text { testing the role and importance of } \\
\text { reform adoption and operation } \\
\text { factors identified in questions } 2 \\
\text { and } 3\end{array}$ & $\begin{array}{l}\text { Question } 6 \\
\text { Can you think of a sound/feasible corporate governance reform that was } \\
\text { not able to be implemented? What was the reason for the } \\
\text { implementation failure? } \\
\text { 1. Low Organisational support level } \\
\text { 2. Poor implementation plan } \\
\text { 3. Insufficient resourcing } \\
\text { 4. Unforeseen consequences } \\
\text { 5. Other (please specify) }\end{array}$ \\
\hline $\begin{array}{l}\text { Gather further information about } \\
\text { corporate governance reform } \\
\text { processes, including how } \\
\text { participants address adoption and } \\
\text { operation factors identified in } \\
\text { questions } 2 \text { and } 3\end{array}$ & $\begin{array}{l}\text { Question } 8 \\
\text { What has your role been in adopting and implementing corporate } \\
\text { governance reform? }\end{array}$ \\
\hline
\end{tabular}




\begin{tabular}{|l|l|}
\hline Interview objective & Questions \\
\hline & $\begin{array}{l}\text { Question 9 } \\
\text { Have you had to build support for corporate governance reform? }\end{array}$ \\
$1 . \quad$ Support amongst your peers \\
$2 . \quad$ Support from subordinates \\
$3 . \quad$ Support from superiors
\end{tabular}




\subsubsection{Data analysis}

This section discusses the results of the phase one investigations in relation to the interview objectives as set out in Table 7: phase one interview questions and objectives on page 108.

\subsubsection{Drivers of public sector reform}

Interview subjects confirmed the existence of the expected drivers of public sector reform. These included externally imposed requirement for improved (or changed) accountability, internally-led endeavours to improve decision making, poor performance and productivity requirements. Two additional factors related to externally imposed requirements for change were also identified by respondents:

1. implementation of new government policy

2. compliance with regulatory requirements

These are discussed in more detail below.

Overall there was strong agreement that the drivers of reform varied and, as the context for each corporate governance change was different, a common set of influences could not be identified. Despite this, most interview subjects agreed that the need to improve performance played a role in many corporate governance changes implemented in the department. Similarly, most subjects considered internal drivers played a more prominent 
role in reform than externally imposed requirements. Reasons given for this primacy centred on notions that external influences did not dominate the department's decision making and that the organisation, along with Ministers, were responsible for setting the state’s human services performance agenda.

There was no substantial difference in responses between strata 1 and strata 2 participants about corporate governance reform drivers, other than differences in importance assigned to externally-led accountability changes and efforts to improve productivity.

\section{Internally-led endeavours to improve decision making}

Responses to this driver included views that many corporate governance reforms are really internal issues and that the department's 'Secretary was the strongest driver for change', based on her schedule to improve organisational performance.

\section{Externally imposed requirement for improved (or changed) accountability}

Only stratum 1 interviewees identified externally imposed requirements as a factor in government reform, although this was not considered to dominant change:

There was some external pressure for the creation of geographic health divisions, but it was much more driven by (an internal) need for service integration

Part of geographic health division creation was meeting the public administration view of Premier and Cabinet Secretary 


\section{Poor performance}

Responses to this driver focused on improving performance from satisfactory rather than unsatisfactory levels. Most considered poor performance to have little effect on reform efforts, rather the pressure for change was based around improving performance 'not because performance was poor but improvement was possible'. In support of this, one interviewee identified that the department's creation of strategic projects to deal with high priority issues was 'driven by an analysis that our closure of projects could be improved'.

It was also observed that the department's corporate governance reforms have not recently been driven to the extent that poor human services performance has in other states, such as corporate governance changes in Queensland associated with child protection and medical registration. An interviewee commented that this may be because 'Victoria's era of scandalous child protection performance was in the 1980's and resulted in the introduction of mandatory reporting'.

\section{Productivity requirements}

There was no consensus about the role of productivity improvement in driving corporate governance reform; several interview subjects disagreed strongly with the suggestion that reform was a result of productivity improvement (these subjects tended to be more senior staff) while others subjects could identify at least one reform they considered to be heavily driven by budget savings. 
It appeared that that most interviewees viewed productivity improvement to be associated with budget savings. Consequently interviewees considered it be a negative organisational requirement focused on reducing staffing or service levels.

In disagreeing with the suggestion that productivity improvement led corporate governance reform, senior staff stated 'nothing was done for productivity reasons' and 'no reforms were driven by productivity'. This contrasts with stratum 2 respondents who considered that 'savings requirements often drive changes, the job of the department is to determine what is politically acceptable' and many considered 'regional amalgamation to be a clear example'. Most statum 1 interviewees considered regional amalgamation not to be driven by productivity requirements.

The differences between stratum 1 and stratum 2 may be a result of poor communication, see below for a discussion of the role of communication in corporate governance reform.

\section{New government policy}

This new factor was identified by several interviewees. A range of examples in support of the factor were identified. These included:

Joining up government is externally driven as it is a policy and philosophy of current government

Creation of an Office for Children was driven by political forces....the Premier's Committee on Early childhood was the genesis. No bureaucrat was on the committee 
Both had an impact on the department's corporate governance, involving changes to processes for decision-making and resource allocation. Government policy exists partly through its organisation (Arts \& Van Tatenhove, 2004) which includes departments, instruments and the division of tasks. Indeed, several studies have identified a shift in policy to be a fundamental component in corporate governance changes in many industrialised states (Jordan, Wurzel, \& Zito, 2005).

Interviewees identified new government policy as different from externally imposed requirements because the focus was on the implementation of government policy as an ongoing function of the department.

\section{Regulator requirements}

This new factor was also identified from interview responses. Examples of regulatory requirements included:

Risk management was imposed by the Auditor General and Department of Treasury and Finance.

Occupational health and safety changes have been driven by legislation and our need to satisfy the regulator

Enhanced scrutiny of Auditor General has led to changes, particularly around business plans and risk management 
Regulation has important implications for public sector functions. External scrutiny by government audit agencies frequently impacts on the administration of organisational entities (Grasso \& Sharkansky, 2001), particularly as auditing is increasingly seen as the solution to an ever-widening range of public policy problems (Scott, 2003).

The underlying assumption of public sector auditing is that funding is allocated by Parliament and appropriated to Executive, including its public sector organisations, to carry out certain tasks. Public audit offices were established to ensure that the regularity and probity of the expenditure of these funds were consistent with the intentions of Parliament (Scott, 2003) and the fundamental role of Auditors-General remain the same (Barrett, 2003).

As discussed above, several respondents identified compliance with occupational health and safety $(\mathrm{OH} \& \mathrm{~S})$ regulation as a driver of corporate governance change. Within Australia each state and territory has a principal OH\&S Act, setting out requirements for ensuring that workplaces are safe and healthy (Commonwealth of Australia, 2008). These requirements ouline the duties of people, including public sector managers, who play a role in workplace health and safety. 


\subsubsection{Factors that impact on the adoption corporate corporate governance reform}

As set out in Table 7: phase one interview questions and objectives on page 108 interview subjects were next asked about the specific factors that had impacted on the adoption of corporate governance reform.

Interview subjects confirmed the existence of the expected factors which included availability of resources, corporate governance knowledge and skills, decision making processes, influence of interest groups and competing organisational priorities. The influence of resource availability was not identified by interviewees as a factor that impacted on the adoption of corporate governance changes

An additional factor was also identified by many interviewees: leadership.

There was no substantial difference in responses between stratum 1 and stratum 2 about factors impacting on the adoption of corporate governance reform.

\section{Leadership}

The role of leadership in reform adoption was identified. There was strong agreement that this was a key factor in many reforms:

The Secretary was the strongest driver for change 
Many interview subjects reflected on the different leadership styles evident in the organisation and that the current leader displayed a consensus approach which was a positive feature for many successful corporate governance reforms:

Secretary's leadership is consistent with the government's approach: look for agreed paths, seek cooperation and don't battle for things

This view was supported by another interviewee who observed that the role of the Secretary’s leadership was supported by an external influences:

There is an external element that coincides with the Secretary's agenda

Organisational leadership is often distinguished from management by its focus on adapting organisations to changing circumstances while management is primarily concerned with processes that keep a complicated system of people and technology functioning smoothly (Kotter, 1996).

Successful leadership itself can been distinguished into two distinct styles - transactional and transformational (Bass, 1985). Transactional leaders seek to maintain the existing culture and system of an organisation (Bass, 1985) while transformational leaders seek to shift the beliefs and values of followers so as to transform organisations from one archetype to another (Burns, 1978). The distinction between these two types of leaders is 
not however always clear (Waldham, Bass, \& Yammarino, 1990). Transactional leaders can act transformationally and transformational leaders can take on a transactional role.

There is also evidence that the personality, power and knowledge of an organisation's leader differentiates structures that innovate, encourage innovation, from those that do not (Robbins et al., 2001).

\section{Resource availability}

Resource availability was not acknowledged as an adoption factor. Although as observed by one interview subject, this may be a result of the size of the department's existing resource levels and the ability to reallocate these where necessary:

Resources not usually an issue - DHS is big enough to find resources to make things happen

\section{Corporate governance knowledge and skills}

There was also partial disagreement about the role of corporate governance knowledge and skills in reform adoption. Several interview subjects stressed the importance of existing skills levels:

\section{All reform is influenced by knowledge and skills levels}

Others did not see existing corporate governance knowledge and skills levels as critical, partly because they considered the department has the ability to acquire these as required: 
Given the size of DHS and its resources, we can gain these when needed

These responses distinguish corporate governance knowledge and skills in two ways:

1. existing levels; and

2. achievable levels.

Interviewees considered that it was appropriate to operate at a defined level of knowledge while ensuring the organisation retained a capacity to build up these levels as required.

\section{Competing organisational priorities}

There was general agreement that competing priorities played a role in reform adoption:

Focus on divisional business can mean that broader governance issues are sometimes required to compete with ongoing operations

Generally an obstacle to change (competing organisational priorities); it is hard to implement change if it is not proposed partner's priority

Interviewees spoke about the difficulty in improving service coordination between two or more programs where one party did not consider it a priority. 


\section{Decision making processes}

Most interviewees agreed that decision making processes played a role in reform adoption.

Some interviewees suggested that the department employed a strong 'filtering process' to ensure only sound reform proposals were adopted and implemented (see discussion on reform failure below for more information). It was also suggested that this led some staff to see decision-making processes as convoluted as it 'can take time to get things up'. Most interviewees saw the Department of Human services as a complex organisation with many different groups involved in decision making.

\section{Interest group influences}

Interviewees generally acknowledged that 'interest groups do have sway' in the department's approach to corporate governance change. Many commented that 'most of DHS services involve interest groups......they don’t stop things happening but they do shape the way change occurs' and as a result reform 'depends on relationships....you must find people to work with if you don’t have line authority’. One interviewee commented that due to the centralised nature of decision making in the department, the role of most managers in the reform process 'is explaining and persuading interest groups after a reform decision has been made’.

\subsubsection{Factors that impact on the operation of corporate governance reform}

The next interview question related to the specific factors that impacted on the operation of corporate governance reform (refer to Table 7 on page 18). 
Interview subjects confirmed the existence of the expected operation factors. No additional factors were identified. There was no agreement about which factor was the most important during the operation of corporate governance reforms, although most subjects agreed that change management knowledge and skills continued to play a key role during the bedding down and operation of reform

There were differences in stratum 1 and stratum 2 responses in relation to resource availability.

\section{Resource availability}

The was a difference in between stratum 1 and stratum 2 interview subjects about the role of resource availability. Most stratum 1 subjects considered the department to provide adequate resourcing to operate corporate governance reforms while most stratum 2 subjects did not. One stratum 2 interviewee commented that 'there can be lots of support (in the organization) based on the nature of a problem, yet significant resources are still not allocated'.

The difference between stratas may be attributable to stratum 1 subjects having responsibility for allocating resources and therefore were reluctant to criticise past resourcing decisions. Only stratum 1 subjects identified staffing arrangements as playing an important role in the operation of reforms: 
People chosen to run divisions were very important......it was an idea on paper - needed to get someone who could make it happen

Again, this difference may be attributable to stratum 1 subjects being primarily responsible for the selection of personnel to lead corporate governance reforms.

\section{Corporate governance knowledge and skills}

Most interviewees agreed that corporate governance skill and knowledge levels play an important role in reform operation.

People who implement change must have the knowledge, competence and organising capacity to implement it effectively

For this reason, several interviewees observed that as it can take time to build up necessary skill levels, corporate governance reform is often scaled up once a pilot or small scale reform is successfully implemented:

reform often starts smaller than we would have liked

This is consistent with comments made by interviewees about the impact of knowledge and skills on reform adoption. Several interviewees indicated that during reform adoption prerequisite knowledge and skills would be acquired as necessary. This approach results in reform being scaled up as knowledge and skills are acquired. 
Only one interviewee commented about the difficultly applying corporate governance knowledge and skills in a public sector environment:

Public servants understand governance, we find it very difficult to manage change though due to contested environment

Research suggests that public officials often find it difficult to influence political decision making through the norms of non-political processes, even with their informational advantages (Bourdeaux, 2007).

\section{Change management knowledge and skills}

In addition to corporate governance knowledge and skills, interviewees generally agreed that change management knowledge and skills were also very important:

Once you have made a decision to adopt, and if this is based on a well researched and informed basis, then what happens depends on skills and communication rather than reform attributes

Some interviewees considered the department to have less well developed change management skills:

Change management is hard going and we are not very good at it 


\section{Organisational control processes}

Interviewees agreed that this factor played an important role in the operation of reform.

Most responses to this factor centred around the size of the department and issues

associated with coordinating the operation of reform within a large organisation:

Given the number of layers in DHS it is sometimes difficult to

ensure all organisational control processes are complied with

Only slices of DHS are interested in change at any one time

\subsubsection{The role and importance of organisational culture in corporate governance reform processes}

As set out in Table 7 on page 108, interview subjects were next asked about the role and importance of organisational culture in corporate governance reform processes. Responses to this question appeared dependent on the subject's position in the organisational hierarchy (more senior staff likely to give positive view of the department's culture) and time in the organisation (several subjects employed by the department for more than 5 years found it difficult to give a single opinion on the organisation's culture as they considered it had changed considerably over the length of their employment).

There was general consensus that culture is a key factor in corporate governance reform. In particular several subjects considered the need to manage corporate governance reform in the context of known organisational cultural features such as professional differences between the department's health and community services divisions: 
There is no single DHS culture; it varies between programs and regions

The proliferation of subcultures within organisations, particularly large ones, is recognised as frequently presenting additional management issues and obstacles to change (Parker \& Bradley, 2000; Schien, 2004). Other responses focused on how to approach organizational culture in the context of corporate governance change:

Command and control-type change is not effective in governance context. If serious about change, then you need agreement that change is necessary

Other interviewees commented on the relationship between changes in the department's organisational culture and leadership:

Cooperative nature of DHS is improving; bought about through Secretary's leadership

This reinforces the importance of leadership in organisational change as identified and discussed earlier. 


\subsubsection{The role and importance of communication in corporate governance change processes}

Interview subjects were also asked to comment on the role and importance of communication in the corporate governance change process (refer Table 7 on page 108).

The role of communication in corporate governance reform was acknowledged as important by interview subjects

Communication is the most fundamental thing in change....important at all stages

However there was no agreement about the most effective method of communication. For example, some interview subjects considered the primacy of formal communications while others held that informal communication was far more effective:

People are cynical about formal communication as it tends to be overly positive and one sided. Informal communications are very important and depend on relationships between people

There was also disagreement about the effectiveness of the department's communication processes:

DHS struggles with it (communication) because we communicate once and then move on 
One interview subject noted that the success of communication can be restricted by political influences:

Your ability to communicate may be restricted due to political involvement; a communication strategy may not be deployed due to absence of ministerial approval

There was no substantial difference in responses between stratum 1 and stratum 2 participants about the role of communication in corporate governance reform.

\subsubsection{Impediments to corporate governance reform}

Interview subjects were next asked to identify impediments to corporate governance reform (refer Table 7: phase one interview questions and objectives on page 108). Most subjects found it difficult to cite a corporate governance reform that had failed. This may be a result of the detailed filtering process used by the department to identify, implement and operate change. For this reason, responses to this question mainly related to difficulties associated with implementing a corporate governance reform, rather than reasons for reform failure.

One interview subject commented that the department implements many things badly but just keeps going. Reasons given for reform implementation difficulties included:

- low levels of organisational support for change

- inadequate implementation planning 
- inadequate resourcing (as discussed earlier, this was only identified by strata 2 participants).

\section{Low organisational support}

Low organisational support primarily included issues associated with the failure to build and communicate an effective case for change, including dealing with the hierarchical nature of the public service. Responses included:

- Reforms have to wait for their time, examples include Chief Information Officer and Risk Management

- Generally if you can’t convince people then you don't get organisational support

- Less sexy things hard to get up - need longer to build a case, especially for corporate issues such as payroll

- Not only about number of people supporting change but support in hierarchy

- You can under estimate level of resistance to change

- If it is a good idea and you can't communicate it, then it is a communication issue

\section{Inadequate implementation planning}

Issues associated with poor implementation planning centered on not adequately addressing organisational resistance to change. Responses included:

- We had done a lot of implementation planning but under estimated resistance 


\section{Inadequate resourcing}

Inadequate resourcing issues appeared to be a consequence of having low levels of organisational support (identified as an earlier impediment to reform). Responses included:

- Inadequate resourcing is a common problem, not just for corporate governance-related projects

- Could not convince divisions of value....because of the loose nature of DHS there is no mechanism to make them contribute

These influences primarily reflect the issues identified and discussed earlier.

\subsubsection{Further information about corporate governance reform processes, including how participants address adoption and operation factors}

Interview subjects were asked to provide further information about corporate governance reform processes, including how they address adoption and operation factors (refer Table 7 on page 108). Themes that emerged from comments made by subjects about how they addressed adoption and operation factors included:

- Role in change process

- Approaches to building support 


\section{Role in change process}

Few interview subjects identified themselves as the instigator of corporate governance reform. Several stratum 1 subjects defined their role as somewhere between instigator and participant. For that reason a new category as 'leader', described below, was established. This included significant elements of the instigator role, although without the accountability responsibilities. It was not clear from interview responses if there was a significant difference in practice between leader and participant. The reluctance of interview subjects to characterise their role as an instigator contrasts with the strong view of many subjects that corporate governance reform in the department was driven by internal rather than external influences.

Most stratum 2 subjects identified their role as either participant or observer.

\section{Instigator}

The role and actions identified by subjects accord with several corporate governance reform adoption and operation factors identified earlier. Most actions associated with the instigator role exhibit attributes of leadership (refer Table 8: Role of instigator in corporate governance change for a summary of instigator characteristics, as identified by subjects, and their relationship to the factors contained in the conceptual model). The role of instigator included building a case for change, selling that case and then establishing the processes to make it happen. 
Table 8: Role of instigator in corporate governance change

\begin{tabular}{|c|c|}
\hline Actions & Factors addressed \\
\hline $\begin{array}{l}\text { - Act as a consultant; listened to people } \\
\text { and put together options that matched }\end{array}$ & $\begin{array}{l}\text { - Leadership } \\
\text { - Low levels of organisational support }\end{array}$ \\
\hline - Lobby for change & $\begin{array}{l}\text { - Leadership } \\
\text { - } \text { Allocate resources }\end{array}$ \\
\hline $\begin{array}{l}\text { - Convince people intellectually and } \\
\text { emotionally about change }\end{array}$ & $\begin{array}{l}\text { - Leadership } \\
\text { - Communication and information } \\
\text { sharing }\end{array}$ \\
\hline $\begin{array}{l}\text { - Build a body of steam and get ahead of } \\
\text { opinion }\end{array}$ & $\begin{array}{l}\text { - Leadership } \\
\text { - } \quad \text { Interest group influences }\end{array}$ \\
\hline - $\quad$ Build formal process & - Organisational control processes \\
\hline
\end{tabular}

\section{Leader}

This was a new role identified by several interviewees who felt that they could not be considered to be an instigator of change, rather they became involved in directing change after reform had been agreed. Table 9 provides a summary of leader characteristics, as identified by subjects, and their relationship to the factors contained in the conceptual model

Table 9: Role of leader in goverance change

\begin{tabular}{|l|l|}
\hline Actions & Factors addressed \\
\hline - Work with instigator and act as an & - Knowledge and skills \\
advisor & \\
\hline
\end{tabular}




\section{Participant}

The attributes associated with the participant role is set out in Table 10: Role of participant in corporate governance change, along with details of those conceptual framework factors relating to the role. Key activities included facilitating change, either though staffing arrangements or supporting change at decision making points.

Table 10: Role of participant in corporate governance change

\begin{tabular}{|l|l|}
\hline Actions & Factors addressed \\
\hline - Made sure had the best staff to do jobs & - Allocate resources \\
required including bending rules to get & \\
right people into jobs (eg EO2 in EO3 & \\
position) & \\
\hline Facilitate decision making & - Communication and information \\
& sharing \\
\hline
\end{tabular}

\section{Observer}

The attributes associated with the observer role is set out in Table 11: Role of observer in change process. This role was more active than passive as the observer role was considered by interviewees to include taking part in debate about change and subsequently supporting its implementation. 
Table 11: Role of observer in change process

\begin{tabular}{|l|l|}
\hline Actions & Factors addressed \\
\hline - even as an observer need to show & - Organisational culture \\
support and be happy to be consulted & \\
\hline - Take part in debate & - Decision making processes \\
\hline
\end{tabular}

\section{Building support for corporate governance change}

Many interview subjects observed that their actions to build support for reform did not vary significantly across organisational roles and levels. They fulfilled the same role in building support at superior, peer and subordinate levels. The role of communication processes was highlighted in many responses to this question, particularly the need to provide people with the information they need at the point they required it.

There was no substantial difference in responses between stratum 1 and stratum 2 participants about building support for corporate governance reform.

Approaches to building support for change, as identified by interview subjects, are set out in Table 12: Approaches to building support for corporate governance reform. They include the need to work at a Ministerial level to build support of superiors; engaging, consulting and supporting others to build support amongst peers; communicating the advantages of change and building trust at subordinate level; along with ensuring the information needs of all people involved in change are met. 
Table 12: Approaches to building support for corporate governance reform

\begin{tabular}{|c|c|}
\hline Support level & Actions to build support \\
\hline Superior support & $\begin{array}{l}\text { - Work closely with Ministers to ensure changes will serve them; not } \\
\text { required to gain their approval but need to make sure they are happy }\end{array}$ \\
\hline Peer support & $\begin{array}{l}\text { - } \text { Be clear about rationale and implications for others } \\
\text { - } \quad \text { Support your peers when they are implementing change } \\
\text { are a common ally } \\
\text { - Walk around and ask them what they think } \\
\text { - Clarify roles and responsibilities } \\
\text { - Understand dynamics }\end{array}$ \\
\hline Subordinate support & $\begin{array}{l}\text { - Work to make sure people don't see change as an effort to save money } \\
\text { - Don't speak to people about why we are going to do it, rather how we } \\
\text { are going to do it } \\
\text { - Demonstrate when differences will be made } \\
\text { - Build trust }\end{array}$ \\
\hline General & $\begin{array}{l}\text { - information needs vary between levels; need to give respective levels } \\
\text { the information they need } \\
\text { - If people have competing interests need to identify these and deal with } \\
\text { them } \\
\text { - If you are going to deliver something it is important that you } \\
\text { demonstrate what you have done so next time you go through a similar } \\
\text { process you have credibility }\end{array}$ \\
\hline
\end{tabular}




\subsubsection{Reflections on how corporate governance reform processes operate and how they could be improved}

The last interview question invited participants to reflect on how corporate governance change processes operate and how they could be improved (refer Table 7: phase one interview questions and objectives on page 108).

Reflections centred on

- The department's acceptance of change

- Change in the department's reform capabilities

\section{Department's acceptance of change}

There were significant differences in responses to this question, particularly between stratum 1 and stratum 2 subjects. Stratum 1 subjects were generally more positive about the department's overall reception of change while stratum 2 subjects were generally more likely to identify parts of the department as resistant to change.

Interviewees responses have been categorised as relating to either change receptivity or resistance (refer to Table 13: Characterisation of change in DHS) 
Table 13: Characterisation of change in DHS

\section{Change receptive \\ - DHS accepts change \\ - We are pretty good at it now, as long as it is not too much at once}

- Dilemma is you need to get Executive buy in for change but there are not that many people to be involved and there is a lot of change

- What standard do we judge? By government standards we are OK

- We adapt our position to match government expectations and requirements - we are not the determinant of change

\section{Change resistant}

- Auditor General-led change frequently resisted

- Need to see change has a purpose, as we are a bunch of sceptics (long term DHS employee)

- People’s capacity to resist change is quite strong

- People in the department have a low tolerance for things not working well (long term dhs employee)

- Superficially we accept change, but then do not embed all change well (strata 2)

- By solving one problem we may create another (long term dhs employee)

Most characterisations of the department's resistance to change relate to cultural elements and the capacity of people to resist change, rather than structural impediments to reform. Most characterisation of the department's acceptance of change however, are qualified. This suggests that the acceptance of change cannot be assumed. 


\section{Change in department's reform capabilities}

Most interview subjects agreed that the department's capacity to implement corporate governance reform is improving. There were, however, several qualifications such as poor reform capacity over shared functions and a perception that a reform in one area will have a detrimental impact on another. Several interviewees identified early difficulties associated with coordinating reform across geographic based health divisions (formerly organized around function rather than location)

Some stratum 1 subjects also identified resistance to change in lower level staff as an impediment to improvements. Apart from this difference there was no major variation in responses between stratum 1 and stratum 2 subjects.

Interviewees responses have been categorized as positive and negative changes to reform capabilities Table 14: Changes in DHS reform capabilities. Positive changes related mainly to organisational culture and included a greater acceptance of change by staff (at all levels), particularly resulting from a public sector wide realization that change is now more likely to be a constant occurrence. Negative changes were also primarily based around organisational culture. They included issues associated with the organisation's hierarchy and its tendency to employ stability seeking responses to change. 
Table 14: Changes in DHS reform capabilities

\begin{tabular}{|c|c|}
\hline \multicolumn{2}{|c|}{ Subject responses } \\
\hline Positive change & Negative change \\
\hline $\begin{array}{l}\text { - We no longer do 'big bang’ changes; we prefer } \\
\text { to do things organically as the need arises } \\
\text { - While we may be less change adverse we are } \\
\text { change weary } \\
\text { - More expert and accepting of change as a } \\
\text { constant } \\
\text { - Good at things we are really clear on } \\
\text { changed in sense that under previous Secretary } \\
\text { change was seen as imposed rather than though } \\
\text { - Don’t think that there are many people in the } \\
\text { department that do not expect change }\end{array}$ & $\begin{array}{l}\text { - Not good at things that are shared, overlapping } \\
\text { or not 'owned' } \\
\text { - Sometimes because the department is big we } \\
\text { search for solution but create a problem } \\
\text { somewhere else } \\
\text { - As you go down the department's hierarchy } \\
\text { there is a high resistance to change. This is } \\
\text { almost natural, partly because of performance } \\
\text { incentives } \\
\text { - There is a fundamental conflict between } \\
\text { corporate governance of outcomes and } \\
\text { governance of outputs - government does not } \\
\text { know how to deal with this }\end{array}$ \\
\hline
\end{tabular}




\subsubsection{General discussion}

The aim of stage 1 interviews was to develop a deeper and broader understanding of corporate governance reform factors by gathering observations within the context of the Victorian Department of Human Services.

Interview questions attempted to draw responses from interviewees to the concepts that emerged from the literature review. Overall the responses contributed positively to these concepts. There were no interview responses that challenged the concepts in a way that would require a fundamental review. The following are observations made from themes contained within interview responses.

\section{Importance of leadership}

This was a new factor identified from interview responses. It was evident at several stages of the change process, including adoption, implementation and communication.

It was seen by many interviewees as critical to the identification of reform opportunities and subsequent success. The literature supports the notion of leadership playing a significant role in any change process (Schien, 2004).

\section{Reform primarily effected by (perceived) leader}

Interview responses however tended to only identify the role of the department's Secretary in corporate governance reform. Few other senior staff identified themselves as a 'reform 
leader'. This is an interesting result as most senior staff tended to defer to the department's Secretary. This may reflect the Secretary’s responsibility for overall departmental corporate governance but many reforms identified by interviewees could be led by staff at lower organisational levels and assumes that the role of leadership can only be performed by a single actor throughout the whole change process.

This role of leadership in corporate governance reform at different organisational levels should be further investigated in Stage 2.

\section{Strong filtering of reform proposals}

As observed in responses to questions associated with DHS decision making processes and reform failure, there appeared to be a strong filtering process in the department around corporate governance reform proposals. The commissioning of change only after extensive consultation and often only after it had been successfully piloted, were features of this filtering process. The filtering process was so effective that many interviewees were unable to identify a corporate governance reform where implementation was considered to have failed.

\section{Strong focus on the corporate governance of external relationships}

There was evidence that corporate governance of internal relationships within the Department of Human Services was considered secondary to the corporate governance of external relationships. Several interviewees found it difficult to identify DHS corporate governance initiatives. It appeared that these interviewees viewed corporate governance as centred on the relationships between the department and the organisations that it funds to 
deliver services, such as metropolitan health services and major welfare organisations. Corporate governance within the department was seen by some of these interviewees as ‘just organisational change’.

It is proposed to further assess the priority assigned to internal and external corporate governance reforms within stage 2 . 


\subsubsection{Conclusions}

\subsubsection{Changes to conceptual framework}

Overall the stage 1 results confirmed the conceptual framework. Results identified additional factors that are to be included as RA and RO factors:

RA factors

- Leadership: the process where an individual provides a way for others to develop, understand, accept, and work toward achieving goals, without recourse to methods of domination (Muldoon, 2003).

- New government policy: the requirement to implement government decisions that direct public resources in one direction but not another (Bridgeman \& Davis, 2000).

- Regulatory requirements: the requirement to comply with restrictions imposed by law (Grasso \& Sharkansky, 2001).

RO factors

- Leadership: the process where an individual (the leader) provides a way for others to develop, understand, accept, and work toward achieving collective (group or organisational) goals, without recourse to methods of domination.

The revised conceptual framework is set out in Figure 7: Revised conceptual framework. 


\section{Retention of influences for phase 2 testing}

It is proposed that the following influences that were not identified during phase one investigations, be retained for testing during phase two.

- Recurrent and capital cost, including availability of resources

- Redistributive effect on power and institutional relationships

These are also identified in Figure 7: Revised conceptual framework. 


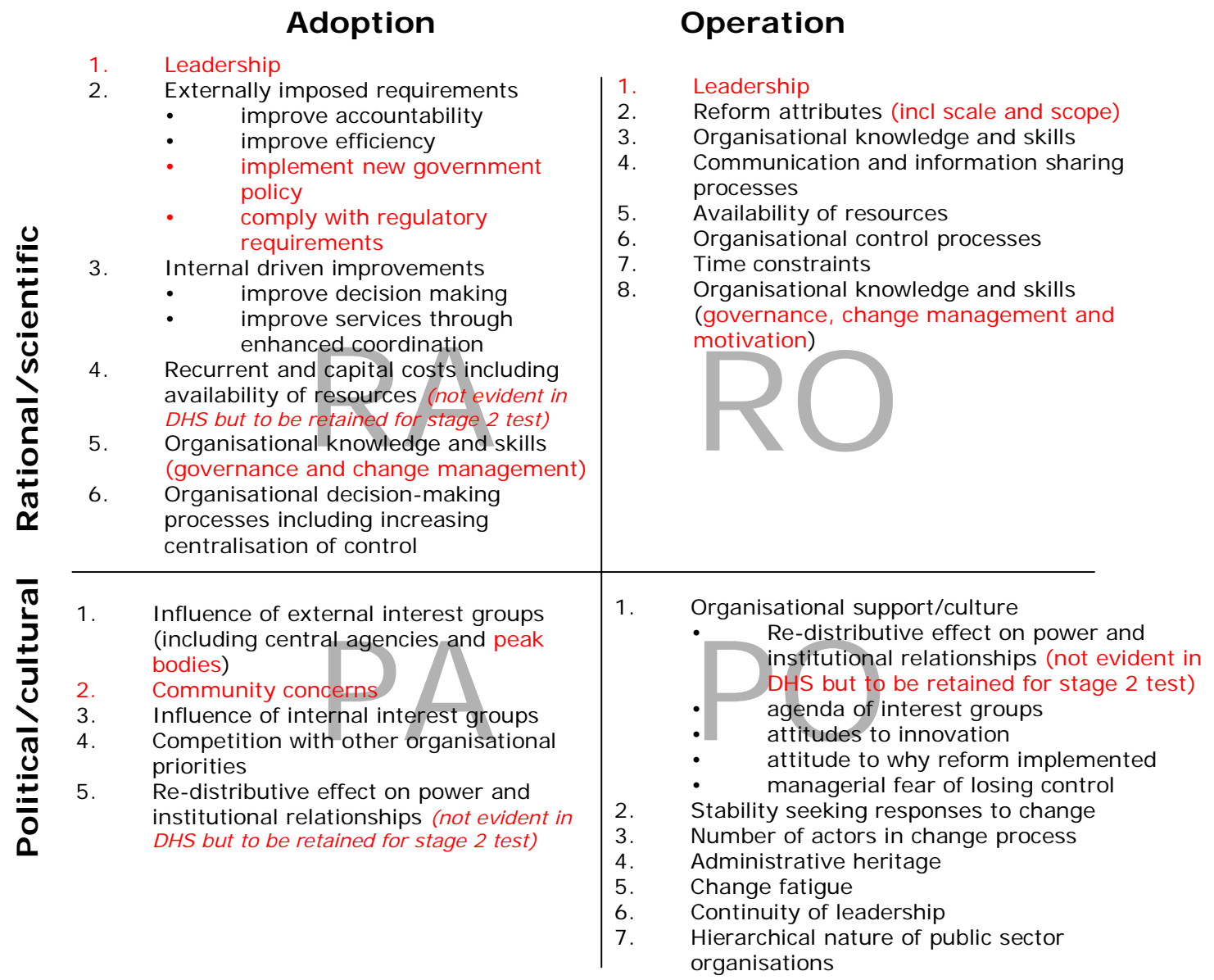

Changes associated with Stage 1 results shown in red text

Figure 7: Revised conceptual framework

\section{Changes to phase two survey instrument}

Based on the revised conceptual framework, changes to the phase two survey instrument include: 
- Addition of new reform drivers (implement new government policy and comply with regulatory requirements)

- Addition of leadership, including assessment of leadership at different organisational levels

- Focus assigned to internal and external corporate governance reforms 


\section{Chapter seven - Phase two results}

This chapter presents results relating to the questionnaire that forms the basis of phase two investigations. It is divided into three sections. The first begins with the response rate of the survey, a short discussion on the characteristics of the respondents and then presents and discusses the frequency distributions of the data as they relate to the variables under investigation, including observed differences. The second section presents the multivariate analyses, including factor analysis. Factor analysis scale reliability testing is also specified in this section. The third section presents an analysis of the qualitative data collected.

\subsection{Response rate}

Questionnaires were distributed via email to four hundred and sixty four chief executive and senior managers employed in ninety seven state government departments across Australia. The first email invitation was sent on 19 November 2007. Reminders were sent on the 23 November 2007 and 30 November 2007. A final reminder was sent 5 December 2007. Respondents who had commenced, but not completed the survey, were sent a further email reminder in early December 2007 (see chapter four for a discussion of the method used to select the sample and conduct the survey).

Two hundred and thirty two surveys were completed. This gives a response rate of fifty percent. A further fifty two people chose the option to 'opt out' of the survey process. 
Approximately nineteen percent of the completed surveys were provided by Chief Executive Officers. Eighty one percent of the completed surveys were provided by senior executives and other managers (refer to Table 15: Sample response rate).

Table 15: Sample response rate

\begin{tabular}{|l|r|r|r|r|r|}
\hline Sample strata & Distribution & $\begin{array}{l}\text { \% total } \\
\text { sample }\end{array}$ & Completed & $\begin{array}{c}\text { \% } \\
\text { completed }\end{array}$ & $\begin{array}{c}\text { \% of total } \\
\text { completed }\end{array}$ \\
\hline Chief Executive Officers & 97 & $21 \%$ & 43 & $44 \%$ & $19 \%$ \\
$\begin{array}{l}\text { Senior executives and other } \\
\text { managers }\end{array}$ & 367 & $79 \%$ & 189 & $51 \%$ & $81 \%$ \\
Total & 464 & & 232 & $50 \%$ & $100 \%$ \\
\hline
\end{tabular}

Chief Executive Officers comprised twenty one percent of the stratified sample. Senior executives and other managers comprised seventy nine percent of the stratified sample.

The response rate reflects the proportionate size of the stratified sample and consequently is seen to be representative of the study population.

A review of the literature reveals a wide variation in the description of an appropriate response rate. For example, Babbie (Babbie, 1998) suggests that a response rate of $50 \%$ is adequate for analysis and reporting. Sekaran (Sekaran, 2000) believes that a 30\% response rate is acceptable. Singleton (Singleton, 1993) does not identify a specific percent but considers ‘moderate response rates are satisfactory’ ( $p$ 265).

In recognition of the fact that the response rate is representative of the stratified sample and falls within the range identified as acceptable by Babbie (1998) and Sekaran (2000), the response rate is considered to be sufficient to ensure validity. 


\subsection{Description of the sample}

\subsubsection{Individuals}

Most respondents (seventy percent) were male (refer Table 16: Respondents’).

Table 16: Respondents' gender

\begin{tabular}{|ll|r|r|r|r|}
\hline & & & & $\begin{array}{c}\text { Cumulative } \\
\text { Percent }\end{array}$ \\
\hline Valid & Male & 163 & 70.3 & 70.6 & 70.6 \\
& Female & 68 & 29.3 & 29.4 & 100.0 \\
& Total & 231 & 99.6 & 100.0 & \\
Missing & System & 1 & .4 & & \\
Total & & 232 & 100.0 & & \\
\hline
\end{tabular}

Of the two hundred and thirty two people who answered, twenty two percent or fifty two respondents, were from Western Australia. Twenty one percent were from Queensland, seventeen percent were from New South Wales and fifteen percent were from South Australia. There were fewer respondents from Victoria (fourteen percent) and Tasmania (ten percent) (refer Table 17: Respondents’ location). These frequencies broadly reflect the higher number of individual state government departments in Western Australia ( $n=24)$ and Queensland ( $\mathrm{n}=22)$ compared to 'mega department' states such as Victoria $(\mathrm{n}=10)$ and Tasmania $(n=9)$.

Table 17: Respondents' location

\begin{tabular}{|ll|r|r|r|r|}
\hline & Frequency & Percent & Valid Percent & $\begin{array}{c}\text { Cumulative } \\
\text { Percent }\end{array}$ \\
\hline Valid & Victoria & 32 & 13.8 & 13.8 & 13.8 \\
& New South Wales & 40 & 17.2 & 17.2 & 31.0 \\
& Queensland & 49 & 21.1 & 21.1 & 52.2 \\
South Australia & 35 & 15.1 & 15.1 & 67.2 \\
Western Australia & 52 & 22.4 & 22.4 & 89.7 \\
Tasmania & 24 & 10.3 & 10.3 & 100.0 \\
Total & 232 & 100.0 & 100.0 & \\
\hline
\end{tabular}


Thirty four percent of respondents said they had worked for their current department for more than ten years (Table 18: Respondent's length of employment). However, approximately twenty five percent of respondents said they had only been working in their current department for less than two years, while around twenty four percent said they had been working in their current department for under five years.

Table 18: Respondent's length of employment

\begin{tabular}{|ll|r|r|r|r|}
\hline & & & & \multicolumn{1}{c|}{$\begin{array}{c}\text { Cumulative } \\
\text { Percent }\end{array}$} \\
\hline Valid & 0-2 years & 57 & 24.6 & 24.6 & 24.6 \\
& 3-5 years & 55 & 23.7 & 23.7 & 48.3 \\
6-10 years & 41 & 17.7 & 17.7 & 65.9 \\
> 10 years & 79 & 34.1 & 34.1 & 100.0 \\
Total & 232 & 100.0 & 100.0 & \\
\hline
\end{tabular}

\subsubsection{Organisational size}

As set out in Table 19: Agency size - staff, the largest single group of respondents (seventy one percent) worked in departments employing more than five hundred people. Sixteen percent of respondents worked in departments employing between 201-500 staff while seven percent of respondents worked in departments employing 101-200 staff. Only seven percent, or fifteen respondents, worked in departments employing less than 100 people 
Table 19: Agency size - staff

\begin{tabular}{|rl|r|r|r|r|}
\hline & & Frequency & Percent & Valid Percent & $\begin{array}{c}\text { Cumulative } \\
\text { Percent }\end{array}$ \\
\hline Valid & $<100$ & 15 & 6.5 & 6.5 & 6.5 \\
& $101-200$ & 17 & 7.3 & 7.3 & 13.8 \\
& $361-500$ & 15.5 & 15.5 & 29.3 \\
& 3500 & 164 & 70.7 & 70.7 & 100.0 \\
& Total & 232 & 100.0 & 100.0 & \\
\hline
\end{tabular}

Approximately thirty eight of respondents worked in departments with an annual budget between $\$ 101 \mathrm{~m}$ and $\$ 500 \mathrm{~m}$ (refer Table 20: Agency size - budget). Nearly twenty eight percent of people who answered this question worked in a department with an annual budget in excess of $\$ 1$ billion, while twenty percent worked in departments with budgets less than $\$ 100 \mathrm{~m}$.

Table 20: Agency size - budget

\begin{tabular}{|ll|r|r|r|r|}
\hline & & & & \multicolumn{1}{c|}{$\begin{array}{c}\text { Cumulative } \\
\text { Percent }\end{array}$} \\
\hline Valid & $<\$ 100 \mathrm{~m}$ & Frequency & Percent & Valid Percent & 20.3 \\
& $\$ 101-500 \mathrm{~m}$ & 20.3 & 20.3 & 20.3 \\
& 88 & 37.9 & 37.9 & 58.2 \\
& $\$ 501-1,000 \mathrm{~m}$ & 33 & 14.2 & 14.2 & 72.4 \\
& $>\$ 1,001 \mathrm{~m}$ & 64 & 27.6 & 27.6 & 100.0 \\
& Total & 232 & 100.0 & 100.0 & \\
\hline
\end{tabular}

Most respondents worked in departments that operated from more than ten locations (sixty nine percent) (refer Table 21: Agency size - operational locations). Only ten percent of respondents worked in departments with only one location.

Table 21: Agency size - operational locations

\begin{tabular}{|rl|r|r|r|r|}
\hline & & & & \multicolumn{2}{c|}{$\begin{array}{c}\text { Cumulative } \\
\text { Percent }\end{array}$} \\
\hline Valid & Frequency & Percent & Valid Percent & 9.9 \\
& 23 & 9.9 & 9.9 & 22.4 \\
& $29-10$ & 12.5 & 12.5 & 31.5 \\
& 21 & 9.1 & 9.1 & 100.0 \\
& Total & 159 & 68.5 & 68.5 & \\
\hline
\end{tabular}


The cross section of departments in terms of number of employees, operating budget and number of locations provides a good representation of different sized organisations.

\subsubsection{Organisational functions}

Of the respondents who answered this question (refer Table 22: Organisational functions), most identified their department as providing a policy development function (90\%).

Eighty one percent of departments were responsible for delivering services and seventy two percent of departments provided regulatory services. Only forty percent of respondents identified their department as fulfilling a service purchasing function. Seventeen percent of respondents identified 'other functions' as being delivered by their department.

Table 22: Organisational functions

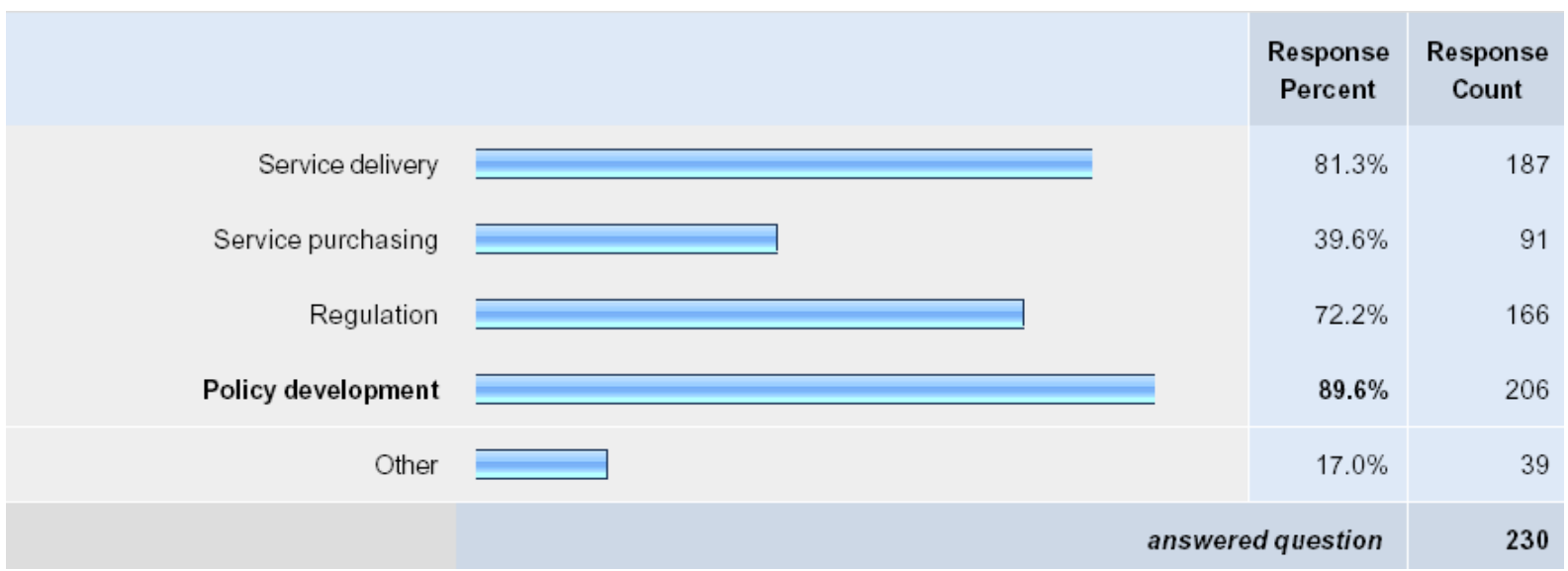

The types of services provided by departments were broadly distributed across the options provided for in the survey instrument (Table 23: Services provided by departments).

Twenty two percent of respondents identified their department as delivering 'other services'. Analysis of these responses indicate six additional types of services: natural 
resource management ( $n=40)$; planning and local government services $(n=9)$; arts, sport and recreation $(n=8)$; utility regulation $(n=3)$; employment and industrial relation services $(n=5)$; and other government services $(n=15)$.

Table 23: Services provided by departments

\begin{tabular}{|c|c|c|c|}
\hline & & $\begin{array}{l}\text { Response } \\
\text { Percent }\end{array}$ & $\begin{array}{l}\text { Response } \\
\text { Count }\end{array}$ \\
\hline Education & $=$ & $14.7 \%$ & 34 \\
\hline Children's services & $=$ & $12.1 \%$ & 28 \\
\hline Justice & 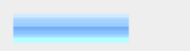 & $14.7 \%$ & 34 \\
\hline Emergency management & 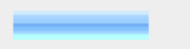 & $17.2 \%$ & 40 \\
\hline Health & $\Longrightarrow$ & $6.5 \%$ & 15 \\
\hline Community Services & $\bar{\square}$ & $19.4 \%$ & 45 \\
\hline Housing & $\Longrightarrow$ & $8.6 \%$ & 20 \\
\hline Economic development & 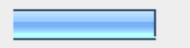 & $18.1 \%$ & 42 \\
\hline Infrastructure & $\overline{\underline{ }}$ & $15.9 \%$ & 37 \\
\hline Primary industries & $\Longrightarrow$ & $12.5 \%$ & 29 \\
\hline Natural resource management & $\bar{\square}$ & $17.2 \%$ & 40 \\
\hline $\begin{array}{r}\text { State administration (including } \\
\text { Treasury and Premier and Cabinet) }\end{array}$ & $\Longrightarrow$ & $19.4 \%$ & 45 \\
\hline Transport & $=$ & $6.0 \%$ & 14 \\
\hline Aged care & 1 & $9.5 \%$ & 22 \\
\hline Other (please specify) & 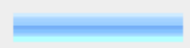 & $22.0 \%$ & 51 \\
\hline \multicolumn{3}{|c|}{ answered question } & 232 \\
\hline
\end{tabular}


Most respondents (forty four percent) identified their department as having a hybrid of functional and divisional organisational structures (refer Table 24: Organisational structure). Thirty three percent of respondents worked in departments with a divisional organisational structure while twenty two percent of respondents worked in departments with a functional organisational structure. Two respondents (approximately one percent of all responses) indicated that their organisation had 'other' organisational structure arrangements.

Table 24: Organisational structure

\begin{tabular}{|ll|r|r|r|r|}
\hline & & & & $\begin{array}{c}\text { Cumulative } \\
\text { Percent }\end{array}$ \\
\hline Valid & Functional & 50 & 21.6 & 21.6 & 21.6 \\
& Divisional & 76 & 32.8 & 32.9 & 54.5 \\
& Hybrid & 103 & 44.4 & 44.6 & 99.1 \\
& Other & 2 & .9 & .9 & 100.0 \\
& Total & 231 & 99.6 & 100.0 & \\
Missing & System & 1 & .4 & & \\
Total & & 232 & 100.0 & & \\
\hline
\end{tabular}

The cross section of departments in terms of services, functions and organisational design provides a good representation of different types of organisations. 


\subsection{Characteristics of corporate corporate governance adoption in departments}

This section presents the results of responses to the rational/scientific and political/cultural factors affecting the adoption of phase of reform.

Most respondents considered that corporate governance reform in their department was usually successful (refer Figure 8: Corporate governance reform adoption success).

However, a large number of respondents (twenty three percent) did not agree or disagree that reform adoption was usually successful. This result is discussed further below (see section titled observed differences). Around eight percent of respondents disagreed (either strongly disagreed or disagreed) that reform adoption was usually successful in their organisation.

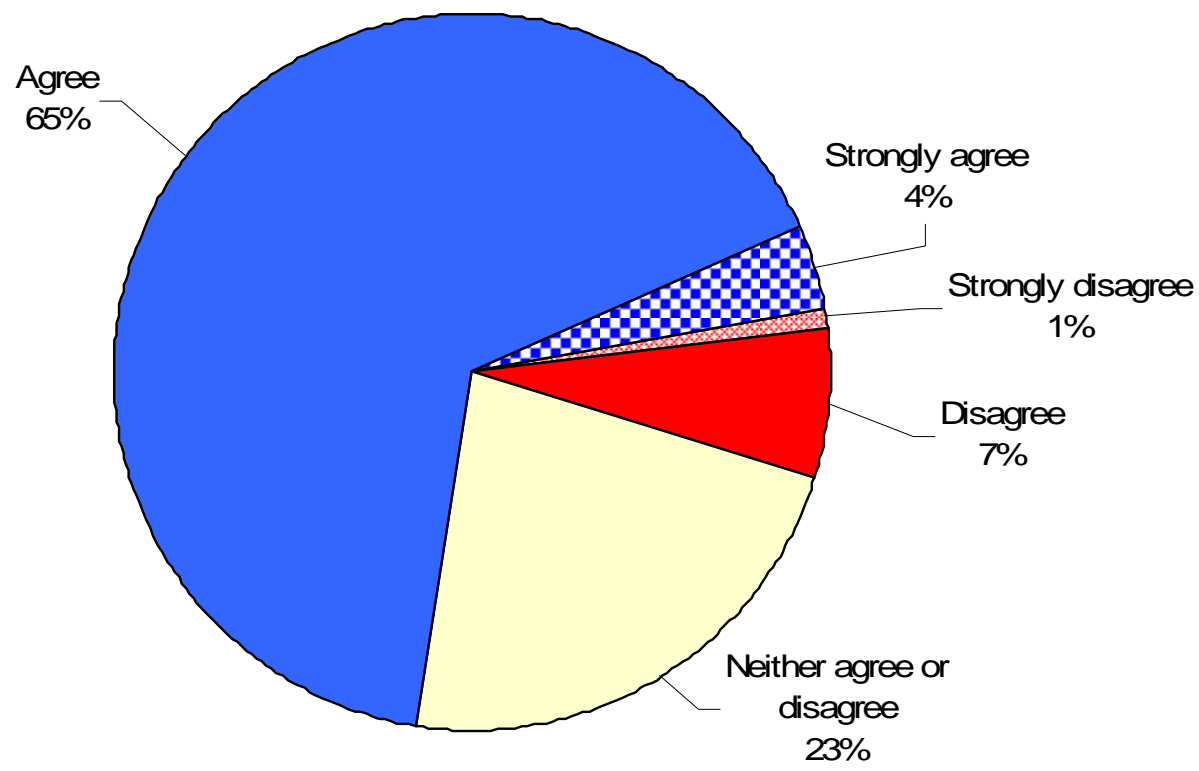

Figure 8: Corporate governance reform adoption success 


\subsubsection{Rational/scientific factors impacting on reform adoption}

Table 25: Frequency distributions of responses to rational/scientific factors shows the responses to the Likert-scaled items used to measure rational/scientific factors during the reform adoption stage.

Table 25: Frequency distributions of responses to rational/scientific factors impacting on reform adoption (RA)

\begin{tabular}{|c|c|c|c|c|c|c|c|c|c|c|c|}
\hline \multirow[t]{2}{*}{ RA factor } & \multicolumn{2}{|c|}{$\begin{array}{l}\text { Strongly } \\
\text { disagree }\end{array}$} & \multicolumn{2}{|c|}{ Disagree } & \multicolumn{2}{|c|}{$\begin{array}{l}\text { Neither } \\
\text { agree or } \\
\text { disagree }\end{array}$} & \multicolumn{2}{|c|}{ Agree } & \multicolumn{2}{|c|}{$\begin{array}{l}\text { Strongly } \\
\text { agree }\end{array}$} & \multirow[t]{2}{*}{ Total } \\
\hline & Freq & (\%) & Freq & (\%) & Freq & (\%) & Freq & (\%) & Freq & (\%) & \\
\hline $\begin{array}{l}\text { External } \\
\text { accountability } \\
\text { requirements }\end{array}$ & 2 & $(0.9)$ & 9 & (3.9) & 34 & (14.7) & 157 & $(67.7)$ & 30 & (12.9) & 232 \\
\hline $\begin{array}{l}\text { External efficiency } \\
\text { requirements }\end{array}$ & 2 & $(0.9)$ & 16 & (6.9) & 35 & (15.1) & 158 & (68.1) & 21 & (9.1) & 232 \\
\hline $\begin{array}{l}\text { Implement new } \\
\text { government policy }\end{array}$ & 0 & $(0.0)$ & 2 & $(0.9)$ & 23 & $(9.9)$ & 145 & (62.5) & 62 & $(26.7)$ & 232 \\
\hline $\begin{array}{l}\text { Regulatory } \\
\text { compliance }\end{array}$ & 2 & $(0.9)$ & 16 & $(6.9)$ & 31 & $(13.4)$ & 145 & $(62.5)$ & 38 & (16.4) & 232 \\
\hline $\begin{array}{l}\text { Improve decision } \\
\text { making }\end{array}$ & 0 & $(0.0)$ & 8 & $(3.4)$ & 18 & $(7.8)$ & 158 & (68.1) & 48 & (20.7) & 232 \\
\hline $\begin{array}{l}\text { Improve service } \\
\text { coordination }\end{array}$ & 0 & $(0.0)$ & 14 & $(6.0)$ & 26 & $(11.2)$ & 141 & $(60.8)$ & 51 & (22.0) & 232 \\
\hline $\begin{array}{l}\text { Knowledge and skill } \\
\text { levels }\end{array}$ & 0 & $(0.0)$ & 6 & $(2.6)$ & 25 & (10.8) & 129 & $(55.6)$ & 72 & (31.0) & 232 \\
\hline $\begin{array}{l}\text { Decision making } \\
\text { processes }\end{array}$ & 0 & $(0.0)$ & 12 & $(5.2)$ & 30 & $(12.9)$ & 145 & (62.5) & 45 & $(19.4)$ & 232 \\
\hline CEO leadership & 0 & $(0.0)$ & 2 & $(0.9)$ & 8 & $(3.4)$ & 71 & $(30.6)$ & 151 & $(65.1)$ & 232 \\
\hline $\begin{array}{l}\text { Senior manager } \\
\text { leadership }\end{array}$ & 1 & $(0.4)$ & 5 & $(2.2)$ & 9 & $(3.9)$ & 101 & $(43.5)$ & 116 & $(50.0)$ & 232 \\
\hline Implementation costs & 1 & $(0.4)$ & 26 & $(11.2)$ & 48 & (20.7) & 131 & $(56.5)$ & 26 & $(11.2)$ & 232 \\
\hline
\end{tabular}

As set out in Table 25 there was strong agreement from respondents to all RA factors.

Leadership by the chief executive officer and other senior managers in the reform process was prominent (approximately 96\% and 94\% of respondents respectively agreed that leadership impacted on reform adoption). The need to implement government policy and efforts to improve decision making had the next highest levels of support (89\%), followed by the level of knowledge and skills with an organisation (87\%). The highest levels of disagreement were recorded for implementation costs (12\%), compliance with regulatory requirements and external requirements to improve efficiency (both 8\%). 


\section{Implementation costs}

Eleven percent of respondents strongly shown in agreed that costs associated with implementing change had an impact on the adoption of corporate governance reform. Fifty seven percent agreed with this RA factor. Twenty one percent of respondents neither agreed or disagreed. Approximately eleven percent of respondents disagreed and approximately half a percent strong disagreed. This was the second highest level of disagreement to an RA factor.

\section{Leadership}

In terms of RA leadership factors, fifty percent of respondents strongly agreed that leadership shown by senior managers had an impact on the adoption of reform. A further forty four percent agreed while only two percent disagreed and $0.4 \%(n=1)$ strongly disagreed. This compares to sixty five percent of respondents who strongly agreed, and thirty one percent of respondents who agreed, that leadership shown by the organisation's chief executive officer had an impact on the adoption of corporate governance reform. Less than one percent of respondents disagreed with the CEO leadership factor. It is important to

\section{Decision making processes}

Nineteen percent of respondents strongly agreed that the processes used by their organisation to make decisions had an impact on the adoption of reform. Approximately sixty three percent agreed while five percent disagreed. Thirteen percent of respondents neither agreed or disagreed with this RA factor. 


\section{Knowledge and skill levels}

Thirty one percent of responses strongly agreed with the RA factor associated with the level of knowledge and skills in an organisation. Fifty six percent agreed. Only three percent disagreed and eleven percent neither agreed or disagreed.

\section{Decision making and service coordination improvements}

There continued to be strong agreement with RA factors associated with internally-led drives to improve decision making and service coordination. Twenty two percent of respondents agreed that internally led drives to improve service coordination had an impact on corporate governance reform. Sixty one percent agreed while six percent disagreed. Eleven percent neither agreed or disagreed.

Twenty one percent of respondents strongly agreed that internally-led drives to improve decision making had an impact on corporate governance reform. Sixty eight percent agreed and three percent disagreed. Approximately eight percent of respondents neither agreed or disagreed.

\section{Government policy implementation and regulatory compliance}

Similarly, respondents generally supported the importance of implementing new government policy and complying with regulatory requirements. Sixteen percent strongly agreed that the requirement to comply with regulatory requirements impacted on reform adoption. Sixty three percent agreed. Seven percent disagreed and one percent strongly 
disagreed - this was the highest level of disagreement recorded for an RA factor. Thirteen percent neither agreed or disagreed about the impact of regulatory compliance.

Twenty seven percent of respondents strongly agreed that the requirement to implement new government policy impacted on the adoption of corporate governance reform. Sixty three percent agreed with this RA factor and only one percent disagreed. Ten percent of respondents neither agreed or disagreed.

\section{External accountability and efficiency requirements}

The impact of externally led-drives to improve accountability and efficiency were supported by respondents. Nine percent strongly agreed that externally-led drives to improve efficiency had an impact on corporate governance reform adoption. Sixty eight percent agreed while fifteen percent neither agreed or disagreed. Seven percent of respondents disagreed about the impact of external efficiency requirements and one percent strongly disagreed.

Thirteen percent of respondents strongly agreed that external drives to improve accountability impacted on reform adoption and sixty eight percent agreed. Four percent disagreed with this RA factor and one percent strongly disagreed. Fifteen percent of respondents neither agreed or disagreed about the influence of external accountability requirements. 


\subsubsection{Political/cultural factors impacting on reform adoption}

The frequency distribution of responses to political/cultural factors impacting on reform (refer Table 26) shows the responses to the Likert-scaled items used to measure political/cultural factors during the reform adoption stage.

Table 26: Frequency distribution of responses to political/cultural factors impacting on reform adoption (PA)

\begin{tabular}{|c|c|c|c|c|c|c|c|c|c|c|c|}
\hline \multirow[t]{2}{*}{ PA factor } & \multicolumn{2}{|c|}{$\begin{array}{l}\text { Strongly } \\
\text { disagree }\end{array}$} & \multicolumn{2}{|c|}{ Disagree } & \multicolumn{2}{|c|}{$\begin{array}{l}\text { Neither } \\
\text { agree or } \\
\text { disagree }\end{array}$} & \multicolumn{2}{|c|}{ Agree } & \multicolumn{2}{|c|}{$\begin{array}{c}\text { Strongly } \\
\text { agree }\end{array}$} & \multirow[t]{2}{*}{ Total } \\
\hline & Freq & $(\%)$ & Freq & $(\%)$ & Freq & $(\%)$ & Freq & (\%) & Freq & (\%) & \\
\hline $\begin{array}{l}\text { External group } \\
\text { influences }\end{array}$ & 1 & $(0.4)$ & 19 & $(8.2)$ & 34 & (14.7) & 135 & (58.2) & 43 & (18.5) & 232 \\
\hline $\begin{array}{l}\text { Internal group } \\
\text { influences }\end{array}$ & 0 & $(0.0)$ & 25 & (10.8) & 52 & (22.4) & 139 & (59.9) & 16 & (6.9) & 232 \\
\hline $\begin{array}{l}\text { Competition with } \\
\text { other priorities }\end{array}$ & 4 & (1.7) & 49 & (21.1) & 39 & (16.8) & 105 & (45.3) & 35 & (15.1) & 232 \\
\hline $\begin{array}{l}\text { Power and } \\
\text { institutional } \\
\text { relationships }\end{array}$ & 0 & $(0.0)$ & 22 & (9.5) & 66 & (28.4) & 121 & (52.2) & 23 & $(9.9)$ & 232 \\
\hline
\end{tabular}

There was strong support for all PA factors, although in general the level of support was not as strong as the respondent support recorded for RA factors. The highest level of support was recorded for the influence of external groups (77\%) and the influence of internal groups (67\%). The lowest level of support was recorded for the impact that competition with other priorities has on the adoption of reform (23\% of respondents disagreed).

\section{Power and institutional relationships}

Ten percent of respondents strongly agreed that the effect of corporate governance changes on power and institutional relationships affected that adoption of corporate governance 
reform. Fifty two percent agreed and ten percent disagreed with this PA factor. Twenty nine percent of respondents neither agreed or disagreed - the highest level recorded for any PA (or RA) factor.

\section{Competition with other priorities}

Fifteen percent of responses strongly agreed that the adoption of corporate governance reform was subject to competition with other organisational priorities. Forty five percent of respondents agreed. The highest level of disagreement was recorded for this factor (either PA or RA) - twenty one percent disagreed while two percent strongly disagreed. Seventeen percent of respondents neither agreed or disagreed.

\section{Influence of interest groups}

Respondents generally supported the PA factors associated with the influence of interest groups.

Seven percent strongly agreed that reform adoption was influenced by internal interest groups and sixty percent agreed. Eleven percent disagreed. Twenty two percent neither agreed or disagreed.

Nineteen percent strongly agreed that the influence of external groups (such as the Auditor General) had an impact on the adoption of reform in their organisation. Fifty eight percent agreed. Eight percent disagreed and less than one percent strongly disagreed. Fifteen percent of respondents neither agreed or disagreed that external interest groups influence reform adoption. The level of support for this PA factor is consistent with the level of 
support shown for the related RA factors - external drives to improve accountability and efficiency.

\subsubsection{Other factors impacting on reform adoption}

Respondents were also invited to identify any additional factors that they considered to have impacted on corporate governance reform adoption. Fifty six respondents nominated additional factors. The majority of these were variations on existing factors (such as compliance with regulatory requirements). However three new factors impacting on the adoption of corporate governance reform were identified from the responses provided. These included:

1. organisational restructuring and machinery of government changes, including amalgamation of departments (identified by seven respondents)

2. changes in organisation resource levels, including the dedication of resources to process and corporate governance improvements (identified by five respondents)

3. managing risks to organisational reputation (identified by three respondents)

The first two of these new factors present as rational/scientific influences. The need to manage risks to organisational reputation can be seen as a political/cultural influence given its focus on identifying and responding to stakeholder perceptions. 


\subsubsection{Most important factors impacting on reform adoption}

Respondents were asked to identify the five most important factors that have impacted on reform adoption in their organisation. Figure 9: Most important reform adoption factors sets out the responses to this question.

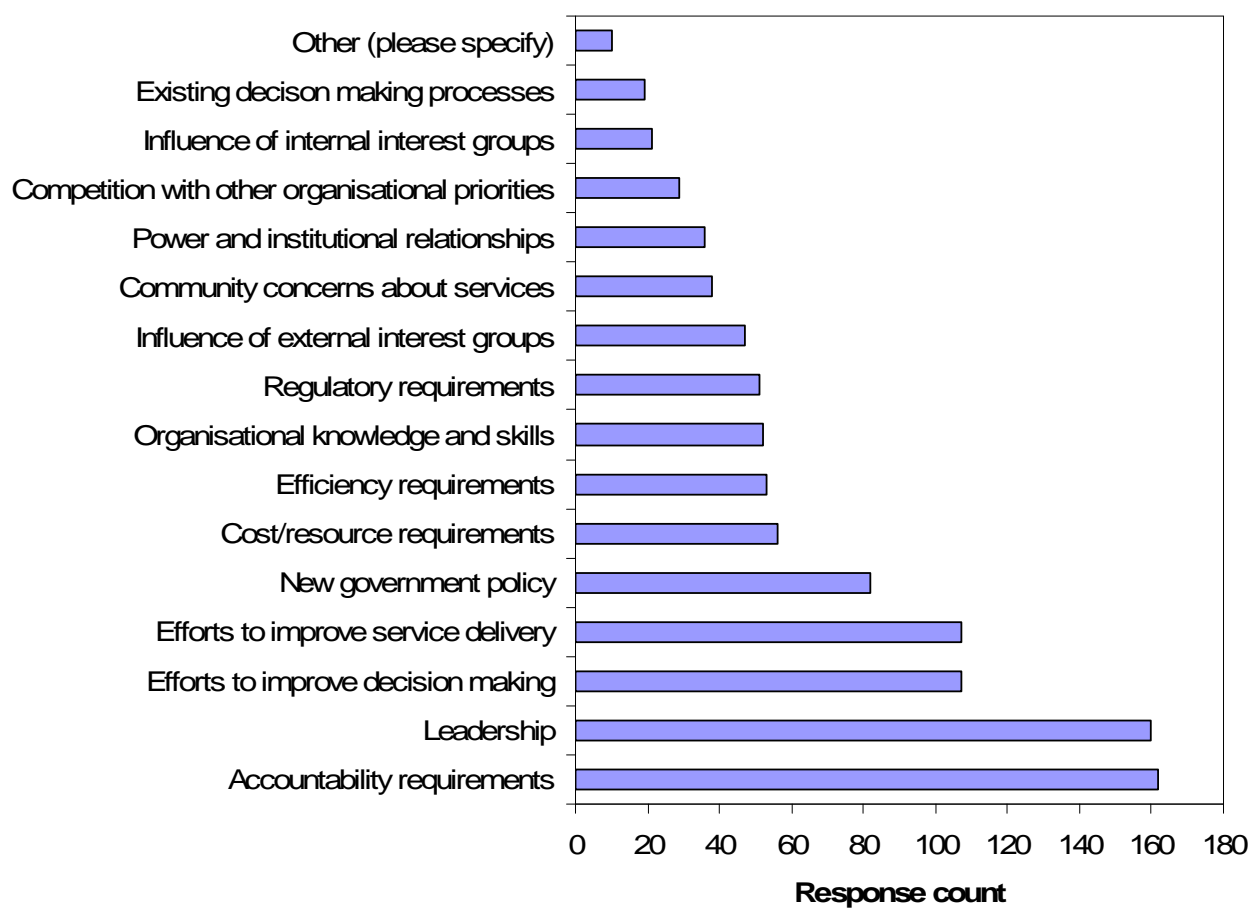

Figure 9: Most important reform adoption factors

The top nine nominated factors represent RA influences. The dominance of these influences are confirmed by a separate calculation of the weighted average of the earlier Likert based questions (Table 27: Corporate governance adoption influences - Likert score (average)). Although the order produced from this calculation varies slightly, it identifies the top nine influences as RA factors. 
Table 27: Corporate governance adoption influences - Likert score (average)

\begin{tabular}{llr}
\hline Reform adoption factor & Weighted average \\
\hline 1. & CEO leadership & 4.60 \\
\hline 2. & Senior manager leadership & 4.41 \\
\hline 3. Implement new government policy & 4.15 \\
\hline 4. & Knowledge and skill levels & 4.15 \\
\hline 5. Improve decision making & 4.06 \\
\hline $6 . \quad$ Improve service coordination & 3.99 \\
\hline 7. Decision making processes & 3.96 \\
\hline 8. & External accountability requirements & 3.88 \\
\hline 9. Regulatory compliance & 3.87 \\
\hline 10. External group influences & 3.86 \\
\hline 11. External efficiency requirements & 3.78 \\
\hline 12. Implementation costs & 3.67 \\
\hline 13. Internal group influences & 3.63 \\
\hline 14. Power and institutional relationships & 3.63 \\
\hline 15. Competition with other priorities & 3.51 \\
\hline
\end{tabular}

\subsubsection{Differences between groups}

Observed differences are set out below. The implications of these differences are discussed in Chapter eight.

\section{Characteristics of successful reform adoption}

The first set of observed differences suggest a series of characteristics common in reforms that have been successfully adopted.

- Respondents who agreed that the implementation of new government policy had impacted on the adoption of reform were more likely to agree that the adoption of reform was usually successful. The relationship between these variables is significant $-\mathrm{x}^{2}(\mathrm{df} 4, \underline{\mathrm{N}}=232)=10.29, \mathrm{p}<.05$ (refer to Table 1 in Appendix 6: Descriptive statistics). This suggests that departments have more success in adopting corporate governance reforms associated with the implementation of 
government policies. This is consistent with an increasing responsiveness of government departments (White 2000).

- Respondents who agreed that an internal drive to improve service coordination had impacted on the adoption of reform were more likely to agree that the adoption of reform was usually successful. The relationship between these variables is significant $-\mathrm{x}^{2}(\mathrm{df} 4, \underline{\mathrm{N}}=232)=28.83, \mathrm{p}<.05$ (refer to Table 3 in Appendix 6: Descriptive statistics ). This suggests that departments have more success in adopting corporate governance reforms associated with internally led service coordination improvements.

- Respondents who agreed that the influence of internal interest groups impacted on the adoption of reform were more likely to agree that the adoption of reform was usually successful. The relationship between these variables is significant $-x^{2}(\mathrm{df} 4$, $\underline{\mathrm{N}}=232$ ) $=29.82, \mathrm{p}<.05$ (refer to Table 5 in Appendix 6: Descriptive statistics ). This suggests that departments have more success in adopting corporate governance reforms where internal groups were involved.

- Respondents who agreed that the adoption of reform was subject to competition with other organisational priorities were more likely to agree that the adoption of reform was usually successful. The relationship between these variables is significant $-\mathrm{x}^{2}(\mathrm{df} 4, \underline{\mathrm{N}}=232)=10.61, \mathrm{p}<.05$ (refer to Table 7 in Appendix 6: Descriptive statistics ). This suggests that a competition between organisational priorities results in a corporate governance reform more likely to be successfully adopted. This is consistent with the stage 1 result (Department of Human Services) where it was found that a strong filtering process around corporate governance reforms resulted in very few cases of reform failure. 
- Respondents who agreed that the adoption of reform was impacted by senior management leadership were more likely to agree that the adoption of reform was usually successful. The relationship between these variables is significant $-\mathrm{x}^{2}(\mathrm{df} 4$, $\underline{\mathrm{N}}=232$ ) $=18.64, \mathrm{p}<.05$ (refer to Table 9 in Appendix 6: Descriptive statistics ). This suggests leadership plays an important role in the adoption of reform.

- There was a significant difference in the length of a respondent's employment and the frequency of agreement with the success of reform adoption. Respondents employed for less than two years were more likely not to agree (either disagree or neither agree or disagree) that the adoption of reform was usually successful. The relationship between these variables is significant $-\mathrm{x}^{2}(\mathrm{df} 6, \underline{\mathrm{N}}=232)=14.42, \mathrm{p}<.05$ (refer Table 11 in Appendix 6). This suggests that new employees are less likely to agree that the adoption of reform in their organisation was usually successful.

\section{Organisational characteristics of reform adoption}

The second series of observed differences relate to the nature of organisations that successfully adopt reform.

- Respondents who worked in organisations with a budget in excess of \$1 billion were more likely to agree that an external drive to improve accountability impacted on the adoption of reform. The relationship between these variables is significant $\mathrm{x}^{2}(\mathrm{df} 4, \underline{\mathrm{N}}=232)=11.64, \mathrm{p}<.05$ (refer to Table 13 in Appendix 6: Descriptive statistics ). This suggests that larger organisations have increased external pressure to be accountable for their performance.

- Respondents who worked in organisations with a budget between \$501 million and $\$ 1$ billion were more likely to agree that an internal drive to improve service 
coordination impacted on the adoption of reform. The relationship between these variables is significant $-\mathrm{x}^{2}(\mathrm{df} 4, \underline{\mathrm{N}}=232)=12.11, \mathrm{p}<.05$ (refer to Table 15 in Appendix 6: Descriptive statistics ). This suggests that mid range organisations (those with a budget between $\$ 500$ million and $\$ 1$ billion) are more likely than smaller or larger organisations to focus on service coordination improvement.

- Respondents who worked in organisations with a budget in excess of $\$ 1$ billion were more likely that other respondents to disagree that organisational decision making processes impacted on the adoption of reform. The relationship between these variables is significant $-\mathrm{x}^{2}(\mathrm{df} 4, \underline{\mathrm{N}}=232)=15.15, \mathrm{p}<.05$ (refer to Table 17 in Appendix 6: Descriptive statistics ). This suggests that the adoption of corporate governance reform in larger organisations is less likely to be constrained by decision making processes. This is varies from the literature which has traditionally suggested that larger organisations are more bueauracatratic and more likely to use decision making processes that restrain change.

- Respondents who were employed for between 0-2 years were less likely to agree (either disagree or neither agree or disagree) that internal groups influenced the adoption of corporate governance reform. The relationship between these variables is significant $-\mathrm{x}^{2}(\mathrm{df} 4, \underline{\mathrm{N}}=232)=9.79, \mathrm{p}<.05$ (refer to Table 19 in Appendix 6: Descriptive statistics ). This suggests that new employees are less likely to associate internal group with the adoption of corporate governance reform.

- Respondents who were employed for less than two years were more likely to agree that the costs associated with implementing change impacted on the adoption of reform. The relationship between these variables is significant $-x^{2}(\mathrm{df} 4$, $\underline{\mathrm{N}}=232$ ) $=10.57, \mathrm{p}<.05$ (refer to Table 21 in Appendix 6: Descriptive statistics ). 
Ths suggests new employees are more likely than others to see the adoption of reform as being influenced by cost. When this finding is considered with the previous finding (new employees less likely to see reform adoption influenced by internal groups) it suggests that new employees are more likely to view the adoption of corporate governance reform as being influenced by rational/scientific factors (cost) than political/cultural factors (influence of internal groups). 


\subsection{Characteristics of corporate governance operation in departments}

This section details responses to factors impacting on the operation of corporate governance reforms in departments.

Most respondents considered that corporate governance reform in their department was usually successful (sixty six percent - refer

Figure 10: Success in operating corporate governance reform). However, a large number of respondents (twenty five percent did not agree or disagree that reform adoption is usually successful. Nine percent of respondents disagreed (either disagreed or strongly disagreed) that reform operation is usually successful in their organisation. This is an increase of one percent of respondents who disagreed about the success of reform adoption. 


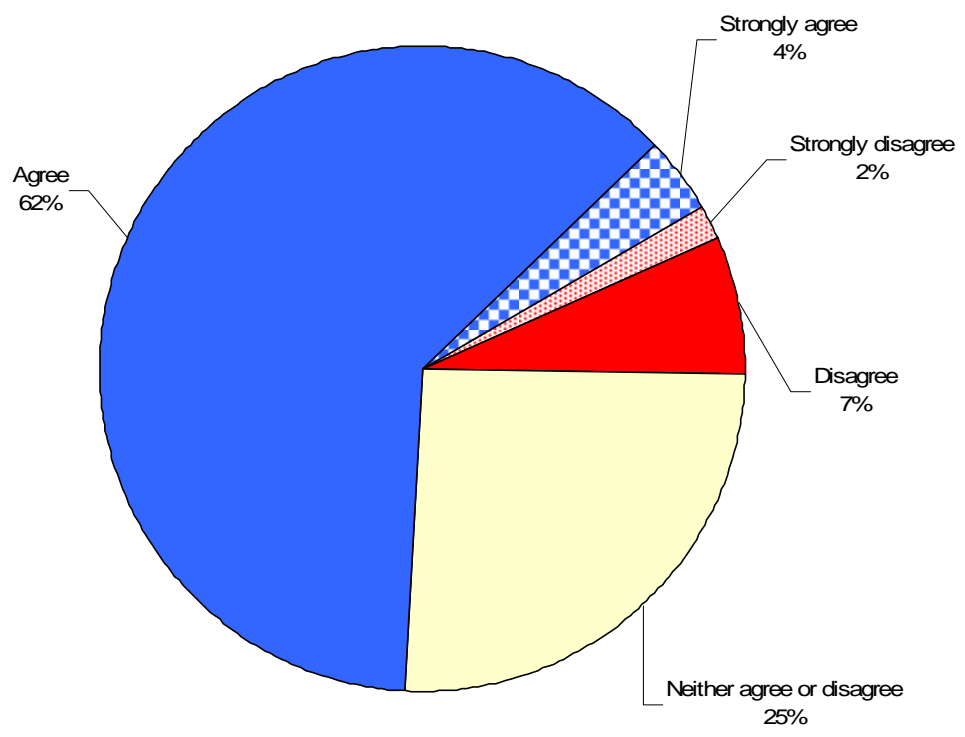

Figure 10: Success in operating corporate governance reform

\subsubsection{Rational/scientific factors impacting on reform operation}

Table 28: Frequency distribution of responses to rational/scientific factors impacting on reform operation (RO) shows the responses to the Likert-scaled items used to measure political/cultural factors during the reform operation stage.

Table 28: Frequency distribution of responses to rational/scientific factors impacting on reform operation (RO)

\begin{tabular}{|l|r|r|r|r|r|r|r|r|r|r|r|}
\hline \multicolumn{1}{|c|}{ RA factors } & \multicolumn{2}{|c|}{$\begin{array}{l}\text { Strongly } \\
\text { disagree }\end{array}$} & \multicolumn{2}{|c|}{ Disagree } & \multicolumn{2}{c|}{$\begin{array}{l}\text { Neither } \\
\text { agree or } \\
\text { disagree }\end{array}$} & \multicolumn{3}{c|}{$\begin{array}{c}\text { Agree } \\
\text { Strongly } \\
\text { agree }\end{array}$} & $\begin{array}{l}\text { Total } \\
\end{array}$ \\
\hline Freq & $\mathbf{( \% )}$ & Freq & $\mathbf{( \% )}$ & Freq & $\mathbf{( \% )}$ & Freq & $\mathbf{( \% )}$ & Freq & $\mathbf{( \% )}$ & \\
\hline $\begin{array}{l}\text { Organisational } \\
\text { attributes }\end{array}$ & 0 & $(0.0)$ & 27 & $(11.6)$ & 51 & $(22.0)$ & 124 & $(53.4)$ & 30 & $(12.9)$ & 232 \\
\hline $\begin{array}{l}\text { Organisational } \\
\text { control processes }\end{array}$ & 0 & $(0.0)$ & 7 & $(3.0)$ & 42 & $(18.1)$ & 161 & $(69.4)$ & 22 & $(9.5)$ & 232 \\
\hline $\begin{array}{l}\text { Communication } \\
\text { and information } \\
\text { sharing }\end{array}$ & 0 & $(0.0)$ & 4 & $(1.7)$ & 20 & $(8.6)$ & 128 & $(55.2)$ & 80 & $(34.5)$ & 232 \\
\hline $\begin{array}{l}\text { Knowledge and } \\
\text { skill levels }\end{array}$ & 0 & $(0.0)$ & 8 & $(3.4)$ & 32 & $(13.8)$ & 134 & $(57.8)$ & 58 & $(25.0)$ & 232 \\
\hline Reform scale and & 0 & $(0.0)$ & 7 & $(3.0)$ & 31 & $(13.4)$ & 142 & $(61.2)$ & 52 & $(22.4)$ & 232 \\
\hline
\end{tabular}




\begin{tabular}{|l|r|r|r|r|r|r|r|r|r|r|r|}
\hline scope & & & & & & & & & & & \\
\hline $\begin{array}{l}\text { Leadership } \\
\text { continuity }\end{array}$ & 0 & $(0.0)$ & 10 & $(4.3)$ & 37 & $(15.9)$ & 123 & $(53.0)$ & 62 & $(26.7)$ & 232 \\
\hline $\begin{array}{l}\text { Senior manager } \\
\text { leadership }\end{array}$ & 0 & $(0.0)$ & 5 & $(2.2)$ & 6 & $(2.6)$ & 104 & $(44.8)$ & 117 & $(50.4)$ & 232 \\
\hline CEO leadership & 0 & $(0.0)$ & 1 & $(0.4)$ & 12 & $(5.2)$ & 80 & $(34.5)$ & 139 & $(59.9)$ & 232 \\
\hline $\begin{array}{l}\text { Resource } \\
\text { availability }\end{array}$ & 0 & $(0.0)$ & 15 & $(6.5)$ & 35 & $(15.1)$ & 132 & $(56.9)$ & 50 & $(21.6)$ & 232 \\
\hline $\begin{array}{l}\text { Time to implement } \\
\text { change }\end{array}$ & 1 & $(0.4)$ & 21 & $(9.1)$ & 28 & $(12.1)$ & 143 & $(61.6)$ & 39 & $(16.8)$ & 232 \\
\hline
\end{tabular}

There continued to be strong support for RO factors during the operation stage.

Leadership continued to be a prominent factor (95\% of respondents agreed that senior management leadership impacted on reform operation while $94 \%$ agreed that the leadership of the CEO was important). The highest level of disagreement was recorded for the impact of organisational attributes on the operation of reform $(12 \%$ of respondents disagreed with this factor). Each factor is described in more detail below.

\section{Organisational attributes}

Thirteen percent of respondents strongly agreed that organisational attributes such as workforce size, had an impact on reform operation. A further fifty three percent of respondents agreed with this RO factor. Twelve percent did not agree and twenty two percent did not agree or disagree.

\section{Organisational control processes}

A majority of respondents agreed that organisational control processes impacted on the operation of reform - ten percent strongly agreed and seventy percent agreed. Only three percent disagreed with approximately eighteen percent neither agreeing or disagreeing. 


\section{Communication and information sharing processes}

Only two percent of respondents disagreed that communication and information sharing processes impacted on reform operation. Thirty five percent of respondents strongly agreed with this RO factor and a further fifty five percent agreed. Nine percent did not agree or disagree.

\section{Knowledge and skills levels}

There was also little disagreement about the impact of organisational knowledge on reform operation, including knowledge related to corporate governance, change management and innovation. Twenty five percent of respondents strongly agreed about the impact on this factor. A further fifty eight percent agreed. Only three percent disagreed with approximately thirteen percent of respondent neither agreeing or disagreeing.

\section{Reform scale and scope}

Impacts related to the scale and scope of reform was strongly supported by around a quarter of respondents. Sixty one percent agreed, while only three percent disagreed. Thirteen percent of respondents did not agree or disagree.

\section{Leadership}

The three RO factors related to leadership (CEO leadership, senior manager leadership and continuity of leadership) received the strongest support from respondents.

Twenty seven percent of respondents strongly agreed that continuity of leadership from the adoption stage impacted on reform operation. A further fifty three percent agreed with this 
factor. Four percent did not agree. Sixteen percent did not agree or disagree about leadership continuity.

Fifty percent of responses strongly agreed that leadership shown by senior managers impacted on reform operation. Forty five percent agreed. Only two percent disagreed and a further three percent neither agreed or disagreed.

Strongest support was shown for chief executive officer leadership. Sixty percent of respondents strongly agreed and thirty five percent agreed. Only one respondent disagreed with this RO factor (less than half a percent of total responses). Five percent did not agree or disagree.

\section{Resource availability}

Most respondents agreed that the availability of resources had an impact on reform operation (twenty two percent strongly agreed and fifty seven percent agreed). Seven percent of respondents disagreed, while fifteen percent did not agree or disagree. Agreement to the impact of this RO factor differs from the results obtained during the Stage 1 (Human Services’ Department) case study. Results from the case study showed little support for the impact of resource availability on reform operation.

\section{Time to implement reform}

There was also majority support for the last RO factor included in the study - time available to implement change. Seventeen percent of respondents strongly agreed that this factor impacted on the operation of corporate governance reform. Sixty two percent 
agreed. Nine percent of respondent disagreed about the impact of this factor and $0.4 \%$ strongly disagreed (the only RO factor to record strong disagreement from respondents). Approximately twelve percent did not agree or disagree about the impact of available time.

\subsubsection{Political/cultural factors impacting on reform operation}

Table 29 shows the responses to the Likert-scaled items used to measure political/cultural factors during the reform operation stage. There was a high level of support for the first three factors shown in the table (69\% of respondents agreed that change fatigue has an impact on reform operation and $68 \%$ of respondents agreed with each of the factors associated with attitudes to organisational change and innovation). There was less support for the notion that the hierarchical nature of public services impacted on reform adoption (13\% disagreed).

Table 29: Frequency distribution of responses to political/cultural factors impacting on reform operation

\begin{tabular}{|c|c|c|c|c|c|c|c|c|c|c|c|}
\hline \multirow[t]{2}{*}{ PO factors } & \multicolumn{2}{|c|}{$\begin{array}{l}\text { Strongly } \\
\text { disagree }\end{array}$} & \multicolumn{2}{|c|}{ Disagree } & \multicolumn{2}{|c|}{$\begin{array}{l}\text { Neither } \\
\text { agree or } \\
\text { disagree }\end{array}$} & \multicolumn{2}{|c|}{ Agree } & \multicolumn{2}{|c|}{$\begin{array}{l}\text { Strongly } \\
\text { agree }\end{array}$} & \multirow[t]{2}{*}{ Total } \\
\hline & Freq & $(\%)$ & Freq & $(\%)$ & Freq & $(\%)$ & Freq & $(\%)$ & Freq & $(\%)$ & \\
\hline Change fatigue & 2 & $(0.9)$ & 23 & (9.9) & 48 & (20.7) & 118 & (50.9) & 41 & (17.7) & 232 \\
\hline $\begin{array}{l}\text { Attitudes to } \\
\text { organisational } \\
\text { change }\end{array}$ & 2 & $(0.9)$ & 23 & (9.9) & 50 & (21.6) & 126 & (54.3) & 31 & (13.4) & 232 \\
\hline $\begin{array}{l}\text { Attitudes to } \\
\text { innovation }\end{array}$ & 2 & $(0.9)$ & 23 & (9.9) & 50 & (21.6) & 126 & (54.3) & 31 & (13.4) & 232 \\
\hline $\begin{array}{l}\text { Hierarchical nature } \\
\text { of public services }\end{array}$ & 0 & $(0.0)$ & 29 & (12.5) & 62 & (26.7) & 108 & $(46.6)$ & 33 & $(14.2)$ & 232 \\
\hline $\begin{array}{l}\text { Number of change } \\
\text { actors }\end{array}$ & 0 & $(0.0)$ & 19 & $(8.2)$ & 59 & (25.4) & 123 & (53.0) & 31 & (13.4) & 232 \\
\hline $\begin{array}{l}\text { Managerial loss of } \\
\text { control }\end{array}$ & 0 & $(0.0)$ & 22 & (9.5) & 55 & (23.7) & 108 & $(46.6)$ & 47 & (20.3) & 232 \\
\hline $\begin{array}{l}\text { Power and } \\
\text { institutional } \\
\text { relationships }\end{array}$ & 0 & $(0.0)$ & 10 & (4.3) & 62 & (26.7) & 121 & $(52.2)$ & 39 & (16.8) & 232 \\
\hline
\end{tabular}




\section{Change fatigue}

Most respondents agreed that corporate governance reform in their organisation was impacted by change fatigue. Eighteen percent of respondents strongly agreed with this factor and a further fifty one percent agreed. Ten percent of respondents did not agree that change fatigue had an impact while a further one percent strongly disagreed. Twenty one percent of respondents did not agree or disagree.

\section{Attitudes to organisational change}

There was limited agreement by respondents with the notion that their organisation easily accepted change. Only two percent of respondents strongly agreed that their organisation easily accepted organisational change. And while a further thirty three percent of respondents agreed that change was easily accepted in their organisation, a similar proportion of respondents (twenty eight percent) of respondents did not agree and four percent strongly disagreed. A high proportion of respondents (thirty three percent) did not agree or disagree. This factor received the least support of any factor - RA, PA, RO and PO.

\section{Attitudes to innovation}

There was more support from respondents about their organisation's attitude to innovation. Thirteen percent strongly agreed that innovation was encouraged and fifty four percent agreed. Around ten percent of respondents did not agree that innovation was encouraged while a further one percent strongly disagreed. Twenty two percent of respondents did not agree or disagree. 


\section{Hierarchical nature of public sector organisations}

The majority of respondents agreed that the hierarchical nature of the public service impacted on the operation of reform. Fourteen percent of respondents strongly agreed with this factor and a further forty seven percent agreed. Thirteen percent of respondents disagreed. A high proportion of respondents (twenty seven percent) did not agree or disagree.

\section{Number of change actors}

Thirteen percent of respondents agreed that the number of actors in the change process impacted on reform operation. Fifty three percent agreed while only eight percent of respondents disagreed. Twenty six percent of respondents did not agree or disagree.

\section{Managerial fear of control loss}

Twenty percent of respondents strongly agreed that a manager's fear of losing control had an impact on the operation of reform. Forty seven percent agreed with this PO factor while ten percent did not. There continued to be a high proportion of respondents (Twenty five percent) who did not agree or disagree. 


\section{Power and institutional relationships}

A clear majority of respondents agreed that the effect of corporate governance changes on power and institutional relationships had an impact on reform operation. Fifty two percent of respondents agreed with this factor and a further seventeen percent strongly agreed. Only four percent of respondents disagreed. Twenty five percent of respondents did not agree or disagree.

\subsubsection{Other factors impacting on reform operation}

Respondents were also invited to identify any additional factors that they considered to have impacted on the operation of corporate governance reform in their organisation. Seventeen respondents nominated additional factors. Again, the majority of these were variations on existing factors (such as the availability of resources and communication processes). However one new factor impacting on the operation of corporate governance reform were identified from the responses provided.

This was:

- frequency of change - this is distinguished from change fatigue as several respondents considered that the increasing frequency of change enabled successful change (identified by two respondents)

This new factor can be considered to be a political/cultural influence, that is to say the frequency of change has created a new culture more likely to accept of change. 


\subsubsection{Most important factors impacting on reform operation}

Respondents were asked to rank the factors that impacted on reform operation in their organisations. Figure 11: Most important reform operation factors sets out the responses to this question. These results indicate that rational/scientific factors appear to continue to dominate the reform process. The top seven factors can be identified as RO influences.

Figure 11: Most important reform operation factors

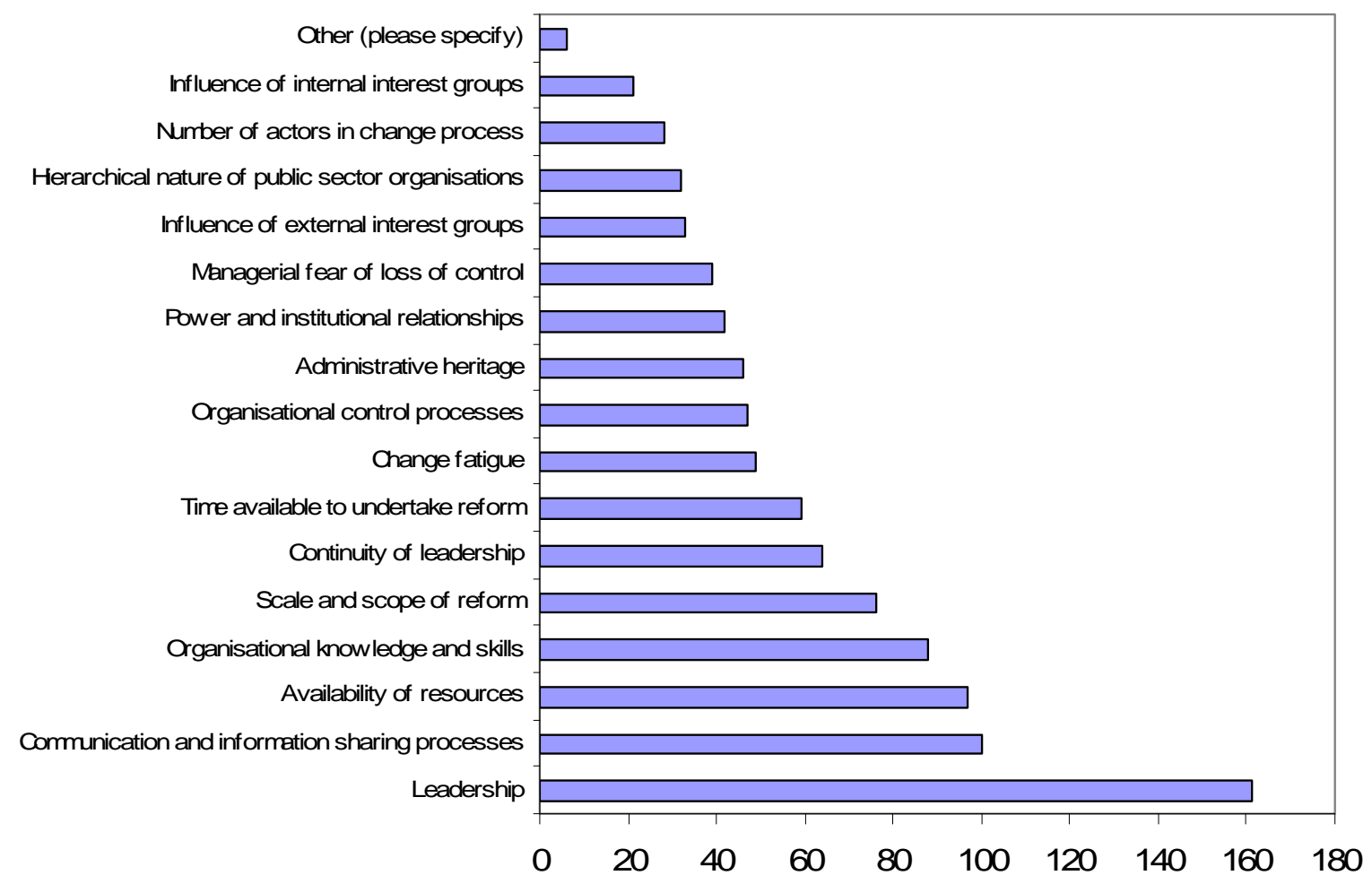

A separate calculation of the weighted average of responses to Likert-based questions about reform operation confirms most respondents attribute greater influence to RO factors 
(refer Table 30: Corporate governance operation influences - Likert scores (average)).

This result is discussed in more detail in the following chapter.

Table 30: Corporate governance operation influences - Likert scores (average)

\begin{tabular}{lr}
\hline Reform operation factor & Weighted average \\
\hline 1. CEO leadership & 4.54 \\
\hline 2. Senior manager leadership & 4.44 \\
\hline 3. Communication and information sharing & 4.22 \\
\hline 4. Knowledge and skill levels & 4.04 \\
\hline 5. Reform scale and scope & 4.03 \\
\hline 6. Leadership continuity & 4.02 \\
\hline 7. Resource availability & 3.94 \\
\hline 8. Time to implement change & 3.85 \\
\hline 9. Organisational control processes & 3.85 \\
\hline 10. Power and institutional relationships & 3.81 \\
\hline 11. Managerial loss of control & 3.78 \\
\hline 12. Change fatigue & 3.75 \\
\hline 13. Number of change actors & 3.72 \\
\hline 14. Attitudes to organisational change & 3.69 \\
\hline 15. Attitudes to innovation & 3.69 \\
\hline 16. Organisational attributes & 3.68 \\
\hline 17. Hierarchical nature of public services & 3.63 \\
\hline
\end{tabular}

\subsubsection{Corporate governance reform focus}

Respondents were asked to provide information about the focus of governance reform in their organisation. Sixty eight percent of respondents identified internal decision making and control processes as the focus of governance reform in their organisations ( refer to Figure 12: Governance reform focus). However, a large proportion of respondents identified governance reform as focusing on the relationships with external agencies, including those with a funding relationship. Ten percent of respondents indicated that governance reform in their organisation focused on other issues. The majority of these responses identified reform as driven by both internal decision making processes and external relationships - 'it is not an either/or'. Other responses were centred on variations to internal control issues, such as performance measurement, resource management and compliance. 


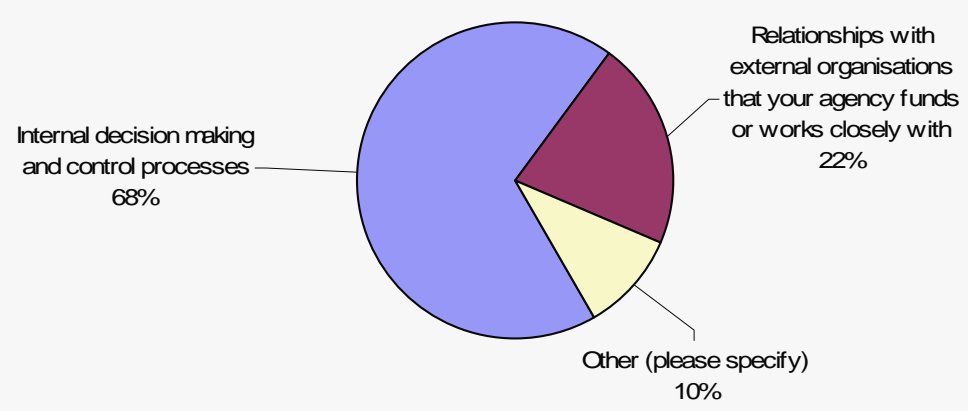

Figure 12: Governance reform focus

\subsubsection{Volume of governance reforms}

The number of governance reforms undertaken during the employment of respondents were also obtained through the survey - refer to Table 31: Governance reforms undertaken during employment of respondent.

Table 31: Governance reforms undertaken during employment of respondent

\begin{tabular}{|ll|r|r|r|r|}
\hline & & & & \multicolumn{1}{c|}{$\begin{array}{c}\text { Cumulative } \\
\text { Percent }\end{array}$} \\
\hline Valid & $1-5$ & 85 & 36.6 & 44.5 & 44.5 \\
& $6-10$ & 57 & 24.6 & 29.8 & 74.3 \\
& $11-20$ & 31 & 13.4 & 16.2 & 90.6 \\
& $21-50$ & 12 & 5.2 & 6.3 & 96.9 \\
& $>50$ & 6 & 2.6 & 3.1 & 100.0 \\
& Total & 191 & 82.3 & 100.0 & \\
Missing & System & 41 & 17.7 & & \\
Total & & 232 & 100.0 & & \\
\hline
\end{tabular}


Forty four percent of respondents who answered this question reported experiencing less that five governance reforms. Thirty percent of respondents reported between six and ten reforms during their employment while sixteen percent indicated they had experienced between eleven and twenty reforms. Six percent of respondents had experienced between twenty one and fifty governance reforms. Six respondents (three percent of people who responded to this question) had seen in excess of fifty governance changes during their employment with the organisation.

\subsubsection{Governance training}

Respondents were also asked to indicate if they had received any training related to reforming corporate governance arrangements. Fifty six percent of respondents who answered this question indicated that training had been provided (refer Table 32: Has corporate governance reform training been provided). A significant number of respondents, forty three percent, had not however received any training.

Table 32: Has corporate governance reform training been provided

\begin{tabular}{|ll|r|r|r|r|}
\hline & & & & \multicolumn{1}{c|}{$\begin{array}{c}\text { Cumulative } \\
\text { Percent }\end{array}$} \\
\hline Valid & Yes & 111 & 47.8 & 56.6 & 56.6 \\
& No & 85 & 36.6 & 43.4 & 100.0 \\
& Total & 196 & 84.5 & 100.0 & \\
Missing & System & 36 & 15.5 & & \\
Total & & 232 & 100.0 & & \\
\hline
\end{tabular}

\subsubsection{Differences between groups}

Observed differences related to

- Characteristics of successful reform operation 
- Organisational characteristics of reform operation

are set out below. The implications of these differences are discussed in Chapter seven.

\section{Characteristics of successful reform operation}

- Respondents who agreed that their organisation accepted innovation were more likely to agree that the operation of reform was usually successful. Similarly, respondents who disagreed that their organisation accepted innovation were more likely to disagree that the operation of reform was usually successful. The relationship between these variables is significant $-\mathrm{x}^{2}(\mathrm{df} 4, \underline{\mathrm{N}}=232)=109.77, \mathrm{p}<.05$ (refer to Table 23 in Appendix 6: Descriptive statistics ). This suggests organisations that readily accept innovation are more likely to successfully operate reform.

- Respondents who agreed that their organisation easily accepted change were more likely to agree that the operation of reform was usually successful. Similarly, respondents who disagreed that their organisation easily accepted change were more likely to disagree that the operation of reform was usually successful. The relationship between these variables is significant $-\mathrm{x}^{2}(\mathrm{df} 4, \underline{\mathrm{N}}=232)=65.31, \mathrm{p}<.05$ (refer to Table 25 in Appendix 6: Descriptive statistics ). This suggests organisations that readily accept change are more likely to successfully operate reform.

- Respondents who agreed that the number of actors in the change process impacted on the operation of reform were more likely to agree that the operation of reform was usually successful. The relationship between these variables is significant - 
$\mathrm{x}^{2}(\mathrm{df4}, \underline{\mathrm{N}}=232)=14.53, \mathrm{p}<.05$ (refer to Table 27 in Appendix 6: Descriptive statistics ). This suggests that change actors actively involved in the operation of reform will produce a corporate governance change more likely to succeed.

- Respondents employed less than two years were less likely to agree (either disagree or neither agree or disagree) that reform operation was usually successful. This reflects the difference observed between the success of reform adoption and length of respondent employment. The relationship between these variables is significant $-\mathrm{x}^{2}(4, \underline{\mathrm{N}}=232)=17.54, \mathrm{p}<.05$ (refer to Table 29 in Appendix 6: Descriptive statistics ). This suggests that new employees are less likely to agree that the operation of reform in their organisation was usually successful. A similar finding was made about new employees and the successful adoption of corporate governance reform.

- There was a significant difference between states in the frequency of respondent agreement that reform operation was usually successful. High levels of agreement with this factor were recorded for Victoria and Queensland while respondents from Tasmania recorded significantly lower levels of agreement. The relationship between these variables is significant $-\mathrm{x}^{2}(\mathrm{df} 10, \underline{\mathrm{N}}=232)=19.03, \mathrm{p}<.05$ (refer to Table 31 in Appendix 6: Descriptive statistics ). This suggests that corporate governance reform is more likely to be successful operated in Victorian and Queensland government departments than Tasmanian departments.

- Respondents in organisations with a hybrid organisational structure were less likely to agree that reform was usually successful. The relationship between these variables is significant $-\mathrm{x}^{2}(\mathrm{df} 4, \underline{\mathrm{N}}=232)=11.74, \mathrm{p}<.05$ (refer to Table 33 in Appendix 6: Descriptive statistics ). This suggests that corporate governance 
reform is less likely to be successfully operated in government departments with a hybrid organisational structure.

\section{Organisational characteristics of reform operation}

- Respondents who worked in an organisation with a budget between $\$ 100-\$ 500$ million were more likely to agree that organisational attributes impacted on the operation of reform. The relationship between these variables is significant $\mathrm{x}^{2}(\mathrm{df} 4, \underline{\mathrm{N}}=232)=11.39, \mathrm{p}<.05$ (refer to Table 35 in Appendix 6: Descriptive statistics ). This suggests that smaller organisations are more likely to be affected by organisational attributes.

- Respondents who worked in organisations with fewer than five sites were less likely to agree that the number of actors in the change process impacted on the operation of reform. The relationship between these variables is significant $\mathrm{x}^{2}(\mathrm{df} 4, \underline{\mathrm{N}}=232)=10.58, \mathrm{p}<.05$ (refer to Table 37 in Appendix 6: Descriptive statistics ). This suggests that corporate governance reform in organisations with few sites are less likely to be affected by the number of change actors.

- Respondents who were employed for less than two years were less likely to agree that their organisation accepted innovation. The relationship between these variables is significant $-\mathrm{x}^{2}(\mathrm{df} 4, \underline{\mathrm{N}}=232)=13.70, \mathrm{p}<.05$ (refer to Table 39 in Appendix 6: Descriptive statistics ). This suggests new employees are less likely to see their organisation as innovative.

- Respondents who were employed for less than two year were more likely to disagree that their organisation easily accepted change. The relationship between these variables is significant $-\mathrm{x}^{2}(\mathrm{df} 4, \underline{\mathrm{N}}=232)=13.45, \mathrm{p}<.05$ (refer to Table 41 in 
Appendix 6: Descriptive statistics ). This suggests that new employees are less likely to see their organisation as accepting of change.

- Respondents who worked in an organisation with a divisional structure were more likely to agree that organisational attributes impacted on the operation of reform. The relationship between these variables is significant $-x^{2}(\mathrm{df} 4, \underline{N}=232)=12.70$, $\mathrm{p}<.05$ (refer to Table 43 in Appendix 6: Descriptive statistics ). This suggests that divisional organisational structures are more likely to be affected by organisational attributes during the operation of corporate governance reform.

\section{Other observed differences}

- There was a significant difference between states in the frequency of agreement with the factor associated with acceptance of change. High levels of agreement with this factor were recorded for South Australia and Western Australia while respondents from Tasmania recorded high levels of disagreement. The relationship between these variables is significant $-\mathrm{x}^{2}(\mathrm{df10}, \underline{\mathrm{N}}=201)=21.26, \mathrm{p}<.05$ (refer to Table 45 in Appendix 6: Descriptive statistics ). This suggests that government departments in South Australia and Western Australia are more accepting of change than departments in Tasmania. This is consistent with the earlier finding that the operation of corporate governance reform is less likely to be successful in Tasmania.

- Respondents who were employed between three and ten years were more likely than other respondents to have received corporate governance reform training. Respondents employed for less than two years were less likely to have received training. The relationship between these variables is significant $-x^{2}(\mathrm{df} 2$, 
$\underline{\mathrm{N}}=232$ ) $=6.65, \mathrm{p}<.05$ (refer to Table 47 in Appendix 6: Descriptive statistics ). This suggests that people who work for a government department are less likely to have received training in government reform if they have been employed for less than three years, or more than ten.

- Respondents in organisations with a functional organisational structure were less likely to have received corporate governance reform training. The relationship between these variables is significant $-\mathrm{x}^{2}(\mathrm{df} 2, \underline{\mathrm{N}}=232)=10.20, \mathrm{p}<.05$ (refer to Table 49 in Appendix 6: Descriptive statistics ). This suggests that people who work in a department with a functional organisational structure are less likely to have been trained in corporate governance reform.

- There was significant difference between states and the length of respondent employment. Respondents from Queensland and Western Australian were more likely than other respondents to have been employed for more than ten years while respondents from Victoria were more likely to have been employed for between three and ten years. Tasmanian respondents were more likely than other respondents to be employed for less than two years. The relationship between these variables is significant $-\mathrm{x}^{2}(\mathrm{df} 10, \underline{\mathrm{N}}=232)=22.64, \mathrm{p}<.05$ (refer to Table 51 in Appendix 6: Descriptive statistics ). This suggests that government departments in Queensland and Western Australia are more likely to have senior staff than have been employed for more than ten years.

- There was a significant difference between states and the size of an organisation's budget. Budgets in Victorian organisations were more likely to be in excess of $\$ 1$ billion while the budget for organisations in Western Australia were more likely than those in other states to be less than $\$ 500$ million. The relationship between 
these variables is significant $-\mathrm{x}^{2}(\mathrm{df10}, \underline{\mathrm{N}}=232)=33.74, \mathrm{p}<.05$ (refer to Table 53 in Appendix 6: Descriptive statistics ). This suggests that government departments in Victoria have bigger budgets.

- Respondents who were employed the longest were more likely to have experienced more corporate governance change. The relationship between these variables is significant $-\mathrm{x}^{2}(\mathrm{df8}, \underline{\mathrm{N}}=232)=50.62, \mathrm{p}<.05$ (refer to Table 55 in Appendix 6:

Descriptive statistics ). This suggests that the longer a person is employed in an organisation the more likely they are to experience changes to corporate governance arrangements. 


\subsection{Multivariate analyses}

Likert-scaled variables were subjected to factor analysis. The principal component method was used to extract the factors. This method is the most frequently used approach and transforms correlated variables into a new set of principal components not correlated to each other (Cooper \& Schindler, 1998). The linear combination of these components, called factors, then account for the variance in the data.

Extraction was followed with an oblique rotation as the orthogonal rotation obtained an ambiguous structure. This was expected as factors used to measure single constructs, such as corporate governance reform adoption or operation, are likely to be highly correlated and therefore an oblique rotation that produces a more interpretable solution, such as Direct Oblimin, is a more appropriate choice (Coakes \& Steed, 2007).

The purpose of factor analysis is to uncover relationships among many variables and to allow numerous interconnected variables to be condensed into fewer dimensions, called factors. This permits the validation of the construct built around the conceptual framework.

As set out in the conceptual framework, corporate governance reform is subject to rational/scientific and political/cultural influences at the adoption and operation stages of reform (these have been previously categorised as RA, PA, RO and PO influences). Based on the data, an attempt has been made to validate the conceptual framework. The factors influencing reform has been confirmed through this analysis. 


\subsubsection{Factor analysis - adoption of corporate governance reform}

An examination of Bartlett's test of sphericity suggests that the strength of the relationship amongst the variables is strong and the Kaiser-Meyer-Olkin measure of sampling adequacy is greater than the acceptable level of 0.5 (refer Table 33: KMO and Bartlett's test corporate governance adoption).

Table 33: KMO and Bartlett's test - corporate governance adoption KMO and Bartlett's Test

\begin{tabular}{|c|c|c|}
\hline \multicolumn{2}{|c|}{$\begin{array}{l}\text { Kaiser-Meyer-Olkin Measure of Sampling } \\
\text { Adequacy. }\end{array}$} & .653 \\
\hline $\begin{array}{l}\text { Bartlett's Test of } \\
\text { Sphericity }\end{array}$ & $\begin{array}{l}\text { Approx. Chi-Square } \\
\text { df } \\
\text { Sig. }\end{array}$ & $\begin{array}{r}859.025 \\
105 \\
.000\end{array}$ \\
\hline
\end{tabular}

The Scree test, which displays the eigenvalues for each factor, was used as part of the decision criteria for retaining factors (Figure 13: Scree plot - corporate governance reform adoption). In addition only factors with a loading above 0.5 were retained. There is no established rule for what constitutes a 'high’ loading for a variable. Hatcher (Hatcher, 1994) identifies a minimum level of .4 while Ticehurst and Veal (Ticehurst \& Veal, 2000) suggest an acceptance level of .5. 


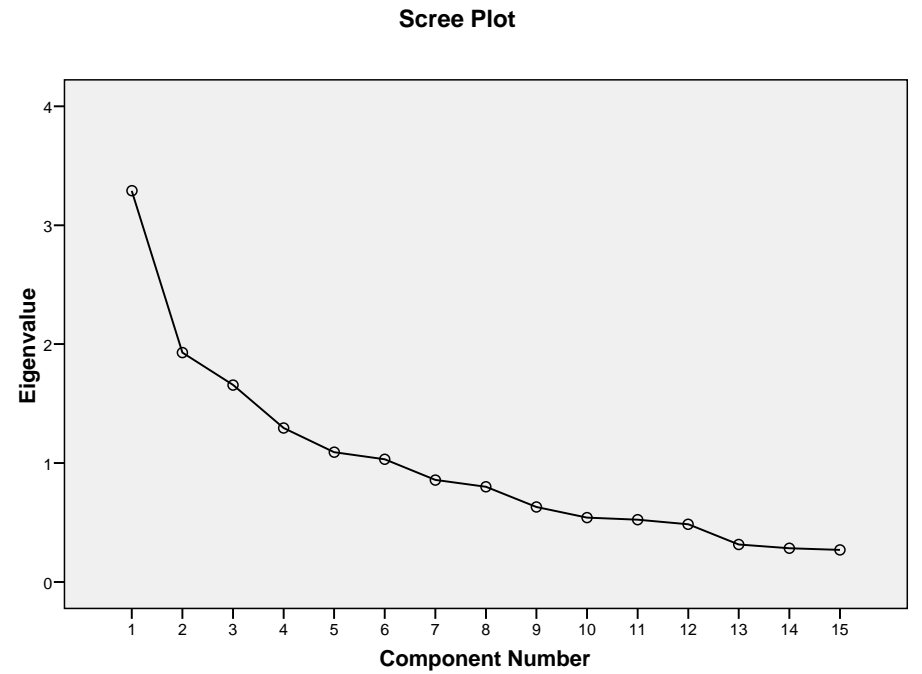

Figure 13: Scree plot - corporate governance reform adoption

Six factors were extracted (refer Table 34: Total variance explained - corporate governance adoption) that explained sixty nine percent of the variance. This suggests that there are up to six dimensions that make up the corporate governance reform adoption construct.

Table 34: Total variance explained - corporate governance adoption

Total Variance Explained

\begin{tabular}{|c|c|c|c|c|c|c|c|}
\hline \multirow[b]{2}{*}{ Component } & \multicolumn{3}{|c|}{ Initial Eigenvalues } & \multicolumn{3}{|c|}{ Extraction Sums of Squared Loadings } & \multirow{2}{*}{$\begin{array}{c}\text { Rotation } \\
\text { Total }\end{array}$} \\
\hline & Total & $\%$ of Variance & Cumulative $\%$ & Total & $\%$ of Variance & Cumulative $\%$ & \\
\hline 1 & 3.289 & 21.930 & 21.930 & 3.289 & 21.930 & 21.930 & 2.362 \\
\hline 2 & 1.929 & 12.862 & 34.792 & 1.929 & 12.862 & 34.792 & 2.094 \\
\hline 3 & 1.656 & 11.043 & 45.835 & 1.656 & 11.043 & 45.835 & 1.835 \\
\hline 4 & 1.294 & 8.629 & 54.464 & 1.294 & 8.629 & 54.464 & 1.994 \\
\hline 5 & 1.092 & 7.278 & 61.742 & 1.092 & 7.278 & 61.742 & 1.859 \\
\hline 6 & 1.031 & 6.876 & 68.618 & 1.031 & 6.876 & 68.618 & 1.807 \\
\hline 7 & .857 & 5.715 & 74.333 & & & & \\
\hline 8 & .800 & 5.334 & 79.667 & & & & \\
\hline 9 & .631 & 4.205 & 83.872 & & & & \\
\hline 10 & .540 & 3.603 & 87.474 & & & & \\
\hline 11 & .524 & 3.493 & 90.968 & & & & \\
\hline 12 & .485 & 3.236 & 94.204 & & & & \\
\hline 13 & .315 & 2.103 & 96.307 & & & & \\
\hline 14 & .284 & 1.892 & 98.199 & & & & \\
\hline 15 & .270 & 1.801 & 100.000 & & & & \\
\hline
\end{tabular}

Extraction Method: Principal Component Analysis.

a. When components are correlated, sums of squared loadings cannot be added to obtain a total variance. 
Table 35: Factor pattern matrix - corporate governance adoption shows the factor loadings of the variables.

Table 35: Factor pattern matrix - corporate governance adoption

Pattern Matrix

\begin{tabular}{|c|c|c|c|c|c|c|}
\hline & \multicolumn{6}{|c|}{ Component } \\
\hline & 1 & 2 & 3 & 4 & 5 & 6 \\
\hline $\begin{array}{l}\text { Adoption - External drive } \\
\text { to improve accountability } \\
\text { Adoption - External drive } \\
\text { to improve efficiency } \\
\text { Adoption - Implement new } \\
\text { govt policy } \\
\text { Adoption - Comply with } \\
\text { regulatory requirements } \\
\text { Adoption - Internal drive to } \\
\text { improve decision making } \\
\text { Adoption - Internal drive to } \\
\text { improve service } \\
\text { coordination } \\
\text { Adoption - Level of } \\
\text { knowledge and skills } \\
\text { Adoption - Organisational } \\
\text { decision making } \\
\text { processes } \\
\text { Adoption - Influence of } \\
\text { external groups } \\
\text { Adoption - Influence of } \\
\text { internal groups } \\
\text { Adoption - Competition } \\
\text { with other organisational } \\
\text { priorities } \\
\text { Adoption - Effect on power } \\
\text { and relationships } \\
\text { Adoption - CEO } \\
\text { leadership } \\
\text { Adoption - Snr manager } \\
\text { leadership } \\
\text { Adoption - Costs } \\
\text { associated with } \\
\text { implementing change }\end{array}$ & 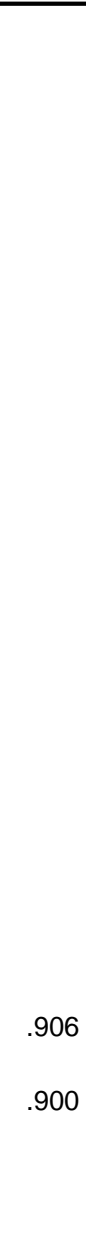 & $\begin{array}{l}.907 \\
.887\end{array}$ & 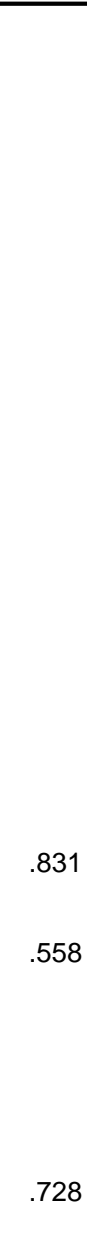 & 列 & $\begin{array}{l}.835 \\
.769\end{array}$ & $\begin{array}{l} \\
-.856 \\
-.826\end{array}$ \\
\hline
\end{tabular}

Extraction Method: Principal Component Analysis. Rotation Method: Oblimin with Kaiser Normalization.

a. Rotation converged in 12 iterations. 
Factor one appears to be related to leadership. It includes variables related to chief executive and senior manager leadership. These variables represent RA influences.

Factor two appears to be related to external improvement drivers. It includes variables related to external requirements to improve accountability and efficiency. These represent RA influences.

Factor three appears to be related to 'organisational politics'. It includes variables related to competition with other organisational priorities and the effect of reform on power and institutional relationships. The cost of reform is also loaded into this factor (possibly representing extension of the competition with other organisational priorities). These primarily represent PA influences (cost of reform is a RA influence).

Factor four appears to be related to internal improvement drivers. It includes variables related to internal requirements to improve service coordination and decision making. These also represent RA influences.

Factor five appears to be related to an organisation's capacity to act on knowledge. It includes variables related to organisational decision making processes and the level of knowledge and skills in the organisation. These represent RA influences.

Factor six appears to be related to changing operating requirements. It includes compliance with regulatory requirements and implementation of new government policy. The negative loadings for these influences suggest that where there was no requirement to 
comply with regulation, or implement new policy, the influences did not impact on reform adoption. These represent RA influences.

The final step in the factor analysis was to determine Cronbach's alpha coefficient of internal consistency to ensure that the items used to test the original construct based around the adoption of reform produced a reliable scale. Reliability and factor analysis are complementary procedures in scale construction and definition (Coakes \& Steed, 2007).

Reliabilities less than .6 are generally considered to be poor and those in the .7 range to be acceptable (Sekaran, 2000).

Reliability was confirmed (refer Table 36: Reliability statistics - corporate governance reform adoption) that the items used to measure the rational/scientific construct was a reliable measure of the factor.

Table 36: Reliability statistics - corporate governance reform adoption

\begin{tabular}{|c|c|r|}
\hline $\begin{array}{c}\text { Cronbach's } \\
\text { Alpha }\end{array}$ & $\begin{array}{c}\text { Cronbach's } \\
\text { Alpha Based } \\
\text { on } \\
\text { Standardized } \\
\text { Items }\end{array}$ & N of Items \\
\hline .723 & .732 & 15 \\
\hline
\end{tabular}




\subsubsection{Factor analysis - operation of corporate governance reform.}

An examination of Bartlett's test of sphericity suggests that strength of the relationship amongst the variables associated with corporate governance operation is strong and the Kaiser-Meyer-Olkin measure of sampling adequacy is greater than the acceptable level of 0.5 (refer Table 37: KMO and Bartlett's test: corporate governance operation).

Table 37: KMO and Bartlett's test: corporate governance operation

\begin{tabular}{|c|c|c|}
\hline \multicolumn{2}{|c|}{$\begin{array}{l}\text { Kaiser-Meyer-Olkin Measure of Sampling } \\
\text { Adequacy. }\end{array}$} & .768 \\
\hline Bartlett's Test of & Approx. Chi-Square & 938.266 \\
\hline Sphericity & & 13 \\
\hline & Sig. & .00 \\
\hline
\end{tabular}

The criteria used to retain factors during corporate governance adoption was also applied to the factor analysis of corporate governance reform operation (refer Figure 14).

Scree Plot

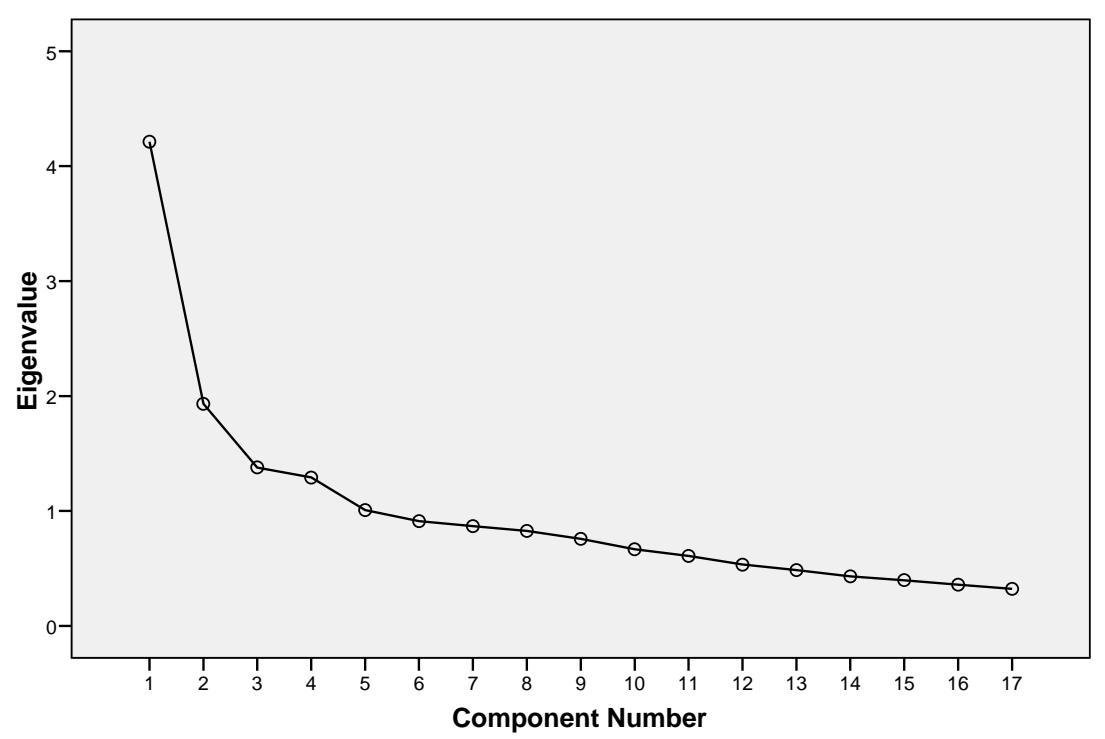

Figure 14: Scree plot - corporate governance reform operation 
Five factors were extracted (refer Table 38: Total variance explained - corporate governance reform operation) that explained fifty eight percent of the variance. This suggests that there are up to five dimensions that make up the corporate governance reform operation construct.

Table 38: Total variance explained - corporate governance reform operation

Total Variance Explained

\begin{tabular}{|c|c|c|c|c|c|c|c|}
\hline \multirow[b]{2}{*}{ Component } & \multicolumn{3}{|c|}{ Initial Eigenvalues } & \multicolumn{3}{|c|}{ Extraction Sums of Squared Loadings } & \multirow{2}{*}{$\frac{\text { Rotation }}{\text { Total }}$} \\
\hline & Total & $\%$ of Variance & Cumulative \% & Total & $\%$ of Variance & Cumulative $\%$ & \\
\hline 1 & 4.214 & 24.785 & 24.785 & 4.214 & 24.785 & 24.785 & 2.821 \\
\hline 2 & 1.933 & 11.371 & 36.157 & 1.933 & 11.371 & 36.157 & 2.388 \\
\hline 3 & 1.379 & 8.109 & 44.266 & 1.379 & 8.109 & 44.266 & 1.673 \\
\hline 4 & 1.292 & 7.598 & 51.864 & 1.292 & 7.598 & 51.864 & 1.922 \\
\hline 5 & 1.008 & 5.928 & 57.792 & 1.008 & 5.928 & 57.792 & 2.722 \\
\hline 6 & .912 & 5.365 & 63.157 & & & & \\
\hline 7 & .868 & 5.105 & 68.262 & & & & \\
\hline 8 & .827 & 4.865 & 73.126 & & & & \\
\hline 9 & .759 & 4.462 & 77.588 & & & & \\
\hline 10 & .667 & 3.926 & 81.514 & & & & \\
\hline 11 & .610 & 3.587 & 85.101 & & & & \\
\hline 12 & .534 & 3.143 & 88.244 & & & & \\
\hline 13 & .486 & 2.862 & 91.106 & & & & \\
\hline 14 & .431 & 2.537 & 93.643 & & & & \\
\hline 15 & .398 & 2.343 & 95.986 & & & & \\
\hline 16 & .360 & 2.115 & 98.102 & & & & \\
\hline 17 & .323 & 1.898 & 100.000 & & & & \\
\hline
\end{tabular}

Extraction Method: Principal Component Analysis.

a. When components are correlated, sums of squared loadings cannot be added to obtain a total variance.

Table 39: Factor pattern matrix - corporate governance reform operation shows the factor loadings of the variables. 
Table 39: Factor pattern matrix - corporate governance reform operation

Pattern Matrix

\begin{tabular}{|c|c|c|c|c|c|}
\hline & \multicolumn{5}{|c|}{ Component } \\
\hline & 1 & 2 & 3 & 4 & 5 \\
\hline $\begin{array}{l}\text { Operation - time to } \\
\text { implement change } \\
\text { Operation - availability of } \\
\text { resources }\end{array}$ & .508 & & & & \\
\hline $\begin{array}{l}\text { Operation - CEO } \\
\text { leadership }\end{array}$ & .505 & & & & \\
\hline $\begin{array}{l}\text { Operation - Snr manager } \\
\text { leadership }\end{array}$ & .650 & & & & \\
\hline $\begin{array}{l}\text { Operation - leadership } \\
\text { continuity from adoption }\end{array}$ & .617 & & & & \\
\hline $\begin{array}{l}\text { Operation - Scale and } \\
\text { scope of reform }\end{array}$ & .613 & & & & \\
\hline $\begin{array}{l}\text { Operation - Level of } \\
\text { knowledge and skills }\end{array}$ & & & & & -.573 \\
\hline $\begin{array}{l}\text { Operation - } \\
\text { Communication and } \\
\text { information sharing } \\
\text { processes }\end{array}$ & & & & & -.752 \\
\hline $\begin{array}{l}\text { Operation - } \\
\text { Organisational control } \\
\text { processes }\end{array}$ & & & & & -.700 \\
\hline $\begin{array}{l}\text { Operation - Effect on } \\
\text { power and relationships }\end{array}$ & & & & .719 & \\
\hline $\begin{array}{l}\text { Operation - Managerial } \\
\text { fear of loss of control }\end{array}$ & & & & .753 & \\
\hline $\begin{array}{l}\text { Operation - Number of } \\
\text { actors in the change } \\
\text { process }\end{array}$ & & -.527 & & & \\
\hline $\begin{array}{l}\text { Operation - } \\
\text { Organisational attributes } \\
\text { incl workforce size }\end{array}$ & & -.799 & & & \\
\hline $\begin{array}{l}\text { Operation - Hierarchical } \\
\text { nature of public sector }\end{array}$ & & -.545 & & & \\
\hline $\begin{array}{l}\text { Operation - Organisation } \\
\text { accepts innovation }\end{array}$ & & & .871 & & \\
\hline $\begin{array}{l}\text { Operation - Organisation } \\
\text { easily accepts change }\end{array}$ & & & .831 & & \\
\hline $\begin{array}{l}\text { Operation - Change } \\
\text { fatigue has an impact }\end{array}$ & & & & & \\
\hline
\end{tabular}

Extraction Method: Principal Component Analysis.

Rotation Method: Oblimin with Kaiser Normalization.

a. Rotation converged in 21 iterations.

Factor one appears to be related to how organisation is led and the reform controlled, including the time available to implement change and the scale and scope of reform. These represent RO influences. 
Factor two also appears to also be related to implementation issues, although in a more applied manner. This factor includes variables associated with the number of actors in the change process, the attributes of the organisation and the hierarchical nature of the public sector. The negative loadings for this factor suggest that where there are few actors in the change process, an organisation has attributes that do not impact on change and where there is a limited hierarchy, this factor does not impact on reform operation. This factor represents a mix of $\mathrm{RO}$ and $\mathrm{PO}$ influences.

Factor three appears to be related to attitudes to change. It includes variables related to organisational innovation and change. These represent PO influences.

Factor four appears to be related to 'organisational politics'. It includes variables related to the impact of reform on power and institutional relationships and managerial fear of loss of control. These represent PO influences.

Factor five appears to be related to an organisation's ability to understand change. It includes variable associated with knowledge and skills, communication processes and organisational control processes. The negative loadings for this factor suggest that where communication and information sharing is poor, organisational knowledge and skills are low and organisational control processes are weak, there is no impact on reform operation. These represent RO influences, but can be seen as particularly important ways of dealing with PO influences, such as attitudes to change. 
The final step in the factor analysis was to again determine Cronbach's alpha coefficient of internal consistency for the original construct used to test influences impacting on reform operation. Reliability was confirmed by a Cronbach’s alpha above .7 (refer Table 40: Reliability statistics - corporate governance operation).

Table 40: Reliability statistics - corporate governance operation

\begin{tabular}{|c|c|r|}
\hline $\begin{array}{c}\text { Cronbach's } \\
\text { Alpha }\end{array}$ & $\begin{array}{c}\text { Cronbach's } \\
\text { Alpha Based } \\
\text { on } \\
\text { Standardized } \\
\text { Items }\end{array}$ & N of Items \\
\hline .736 & .758 & 17 \\
\hline
\end{tabular}




\subsection{Qualitative responses}

Respondents were also asked three open ended questions.

\subsubsection{Open-ended question one: adoption of corporate governance reform}

Thirty four responses were provided to the question 'is there anything else that you would like to tell us about the adoption of corporate governance reform in your organisation?' Themes identified from these responses included:
I. Adoption drivers
II. Adoption enablers
III. Adoption constraints

\section{Adoption drivers}

Respondents reiterated a number of influences identified in the survey instrument as driving reform in their organisations. These influences included externally imposed requirements such as:

Central government imposes regular changes and extra processes on line agencies such as ours, despite various red tape reduction programs and commitments. Many are budget driven. 
There is a link between governance and external scrutiny. In jurisdictions where parliamentary and other institutional arrangements for external are weak, poor corporate governance will result.

Several respondents highlighted the importance of leadership:

Our experience is that this is best driven from the Office of the Director General.

The role of 'learning' was identified by one respondent, in particular learning from the private sector and from their own failure:

There is a strong commitment to learning from private sector models. The department's audit committee is now headed by an independent chair with a further independent representative. The department also has a strong commitment to learning from its mistakes and using independent audit to improve in the future.

\section{Adoption enablers}

Respondents identified the importance of have appropriate structures and frameworks to guide the adoption of reform: 
Have to determine the right structure for managing the reform process and for managing the ongoing monitoring and reporting.

The importance of a framework that is easily understood and focuses on the areas - ie Business Excellence Framework

Other issues raised by respondents included that reform was becoming easier due to the frequency of change and that efforts to improve corporate governance arrangements can benefit from policy shifts.

Some respondents highlighted the importance of communication to gain support for reform. However, at least one respondent saw 'political will' as more important in overcoming resistance to change:

Political will is vital. The longer the pain of reform goes on especially when that reform results in service delivery changes the greater the likelihood political will wane......reform cannot be by consensus and, in the end, resistance must be overcome or reform will languish. 


\section{Adoption constraints}

Time, or lack of it, was raised as a fundamental constraint in assessing the success of reform adoption:

Needs to be recognised that structural reform - form - takes much time before one can actually start performing

The importance of organisational culture, and the potential for it to impede change was also raised by several respondents:

Governance reform that requires cultural change takes years - not weeks or months to embed

It needs to be built into the culture and simply a way to do business on a daily basis.

Strong internal "silos" work actively against reform

Others went further and highlighted the role individuals can play in preventing the adoption of change:

The success or failure of a particular reform will ultimately depend on those involved in the change concluding that there are benefits to themselves and/or the organisation as a result of the proposed 
change........if you can build early commitment to the change and detail clear benefits then the adoption of reform is easier.

Other responses to this question raised issues associated with the adoption of reform seen to be reactive:

Frequently, controls are added in response to audits etc. They tend to result in gold plating of process, which stifles innovation and distracts from service delivery

The adoption of governance reform is adhoc rather than systematic.

The ability for the public sector to adapt to changing environments was raised by one respondent, highlighting tensions between accountability and flexibility:

Both as employers and deliverers of services, we struggle in increasingly diverse and complex environments as we are held to rigid and outdated definitions of accountability and flexibility that anchor us in the last century. 


\title{
7.6.2 Open-ended question two: operation of corporate governance reform
}

Twenty one responses were provided to the question 'is there anything else that you would like to tell us about the adoption of corporate governance reform in your organisation?' Themes identified from these include:

\author{
I. Leadership \\ II. Communication \\ III. Attributes of reform
}

These reflect RO and PO influences.

\section{Leadership}

There was a general consensus about the importance of leadership in operating reform:

Genuine commitment from the CEO is essential otherwise don't bother.

Leadership is the most important ingredient

The organisation has strong leadership with the 2 top positions very supportive of governance reform and this is having a positive impact.

However, several respondent identified limitations to the role leadership can play:

Leadership is constrained by managing influential "silos" 
Leaders have to understand evolving standards in governance in other sectors and the need to enforce standards to protect agency from political interference.

This confirms the importance of leadership identified in responses to the Likert-scaled questions related to leadership, and the findings of the phase one case study.

\section{Communication}

The role of communication was also highlighted by responses to this question:

Change takes time and communication is the key to success

Requires communication to get the message out there and convince people of the need

Importance of being able to articulate and measure success, improvement, etc and to promote the benefits realised

One response emphasised the need to target communication:

Processes could be better communicated to staff below executive level 


\section{Attributes of reform}

Several comments were made about the nature of reform. This included the need to avoid a ‘one size fits all approach' to corporate governance change:

Each reform is unique - some reforms happen easily and simply......others struggle to even start. It is clear that every change circumstance is different and potentially should be managed on its merits rather than to suggest that one size fits all

This is consistent with the need to align corporate governance processes with organisational requirements as recommended by the literature (Uhrig, 2003).

One respondent commented on the distinction between individual reform and systemic reform:

Reform is often incremental and it is not possible to say how many reform processes have been undertaken. Maybe they are all one extended process? 


\title{
7.6.3 Open-ended question three: future corporate governance
} reforms

Thirty two responses were provided to the 'question have you any suggestion for future corporate governance reforms in your organisation?' Themes identified from these responses include:

\author{
I. approaches to change \\ II. communication \\ III. training
}

\section{Approaches to change}

Responses focused on the need to maintain the manageability of reform and to frame corporate governance change within a strategic management approach.

Manageability comments included:

Continue to see through reforms already embarked upon.

Limit the number of concurrent governance reform processes

Incremental change in manageable quantities.

Clear time frames 
Keeping change to manageable levels and being less ambitious in setting scale and scope.

Some commented on the need to integrate corporate governance improvements within broader corporate management frameworks while others considered it important to benchmark corporate governance arrangements to ensure they meet requirements and inform further reforms.

Comments were made about developing strategic plans to guide reform:

Design a holistic governance framework from ground-up, then implement and keep stable for medium term ie. do not fiddle at the edges, and do not keep changing the model

Have a medium to long term plan for governance reforms rather than dealing always with immediate priorities

\section{Communication}

Comments about communication centred on the need to clearly articulate the need for future reform, including the promotion of reform outcomes. Open consultation and communication processes with stakeholders was also raised as important. 


\section{Training}

There was a consensus about the importance of using training to support corporate governance reform. Comments included:

Staff need to be skilled in governance frameworks and evaluation

Future reform in this agency will need to be underpinned by improved financial management skills at the business level, continued investment in effective management and increased management training at the supervisory/operational level. In my opinion the greatest impact can be had in the last of these as this group of managers inevitably defines the culture of their workplace. 


\section{Chapter eight: Discussion of phase two results}

\subsection{Introduction}

The purpose of this study has been to explore factors impacting on the adoption and operation of corporate governance reform in Australian state government departments.

To fulfil this purpose the researcher collected data in two phases (See chapter four methodology) in order to obtain:

o Open ended contextual information about corporate governance reform in the Victorian Department of Human Services (phase one). This information was used to validate concepts related to reform adoption and operation as set out in the research's conceptual framework.

o Quantitative data about corporate governance reform across a range of Australian state government departments (phase two). This information was used to test the research propositions and hypothesis.

This chapter discusses the results of the study, draws comparisons with the literature and proposes a new model to manage corporate governance change in state government departments.

As predicted by the model set out in Figure 7 (refer page 56), RA, RO, PA and PO factors were present during the adoption and operation stage of corporate governance reform in 
the departments surveyed. Table 41: Summary of research propositions and results reform adoption and Table 45: Summary of research propositions and results - reform operation described below present a summary of results against the research propositions.

\subsection{Research propositions - reform adoption}

The study revealed that both rational/scientific and political/cultural factors were evident during the adoption of corporate governance reform. 
Table 41: Summary of research propositions and results - reform adoption

\begin{tabular}{|c|c|c|}
\hline Research proposition & Result & Finding \\
\hline $\begin{array}{l}\text { Rational/technocratic } \\
\text { factors will have a } \\
\text { positive impact on the } \\
\text { adoption of corporate } \\
\text { governance reform. }\end{array}$ & & $\begin{array}{l}\text { Rational/scientific factors present } \\
\text { during reform adoption, along with } \\
\text { political/cultural factors }\end{array}$ \\
\hline $\begin{array}{l}\text { In particular, the following } \\
\text { factors will impact on the } \\
\text { adoption of corporate } \\
\text { governance reform: }\end{array}$ & & \\
\hline $\begin{array}{l}\text { - External } \\
\text { imposed } \\
\text { requirements }\end{array}$ & $\begin{array}{l}\text { - } 81 \% \text { of respondents reported an } \\
\text { external accountability drive affected } \\
\text { adoption } \\
77 \% \text { of respondents reported an } \\
\text { external efficiency drive affected } \\
\text { adoption } \\
79 \% \text { of respondents reported } \\
\text { compliance with regulatory } \\
\text { requirements affected adoption } \\
\text { - } 89 \% \text { of respondents reported the } \\
\text { implementation of new government } \\
\text { policy affected adoption }\end{array}$ & - Present \\
\hline $\begin{array}{l}\text { - Internally driven } \\
\text { improvements }\end{array}$ & $\begin{array}{l}\text { 83\% of respondents reported an } \\
\text { internal service coordination drive } \\
\text { affected adoption } \\
\text { - } 89 \% \text { of respondents reported an } \\
\text { internal drive to improve decision } \\
\text { making affected adoption }\end{array}$ & - Present \\
\hline $\begin{array}{l}\text { - } \quad \text { Availability of } \\
\text { resources } \\
\text { - Organisational } \\
\text { knowledge and } \\
\text { skills }\end{array}$ & $\begin{array}{l}\text { - } 68 \% \text { of respondents reported } \\
\text { resource availability affected adoption } \\
\text { - } 87 \% \text { of respondents reported levels } \\
\text { of knowledge and skills affected } \\
\text { adoption }\end{array}$ & $\begin{array}{l}\text { - } \text { Present } \\
\text { - } \quad \text { Present }\end{array}$ \\
\hline $\begin{array}{l}\text { - Organisational } \\
\text { control } \\
\text { processes }\end{array}$ & $\begin{array}{l}\text { - } 82 \% \% \text { of respondents reported } \\
\text { control processes affected adoption }\end{array}$ & - Present \\
\hline - Leadership & $\begin{array}{l}\text { - } 96 \% \text { of respondents reported CEO } \\
\text { leadership affected adoption } \\
\text { - } 94 \% \text { of respondents reported senior } \\
\text { manager leadership affected } \\
\text { adoption }\end{array}$ & - Present \\
\hline
\end{tabular}


High levels of agreement were also recorded for PA influences.

However, analysis of the ranking of influences reported in chapter seven (results) indicates that the nine most important influences (accountability requirements; leadership; efforts to improve decision making; efforts to improve service delivery; implement new government policy; cost/resource requirements; efficiency requirements; organisational knowledge and skills; and regulatory requirements) were considered by respondents to be RA factors. This clearly supports the research propositions, and the conceptual framework upon which these are based. In particular, the components comprising the two categories of influences (namely political/cultural and rational/scientific factors) were all identified as present in the adoption stage of reform; no additional factors that compromise this model were identified by respondents; overall rational/scientific factors were found to dominate reform adoption.

\subsubsection{Low levels of disagreement}

Low levels of disagreement were recorded for all reform adoption influences, including those identified during phase one as not present in reforms undertaken by Department of Human Services (those influences included costs associated with reform implementation and the redistributive effect of reform on power and institutional relationships).

Those influences, which at least ten percent of respondents disagreed with, the highest levels of disagreement recorded, are set in Table 42: Disagreement with reform adoption 
influences. These were competition with other priorities, implementation costs and the influence of internal interest groups.

Table 42: Disagreement with reform adoption influences

\begin{tabular}{|l|l|l|}
\hline Influence & \% disagreement & Influence category \\
\hline Competition with other priorities & $23 \%$ & PA \\
\hline Implementation costs & $12 \%$ & RA \\
\hline Internal group influences & $11 \%$ & PA \\
\hline
\end{tabular}

While the level of disagreement with these influences is relatively low, it is useful to consider explanations for this difference. It is possible that the disagreement stems from the simple absence of these influences within the organisations of those respondents who disagreed.

Reasons for this absence relates to the nature of the influences. Namely, not all influences may affect all organisations. It is unlikely that internal group influences would effect all organisations, particularly as not all interest groups exercise the same level of influence in all organisations. Similarly, not all departments would be subject to the same level of competition of priorities. Smaller departments for instance would not be expected to be subject to the same range of priorities as other larger departments, although this may occur in some circumstances.

The influence related to the cost of reform implementation was also identified during the phase one case study of the Victorian Department of Human Services as not present in that organisation. Reasons identified for the absence in that department included the large size 
of that organisation's budget and the strong filtering process it used to identify reforms (resulting in a requirement to fund only a small number of reforms). It is possible that these reasons also explain the high levels of disagreement in other state government departments.

\subsubsection{Newly identified influences}

Several influences not previously included in the conceptual framework were identified by respondents during phase two (as set out in chapter seven). These included:

- Organisational restructuring and machinery of government changes

- Changes in organisational resource levels, including the dedication of resources to corporate governance improvements

- Managing risk to organisational reputation

These influence are all accommodated within the conceptual framework of RA and PA influences.

\section{Organisational restructuring and machinery of government changes}

These represent RA influences. The term organisational restructuring is a broadly used term to describe changes to organisational configuration involving the dismantling and/or rebuilding of functional areas (Pichault \& Schoenaers, 2003). There are degrees of restructuring, ranging from incremental through to transformational change (Armistead \& Meakins, 2007). 
The term 'machinery of government changes', often used interchangeably with the term 'administrative re-arrangements', has a more specific meaning within the public sector and describes a variety of organisational changes affecting government departments.

Common examples of machinery of government changes include (Commonwealth of Australia, 2007):

- Organisation changes following a government decision to abolish or create a department or to move functions/ responsibilities between departments/agencies

- creation of a new statutory agency or executive agency, or abolition of such agencies

- movement of functions into, or out of, the public service.

\section{Changes in organisational resource levels}

Changes to organisational resource levels relate to corporate governance improvements being made possible through increased resourcing. This may be a result of a requirement of one (such as a drive to improve accountability) or a combination of other influences. It is distinguished from other influences due to it being centred around a single defining characteristic, that is to say the allocation of new resources (regardless of the cause). The allocation of new resources generally brings with it stakeholder expectations of delivery. For that reason, it is also distinguished from the other resource-related influence, availability of resources, which is defined around attempts to secure additional funding. Changes to organisational resource levels is also seen as a RA influence. 


\section{Management of organisational reputation risks}

The management of risks to organisational reputation identified by respondents were centred around notions of stakeholder perceptions. Reputation is usually considered at the level of the individual. However, it has been recognised that organisations can find the loss of reputation as harmful as individuals do (Booth, 2000). Although reputation is conferred by external parties or organisations, there are opportunities for an organisation to influence at least some of those who contribute to the making of a reputation (Booth, 2000).

As discussed in chapter seven, several respondents identified the impact on corporate governance change associated with attempts to influence these stakeholders and to manage potential reputational risks. This newly identified influence is accommodated with the conceptual framework as a PA influence. 


\subsubsection{Observed differences}

As described in Chapter 6, the significant differences in responses provide a valuable insight into understanding corporate governance reform in government departments. In particular, these differences identify a series of characteristics that can be broken down into two groups:

1. characteristics of successful reform adoption (refer Table 43: Implications of reform adoption observed differences)

2. organisation characteristics of reform adoption (refer Table 44: Implications of reform adoption observed differences relating to organisational characteristics)

Table 43: Implications of reform adoption observed differences relating to successful adoption of reform

\begin{tabular}{|c|c|}
\hline Observed difference & Implication \\
\hline $\begin{array}{l}\text { Respondents who agreed that new government policy had } \\
\text { impacted on reform adoption were more likely to agree that } \\
\text { corporate governance reform was usually successful }\end{array}$ & $\begin{array}{l}\text { Reform driven by new government } \\
\text { policy is more likely to succeed, } \\
\text { - New government policy is more likely } \\
\text { to drive successful corporate } \\
\text { governance reform than any other } \\
\text { external reform requirement }\end{array}$ \\
\hline $\begin{array}{l}\text { Respondents who agreed that an internal drive to improve } \\
\text { service coordination had impacted on reform adoption were } \\
\text { more likely to agree that corporate governance reform was } \\
\text { usually successful }\end{array}$ & $\begin{array}{l}\text { - } \text { Reform aimed to improve services is } \\
\text { more likely to succeed } \\
\text { - } \quad \text { Service improvement is more likely to } \\
\text { drive successful corporate governance }\end{array}$ \\
\hline
\end{tabular}




\begin{tabular}{|c|c|}
\hline Observed difference & Implication \\
\hline & $\begin{array}{l}\text { reform than any other internal reform } \\
\text { requirement }\end{array}$ \\
\hline $\begin{array}{l}\text { Respondents who agreed that the influence of internal groups } \\
\text { had impacted on reform adoption were more likely to agree } \\
\text { that corporate governance reform was usually successful }\end{array}$ & $\begin{array}{l}\text { - } \text { Reform that includes the involvement of } \\
\text { interest groups is more likely to succeed }\end{array}$ \\
\hline $\begin{array}{l}\text { Respondents who agreed that the adoption of reform was } \\
\text { subject to competition with other organisational priorities } \\
\text { were more likely to agree that corporate governance reform } \\
\text { was usually successful }\end{array}$ & $\begin{array}{l}\text { A ‘competition of ideas’ produces a } \\
\text { reform more likely to succeed }\end{array}$ \\
\hline $\begin{array}{l}\text { Respondents who agreed that the adoption of reform was } \\
\text { impacted by senior management leadership were more likely } \\
\text { to agree that the adoption of reform was usually successful. }\end{array}$ & $\begin{array}{l}\text { - } \text { Reform led by senior managers is more } \\
\text { likely to succeed. } \\
\text { not as important as senior manager } \\
\text { leadership in achieving the successful } \\
\text { adoption of reform }\end{array}$ \\
\hline $\begin{array}{l}\text { Respondents employed less that two years were more likely } \\
\text { not to agree or disagree that the adoption of reform was } \\
\text { usually successful }\end{array}$ & $\begin{array}{l}\text { - New employees are less likely to see } \\
\text { reform adoption as successful } \\
\text { - New employees are less able to judge } \\
\text { the success of reform adoption }\end{array}$ \\
\hline
\end{tabular}

The findings in Table 43 suggest that reform driven by new government policy (external driver) or service delivery improvement imperatives (internal driver) are more likely to succeed than reforms related to other internal and external drivers. Similarly, reforms that have the involvement of internal interest groups, the leadership of senior managers and have been subject to competition with other reforms are more likely to succeed. 
These findings are interesting from several perspectives.

- Accountability requirements have traditionally been advanced as the most pressing reason for corporate governance change in public sector organisations (Mulgan, 2008). There has been limited research into corporate governance changes within Australia associated with the implementation of new government policy.

- A competition of organisational priorities is normally considered in the literature to be a negative outcome of limited resources and organisational capacity (Fozzard, 2001). In this instance, it appears that a competition of priorities produces better corporate governance reform.

- The leadership of Chief Executive Officers are more frequently identified with successful change than lower level staff (Sarros \& Butchatsky, 1996).

- New employees appear reluctant to comment about the success or failure of reform adoption. This suggests that it takes time to know if a reform has succeeded. 
Table 44: Implications of reform adoption observed differences relating to organisational characteristics

\begin{tabular}{|c|c|}
\hline Observed difference & Implication \\
\hline $\begin{array}{l}\text { Respondents who worked in organisations with a budget in } \\
\text { excess of } \$ 1 \text { billion were more likely to agree that an } \\
\text { external drive to improve accountability impacted on the } \\
\text { adoption of reform }\end{array}$ & $\begin{array}{l}\text { - Organisations with large budgets are } \\
\text { more likely to be subject to increased } \\
\text { accountability requirements }\end{array}$ \\
\hline $\begin{array}{l}\text { Respondents who worked in organisations with a budget } \\
\text { between } \$ 501 \text { million and } \$ 1 \text { billion were more likely to } \\
\text { agree that an internal drive to improve service coordination } \\
\text { impacted on the adoption of reform }\end{array}$ & $\begin{array}{l}\text { - Service coordination improvement is } \\
\text { important in departments with mid size } \\
\text { budgets }\end{array}$ \\
\hline $\begin{array}{l}\text { Respondents who worked in organisation with a budget in } \\
\text { excess of } \$ 1 \text { billion were more likely to disagree that } \\
\text { organisational decision making processes impacted on the } \\
\text { adoption of reform }\end{array}$ & $\begin{array}{l}\text { Employees in government departments } \\
\text { with the largest budgets are less } \\
\text { concerned with organisational decision } \\
\text { making processes }\end{array}$ \\
\hline $\begin{array}{l}\text { Respondents who were employed for less than two years } \\
\text { were less likely to agree that internal groups influenced the } \\
\text { adoption of corporate governance reform }\end{array}$ & $\begin{array}{l}\text { - The longer you are employed the more } \\
\text { likely you will consider internal groups } \\
\text { to influence reform } \\
\text { - The influence of internal groups may not } \\
\text { be immediately apparent to new } \\
\text { employees }\end{array}$ \\
\hline $\begin{array}{l}\text { Respondents who were employed for less than two years } \\
\text { were more likely to agree that the costs associated with } \\
\text { change impacted on the adoption of reform }\end{array}$ & $\begin{array}{l}\text { - New employees are more likely to focus } \\
\text { on the cost of reform } \\
\text { - The longer you are employed the less } \\
\text { you will focus on reform costs }\end{array}$ \\
\hline
\end{tabular}


The findings in Table 44 suggest that organisations with larger budgets are subject to different reform drivers than other organisations and that the perceptions of employees about impacts on corporate governance reform change over time (particularly about the influence of internal groups and the cost of reform). The observation about the size of a department's budget and its accountability requirements is supported by the literature (Halligan, 2007; Mulgan, 2008)

\subsubsection{Consistency with phase one findings}

Overall, phase one and phase two findings are consistent for the stage of reform relating to adoption. Phase one and phase two both recorded high levels of agreement for the individual influences comprising RA and PA factors. As discussed earlier, neither produced additional influences that sit outside the research’s conceptual framework.

\section{Confirmation of influences not present in phase one}

As observed earlier, a phase one finding related to the absence of reform implementation cost as an influence affecting reform adoption in the Victorian Department of Human Services. The reason for this absence (namely the ability of that department to allocate resources as required) has been identified as a potential explanation for the high level of disagreement recorded in phase two results for this influence.

The other difference between phase one and phase two related to the impact of reform adoption on power and relationships. While the human services department case study 
found no evidence of the redistributive effect on power and institutional relationship affecting reform adoption, this influence was retained for testing during phase two. Sixty two percent of respondent in phase two agreed that impacts on power and relationships affected the operation of corporate governance reform.

\section{Confirmation of influences identified in phase one}

Influences added to the model as a result of phase one findings were strongly supported by phase two findings. These influences included leadership, requirement to implement new government policy and compliance with regulation. 


\subsection{Research propositions - reform operation}

Table 45: Summary of research propositions and results - reform operation details the research propositions, results and findings related to the operation stage of corporate governance reform.

Table 45: Summary of research propositions and results - reform operation

\begin{tabular}{|c|c|c|}
\hline \multirow[b]{2}{*}{$\begin{array}{l}\text { Research proposition } \\
\text { Political/cultural factors will } \\
\text { have a positive impact on the } \\
\text { operation of corporate } \\
\text { governance reform. }\end{array}$} & \multirow[t]{2}{*}{ Result } & \multirow[b]{2}{*}{$\begin{array}{l}\text { Finding } \\
\text { Political/cultural factors } \\
\text { present during reform } \\
\text { operation, along with } \\
\text { rational/scientific factors }\end{array}$} \\
\hline & & \\
\hline $\begin{array}{l}\text { In particular, the following } \\
\text { factors will impact on the } \\
\text { ongoing operation of } \\
\text { corporate governance reform: }\end{array}$ & & \\
\hline $\begin{array}{l}\text { Organisational } \\
\text { culture (including } \\
\text { impact of reform on } \\
\text { power and } \\
\text { institutional } \\
\text { relationships) }\end{array}$ & $\begin{array}{l}\text { - } 69 \% \text { of respondents reported } \\
\text { power and relationships } \\
\text { affected reform operation; } \\
67 \% \text { of respondents reported } \\
\text { managerial fear of control } \\
\text { loss affected reform operation } \\
68 \% \text { of respondents reported } \\
\text { attitudes to innovation } \\
\text { affected reform operation } \\
68 \% \text { of respondents reported } \\
\text { attitudes to organisational } \\
\text { change affected reform } \\
\text { operation }\end{array}$ & - Present \\
\hline $\begin{array}{l}\text { - Number of actors in } \\
\text { change process }\end{array}$ & $\begin{array}{l}\text { - } 66 \% \text { of respondents reported } \\
\text { the number of change actors } \\
\text { affected reform operation }\end{array}$ & - Present \\
\hline - Change fatigue & $\begin{array}{l}\text { - } 69 \% \text { of respondents reported } \\
\text { change fatigue affected } \\
\text { reform operation }\end{array}$ & - Present \\
\hline $\begin{array}{l}\text { - Hierarchical nature } \\
\text { of public sector }\end{array}$ & $\begin{array}{l}61 \% \text { of respondents reported } \\
\text { the hierarchical nature of } \\
\text { public sector affected reform } \\
\text { operation }\end{array}$ & - Present \\
\hline
\end{tabular}

In addition to the results relating to RO influences, high levels of agreement were also recorded for PO influences. 
Analysis of the ranking of influences reported in chapter seven (results) indicates that while PO factors may be assessed at lower levels of importance when compared to RO factors, they were still present during the operation of corporate governance reform. This supports the research propositions, and the conceptual framework that these are based upon.

In particular, the components comprising the two categories of influences (namely political/cultural and rational/scientific factors) were all identified in the operation stage of reform and no additional factors that compromise this model were identified by respondents.

While the factor analysis suggests the dominance of RA influences, some mixing of influences can be seen within the factors that have been identified. These suggest a complex relationship between RA and PA influences, including the potential for RA influences to 'feed' PA issues.

\subsubsection{Low levels of disagreement}

Low levels of disagreement were recorded for all reform adoption influences, including those identified during phase one as not present in Department of Human Services reforms (these included costs associated with reform implementation and the redistributive effect of reform on power and institutional relationships). 
Those influences that at least ten percent of respondents disagreed with, the highest levels of disagreement recorded, are set in Table 46: Disagreement with reform operation influences

Table 46: Disagreement with reform operation influences

\begin{tabular}{|l|l|l|}
\hline Influence & \% disagreement & Influence category \\
\hline Hierarchical nature of public sector & $13 \%$ & PO \\
\hline Organisational attributes & $12 \%$ & RO \\
\hline Attitudes to innovation & $11 \%$ & PO \\
\hline Attitudes to organisational change & $11 \%$ & PO \\
\hline Change fatigue & $11 \%$ & PO \\
\hline
\end{tabular}

As was the case with reform adoption influences, while the level of disagreement with these influences is relatively low, it is useful to consider explanations for this difference.

The majority of influences that recorded higher level of disagreement related to political/cultural influences, particularly the 'cultural' aspects of organisations (attitudes to innovation, change, hierarchy, change fatigue). This is most likely attributable to respondents not agreeing that these influences have a role in the culture of their organisation.

Twelve percent of respondents disagreed that organisational attributes, such as workforce profile, impacted on reform operation. This is not unexpected as it is unlikely that all organisations will have attributes that impact on the operation of corporate governance reform. 


\subsubsection{Newly identified influences}

A new influence affecting the operation of reform relating to the frequency of change was identified by respondents: “change frequency”. This was distinguished from change fatigue in chapter seven due to its focus on successful rather than unsuccessful promotion of change.

Respondents who identified this influence tended to identify the increased rate of change as establishing a positive force for reform. The literature supports the notion that the increasing frequency of change leads to a shift in change momentum within some organisations (Jansen, 2004). For that reason, this new influence has been identified as a PO influence, supporting the research proposition that PO influence will dominate the operate stage of reform.

\subsubsection{Observed differences}

As described in Chapter 6, the significant differences in responses provide a valuable insight into understanding corporate governance reform operation in government departments. In particular, these differences identify a series of characteristics that can be broken down into three groups:

1. characteristics of successful reform operation (refer Table 47: Implications of observed differences relating to reform success) 
2. organisational characteristics of reform operation (refer Table 48: Implications of observed differences relating to organisational characteristics)

3. other characteristics (refer Table 49: Implications of observed differences relating to other characteristics) 
Table 47: Implications of observed differences relating to reform success and reform operation

\begin{tabular}{|c|c|}
\hline Observed difference & Implication \\
\hline $\begin{array}{l}\text { Respondents who agreed that their organisation } \\
\text { accepted innovation were more likely to agree that } \\
\text { reform operation was usually successful }\end{array}$ & $\begin{array}{l}\text { - Corporate governance changes are more likely to } \\
\text { successful operate in organisations that accept } \\
\text { innovation } \\
\text { - Organisational acceptance of innovation is an } \\
\text { indicator of likely successful corporate } \\
\text { governance reform operation }\end{array}$ \\
\hline $\begin{array}{l}\text { Respondents who agreed that their organisation } \\
\text { easily accepted change were more likely to agree } \\
\text { that reform operation was usually successful }\end{array}$ & $\begin{array}{l}\text { - Corporate governance reform is more likely to } \\
\text { successfully operate in organisation that accept } \\
\text { change } \\
\text { - Organisational acceptance of change is an } \\
\text { indicator of successful corporate governance } \\
\text { reform operation }\end{array}$ \\
\hline $\begin{array}{l}\text { Respondents who agreed that the number of actors } \\
\text { in the change process impacted on the operation of } \\
\text { reform were more likely to agree that the operation } \\
\text { of reform was usually successful }\end{array}$ & $\begin{array}{l}\text { - Change actors actively involved in the operation } \\
\text { of corporate governance reform will increase the } \\
\text { likelihood that the reform will be successful }\end{array}$ \\
\hline $\begin{array}{l}\text { Respondents employed for less than two years were } \\
\text { less likely to agree that reform operation was } \\
\text { usually successful }\end{array}$ & $\begin{array}{l}\text { - New employees are less likely to see reform } \\
\text { operation as successful }\end{array}$ \\
\hline $\begin{array}{l}\text { Respondents in Queensland and Victoria where } \\
\text { more likely to agree that reform operation was } \\
\text { usually successful while respondents in Tasmania } \\
\text { were less likely to agree about reform success }\end{array}$ & $\begin{array}{l}\text { - Victorian and Queensland government } \\
\text { departments have higher success rates in } \\
\text { operating corporate governance reform } \\
\text { - Tasmanian government departments have lower } \\
\text { success rates in operating corporate governance } \\
\text { reform }\end{array}$ \\
\hline
\end{tabular}




\begin{tabular}{|l|l|}
\hline Observed difference & Implication \\
\hline $\begin{array}{l}\text { Respondents in organisations with a hybrid } \\
\text { organisational structure were less likely to agree } \\
\text { that reform operation was usually successful }\end{array}$ & $\begin{array}{l}\text { of divisional and functional structures) may limit } \\
\text { the successful operation of reform }\end{array}$ \\
\hline
\end{tabular}


The findings shown in Table 47 suggest that reform in organisations with a supportive culture, limited number of change actors and located in Queensland or Victoria and with a divisional or functional structure is more likely to be successful.

Observations about these implications include:

- Supportive organisational culture (including attitudes to innovation and change) appears to play a significant role in promoting the successful operation of reform. This is consistent with the literature that suggests that an innovation accepting and an entrepreneurship accommodating culture plays a key role in the acceptance of change (Pärna \& von Tunzelmann, 2007; Rothwell, 1994)

- Limiting the number of actors involved in operating corporate governance reform increases the chance of its success. This suggests large scale change is more difficult to successfully implement than smaller scale change. Research has previously identified the nature of large scale change as requiring more extensive management attention and generally taking the focus from other organisational matters (Meyer \& Stensaker, 2006).

- Queensland and Victoria have higher rates of success in operating reform than other states, particularly Tasmania. More research is required to understand the nature of this difference.

- The organisational structure of an organisation may inhibit successful reform.

Divisional and functional structures are more likely to promote the successful operation of reform than an hybrid of these two structures. This was an unexpected finding as 
the literature does not attribute differences in successful reform to specific types of organisational structure arrangements. Further investigation is required to determine the impact of hybrid organisational arrangements on reform operation.

Table 48: Implications of observed differences relating to organisational characteristics and reform operation

\begin{tabular}{|c|c|}
\hline Observed difference & Implication \\
\hline $\begin{array}{l}\text { Respondents who worked in an organisation with } \\
\text { a budget between } \$ 100-\$ 500 \text { million were more } \\
\text { likely to agree that organisational attributes } \\
\text { impacted on the operation of reform }\end{array}$ & $\begin{array}{l}\text { - Organisations with smaller budgets appear more } \\
\text { likely to have organisational attributes that } \\
\text { impact on reform operation } \\
\text { - Organisations with larger budgets appear less } \\
\text { likely to have organisational attributes that } \\
\text { impact on reform operation }\end{array}$ \\
\hline $\begin{array}{l}\text { Respondents who worked in organisation with } \\
\text { fewer than five sites were less likely to agree that } \\
\text { the number of actors in the change process } \\
\text { impacted on the operation of reform }\end{array}$ & $\begin{array}{l}\text { - Reform in organisations with fewer sites is not } \\
\text { impacted by the number of change actors } \\
\text { - Reform in organisations with more sites is } \\
\text { impacted by the number of change actors }\end{array}$ \\
\hline $\begin{array}{l}\text { Respondents who were employed for less than two } \\
\text { years were less likely to agree that their } \\
\text { organisation accepted innovation }\end{array}$ & $\begin{array}{l}\text { - An organisation's acceptance of innovation is not } \\
\text { easily identifiable by new employees } \\
\text { - The longer you are employed the more likely you } \\
\text { are to think your organisation is innovative }\end{array}$ \\
\hline $\begin{array}{l}\text { Respondents who were employed for less than two } \\
\text { years were more likely to disagree that their } \\
\text { organisation easily accepted change }\end{array}$ & $\begin{array}{l}\text { - The longer you are employed the more likely you } \\
\text { are to think that your organisation easily accepts } \\
\text { change }\end{array}$ \\
\hline $\begin{array}{l}\text { Respondents who worked in an organisation with } \\
\text { a divisional structure were more likely to agree } \\
\text { that organisational attributes impacted on the } \\
\text { operation of reform }\end{array}$ & $\begin{array}{l}\text { - Divisionally structured organisations are more } \\
\text { likely to have attributes that impact on the } \\
\text { operation of reform }\end{array}$ \\
\hline
\end{tabular}


Observations about the implications shown in Table 48 include:

- The size of an organisation's budget impacts on the operation of reform. Traditionally, changes in large organisations has been identified as more difficult. However, further investigation is required to better understand why organisational budget size impacts on corporate governance reform operations.

- The structure of an organisation impacts on the operation of corporate governance reform. The literature has not previously attributed any significant differences to specific types of organisational structure and the success of reform.

- The length of employment impacts on an employee's positive perception of corporate governance reform influences. This result appears to be intuitive. Employees with favourable views of an organisation are more likely remain employed in that organisation. New employees are also not necessarily able to develop an informed view on how various influences impact on reform operation. 
Table 49: Implications of observed differences relating to other characteristics and reform operation

\begin{tabular}{|c|c|}
\hline Observed difference & Implication \\
\hline $\begin{array}{l}\text { Respondents who were employed between three } \\
\text { and ten years were more likely than other } \\
\text { respondents to have received corporate } \\
\text { governance training }\end{array}$ & $\begin{array}{l}\text { - New employees are less likely to have been trained } \\
\text { in corporate governance reform } \\
\text { - People employed for more than ten years are less } \\
\text { likely to have been trained in corporate governance } \\
\text { reform }\end{array}$ \\
\hline $\begin{array}{l}\text { Respondents in organisations with a functional } \\
\text { organisational structure were less likely to have } \\
\text { received corporate governance reform training }\end{array}$ & $\begin{array}{l}\text { - People in organisations with divisional and hybrid } \\
\text { organisational structures are more likely to have } \\
\text { been trained in corporate governance reform }\end{array}$ \\
\hline $\begin{array}{l}\text { Respondents in Western Australia and South } \\
\text { Australia were more likely to agree that their } \\
\text { organisation easily accepted change, while } \\
\text { respondents in Tasmania were less likely }\end{array}$ & $\begin{array}{l}\text { - Government departments in Western Australia and } \\
\text { South Australia are more accepting of change } \\
\text { - Government departments in Tasmania are less } \\
\text { accepting of change }\end{array}$ \\
\hline $\begin{array}{l}\text { Government departments in Victoria were more } \\
\text { likely to have budgets in excess of } \$ 1 \text { billion } \\
\text { while departments in Western Australia were } \\
\text { more likely to have budgets less than } \$ 500 \text { million }\end{array}$ & $\begin{array}{l}\text { - Government departments have bigger budgets in } \\
\text { Victoria } \\
\text { - Government departments have smaller budgets in } \\
\text { Western Australia }\end{array}$ \\
\hline $\begin{array}{l}\text { Respondents who were employed the longest } \\
\text { were more likely to have experienced more } \\
\text { corporate governance reform }\end{array}$ & $\begin{array}{l}\text { - The longer you work the more governance reform } \\
\text { you are likely to experience }\end{array}$ \\
\hline
\end{tabular}


Observations about the implications of the findings shown in Table 49 include:

- Training in corporate governance reform varies according to length of employment and organisational structure. A significant number of respondents had not received training relating to corporate governance reform. This was particularly the case for those employed less than two years or more than ten years, or people working in an organisation with a functional organisational structure. The finding relating to limited training in functional organisations contrasts with the earlier finding that reform in departments with a hybrid structure were less likely to see reform as successful.

- Government departments vary in terms of acceptance of change and budget. In particular, Departments in Western Australia and South Australia are more accepting of change and departments in Victoria are more likely to have larger budgets.

- The longer you are employed the more corporate governance reform you will encounter

\subsubsection{Consistency with phase one findings}

Phase one and phase two findings are again consistent. Phase one and phase two investigations found high levels of agreement for the individual influences comprising RO and PO factors. Neither produced additional influences that sit outside the research's conceptual framework (see earlier discussion of the additional factor identified during phase two as impacting on the operation of corporate governance reform). 


\section{Confirmation of influences not present in phase one}

Phase one research found no evidence of the redistributive effect on power and institutional relationship affecting reform adoption, however this influence was retained for further testing during phase two. Sixty nine percent of respondent in phase two agreed that power and relationships changes affected the operation of corporate governance reform in their organisation.

\section{Confirmation of influences identified in phase one}

The leadership influence that was added as a result of phase one findings was strongly supported by phase two findings (see earlier discussion about the importance of leadership in the reform process). While this may, in part, be attributed to some respondents identifying their own importance as a leader within their respective organisation, the results are consistent with previous studies relating to the role of leadership within organisational change (Burns, 1978; Downes, 1998; Kotter, 1995; Mir \& Rahaman, 2006; Muldoon, 2003). 


\subsection{Implications and discussion of factor analysis results}

A factor analysis of responses to questions related to reform adoption and operation identified a series of unique factors at each stage of the reform process. Six factors affecting reform adoption were identified that explained sixty nine percent of the variance. The factor analysis of reform operation responses identified five factors that explained fifty eight percent of the variance.

\subsubsection{Confirmation of model}

The influences identified through the factor analysis confirmed the existence of political/cultural and rational/scientific influences during reform adoption and operation stages of corporate governance change.

In the adoption stage of reform (refer Table 50: Reform adoption factor analysis categorisation of influences) all but one factor (factor three) are comprised of discrete, self contained RA or PA influences - rational/scientific and political/cultural influences are generally not mixed between factors identified from the factor analysis. 
Table 50: Reform adoption factor analysis - categorisation of influences

\begin{tabular}{|c|c|c|c|c|c|}
\hline $\begin{array}{c}\text { Adoption } \\
\text { Factor } 1 \\
\text { Leadership } \\
\\
\text { RA influences }\end{array}$ & $\begin{array}{c}\text { Adoption } \\
\text { Factor } 2 \\
\text { External } \\
\text { improvement } \\
\text { drivers } \\
\text { RA influences }\end{array}$ & $\begin{array}{c}\text { Adoption } \\
\text { Factor } 3 \\
\text { Organisational } \\
\text { politics } \\
\\
\begin{array}{c}\text { Primarily PA } \\
\text { influences }\end{array} \\
\end{array}$ & $\begin{array}{c}\text { Adoption } \\
\text { Factor } 4 \\
\text { Internal } \\
\text { improvement } \\
\text { drivers } \\
\text { RA influences } \\
\end{array}$ & $\begin{array}{c}\text { Adoption } \\
\text { Factor } 5 \\
\text { Organisational } \\
\text { capacity to interpret } \\
\text { knowledge } \\
\text { RA influences }\end{array}$ & $\begin{array}{c}\text { Adoption } \\
\text { Factor } 6 \\
\text { Operating } \\
\text { environment } \\
\text { changes } \\
\\
\text { RA influences }\end{array}$ \\
\hline CEO leadership & $\begin{array}{l}\text { External drive to } \\
\text { improve } \\
\text { accountability }\end{array}$ & $\begin{array}{l}\text { Competition with } \\
\text { other organisational } \\
\text { priorities }\end{array}$ & $\begin{array}{l}\text { Internal drive to } \\
\text { improve decision } \\
\text { making }\end{array}$ & $\begin{array}{l}\text { Level of knowledge } \\
\text { and skills }\end{array}$ & $\begin{array}{l}\text { Implement new } \\
\text { government } \\
\text { policy }\end{array}$ \\
\hline $\begin{array}{l}\text { Senior manager } \\
\text { leadership }\end{array}$ & $\begin{array}{l}\text { External drive to } \\
\text { improve } \\
\text { efficiency }\end{array}$ & $\begin{array}{l}\text { Effect on power and } \\
\text { relationships } \\
\text { Costs associated } \\
\text { with implementing } \\
\text { change }\end{array}$ & $\begin{array}{l}\text { Internal drive to } \\
\text { improve service } \\
\text { coordination }\end{array}$ & $\begin{array}{l}\text { Organisational } \\
\text { decision making } \\
\text { processes }\end{array}$ & $\begin{array}{l}\text { Comply with } \\
\text { regulatory } \\
\text { requirements }\end{array}$ \\
\hline
\end{tabular}

The factor where both RA and PA influences appear (factor three) appears to suggest that there is a complex relationship between the competition of priorities, power changes and the allocation of resources.

In the operation stage of reform (Table 51: Reform operation factor analysis categorisation of influences) the factors are generally again comprised of discrete, self contained PO or RO influences.

Table 51: Reform operation factor analysis - categorisation of influences

\begin{tabular}{|c|c|c|c|c|}
\hline $\begin{array}{c}\text { Operation } \\
\text { Factor } 1 \\
\text { Leading change } \\
\text { RO influences }\end{array}$ & $\begin{array}{c}\text { Operation } \\
\text { Factor } 2 \\
\text { Embedding change } \\
\\
\text { Primarily PO } \\
\text { influences }\end{array}$ & $\begin{array}{c}\text { Operation } \\
\text { Factor } 3 \\
\text { Attitudes to change } \\
\text { PO influences }\end{array}$ & $\begin{array}{c}\text { Operation } \\
\text { Factor } 4 \\
\text { Organisational } \\
\text { politics } \\
\\
\text { PO influences }\end{array}$ & $\begin{array}{c}\text { Operation } \\
\text { Factor } 5 \\
\text { Organisational capacity to } \\
\text { understand change } \\
\text { RA influences }\end{array}$ \\
\hline $\begin{array}{l}\text { Time to implement } \\
\text { change }\end{array}$ & $\begin{array}{l}\text { Number of actors in } \\
\text { change process }\end{array}$ & $\begin{array}{l}\text { Acceptance of } \\
\text { innovation }\end{array}$ & $\begin{array}{l}\text { Effect on power and } \\
\text { relationships }\end{array}$ & $\begin{array}{l}\text { Level of knowledge and } \\
\text { skill }\end{array}$ \\
\hline CEO leadership & $\begin{array}{l}\text { Organisational } \\
\text { attributes }\end{array}$ & $\begin{array}{l}\text { Acceptance of } \\
\text { organisational } \\
\text { change }\end{array}$ & $\begin{array}{l}\text { Managerial fear of } \\
\text { loss of control }\end{array}$ & $\begin{array}{l}\text { Communication and } \\
\text { information sharing } \\
\text { processes }\end{array}$ \\
\hline $\begin{array}{l}\text { Senior manager } \\
\text { leadership } \\
\text { Leadership } \\
\text { continuity } \\
\text { Scale and scope of } \\
\text { reform }\end{array}$ & $\begin{array}{l}\text { Hierarchical nature } \\
\text { of public sector }\end{array}$ & & & $\begin{array}{l}\text { Organisational control } \\
\text { processes }\end{array}$ \\
\hline
\end{tabular}




\section{Reform adoption - dominance of RA influences}

During the adoption stage of reform the factor analysis reveals the dominance of rational/scientific influences. Five of the six factors reflect rational/scientific influences, while the remaining factor also includes an RA influence.

\section{Reform operation - complex relationship between PO and RO influences}

During the operation stage of reform the factor analysis reveals the dominance of political/cultural influences, although not to the same extent that rational/scientific influences dominate the adoption of corporate governance reform. Two of the five operation factors are comprised of political/cultural influences while a third factor is comprised primarily of political/cultural influences. Although the combination of these factors present a complex relationship between rational/scientific and political/cultural influences, it is clear that the frequency of PO influences is greater than the frequency of RO influences.

\section{A better understanding of corporate governance reform adoption and operation}

The factor analysis extends the conceptual framework by establishing an improved means to understand corporate governance change in an applied setting. Six factors that require management during the adoption of corporate governance reform were identified:

1. Leadership. This includes both chief executive officer leadership and leadership at senior manager level. As discussed earlier, the importance of senior manager leadership should not be underestimated. A significant relationship exists between 
the level of senior management involvement in reform adoption and the successful adoption of reform.

2. External improvement drivers. Requirements to improve departmental accountability and efficiency provide important support for the adoption of reform. This is consistent with the literature (Halligan, 2007; Mulgan, 2008), although there appears to be some uncertainty about the success of reform that has been externally imposed for accountability reasons (refer to observed differences discussed earlier in this chapter).

3. Organisational politics. As expected, the political nature of organisations also impacts on the adoption of corporate governance reform. In particular, competition with other organisational priorities, effects on power and relationships and the resources available to implement change are expected to be key influences that require management.

4. Internal improvement drivers. These drivers coexist with the external drivers identified earlier. Drivers aimed at improving decision making and service coordination provide the impetus for internally led change.

5. Organisational capacity to interpret knowledge. This factor includes rational/scientific influences associated with understanding and applying knowledge about corporate governance reform, namely the level of knowledge and skills in an organisation and the decision making processes used to apply these.

6. Operating environment changes. The need to respond to changes in government policy and to meet regulatory requirements reflect a group of influences associated with an organisation's operating environment. This factor, like the others identified here, require management to optimise their impact on the adoption of reform. 
Five factors that require management during the operation of corporate governance reform have been identified:

1. Leading change. This is an expanded version of the leadership factor identified during the adoption phase of reform. In the operation of reform, leadership includes the oversight of implementation issues such as the time available to establish the reform as well as the scale and scope of the reform.

2. Embedding change. This is a related, but separate factor, to the leading change factor. The embedding change factor relates to how change is fixed into an organisation. It includes political/cultural influences associated with the number of actors in the change process and the hierarchical nature of public sector organisations. The rational/scientific factor associated with organisational attributes, it is included here as it is closely related to the concept of organisational hierarchy.

3. Attitudes to change. This factor includes influences heavily dominated by the culture of an organisation. These includes the acceptance of innovation and change.

4. Organisational politics. The impact of change on employees, along with their stability seeking responses, is well documented (Fontannaz \& Oosthuizen, 2007; Parker \& Bradley, 2000; Robbins \& Barnwell, 2002; Robbins et al., 2001). This factor includes impact of change on power and institutional relationships and managerial fear of loss of control. 
5. Organisational capacity to understand change. This final factor relates to how an organisation understands the change that has been implemented. It includes level of knowledge and skills, communication and information sharing processes and the processes used to direct the organisation (including how to apply knowledge and skills and share information).

More detail on how to apply these factors to future corporate governance reforms, including recommendation for future research, is set out in the next chapter. 


\subsection{Research findings}

\subsubsection{Acceptance of hypothesis}

Based on the research findings from phase one and phase two the following hypothesis are confirmed:

Hypothesis $1\left(\mathrm{H}_{1}\right)$ - that in relation to the corporate governance reform, the adoption of reform was positively related to:

$\mathrm{H}_{1}$ a External (central agency) requirements for improved accountability

$\mathrm{H}_{1} \mathrm{~b} \quad$ External (central agency) requirements for increased efficiency

$\mathrm{H}_{1} \mathrm{C} \quad$ Internal drive to improve services through enhanced coordination

$\mathrm{H}_{1} \mathrm{~d} \quad$ Availability of resources

$\mathrm{H}_{1} \mathrm{e} \quad$ Organisational control processes

Hypothesis $2\left(\mathrm{H}_{2}\right)$ - that in relation to corporate governance reform, the operation of reform was positively related to:

$\mathrm{H}_{2} \mathrm{a}$ Organisational culture (including impact of reform on power and institutional relationships)

$\mathrm{H}_{2} \mathrm{~b} \quad$ Number of actors in change process

$\mathrm{H}_{2} \mathrm{C} \quad$ Change fatigue

$\mathrm{H}_{2} \mathrm{~d} \quad$ Hierarchical nature of public sector 


\subsection{Summary and conclusion}

The next chapter is the concluding chapter which gives an overview of the results discussed so far. It also provides clear recommendations on how Australian government departments can improve the success of corporate governance reform during the adoption and operation of change. 


\section{Chapter nine - Conclusions, recommendations and implications}

\subsection{Introduction}

The aim of this chapter is to provide a summary of previous chapters and to recommend an approach to improving the successful adoption and operation of corporate governance changes in Australian state government departments. It is divided into five sections. The first presents a summary of previous chapters, the second provides a series of recommendations, the third deals with the implications for theory while the forth section sets out implications for policy and practice. The fifth section deals with the limitations of this research and suggests areas for further research.

\subsection{Summary of chapters}

\subsubsection{Chapter 1: Research context, aims and significance of research}

Over the last decade Australian government agencies have adopted many corporate governance reforms. Research into these changes has focused on the nature of reforms and little attention been paid to the way these structural changes have been made. As a result, little is known about how public sector organisations go about adopting and then operating changes to corporate governance arrangements.

This research sought to identify and describe variables associated with corporate governance reform in Australian state government departments, particularly the factors that 
impact on the adoption and operation of reform. The purpose of the research was to develop an improved understanding of issues affecting corporate governance changes in Australian public sector organisations so as to inform and guide future public sector corporate governance reform.

A change model comprised of rational/scientific and political/cultural factors was developed and then tested commencing with a case study centred on the Victorian Department of Human Services. The applicability of these factors to public sector corporate governance reforms in other Australian state government departments was then confirmed though a survey of senior officers in state government departments across Australia.

The project extended the knowledge of corporate governance reform in the Australian public sector by being the first study to explore factors impacting on corporate governance reform in Australian state government departments.

\subsubsection{Chapter 2: literature review}

The literature review provided an outline of public sector corporate governance reform in Australia, describing the concept of corporate governance within a public sector context and highlighting the drivers of corporate governance change.

The various models and elements of organisational change and innovation were also described along with details of previous research associated with barriers to change and 
innovation in the public sector, both within Australia and internationally. This included the many types, levels and degrees of change and the approaches used to understand these, including concepts of scale and change models. Innovation was identified as a special kind of change focused on the introduction of new ideas, objects and practices (Slappendel 1996), although the literature considers that much remains to be learnt about how organisation's innovate (Wade 1994).

Key barriers to change and innovation identified from the literature included the finding that organisations and their members frequently resist change (Robbins, Millett et al. 2001). Reasons for this included self-interest, redistributive effects on power and relationships and the ability of group norms and customs to inhibit change (Trader-Leigh 2002; Robbins 2001). Several unique barriers to change in the public sector were also identified. This included public sector organisations having multiple and conflicting objectives (Osborne and Plastrik 1997) and being subject to a greater range of rules and procedures (Rainey 1983). The literature also included a study into change within the Queensland public sector (Parker and Bradley 2000) that revealed the majority of agencies in that State to be still dominated by hierarchical models of organisation and culture.

To assist the categorisation of factors impacting on organisational change in a public sector setting, the literature review highlighted a study by de Lancer Julnes and Holzer (2001). This research found, amongst other things, that the implementation of performance measurement in American public sector organisations was influenced by two types of factors - rational/technocratic and political/cultural. 
The literature review confirmed that despite significant research into the types and reasons for public sector change there has been relatively little research into how public sector organisations actually go about adopting and implementing corporate governance reforms, particularly in terms of identifying causes of reform failure. This study addresses this gap.

\subsubsection{Chapter 3: Theoretical framework and research questions}

The theoretical framework was a conceptual model designed for the purpose of this research. It extended a model previously identified within a public sector performance measurement context (Ramage \& Armstrong, 2005) based on concepts of reform stages (adoption and operations) and different types of influences (rational/scientific and political/cultural). The theoretical framework aimed to provide an approach to managing future corporate governance change which would assist decision makers and reform project managers.

The analysis and explanation of the theoretical framework was completed by addressing the research propositions and hypothesis. There were two research propositions, the first proposed that rational/technocratic factors would have a positive impact on the adoption of reform and the second proposed that political/cultural factors would have a positive impact on the operation of corporate governance reform. A series of hypothesis were then developed based on the propositions. These were:

Hypothesis $1\left(\mathrm{H}_{1}\right)$ - that in relation to the corporate governance reform, the adoption of reform will be positively related to:

$\mathrm{H}_{1} \mathrm{a} \quad$ External (central agency) requirements for improved accountability 
$\mathrm{H}_{1} \mathrm{~b} \quad$ External (central agency) requirements for increased efficiency

$\mathrm{H}_{1} \mathrm{C} \quad$ Internal drive to improve services through enhanced coordination

$\mathrm{H}_{1} \mathrm{~d} \quad$ Availability of resources

$\mathrm{H}_{1} \mathrm{e} \quad$ Organisational control processes

Hypothesis $2\left(\mathrm{H}_{2}\right)$ - that in relation to corporate governance reform, the operation of reform will be positively related to:

$\mathrm{H}_{2} \mathrm{a} \quad$ Organisational culture (including impact of reform on power and institutional relationships)

$\mathrm{H}_{2} \mathrm{~b} \quad$ Number of actors in change process

$\mathrm{H}_{2} \mathrm{C} \quad$ Change fatigue

$\mathrm{H}_{2} \mathrm{~d} \quad$ Hierarchical nature of public sector

\subsubsection{Chapter 4: Research methodology}

The research was based on both qualitative and quantitative methodologies for which data was collected through two phases. The study was a field study, exploratory in nature and the unit of analysis was Australian state government departments.

Phase one was centred on the Victorian Department of Human Services and involved the collection of data through semi-structured interviewees. The phase one sample was a stratified selective sample comprising senior executives (including the department's Secretary) responsible for the overall adoption and operation of corporate governance 
reform (stratum 1); and executive officers responsible for implementing and operating elements of corporate governance reform (stratum 2).

Phase two involved the collection of data using a questionnaire distributed to all Australian state government departments. The phase one case study was used to inform the development of the survey questionnaire. The phase 2 sample was a purposive judgement sample and focused on staff within each organisation responsible for corporate governance functions, including each organisation's chief executive officer.

The methodology for the project involved the use of both quantitative and qualitative research so that a better understanding of factors impacting on corporate governance reform might be obtained. A qualitative approach was first used as the literature suggests that case studies are particularly well suited to new research areas where there is less experience and theory available to serve as a guide (Eisenhardt 1999; Gharuri, Gronhaug et al. 1995). The results of the case study were then used to inform the development of a quantitative survey instrument. Quantitative data is particularly suited to acceptance, or rejection, of hypotheses (Cooper and Schindler 1998). Surveys provide a quick, inexpensive and accurate means of assessing information about a population. 


\subsubsection{Chapter 5: Context of phase one case study (Department of Human Services cases study)}

This chapter described the context of the phase one case study. It identified that the

Department of Human Services was created in April 1996 by combining agencies responsible for housing, youth affairs and health and community services and that it is the largest of the Victorian 'mega' departments (Department of Human Services (Victoria), 2007b).

The Department of Human Services includes the responsibilities of the Ministers for Health, Mental Health, Community Services and Housing (Department of Human Services (Victoria), 2007a)

Major reforms undertaken in the department that involved corporate governance changes included:

- Project-based approach to strategic issue management

- Creation of geographic-based health divisions

- A strategic approach to risk management

- Establishment of an Office for Children

- Amalgamation of Northern and Western Metropolitan regions

- 'Joining up' decision making in the Health portfolio 


\subsubsection{Chapter 6: Phase one results and discussion (Department of Human Services)}

Sixteen people participated in phase one (eight in each strata of the stratified sample). Phase one results were consistent with the theoretical model and the expected findings. There were no interview responses that challenged the theoretical framework.

However, interview subjects identified the following additional concepts that were subsequently included in the theoretical model for testing during phase two:

- Two additional factors related to externally imposed requirements for corporate governance change:

1. implementation of new government policy

2. compliance with regulatory requirements

- Leadership.

Other phase one findings related to leadership appeared seemingly only to be exercised in relation to corporate governance reform by the organisation's chief executive; there appeared to be a strong filtering process in the department around corporate governance reform proposals that made in difficult for interview subjects to identify an unsuccessful reform; and there was evidence that corporate governance in the Department of Human Services was considered secondary to the corporate governance of external relationships. 


\subsubsection{Chapter 7: Phase two results (government department survey)}

Questionnaires were distributed to four hundred and sixty four chief executive and other senior executives employed in ninety seven state government departments. Two hundred and thirty two surveys were completed. This gave a response rate of fifty percent. Approximately nineteen percent of the completed surveys were provided by Chief Executive Officers. Eighty one percent of the completed surveys were provided by senior executives and other managers.

\subsubsection{Chapter 8: Discussion of phase two results}

As predicted by the theoretical model, rational/technocratic and political/cultural influences were present during the adoption and operation stage of corporate governance reform in the departments surveyed.

A factor analysis of responses to questions related to reform adoption and operation identified a series of unique factors at each stage of the reform process. Six factors affecting reform adoption were identified that explained sixty nine percent of the variance. The factor analysis of reform operation responses identified five factors that explained fifty eight percent of the variance.

The factors identified through the factor analysis confirmed the existence of political/cultural and rational/scientific influences during reform adoption and operation stages of cultural change. This supports the use of a comprehensive approach to corporate governance change in public sector organisations. 
Based on the research findings from phase one and phase two the following hypotheses were confirmed:

Hypothesis $1\left(\mathrm{H}_{1}\right)$ - that in relation to the corporate governance reform, the adoption of reform was positively related to:

$\mathrm{H}_{1}$ a External (central agency) requirements for improved accountability

$\mathrm{H}_{1} \mathrm{~b} \quad$ External (central agency) requirements for increased efficiency

$\mathrm{H}_{1} \mathrm{C} \quad$ Internal drive to improve services through enhanced coordination

$\mathrm{H}_{1} \mathrm{~d} \quad$ Availability of resources

$\mathrm{H}_{1} \mathrm{e} \quad$ Organisational control processes

Hypothesis $2\left(\mathrm{H}_{2}\right)$ - that in relation to corporate governance reform, the operation of reform was positively related to:

$\mathrm{H}_{2} \mathrm{a}$ Organisational culture (including impact of reform on power and institutional relationships)

$\mathrm{H}_{2} \mathrm{~b} \quad$ Number of actors in change process

$\mathrm{H}_{2} \mathrm{C} \quad$ Change fatigue

$\mathrm{H}_{2} \mathrm{~d} \quad$ Hierarchical nature of public sector 


\subsection{Lessons for improving reform adoption and operation}

As outlined earlier, this research has confirmed two separate stages of corporate governance reform, each with a distinct set of influences. By carefully managing these, the success of corporate governance reform in Australian state government departments can be improved at the adoption and operation stages of reform.

In addition to managing these influences, priority should be given to addressing the corporate governance training deficit identified across all jurisdictions; only around one in two senior officers have been trained in corporate governance reform. This training should include details of the influences identified by this research.

Leadership was also identified as a critical factor at both the adoption and operation stages of reform. This aspect of corporate governance change should be addressed through both corporate governance training and management development programs.

\subsubsection{Improving the success of reform adoption}

It is recommended that during the adoption stage of future corporate governance reforms, priority be given to the following:

\section{Capability development}

- Developing the leadership capabilities of chief executive and other senior managers 
- Developing organisational capabilities, particularly the level of knowledge and skills relating to corporate governance

\section{Power relationships}

- Managing 'organisational politics' associated with reform, particularly competition with other organisational priorities and the effect of change on power and institutional relationships

\section{Internal reform drivers}

- Identifying the internal drivers impacting on reform, particularly those related to improved decision making and service coordination

\section{External reform drivers}

- Identifying the external drivers impacting on reform, particularly those related to improved accountability, efficiency requirements, requirements to implement new government policy and compliance with regulatory requirements

\subsubsection{Improving the success of reform operation}

It is recommended that during the adoption stage of future corporate governance reforms, priority be given to the following:

\section{Leading and managing change}

- Developing the leadership capabilities of chief executive and other senior officers 
- Ensuring reform is manageable in terms of time to implement change, and scale and scope

- Developing organisational capabilities in terms of level of knowledge and skills, communication and information sharing and organisational control processes

- Managing implementation and project management issues associated with corporate governance reform, particularly in terms of managing the number of actors in change process, organisational attributes and the hierarchical nature of the public sector

\section{Power relationships}

- Managing the impact of change on power and institutional relationships including addressing managerial fear of loss of control

\section{Attitudes to change}

- Developing organisational acceptance of change and innovation

\subsection{Implications for theory}

The implications to theory from this research are substantial. It was confirmed that two types of influences are present during the adoption and operation stages of corporate governance reform. The notion of scientific management and the ability to address current and emerging corporate governance issues through rational-based actions dominates the adoption stage of reform while organisational culture dominates the operation stage of reform. 
The results of this research are consistent with those reported by de Lancer Julnes and Holzer (2001) about factors impacting on the use of performance measurement systems in American public sector bodies. In particular, similar categories of influences (namely rational and political) were observed along with the finding that the mix of factors found in the successful adoption of reform is different from those found in the reform's successful operation.

This research also suggests that political/cultural influences on decision makers and change actors are just as significant for reform as the purely rational influences. This is consistent with research by others that while an idea for reform generally emerges from a rational perspective (Brunsson \& Olsen, 1993), government officials use factors other than rational ones when determining action, often including a mixture of intuition and analysis or ‘imperfect reasoning’ (Hammond, 1996). This is also consistent with the view of institutional theorists that implementation of change is particularly difficult as reformers and reformees can be expected to act in accordance with pre-determined values, interests and opinions, which frequently results in interest groups exerting pressure on change processes (Brunsson \& Olsen, 1993; Czarniawska \& Sevon, 1996; Zucker, 1983).

The need and capacity for public sector organisations to respond quickly to emerging issues was supported by findings in both phase one and phase two of this research about the frequency and success of change. This is consistent with those who contend that managing change within the public sector has become integral to the success of public sector organisations (White 2000). 
The role and importance of leadership was also confirmed in this study. This extends previous studies (Hennessy, 1998; Isaac-Henry \& Painter, 1991; Stewart \& Kringas, 2003) that have found successful change in public sector organisations is often reliant on effective leadership, along with continuity of that leadership in sustaining momentum.

This project extends previous research by identifying factors impacting on corporate governance reform adoption and operation within an Australian public sector setting. It has filled a gap relating to how public sector organisations go about making corporate governance changes and provides customised and practical recommendations for future corporate governance reforms in Australian state government departments.

\subsection{Implications for policy and practice}

The knowledge gained through this research about how departments across Australia go about reforming corporate governance arrangements offers new insights into managing corporate governance change.

The immediate implication for practice is the definition of a new model to manage corporate governance change. The rational/scientific and political/cultural factors identified by this research provide an integrated approach that can be drawn upon by change actors. It acknowledges the significance of rational/scientific and political/cultural factors that come into play during corporate governance reform. 
During the adoption stages of reform, change managers should primarily focus on the factors identified by this research project and set out in Figure 15: A new model to manage the adoption of corporate governance reform

. This includes establishing clear leadership for the change, identifying internal and external drivers of the reform, managing organisational politics associated (or expected to be associated) with the change, building the organisation's capacity to interpret knowledge and monitoring and responding to changes in the organisation's operating environment to ensure the reform stays on track. 


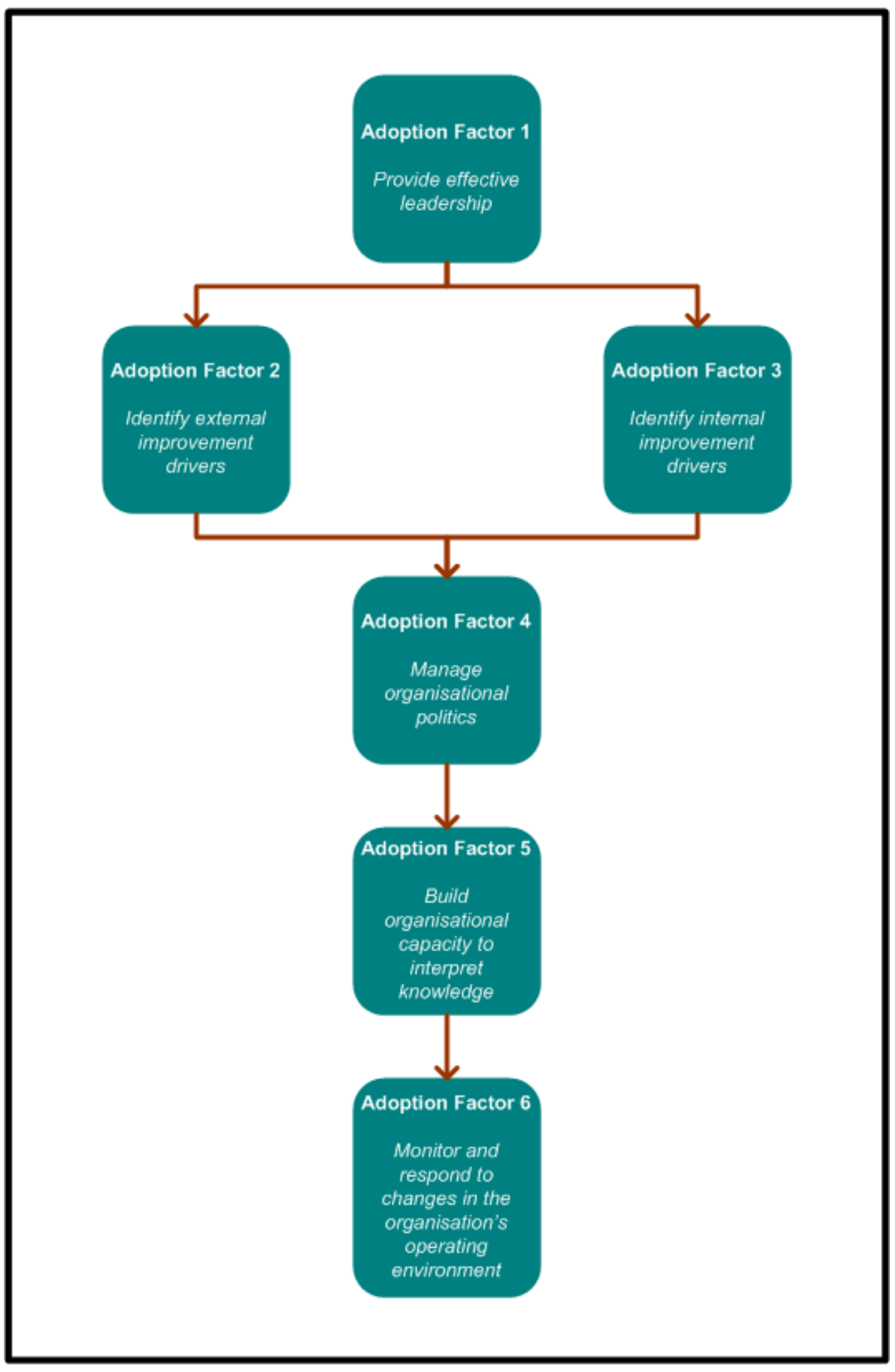

Figure 15: A new model to manage the adoption of corporate governance reform 
During the operation of reform, public sector managers should be aware of the factors influencing the operation of corporate governance reform identified by this research, and take action where required. A summary of factors impacting on reform operation is set out in Figure 16: A new model to manage the operation of corporate governance reform These include ensuring that effective leadership of change continues from the adoption stage, taking action to embed change within the organisation, building a supportive attitude to change, managing organisational politics while building the organisation's capacity to understand change. 


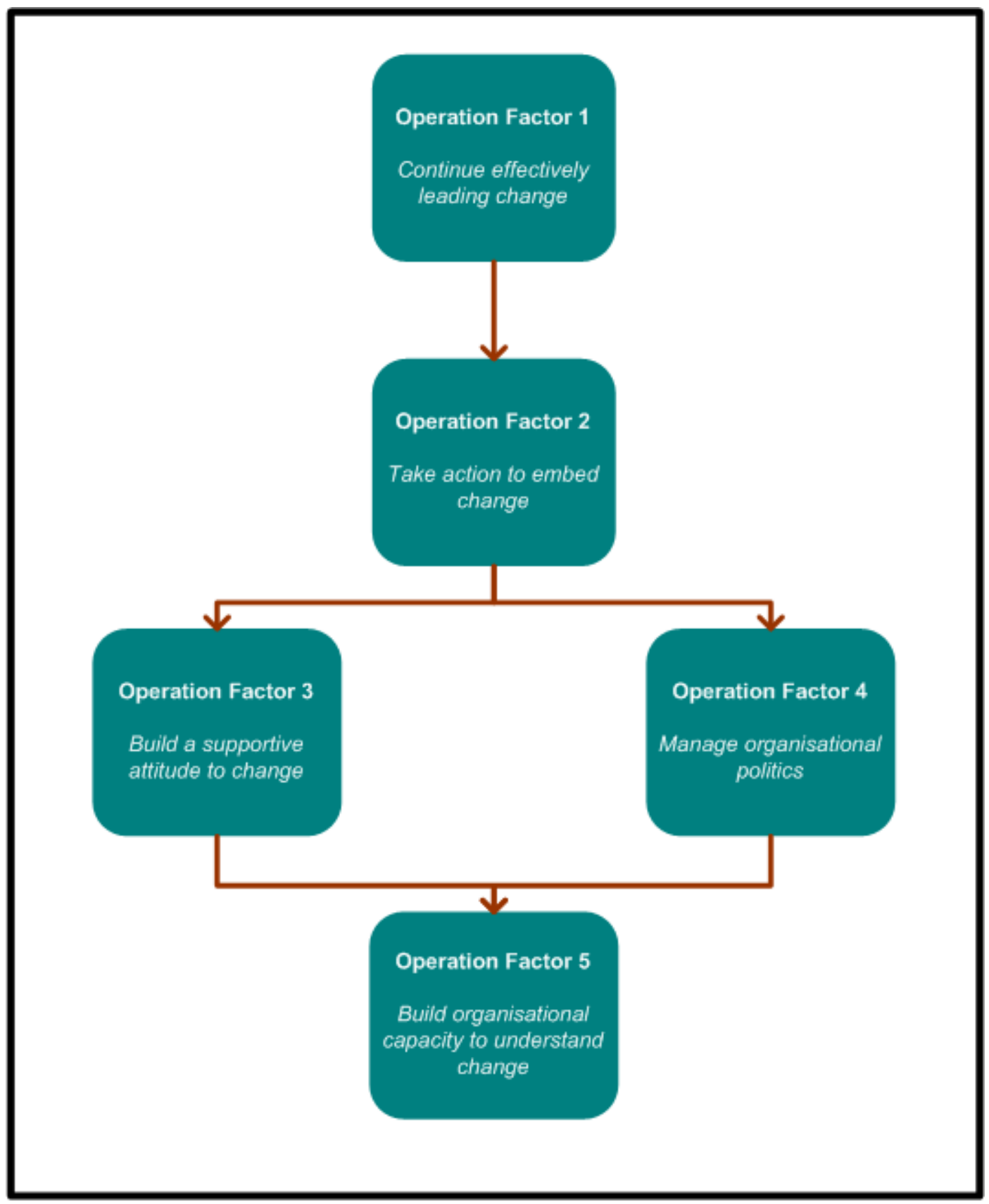

Figure 16: A new model to manage the operation of corporate governance reform

This model is significant because it is mutli-factorial and can be used across the range of government departments in Australia, including departments with different functions, structures and located in different jurisdictions. 


\subsection{Limitations and implications for future research}

\subsubsection{Research limitations}

A limitation of this study is the absence of real time data. The findings from the human services’ case study and the survey of government departments rely on respondents reflecting on experiences over prior periods. The phase one case study provided some protection from skewed or disaffected recollections by permitting both analysis at meta and meso levels and the interrogation of themes by the interviewer. The coding of results during phase one along with the use of matrices to analyse results also deepened the understanding and explanation of results (Miles \& Huberman, 1994).

The use of qualitative data is often cited as making acceptance, or rejection, of hypotheses difficult, particularly as it does not meet minimum standards for comparison (Cooper and Schindler 1998). By using a mixed method approach however, such a limitation has been avoided in this research. In particular, the qualitative data collected in phase one was used to validate the conceptual model which was then tested during phase two using quantitative methods. Indeed some researchers consider that only qualitative methods are sensitive enough to allow the detailed analysis of change (Cassell, 1994).

Quantitative methods too have limitations, such as low response rates and the investigator being prevented from learning the motivation behind a respondent’s answer (Orlich 1978).

The response rate for phase two investigations in this project was 50\%. In recognition that the response rate was representative of the stratified sample and fell within the range 
identified as acceptable by Babbie (1998) and Sekaran (2000), the response rate was considered to be sufficient to ensure validity.

The ability to seek more information about the motivation behind a respondent's answer during phase one was considered to offset the inability to gather further information about themes emerging from the answers of respondents during phase two.

In achieving breath of analysis during this research it is acknowledged that some depth and reliability has been forgone. However, after consideration of the advantages and disadvantages of the methodology, it was considered that the collection of both qualitative data though a case study (phase one) and quantitative data through a survey instrument (phase two) was the most effective and efficient means to collect data for this research project. 


\subsubsection{Future research}

Further research is required to investigate how each factor influences the adoption and operation of reform so that an improved understanding of each influence is obtained, particularly in relation to the observed differences at the adoption and operation stages of reform.

Other aspects that should be further investigated include:

1. Does the model developed by this research feature predictive capabilities? In particular, in an applied setting does the framework improve reform success?

2. How do public sector reform factors (RA, PA, RO and PO) contrast with factors impacting in the private sector?

3. Are rational/scientific and political/cultural factors (RA, PA, RO and PO) consistent across international jurisdictions, particularly across cultural and ethnic divides?

4. Why does reform driven by government policy change have a higher rate of successful adoption and operation than reform resulting from other drivers?

5. Why do some states have higher rates of success in operating reform (Queensland, Victoria) compared with others (Tasmania)?

6. Why do some types of organisational structures (hybrid) appear to limit the successful operation of corporate governance change? 


\section{Bibliography}

Armistead, C., \& Meakins, M. (2007). Managing Knowledge in Times of Organisational Change and Restructuring. Knowledge and Process Management, 14(1), 15-25.

Armstrong, A. (1998). A Comparative Analysis: New Public Management - the Way Ahead? Australian Journal of Public Administration, 57(2), 12-24.

Arts, B., \& Van Tatenhove, J. (2004). Policy and Power: A Conceptual Framework Between the 'Old' and 'New' Idoms. Policy Sciences, 37(3/4), 339-356.

Australian National Audit Office. (1997). Applying Principles and Practice of Corporate Governance in Budget Funded Agencies. Canberra: Commonwealth of Australia.

Babbie, E. R. (1998). The Practice of Social Research. Belmont: Wadsworth Publishing Company.

Barrett, P. (2003). Corporate Governance in the Public Sector Context. Canberra Bulletin of Public Administration, 107, 7-27.

Bass, B. (1985). Leadership and Performance Beyond Expectations. New York: Free Press.

Beer, S. (1995). Beyond Dispute: Beyond the Invention of Team Syntegrity. Chichester: Wiley.

Booth, S. (2000). How Can Organisations Prepare for Reputational Crises? Journal of Contingencies \& Crisis Management, 8(4), 197-207.

Bourdeaux, C. (2007). Conflict, Accommodation, and Bargaining: The Implications of Using Politically Buffered Institutions for Contentious Decision Making. Governance, 20(2), 279-303.

Bovaird, T., \& Loffler, E. (2003). Understanding Public Management and Governance. In T. Bovaird \& E. Loffler (Eds.), Public management and governance (pp. 3-13). Padstow: Routledge.

Bridgeman, P., \& Davis, G. (2000). The Australian Policy Handbook. St Leonards: Allen and Unwin.

Brunsson, N., \& Olsen, J. P. (1993). The Reforming Organization. London: Routledge.

Burns, J. M. (1978). Leadership. New York: Harper and Row. 
Cameron, W. (2003, 15 August 2003). Corporate Governance and Performance Audits. Paper presented at the Public Sector Governance Conference, Melbourne.

Cassell, C. (1994). Qualitative Research in Work Contexts. In C. Cassell \& G. Symon (Eds.), Qualitative Methods in Organizational Research: A Practical Guide. London: Sage.

Cavana, R., Delahaye, B., \& Sekaran, U. (2001). Applied Business Research: Qualitative and Quantitative Methods. Milton: John Wiley and Sons Inc.

Clark, C., \& Corbett, D. (1999). Reforming the Public Sector. St Leonards: Allen and Unwin.

Clegg, S. (1990). Modern Organizations: Organization Studies in the Postmodern World. Newbury Park, CA: Sage.

Coakes, S., \& Steed, L. (2007). SPSS version 14.0 for Windows: Analysis Without Anguish. Milton: John Wiley and Sons Australia.

Collins, D. (1998). Organisational Change. New York: Routledge.

Commonwealth of Australia. (2007). Implementing Machinery of Government Changes: A Good Practice Guide. Canberra: Australian Public Service Commission.

Commonwealth of Australia. (2008). Occupational Health and Safety Acts, Regulations and Codes of Practice. Retrieved 10 April 2008, 2008, from http://www.business.gov.au/Business+Entry+Point/Business+Topics/Occupational+health + and + safety/OH+and $+\mathrm{S}+$ Acts+Regulations+and+Codes+of+Practice.htm

Conger, J. (2005). Leadership. In Blackwell Encyclopedic Dictionary of Organizational Behavior. Oxford: Blackwell Publishing.

Considine, M. (1990). Managerialism Strikes Out. Australian Journal of Public Administration, 49, 166-178.

Considine, M., \& Lewis, J. (1999). Governance at Ground Level: the Frontline Bureaucrat in the Age of Markets and Networks. Public Administration Review, 59(6).

Cooper, D., \& Schindler, P. (1998). Business Research Methods (6th ed.). Boston: Irwin McGraw Hill.

Council of Australian Governments (COAG). (2006). A new National Reform Agenda -. Canberra: Department of Prime Minister and Cabinet,.

Czaja, R., \& Blair, J. (1996). Designing Surveys: a Guide to Decisions and Procedures. Thousand Oaks, CA: Pine Forge Press.

Czarniawska, B., \& Sevon, G. (1996). Translating Organisational Change. Berlin: de Gruyter. 
de Lancer Julnes P, \& Holzer, M. (2001). Promoting the Utilisation of Performance Measures in Public Organisations: an Empirical Study of Factors Affecting Adoption. Public Administration Review, 61(6), 693-670.

Deal, T. E., \& Kennedy, A. A. (1982). Corporate Cultures: the Rites and Rituals of Corporate Life. Harmondsworth: Penguin Books.

Denhardt, R., \& Denhardt, J. (2000). The New Public Service: Serving Rather than Steering. Public Administration Review, 60(6), 549-559.

Dent, M., Chandler, J., \& Barry, J. (2004). Questioning the New Public Management. Aldershot: Ashgate Publishing Company.

Department of Human Services (Victoria). (2004). Risk Management Framework for the Department of Human Services. Melbourne: Department of Human Services (Victoria),.

Department of Human Services (Victoria). (2007a). Departmental Plan 2007-08. Melbourne: Department of Human Services (Victoria),.

Department of Human Services (Victoria). (2007b). Annual Report 2006-07. Melbourne: Department of Human Services (Victoria),.

Department of Treasury and Finance (Victoria). (2003). 2003-04 Victorian Budget, Budget Paper No. 3. Melbourne: Department of Treasury and Finance (Victoria),.

Di Francesco, M. (2001). Process Not Outcomes in New Public Management? Policy Coherence in Australian Government. The Drawing Board: An Australian Review of Public Administration, 1(3), 103-116.

Di Maggio, P., \& Powell, W. (1991). The Iron Cage Revisited: Institutional Isomorphism and Collective Rationality in Organisational Fields. American Sociological Review, 48, 113-123.

Downes, B. (1998). Recent Literature on Leading and Managing Change in Public Service Organisations. Social Science Journal, 35(4), 657-672.

Dunleavy, P., Margetts, H., Bastow, S., \& Tinkler, J. (2005). New Public Management is Dead - Long Live Digital-era Governance. Journal of Public Administration Research and Theory, 16(3), 467-494.

Edwards, M. (2002). Public Sector Governance - Future Issues for Australia. Australian Journal of Public Administration, 61(2), 51-61.

Eisenhardt, K. (1989). Building Theories From Case Study Research. Academy of Management Review, 14(4), 532-550.

Emery, M., \& Purser, R. (1996). The Search Conference. San Francisco: Jossey-Bass. 
Fontannaz, S., \& Oosthuizen, H. (2007). The Development of a Conceptual Framework to Guide Sustainable Organisational Performance. South African Journal of Business Management, 38(4), 9-19.

Fozzard, A. (2001). The Basic Budgeting Problem Approaches to Resource Allocation in the Public Sector and their Implications for Pro-Poor Budgeting. London: Overseas Development Institute.

Frumkin, P. (2003). Making Public Sector Mergers Work: Lessons Learned. Harvard University: IBM Center for the Business of Government Working Paper.

Garside, P. (1998). Organisational Context for Quality: Lessons from the Fields of Organisational Development and Change Management. Quality in health care, 7, s8-s15.

Gay, L., \& Diehl, P. (1992). Research Methods for Business and Management. New York: Macmillian Publishing.

Ghauri, P., Gronhaug, K., \& Kristianslund, I. (1995). Research Methods in Business Studies. New York: Prentice Hall.

Grasso, P., \& Sharkansky, I. (2001). The Auditing of Public Policy and the Politics of Auditing. Governance, 14(1), 1-21.

Greiner, E. (1974). Evolution and Revolution as Organizations Grow. Harvard Business Review, 50(4), 37-46.

Halligan, J. (2001). Political Management in the Australian States. Public Money and Management(April-June), 9-15.

Halligan, J. (2002). Public Sector Reform in Australia. In B. Ahn, J. Halligan \& S. Wilks (Eds.), Reforming Public and Corporate Governance: management and the market in Australia, Britain and Korea. Cheltenham: Edward Elgar Publishing Ltd.

Halligan, J. (2007). Accountability in Australia: Control, Paradox and Complexity. Public Administration Quarterly, 31(4), 453-479.

Hammond, K. (1996). Human Judgement and Social Policy: Irreducible Uncertainty, Inevitable Error, Unavoidable Justice. New York: Oxford University Press.

Hartley, J. (1994). Case Studies in Organisational Research. In C. Cassell \& G. Symon (Eds.), Qualitative methods in organisational research: a practical guide (pp. 208-229). London: Sage.

Hatch, M. J. (1997). Relations Between Organizational Culture, Identity and Image. European Journal of Marketing, 31(5/6), 356-365.

Hatcher, L. (1994). A Step-by-step Approach to Using the SAS System for Factor Analysis and Structural Equation Modeling. Cary, North Carolina: SAS Institute. 
Hennessy, J. (1998). Reinventing Government: Does Leadership Make a Difference? Public Administration Review, 58(6), 522-532.

Heydebrand, W. (1989). New organizational forms. Work and Occupations, 16(3), 323357.

Hoggett, P. (1996). New Modes of Control in the Public Service. Public Administration, 74(Spring), 9-32.

Hood, C. (1991). A Public Management for all Seasons? Public Administration, 69(1), 319.

Hughes, O. (2003). Public Management and Administration: An Introduction. Basingstoke: Palgrave Macmillian.

International Federation of Accountants. (2000). Corporate Governance in the Public Sector: A Governing Body Perspective. New York: International Federation of Accountants,.

Isaac-Henry, K., \& Painter, C. (1991). The Management Challenge in Local Government Emerging Themes and Trends. Local Government Studies, 17(3), 69-90.

James, W. (2005). The Impact of Corporatisation and National Competition Policy: An Exploratory Study of Organisational Change and Leadership Style. Leadership \& Organization Development Journal, 13(4), 289-309.

Jansen, J. (2004). From Persistence to Pursuit: A Longitudinal Examination of Momentum During the Early Stages of Strategic Change. Organization Science, 15(3), 275-294.

Jordan, A., Wurzel, R., \& Zito, A. (2005). The Rise of 'New' Policy Instruments in Comparative Perspective: Has Governance Eclipsed Government? Political Studies, 53(3), 477-496.

Kanter, R. (1993). The Change Masters. London: Allen and Unwin.

Kearnes, K. (1996). Managing for Accountability: Preserving the Public Trust in Public and Nonprofit Organizations. San Francisco: Jossey-Bass.

Kloot, L. (1999). Performance Measurement and Accountability in Victorian Local Government. International Journal of Public Sector Management, 12(7), 565-583.

Kotter, J. (1995). Leading Change: Why Transformation Efforts Fail. Harvard Business Review, 73(2), 59-67.

Kotter, J. (1996). Leading Change. Boston: Harvard University Press.

Laking, R., \& Norman, R. (2007). Imitation and Inspiration in Public Sector Reform: Lessons from Commonwealth Experiences. International Review of Administrative Sciences, 73(4), 517-530. 
Langan, J. (1979). Should Decisions be the the Product of Reason? In J. Haughey (Ed.), Personal Values in Public Policy: Essays and Conversations in Government Decision Making. New York: Paulist Press.

Lewin, K. (1947). Frontiers in Group Dynamics. In D. Cartwright (Ed.), Field Theory in Social Science. London: Social Science Paperbacks.

Lewin, K. (1951). Field Theory in Social Science. New York: Harper and Row.

Lindbloom. (1959). The science of muddling through. Public Administration Review, 19, 79-88.

Lindbloom, C. (1959). The Science of Muddling Through. Public Administration Review, 19, 79-88.

Manning, N. (2000). The New Public Management and its Legacy. Retrieved 16 August 2004, 2004, from www1.worldbank.org/publicsector/civilservice/debate1.htm

Maor, M. (1999). The Paradox of Managerialism. Public Administration Review, 59(1), 518.

McCann, W. (2001). Some Observations about the Profession of Public Service. Australian Journal of Public Administration, 60(2), 111.

McNish, M. (2002). Guidelines for Managing Change: A Case Study of their Effect on the Implementation of New Information Technology Projects in Organisations. Journal of Organisational Change Management, 2(3), 201-211.

Meyer, C. B., \& Stensaker, I. G. (2006). Developing Capacity for Change. Journal of Change Management, 6(2), 217-231.

Miles, M., \& Huberman, A. (1994). Qualitative Data Analysis: An Expanded Sourcebook (3rd ed.). Beverley Hills, CA: Sage.

Minogue, M., Polidano, C., \& D, H. (1998). Beyond the New Public Management: Changing Ideas and Practices in Governance. Cheltenham: Edward Elgar.

Mir, M., \& Rahaman, A. (2006). Leadership, Accounting and the Reform Process of a Public Sector Agency: A Narrative Analysis. Financial Accountability and Management, 22(2), 157-178.

Molinsky, A. (1999). Sanding Down the Edges: Paradoxical Impediments to Organisational Change. Journal of Applied Behavioural Science, 31(1), 8-24.

Moon, J. (1999). The Australian Public Sector and New Governance. Australian Journal of Public Administration, 58(2), 112-120.

Moran, T. (2004). Building a Culture of Innovation in the Public Sector. Paper presented at the IPAA Leadership Series, Brisbane. 
Muldoon, S. (2003). Excellent Managers: Exploring the Acquisition, Measurement, and Impact of Leader Skills in an Australian Business Context. Unpublished PhD thesis, Victoria University, Melbourne.

Mulgan, R. (2008). Public Sector Reform in New Zealand: Issues of Public Accountability. Public Administration Quarterly, 32(1), 1-32.

Municipal Association of Victoria. (2004). Good Governance Guide. Melbourne.

Murdoch, J., \& Abram, S. (1998). Defining the Limits of Community Governance. Journal of Rural Studies, 14(1), 41-50.

National Competition Council. (1998). Compendium of National Competition Policy Agreements. Canberra: Commonwealth of Australia.

Northumbria University. (2007). Change Management. Retrieved 1 May, 2007, from http://www.jiscinfonet.ac.uk/infokits/change-management

NSW Audit Office. (1998). On Board: Guide to Better Practice for Public Sector Governing and Advisory Boards. Sydney: Government of New South Wales.

Osborne, D., \& Gaebler, T. (1992). Reinventing Government: How the Enterpreneurial Spirit is Transforming the Public Sector. New York: Plume.

Osborne, D., \& Plastrik, P. (1997). Banishing Bureaucracy: The Five Strategies for Reinventing Government. Reading: Addison Wesley.

O'Toole, L. (1986). Policy Recommendations for Multi-actor Implementation: An Assessment from the Field. Journal of Public Policy, 6, 181-210.

Parker, R., \& Bradley, L. (2000). Organisational Culture in the Public Sector: Evidence from Six Organisations. International Journal of Public Sector Management, 13(2), 125141.

Pärna, O., \& von Tunzelmann, N. (2007). Innovation in the Public Sector: Key Features Influencing the Development and Implementation of Technologically Innovative Public Sector Services in the UK, Denmark, Finland and Estonia. The International Journal of Government and Democracy, 12(3), 109-125.

Perry, J., \& Rainey, H. (1988). The Public-Private Distinction in Organisational Theory: A Critique and Research Strategy. Academy of Management Review, 13(2), 182-201.

Pettigrew, A., Ferlie, E., \& et al. (1992). Shaping Strategic Change. London: Sage.

Pichault, F., \& Schoenaers, F. (2003). Managing Knowledge in Times of Organisational Change and Restructuring. Applied Psychology: An international review, 52(1), 120-143.

Pollitt, C. (1990). Managerialism and the Public Services: The Anglo-American Experience. Oxford: Blackwell. 
Pollitt, C. (2003). The Essential Public Manager. Maidenhead: Open University Press.

Post, J., \& Altman, B. (1994). Managing the Environmental Change Process: Barriers and Opportunities. Journal of Organisational Change Management, 7(4), 64-81.

Powell, W., \& Di Maggio, P. (1991). The New Institutionalism in Organisational Analysis. Chicago: University of Chicago Press.

Prasser, S. (2004). Poor Decisions, Compliant Management and Reactive Change: The Public Sector in 2003. Australian Journal of Public Administration, 63(1), 94-103.

Public Accounts and Estimates Committee. (2002). Issues Paper: Inquiry into Corporate Governance in the Victorian Public Sector. Melbourne: Parliament of Victoria.

Queensland Government. (2005). Building a Better Health Service for Queensland: An Action Plan. Brisbane: Queensland Health.

Rainey, H. (1983). Public Agencies and Private Firms: Incentives, Goals and Individual Roles. Administration and Society, 15(2), 207-242.

Rainey, H. (2003). Understanding and Managing Public Organisations (3rd Edition ed.). San Francisco: Jossey-Bass.

Ramage, P., \& Armstrong, A. (2005). Measuring success: Factors Impacting on the Implementation and Use of Performance Measurement within Victoria's Human Services Agencies. Evaluation Journal of Australasia, 5(2), 5-17.

Robbins, S., \& Barnwell, N. (2002). Organisational Theory. Frenchs Forest: Pearson Education Australia.

Robbins, S., Millett, B., Cacioppe, R., \& Waters-Marsh, T. (2001). Organisational Behaviour: Leading and Managing in Australia and New Zealand. Frenchs Forest: Pearson Education Australia.

Robertson, P., \& Seneviratne, S. (1995). Outcomes of planned organisational change in the public sector: a meta-analytical comparison to the private sector. Public Administration Review, 55(6), 547-558.

Rothwell, R. (1994). Successful Innovation: Critical Factors for the 1990s,. $R \& D$ Management, 22, 221-239.

Sarros, J., \& Butchatsky, O. (1996). Leadership. Sydney: Harper Business.

Schick, A. (1996). The Spirit of Reform: Managing the New Zealand Public Sector in a Time of Change. Wellington: State Services Commission.

Schien, E. (1984). Coming to a New Awareness of Organizational Culture. Sloan Management Review, Winter 1984, 3-16.

Schien, E. (2004). Organisational Culture and Leadership. San Francisco: Jossey-Bass. 
Scott, C. (2003). Speaking Softly Without Big Sticks: Meta-Regulation and Public Sector Audit. Law and Policy, 25(3), 203-219.

Sekaran, U. (2000). Business Research Methods: A Skill Building Approach. New York: John Wiley and Sons.

Sendt, B. (2001a). And if You Thought Good Governance Was Tough in the Private Sector, Take a Closer Look at Public Sector Issues. Keeping Good Companies, Oct 2001, 516-517.

Sendt, B. (2001b). Best Standards for Public Sector Governance. Paper presented at the Annual Companies Secretaries' Conference, Surfers' Paradise.

Singleton, R. (1993). Approaches to Social Research. New York: Oxford University Press.

Slappendel, C. (1996). Perspectives on Innovation in Organisations. Organisation Studies, 17(1), 107-129.

Standards Australia. (2004a). Applications of Corporate Governance HB 401-2004. Sydney: Standards Australia.

Standards Australia. (2004b). Introduction to Corporate Governance HB 400-2004. Sydney: Standards Australia.

Stewart, J., \& Kringas, P. (2003). Change Management - Strategy and Values in Six Agencies from the Australian Public Service. Public Administration Review, 63(6), 675688.

Stickland, E. (1998). The dynamics of change: insights into organisational transformation from the natural world. London: Routledge.

Strauss, A. (1987). Qualitative Anaylsis for Social Scientists. Cambridge: Cambridge University Press.

Strickland, E. (1998). The Dynamics of Change: Insights into Organisational Transformation From the Natural World. London: Routledge.

Stubbard, C., \& Ramaprasad, A. (1990). Comments on the Empirical Articles and Recommendations for Future Research. In A. Huff (Ed.), Mapping Strategic Thought. Chichester: Wiley.

Teicher, J., \& Van Gramberg, B. (1998). Industrial Relations and Public Sector Reform: the Victorian Case. Australian Journal of Public Administration, 57(2), 60-67.

The Age. (2005). Qld Health Minister Nuttall Resigns. Retrieved 14 May 2007, 2005, from http://www.theage.com.au/news/National/Qld-health-minister-Nuttallquits/2005/07/22/1121539132175.html

Ticehurst, G., \& Veal, A. (2000). Business Research Methods: A Managerial Approach. Frenchs Forest: Pearson Education. 
Tichy, N. (1983). Managing Strategic Change. Detroit: Wiley and Sons.

Trader-Leigh, K. (2002). Case Study: Identifying Resistance in Managing Change. Journal of Organisational Change Management, 15(2), 138-155.

Tsoukas, H. (2005). Afterwords - Why Language Matters in the Analysis of Organisational Change. Journal of Organisational Change Management, 18(1), 96-104.

Turner, B. (1986). Sociological Aspects of Organisational Symbolism. Organisation Studies, 7(2), 101-115.

Uhrig, J. (2003). Review of Corporate Governance of Statutory Authorities and Office Holders. Canberra: Commonwealth of Australia.

Unpublished - Department of Human Services. (2001a). Email communication to DHS staff: Message from Secretary - News on Organisational Structure. In DHS staff (Ed.): Department of Human Services.

Unpublished - Department of Human Services. (2001b). Email communication to DHS staff: Message from the Secretary - Flagship Projects. In DHS staff (Ed.). Melbourne.

Unpublished - Department of Human Services. (2005a). Email communication to DHS staff: Message from the Secretary - DHS Budget Savings. In DHS staff (Ed.). Melbourne.

Unpublished - Department of Human Services. (2005b). Email communication to DHS staff: Message from the Secretary - Creating an Office for Children. In DHS staff (Ed.). Melbourne.

Unpublished - Department of Human Services. (2007a). DHS Dimensions. Melbourne: Department of Human Services.

Unpublished - Department of Human Services. (2007b). Occupational Climate Index. Melbourne: Department of Human Services,.

Waldham, D., Bass, B., \& Yammarino, F. (1990). Adding to Contingent Reward Behaviour: The Augmenting Effect of Charasmatic Leadership. Group and Organisation Studies, 15(4), 381-394.

Weisbord, M., \& Janoff, S. (1995). Future Search. San Francisco: Barret-Koehler.

White, L. (2000). Changing the 'whole system' in the public sector. Journal of Organisational Change Management, 13(2), 162-177.

Wren, D. (2005). History of Management Thought. New York: Wiley.

Yin, R. (2003). Case Study Research: Design and Methods. Thousand Oaks: Sage Publications Ltd.

Zucker, L. (1983). Organisations as Institutions. In S. Bacharach (Ed.), Research in Sociology of Organisations (pp. 1-47). Greenwich: JAI Press. 


\section{Appendices}


Appendix 1: Human Research Ethics Approval 
TO

Prof Anona Armstrong

DATE

$20,07 / 2007$

Centre for International Corporate Govemance

Research

City Flinders Campus

FROM Professor Michael Polonsky

AvChair

Faculty of Business and Law Human Research Ethics

Committee

SUBJECT Ethics Application - HRETH 07/147

Dear Prof Armstrong

Thank you for submitting this application for ethical approval of the project:

HRETH 07/147 Factors impacting on the adoption and operation of corporate governance reform in Australan state govemment. (BHREC 07/34)

The proposed research project has been accepted by the Human Research Ethics Committee, Faculty of Business and Law. Approval for this application has been granted from 19 July 2007 to 31 December 2009 .

Please note that the Human Research Ethics Committee, Faculy of Business and Law, must be informed of the following: any changes to the approved research protocol, project timelines, any serious or unexpected adverse effects on participarts, and unforeseen events that may effect continued ethical acceptability of the project. In these unlikely evertis, researchers must immediately cease all data collection until the Committee has approved the changes.

Continued approval of this research project by the Human Research Ethics Committee, Faculty of Business and Law is conditional upon the provision of a report within 12 months of the above approval date (by 19 July 2008) or upon the completion of the project (if earlier). A report proforma may be downloaded from the VUHREC web site at hitpoliresearch.vu edu. aw hrec.pho

If you have any queries, please do not hesitate to contact me on 99194625.

On behalf of the Committee, I wish you all the best for the conduct of the project.

Professor Michael Polonsky

AlChair

Faculy of Business and Law Human Research Ethics Committee 
"Tina.Jeggo"

<tina.jeggo@vu.edu.au>

11/04/2006 04:00 PM
ToPaul.Ramage@dhs.vic.gov.au

cc Anona Armstrong <anona.armstrong@vu.edu.au>

Subjec Re: Ethics Committee Meeting March 2006

$\mathrm{t}$

\section{VICTORIA}

UNIVERSITY

Dear Paul,

The Chair has confirmed that the application is fine for the interview phase of the project and has also requested that the following sentence (our standard 'Ethics' statement) be incorporated into the plain Language Statement/Information Sheet.

'If you have any queries or complaints about the way you have been treated, you may contact the Secretary, University Human Research Ethics Committee, Victoria University, PO Box 14428, Melbourne 8001 (Tel: 039919 4710)'.

We look forward to receiving the information for the focus group and survey in due course.

Good luck with your data collection.

Regards,

Tina 
Appendix 2: plain language statement for research participants 
Factors impacting on the adoption and operation of corporate governance reform in Australian state government departments

A plain language statement for participants 
You are invited to participate in a research project seeking to document factors impacting on corporate governance reform in Australian state government departments.

We would like to know what factors have impacted on the adoption and operation of corporate governance reform in your organisation.

\section{What is 'corporate governance reform'?}

Corporate governance reform is essentially concerned with changes to the structures and processes for decision-making, accountability, control and behaviour at the top of organisations.

Much research has been conducted into identifying what corporate governance changes have occurred in public sector organisations over the past 10-20 years. Little attention has, however, been given to the way reform decisions have been taken, or how these decisions have been implemented and operated. Consequently, little is known about how corporate governance change is affected by environmental, organisational or other issues.

\section{What will I have to do?}

If you decide to participate, you should complete and return the attached consent form.

An interview time will then be arranged. It is expected that your interview will take no longer than 30 minutes.

\section{What will I gain from participating?}

The information and advice you give will assist the understanding of the practical issues involved in adopting and then implementing corporate governance reform in Australian state government departments.

The methods, procedures and experiences of your organisation will help advance the understanding of corporate governance reform in public sector organisations. Greater understanding will help give recognition to issues involved in adopting and operating reform.

It is also intended that the information you provide will assist the development of a framework to guide future corporate governance reform initiatives.

\section{How will the information I give be used?}

The information you provide is to be used to identify how state government departments decide to adopt and then operate corporate governance changes. 
Information from your organisation, together with that from other state government departments in Australia, will form part of the final report of the project.

Individual responses will be aggregated so that the report will not identify the names of people providing information to the researchers.

\section{The project in more detail}

The major aim of the project is to identify and describe variables associated with corporate governance reform in Australian state government departments, particularly the factors that impact on the adoption and operation of corporate governance change.

The study aims to:

- identify why particular arrangements and processes are used to adopt and operate corporate governance reforms, including the identification of internal and external reform influences;

- explore the nature of internal and external influences and the impact these have on reform;

- categorise influencing factors according to their characteristics;

- demonstrate the applicability of this categorisation to public sector corporate governance reform in Australian state government departments.

\section{How will this project be conducted?}

The data for the study will be collected in two stages.

The first stage is a case study focused on the Victorian Department of Human Services.

The second stage will involve the collection of data through a survey of all state government departments in Australia.

You are being asked to participate in first stage of the study.

Additional information will also be used and will include publicly available information, such as business plans, annual reports and other documentation prepared during or after the implementation of corporate governance reform.

If you have any queries or complaints about the way you have been treated, you may contact the Secretary, University Human Research Ethics Committee, Victoria University, PO Box 14428, Melbourne 8001 (Tel: 03 9919 4710) 
The study is being undertaken by Victoria University's Centre for International Corporate Governance Research (CICGR). CICGR aims to improve the governance of the private and public sectors through the use of independent academic research and consultancies. You can access more information about CICGR at www.business.vu.edu.au/cicgr.

The principal investigator for the study is Professor Anona Armstrong. Professor Armstrong is the Director of CICGR.

The student investigator for the study is Paul Ramage. Paul is currently undertaking his PhD and is a CICGR research associate. Paul works in the Financial and Corporate Services Division of the Department of Human Services. 
Appendix 3: Phase one interview schedule 
Semi-structured interview schedule

Phase One- Department of Human Services

Factors impacting on the adoption and operation of corporate governance reform in Australian State Government Departments

Interview number:

Interview date:

Time:

Gender:

Age:

Position:

Education:

Interview preamble:

This interview is the first part of doctoral research that explores the factors impacting on the adoption and operation of corporate governance reform in Australian State Government Departments.

This interview relates to concepts and issues associated with corporate governance reform in the Department of Human Services.

I am seeking your involvement in this interview to deepen and broaden the level of understanding about corporate governance change in public sector organisations.

You have been invited to participate in this study based on your involvement in key corporate governance reforms implemented in this department.

All responses to this interview are absolutely confidential and results will be presented in an anonymous form.

With your permission, I would like to record the interview to ensure that I don't miss any important points.

Do you have any questions before we commence? 
Question 1

What do you consider have been the key drivers

of corporate governance reform in the

department over the past 5-10 years?

1. Externally imposed requirement for improved (or changed) accountability

2. Internally-led endeavours to improve decision making

3. Poor performance

4. Productivity requirements

5. Other

\section{Question 2}

What impact, if any, do you consider the

following had on reform adoption in DHS

1. Availability of resources

2. Corporate governance knowledge and skills

3. Decision making processes

4. Influence of interest groups

5. Competing organisational priorities

6. Other (please specify)

\section{Question 3}

What impact, if any, do you consider the

following had on reform operation in DHS?

1. Attributes of reform

2. Availability of resources

3. Corporate governance knowledge and skills

4. Change management knowledge and skills

5. Organisational control processes

6. Other (please specify)

\begin{tabular}{|l|l|}
\hline Question 4 & Notes \\
\hline 1. & How would you describe the culture of \\
& DHS?
\end{tabular}

Question 5

What role do you think DHS communication 
processes play in the implementation of corporate governance change?

\begin{tabular}{|l|l|}
\hline Question 6 & Notes \\
\hline Can you think of a sound/feasible corporate & \\
governance reform that was not able to be & \\
implemented? What was the reason for the & \\
implementation failure? & \\
- Low Organisational support level & \\
- Poor implementation plan & \\
- Insufficient resourcing & \\
- Onforeseen consequences & \\
\hline
\end{tabular}

\begin{tabular}{l|l|}
\hline Question 7 & Notes \\
\hline $\begin{array}{l}\text { Do you think the department readily accepts } \\
\text { changes to its corporate governance }\end{array}$ & \\
arrangements? & \\
\end{tabular}

\begin{tabular}{|l|l|}
\hline Question 8 & Notes \\
\hline What has your role been in adopting and & \\
implementing corporate governance reform? & \\
1. Instigator & \\
2. Participant & \\
3. Observer & \\
What did you do? & \\
\hline
\end{tabular}

\begin{tabular}{|l|l|}
\hline Question 9 & Notes \\
\hline Have you had to build support for corporate & \\
governance reform? & \\
1. Support amongst your peers & \\
2. Support from subordinates & \\
3. Support from superiors & \\
How did you go about this? & \\
\hline
\end{tabular}

\begin{tabular}{|l|l|}
\hline Question 10 & Notes \\
\hline $\begin{array}{l}\text { In what way do you think that the ability of the } \\
\text { department to identify, adopt and implement } \\
\text { corporate governance changes is improving? }\end{array}$ & \\
\hline
\end{tabular}

Thank you. 
Appendix 4: Emails to phase two participants 
To: [Email]

From: Paul.Ramage@research.vu.edu.au

\section{Subject: PhD research project - public sector corporate governance reform}

You are invited to participate in a research project that aims to document factors impacting on corporate governance reform in Australian state government departments. The research is being conducted as a PhD project with the Centre for International Corporate Governance Research at Victoria University.

We would like to know what factors have impacted on the adoption and operation of corporate governance reform in your organisation.

Please complete the survey by clicking on this link before Wednesday, 28 November 2007 . It should take you no more than 10 minutes to complete.

(http: $x x x x$ )

The information you provide will be treated as confidential. Neither your name or the name of your organisation will be disclosed; results will be aggregated and only presented by organisational attributes, such as number of employees.

By participating in this survey you will help improve the understanding of how corporate governance reform is adopted and implemented in Australian state government departments. You can find out more about the project by clicking here to read a plain language statement about the research:

www. businessandlaw.vu.edu.au/cicgr/corporate_governance_ reform_project/Plain_language_statement_for_participants.p df

For further information, please contact: 
Paul Ramage

Research Associate

Centre for International Corporate Governance Research

Victoria University

Melbourne Victoria 3000

Telephone: 0390968551

Email: Paul.Ramage@dhs.vic.gov.au

Professor Anona Armstrong

Director

Centre for International Corporate Governance Research

Victoria University

300 Flinders Street

Melbourne Victoria 3000

Telephone: 0399191315

Email: Anona.Armstong@vu.edu.au

www. businessandlaw.vu.edu.au/cicgr/

Please note: This email has been sent to you because of your experience in managing state government organisations. If you do not wish to receive further emails about the survey, please click the link below, and you will be automatically removed from the research project's mailing list.

http://www. surveymonkey.com/optout.aspx 
To: [Email]

From: paul.ramage@research.vu.edu.au

\section{Subject: PhD research project - public sector corporate governance reform (reminder)}

Responses to the survey about factors impacting on the adoption and operation of corporate governance reform in Australian state government departments are now due.

Please take the opportunity to provide your perspective on public sector corporate governance reform. It will be used to build an improved understanding of how to adopt and operate corporate governance reform in organisations such as yours.

Click on this link to complete the survey:

(http: $x x x x x$ )

Responses are confidential and neither your name or the name of your organisation will be disclosed. If you would like more information about the research project, cut and paste this link into your web browser.

www.businessandlaw.vu.edu.au/cicgr/corporate_governance reform_project/Plain_language_statement_for_participants.p df

Regards

Paul Ramage

Centre for International Corporate Governance Research Victoria University, Melbourne

If you do not want to receive further emails about this research, click here to opt out of the project's mailing list: http: //www. surveymonkey.com/optout.aspx 
Appendix 5: Phase two survey instrument 
Corporate governance reform in Australian state government departments

\section{General information}

Please tell us some background information about yourself and your organisation.

1. What is your position in the organisation?

Chief Executive

Osenior Executive

Manager

\section{What is your gender?}

Male

Female

3. How many staff work in your organisation?

$\bigcirc_{101-200}^{<100}$

$\bigcap_{>500}^{201-500}$

4. What is the annual budget of your organisation?

$\begin{cases}<\$ 100 m & \\ \$ 101-500 m & \$ 501-1,000 m \\ >\$ 1,000 m\end{cases}$

5. How many sites does your organisation operate from?

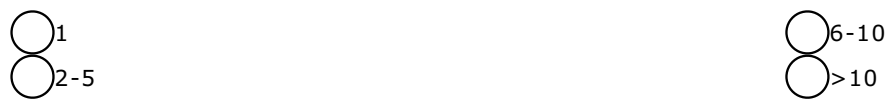

6. What is the organisational structure of your organisation?

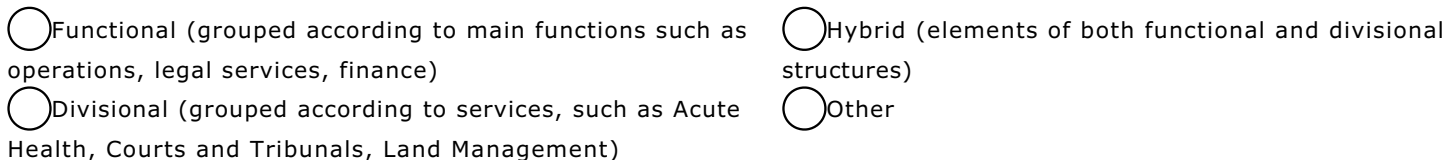

Health, Courts and Tribunals, Land Management)

\section{What functions are performed by your organisation?}

Service delivery

$\square$ Service purchasing

$\square$ Regulation

Policy development

Other

\section{What types of services are provided by your organisation?}
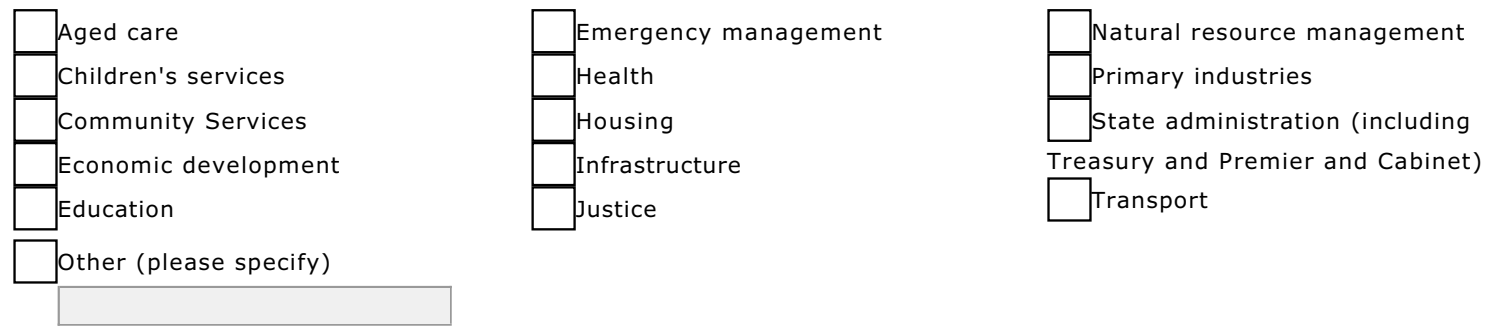

9. In what state is your organisation located?
Victoria
New South Wales

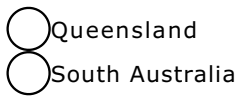
Western Australia
Tasmania

\section{Adoption of governance reform}

Please tell us about the adoption of governance reform in your organisation. Governance reform is essentially concerned with changes to the structures and processes for decision-making, accountability, control and behaviour at the top of organisations. 


\section{Please identify the most appropriate response to each factor.}

\begin{tabular}{|c|c|c|c|c|c|}
\hline & $\begin{array}{l}\text { Strongly } \\
\text { disagree }\end{array}$ & Disagree & $\begin{array}{l}\text { Neither agree } \\
\text { or disagree }\end{array}$ & Agree & $\begin{array}{l}\text { Strongly } \\
\text { agree }\end{array}$ \\
\hline \multicolumn{6}{|l|}{$\begin{array}{l}\text { xternally-led drives to improve accountability } \\
\text { as an impact on the adoption of reform }\end{array}$} \\
\hline \multicolumn{6}{|l|}{$\begin{array}{l}\text { xternally-led drives to improve efficiency has an } \\
\text { mpact on the adoption of reform }\end{array}$} \\
\hline \multicolumn{6}{|l|}{$\begin{array}{l}\text { he requirement to implement new government } \\
\text { olicy has an impact on the adoption of reform }\end{array}$} \\
\hline \multicolumn{6}{|l|}{$\begin{array}{l}\text { he requirement to comply with regulatory } \\
\text { equirements has an impact on the adoption of } \\
\text { eform }\end{array}$} \\
\hline \multicolumn{6}{|l|}{$\begin{array}{l}\text { nternally-led drives to improve decision making } \\
\text { as an impact on the adoption of reform }\end{array}$} \\
\hline \multicolumn{6}{|l|}{$\begin{array}{l}\text { nternally-led drives to improve service } \\
\text { oordination has an impact on the adoption of } \\
\text { orporate governance reform }\end{array}$} \\
\hline \multicolumn{6}{|l|}{$\begin{array}{l}\text { he level of knowledge and skills in the } \\
\text { rganisation has an impact on the adoption of } \\
\text { eform }\end{array}$} \\
\hline \multicolumn{6}{|l|}{$\begin{array}{l}\text { he processes the organisation uses to make } \\
\text { ecisions has an impact on the adoption of } \\
\text { eform }\end{array}$} \\
\hline \multicolumn{6}{|l|}{$\begin{array}{l}\text { he influence of external groups (such as the } \\
\text { uditor General) has an impact on the adoption } \\
\text { f corporate governance reform }\end{array}$} \\
\hline \multicolumn{6}{|l|}{$\begin{array}{l}\text { he influence of internal groups has an impact } \\
n \text { the adoption of corporate governance reform }\end{array}$} \\
\hline \multicolumn{6}{|l|}{$\begin{array}{l}\text { he adoption of corporate governance reform is } \\
\text { ubject to competition from other organisational } \\
\text { riorities }\end{array}$} \\
\hline \multicolumn{6}{|l|}{$\begin{array}{l}\text { he effect of governance changes on power and } \\
\text { istitutional relationships affects the adoption of } \\
\text { orporate governance reform }\end{array}$} \\
\hline \multicolumn{6}{|l|}{$\begin{array}{l}\text { eadership shown by the organisation's chief } \\
\text { xecutive has an impact on the adoption of } \\
\text { orporate governance reform }\end{array}$} \\
\hline \multicolumn{6}{|l|}{$\begin{array}{l}\text { eadership shown by senior managers has an } \\
\text { mpact on the adoption of corporate governance } \\
\text { eform }\end{array}$} \\
\hline $\begin{array}{l}\text { osts associated with implementing change has } \\
\text { impact on the adoption of corporate } \\
\text { overnance reform }\end{array}$ & & & & & \\
\hline
\end{tabular}

2. Are there any other factors that have impacted on the adoption of corporate governance reform in your organisation? If so, please tell us what they were. 


\section{What are the five (5) most important factors that have impacted on the} adoption of governance reform in your organisation?

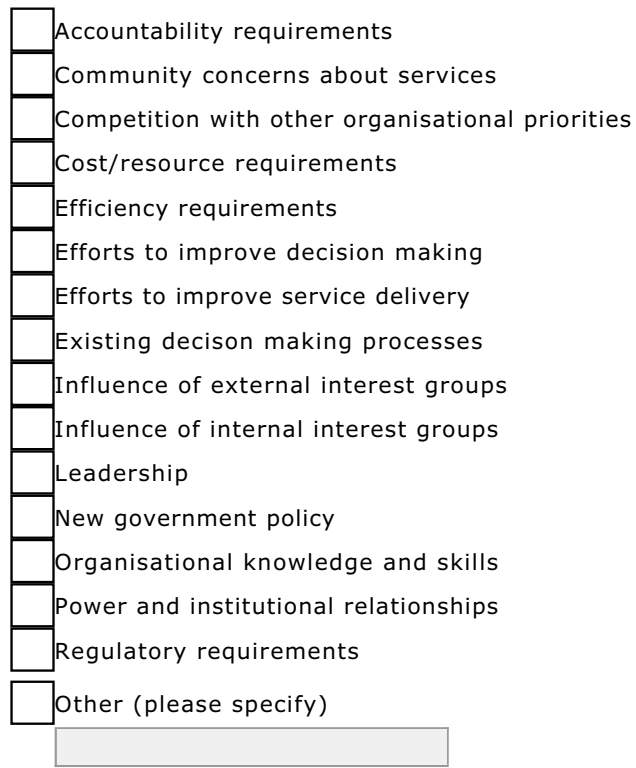

\section{Operation of governance reform}

Please tell us about the factors that have impacted on how corporate governance reform is operated in your organisation.

\section{Please identify the most appropriate response to each factor.}

\begin{tabular}{|c|c|c|c|c|}
\hline & $\begin{array}{l}\text { Strongly } \\
\text { disagree }\end{array}$ & Disagree & $\begin{array}{l}\text { Neither agree } \\
\text { or disagree }\end{array}$ & Agree \\
\hline \multicolumn{5}{|l|}{$\begin{array}{l}\text { The time available to implement change has an } \\
\text { impact on reform operation }\end{array}$} \\
\hline \multicolumn{5}{|l|}{$\begin{array}{l}\text { The availability of resources has an impact on } \\
\text { reform operation }\end{array}$} \\
\hline \multicolumn{5}{|l|}{$\begin{array}{l}\text { Leadership shown by the organisation's chief } \\
\text { executive officer has an impact on reform } \\
\text { operation }\end{array}$} \\
\hline \multicolumn{5}{|l|}{$\begin{array}{l}\text { Leadership shown by senior managers has an } \\
\text { impact on reform operation }\end{array}$} \\
\hline \multicolumn{5}{|l|}{$\begin{array}{l}\text { Continuity of leadership from the adoption stage } \\
\text { has an impact on reform operation }\end{array}$} \\
\hline \multicolumn{5}{|l|}{$\begin{array}{l}\text { The scale and scope of reform has an impact on } \\
\text { reform operation }\end{array}$} \\
\hline \multicolumn{5}{|l|}{$\begin{array}{l}\text { Organisational knowledge, including those } \\
\text { related to governance, change management and } \\
\text { innovation, impact on reform operation }\end{array}$} \\
\hline \multicolumn{5}{|l|}{$\begin{array}{l}\text { Communication and information sharing } \\
\text { processes have an impact on reform operation }\end{array}$} \\
\hline $\begin{array}{l}\text { Organisational control processes have an impact } \\
\text { on reform operation }\end{array}$ & & & & \\
\hline
\end{tabular}

reform operation

Manager's fear of losing control has an impact

on reform operation

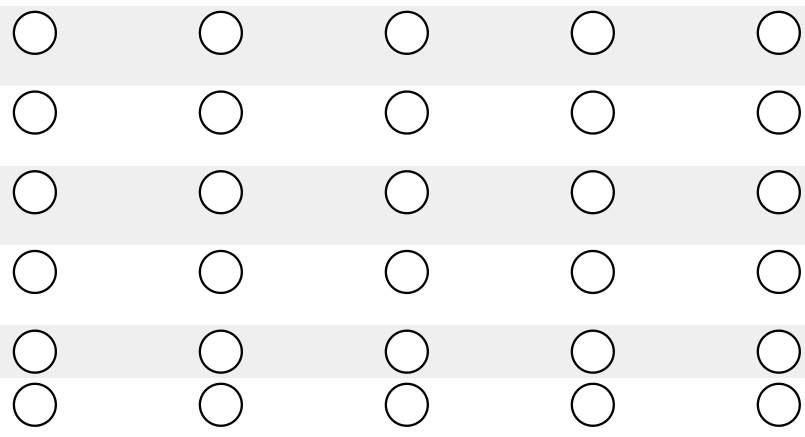

The number of actors in the change process has an impact on reform operations

Organisational attributes, such as workforce size and profile, has an impact on reform operation

The hierarchical nature of public sector

organisations has an impact on reform operation Your organisation encourages innovation

Your organisation easily accepts organisational change 
The operation of corporate governance reform in

your organisation is usually successful
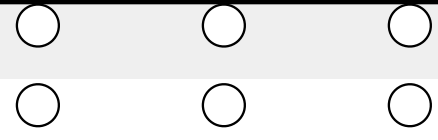

Change fatigue has an impact on governance

reform in our organisation

2. Are there any other factors that have impacted on the operation of governance reform in your organisation? If so, please tell us what they were.

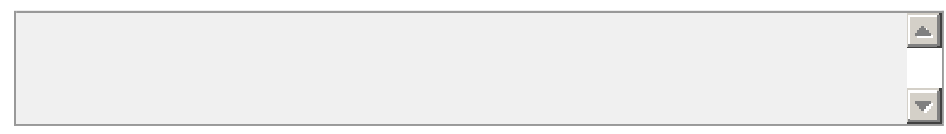

3. Please identify the five most important factors that have impacted on the adoption of governance reform in your organisation

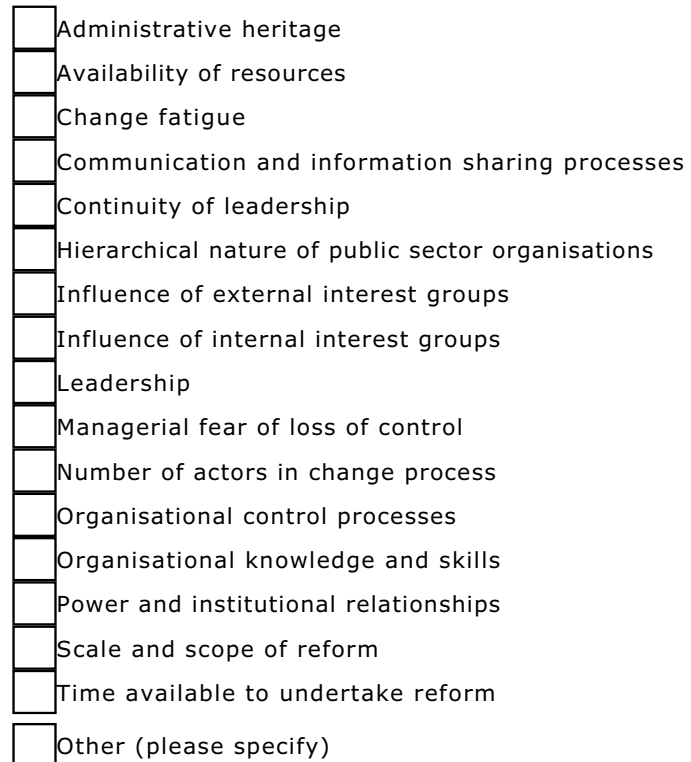

\section{Other information}

Please tell us any other information that you think is important about governance reform in your organisation.

1. Is there anything else that you would like to tell us about the adoption of governance reform in your organisation?

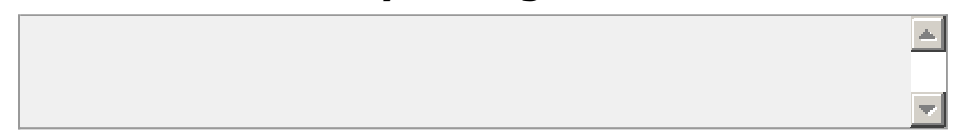

2. Is there anything else that you would like to tell us about the operation of governance reform in your organisation?

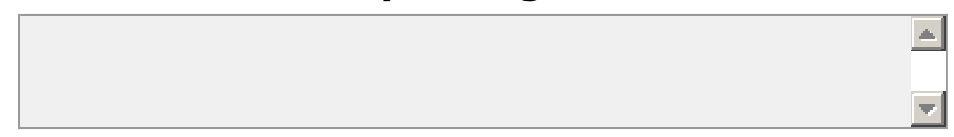


Corporate governance reform in Australian state government departments

3. What has corporate governance change in your organisation primarily focused on?

Internal decision making and control processes

Relationships with external organisations that your agency funds or works closely with

Other (please specify)

4. Have you received any training related to reforming corporate governance? OYes<smiles>[O]</smiles>

5. Have you any suggestions for future governance reforms in your organisation? 
Appendix 6: Descriptive statistics 


\section{Appendix - Descriptive statistics}

\section{Cross tabulations}

Table 1: Cross tabulation of adoption reform success and implementation of new government policy

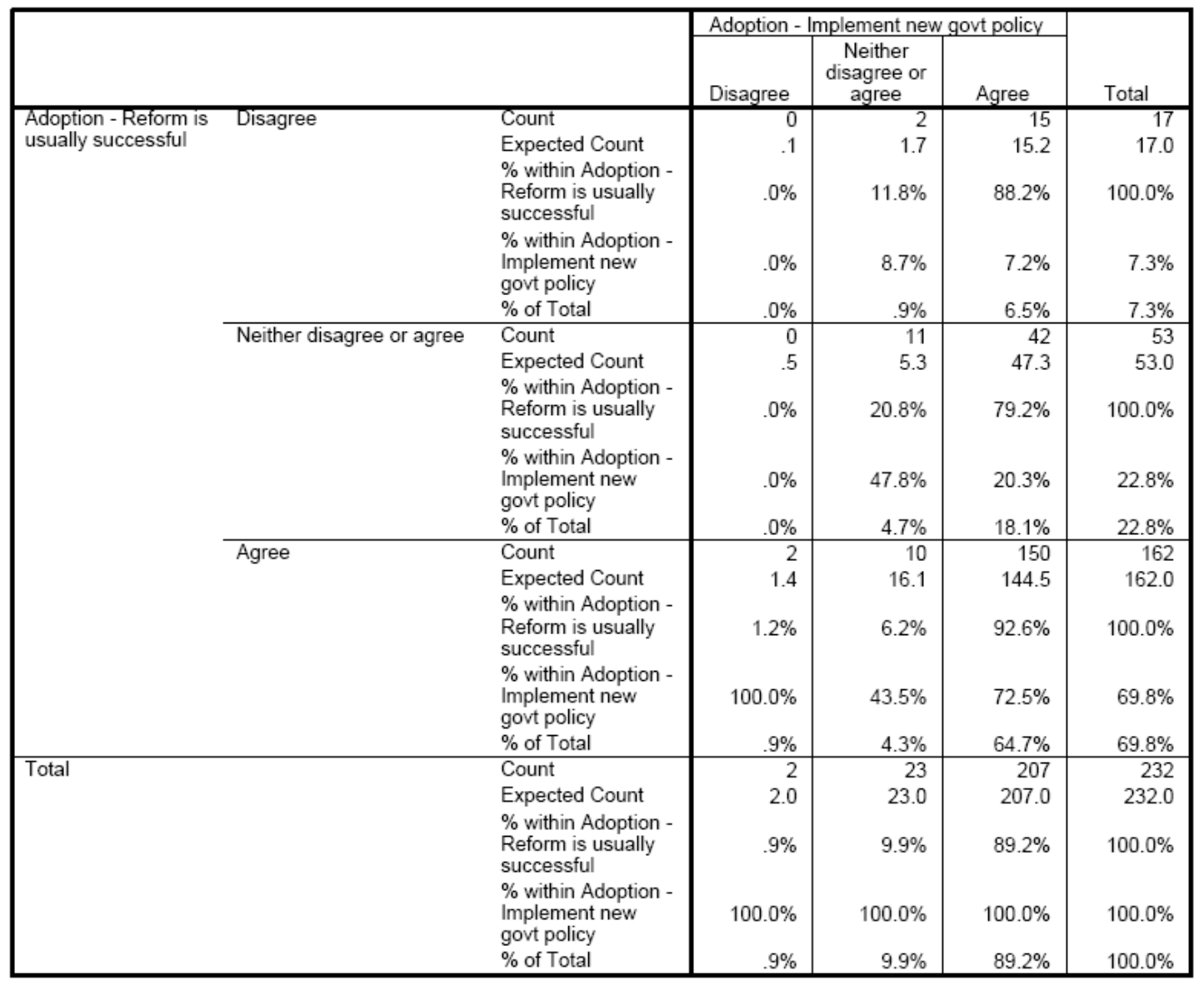

Table 2: Chi-Square test - adoption reform success and implementation of new government policy

\begin{tabular}{|l|r|r|r|}
\hline & \multicolumn{1}{|c|}{ Value } & df & \multicolumn{1}{c|}{$\begin{array}{c}\text { Asymp. Sig. } \\
\text { (2-sided) }\end{array}$} \\
\hline Pearson Chi-Square & $10.292^{3}$ & 4 & .036 \\
Likelihood Ratio & 9.721 & 4 & .045 \\
Linear-by-Linear & 2.230 & 1 & .135 \\
Association & 232 & & \\
N of Valid Cases & & 135 \\
\hline
\end{tabular}

a. 4 cells $(44.4 \%)$ have expected count less than 5 . The minimum expected count is 15 . 
Table 3: Cross tabulation of adoption reform success and internal drive to improve service coordination

\begin{tabular}{|c|c|c|c|c|c|c|}
\hline & & & \multicolumn{3}{|c|}{$\begin{array}{l}\text { Adoption - Internal drive to improve } \\
\text { service coordination }\end{array}$} & \multirow[b]{2}{*}{ Total } \\
\hline & & & Disagree & $\begin{array}{l}\text { Neither } \\
\text { disagree or } \\
\text { agree }\end{array}$ & Agree & \\
\hline \multirow{15}{*}{$\begin{array}{l}\text { Adoption - Reform is } \\
\text { usually successful }\end{array}$} & \multirow[t]{5}{*}{ Disagree } & Count & 6 & 2 & 9 & 17 \\
\hline & & Expected Count & 1.0 & 1.9 & 14.1 & 17.0 \\
\hline & & $\begin{array}{l}\text { \% within Adoption - } \\
\text { Reform is usually } \\
\text { successful }\end{array}$ & $35.3 \%$ & $11.8 \%$ & $52.9 \%$ & $100.0 \%$ \\
\hline & & $\begin{array}{l}\% \text { within Adoption - } \\
\text { Internal drive to improve } \\
\text { service coordination }\end{array}$ & $42.9 \%$ & $7.7 \%$ & $4.7 \%$ & $7.3 \%$ \\
\hline & & $\%$ of Total & $2.6 \%$ & $.9 \%$ & $3.9 \%$ & $7.3 \%$ \\
\hline & \multirow[t]{5}{*}{ Neither disagree or agree } & Count & 3 & 7 & 43 & 53 \\
\hline & & Expected Count & 3.2 & 5.9 & 43.9 & 53.0 \\
\hline & & $\begin{array}{l}\text { \% within Adoption - } \\
\text { Reform is usually } \\
\text { successful }\end{array}$ & $5.7 \%$ & $13.2 \%$ & $81.1 \%$ & $100.0 \%$ \\
\hline & & $\begin{array}{l}\% \text { within Adoption - } \\
\text { Internal drive to improve } \\
\text { service coordination }\end{array}$ & $21.4 \%$ & $26.9 \%$ & $22.4 \%$ & $22.8 \%$ \\
\hline & & $\%$ of Total & $1.3 \%$ & $3.0 \%$ & $18.5 \%$ & $22.8 \%$ \\
\hline & \multirow[t]{5}{*}{ Agree } & Count & 5 & 17 & 140 & 162 \\
\hline & & Expected Count & 9.8 & 18.2 & 134.1 & 162.0 \\
\hline & & $\begin{array}{l}\text { \% within Adoption - } \\
\text { Reform is usually } \\
\text { successful }\end{array}$ & $3.1 \%$ & $10.5 \%$ & $86.4 \%$ & $100.0 \%$ \\
\hline & & $\begin{array}{l}\% \text { within Adoption - } \\
\text { Internal drive to improve } \\
\text { service coordination }\end{array}$ & $35.7 \%$ & $65.4 \%$ & $72.9 \%$ & $69.8 \%$ \\
\hline & & $\%$ of Total & $2.2 \%$ & $7.3 \%$ & $60.3 \%$ & $69.8 \%$ \\
\hline \multirow{5}{*}{\multicolumn{2}{|c|}{ Total }} & Count & 14 & 26 & 192 & 232 \\
\hline & & Expected Count & 14.0 & 26.0 & 192.0 & 232.0 \\
\hline & & $\begin{array}{l}\text { \% within Adoption - } \\
\text { Reform is usually } \\
\text { successful }\end{array}$ & $6.0 \%$ & $11.2 \%$ & $82.8 \%$ & $100.0 \%$ \\
\hline & & $\begin{array}{l}\% \text { within Adoption - } \\
\text { Internal drive to improve } \\
\text { service coordination }\end{array}$ & $100.0 \%$ & $100.0 \%$ & $100.0 \%$ & $100.0 \%$ \\
\hline & & $\%$ of Total & $6.0 \%$ & $11.2 \%$ & $82.8 \%$ & $100.0 \%$ \\
\hline
\end{tabular}

Table 4: Chi-Square test - adoption reform success and internal drive to improve service coordination

\begin{tabular}{|l|c|r|r|}
\hline & Value & df & \multicolumn{1}{|c|}{$\begin{array}{c}\text { Asymp. Sig. } \\
\text { (2-sided) }\end{array}$} \\
\hline Pearson Chi-Square & $28.837^{\mathrm{a}}$ & 4 & .000 \\
Likelihood Ratio & 16.737 & 4 & .002 \\
Linear-by-Linear & 16.209 & 1 & .000 \\
Association & 232 & & \\
N of Valid Cases & & \\
\hline
\end{tabular}

a. 3 cells $(33.3 \%)$ have expected count less than 5 . The minimum expected count is 1.03 . 
Table 5: Cross tabulation of adoption reform success and influence of internal groups

\begin{tabular}{|c|c|c|c|c|c|c|}
\hline & & & Adoption - & fluence of int & al groups & \\
\hline & & & Disagree & $\begin{array}{l}\text { Neither } \\
\text { disagree or } \\
\text { agree }\end{array}$ & Agree & Total \\
\hline Adoption - Reform is & Disagree & Count & 8 & 2 & 7 & 17 \\
\hline & & Expected Count & 1.8 & 3.8 & 11.4 & 17.0 \\
\hline & & $\begin{array}{l}\% \text { within Adoption - } \\
\text { Reform is usually } \\
\text { successful }\end{array}$ & $47.1 \%$ & $11.8 \%$ & $41.2 \%$ & $100.0 \%$ \\
\hline & & $\begin{array}{l}\text { \% within Adoption - } \\
\text { Influence of } \\
\text { internal groups }\end{array}$ & $32.0 \%$ & $3.8 \%$ & $4.5 \%$ & $7.3 \%$ \\
\hline & & $\%$ of Total & $3.4 \%$ & $.9 \%$ & $3.0 \%$ & $7.3 \%$ \\
\hline & Neither disagree or agree & Count & 3 & 18 & 32 & 53 \\
\hline & & $\begin{array}{l}\text { Expected Count } \\
\% \text { within Adoption - }\end{array}$ & 5.7 & 11.9 & 35.4 & 53.0 \\
\hline & & $\begin{array}{l}\text { Reform is usually } \\
\text { successful }\end{array}$ & $5.7 \%$ & $34.0 \%$ & $60.4 \%$ & $100.0 \%$ \\
\hline & & $\begin{array}{l}\text { \% within Adoption - } \\
\text { Influence of } \\
\text { internal groups }\end{array}$ & $12.0 \%$ & $34.6 \%$ & $20.6 \%$ & $22.8 \%$ \\
\hline & & $\%$ of Total & $1.3 \%$ & $7.8 \%$ & $13.8 \%$ & $22.8 \%$ \\
\hline & Agree & Count & 14 & 32 & 116 & 162 \\
\hline & & $\begin{array}{l}\text { Expected Count } \\
\% \text { within Adoption - }\end{array}$ & 17.5 & 36.3 & 108.2 & 162.0 \\
\hline & & $\begin{array}{l}\text { Reform is usually } \\
\text { successful }\end{array}$ & $8.6 \%$ & $19.8 \%$ & $71.6 \%$ & $100.0 \%$ \\
\hline & & $\begin{array}{l}\text { \% within Adoption - } \\
\text { Influence of } \\
\text { internal groups }\end{array}$ & $56.0 \%$ & $61.5 \%$ & $74.8 \%$ & $69.8 \%$ \\
\hline & & $\%$ of Total & $6.0 \%$ & $13.8 \%$ & $50.0 \%$ & $69.8 \%$ \\
\hline Total & & Count & 25 & 52 & 155 & 232 \\
\hline & & Expected Count & 25.0 & 52.0 & 155.0 & 232.0 \\
\hline & & $\begin{array}{l}\text { \% within Adoption - } \\
\text { Reform is usually } \\
\text { successful }\end{array}$ & $10.8 \%$ & $22.4 \%$ & $66.8 \%$ & $100.0 \%$ \\
\hline & & $\begin{array}{l}\text { \% within Adoption - } \\
\text { Influence of } \\
\text { internal groups }\end{array}$ & $100.0 \%$ & $100.0 \%$ & $100.0 \%$ & $100.0 \%$ \\
\hline & & $\%$ of Total & $10.8 \%$ & $22.4 \%$ & $66.8 \%$ & $100.0 \%$ \\
\hline
\end{tabular}

Table 6: Chi-Square test - reform adoption success and influence of internal groups

\begin{tabular}{|c|c|c|c|}
\hline & Value & df & $\begin{array}{c}\text { Asymp. Sig. } \\
\text { (2-sided) }\end{array}$ \\
\hline Pearson Chi-Square & $29.823^{a}$ & 4 & .000 \\
\hline Likelihood Ratio & 20.662 & 4 & .000 \\
\hline $\begin{array}{l}\text { Linear-by-Linear } \\
\text { Association }\end{array}$ & 11.540 & 1 & .001 \\
\hline $\mathrm{N}$ of Valid Cases & 232 & & \\
\hline
\end{tabular}

a. 2 cells $(22.2 \%)$ have expected count less than 5 . The minimum expected count is 1.83 . 
Table 7: Cross tabulation of adoption reform success and competition with other organisational priorities

\begin{tabular}{|c|c|c|c|c|c|c|}
\hline & & & \multicolumn{3}{|c|}{$\begin{array}{l}\text { Adoption - Competition with other } \\
\text { organisational priorities }\end{array}$} & \multirow[b]{2}{*}{ Total } \\
\hline & & & Disagree & $\begin{array}{l}\text { Neither } \\
\text { disagree or } \\
\text { agree }\end{array}$ & Agree & \\
\hline \multirow{15}{*}{$\begin{array}{l}\text { Adoption - Reform is } \\
\text { usually successful }\end{array}$} & \multirow[t]{5}{*}{ Disagree } & Count & 2 & 1 & 14 & 17 \\
\hline & & Expected Count & 3.9 & 2.9 & 10.3 & 17.0 \\
\hline & & $\begin{array}{l}\text { \% within Adoption - } \\
\text { Reform is usually }\end{array}$ & $11.8 \%$ & $5.9 \%$ & $82.4 \%$ & $100.0 \%$ \\
\hline & & $\begin{array}{l}\text { successiul } \\
\% \text { within Adoption - } \\
\text { Competition with other } \\
\text { organisational priorities }\end{array}$ & $3.8 \%$ & $2.6 \%$ & $10.0 \%$ & $7.3 \%$ \\
\hline & & $\%$ of Total & $.9 \%$ & $.4 \%$ & $6.0 \%$ & $7.3 \%$ \\
\hline & \multirow[t]{5}{*}{ Neither disagree or agree } & Count & 7 & 7 & 39 & 53 \\
\hline & & & 12.1 & 8.9 & 32.0 & 53.0 \\
\hline & & $\begin{array}{l}\text { Reform is usually } \\
\text { successful }\end{array}$ & $13.2 \%$ & $13.2 \%$ & $73.6 \%$ & $100.0 \%$ \\
\hline & & $\begin{array}{l}\% \text { within Adoption - } \\
\text { Competition with other } \\
\text { organisational priorities }\end{array}$ & $13.2 \%$ & $17.9 \%$ & $27.9 \%$ & $22.8 \%$ \\
\hline & & $\%$ of Total & $3.0 \%$ & $3.0 \%$ & $16.8 \%$ & $22.8 \%$ \\
\hline & \multirow[t]{5}{*}{ Agree } & Count & 44 & 31 & 87 & 162 \\
\hline & & Expected Count & 37.0 & 27.2 & 97.8 & 162.0 \\
\hline & & $\begin{array}{l}\text { \% within Adoption - } \\
\text { Reform is usually } \\
\text { successful }\end{array}$ & $27.2 \%$ & $19.1 \%$ & $53.7 \%$ & $100.0 \%$ \\
\hline & & $\begin{array}{l}\% \text { within Adoption - } \\
\text { Competition with other } \\
\text { organisational priorities }\end{array}$ & $83.0 \%$ & $79.5 \%$ & $62.1 \%$ & $69.8 \%$ \\
\hline & & $\%$ of Total & $19.0 \%$ & $13.4 \%$ & $37.5 \%$ & $69.8 \%$ \\
\hline \multirow{5}{*}{\multicolumn{2}{|c|}{ Total }} & Count & 53 & 39 & 140 & 232 \\
\hline & & Expected Count & 53.0 & 39.0 & 140.0 & 232.0 \\
\hline & & $\begin{array}{l}\text { Reform is usually } \\
\text { successful }\end{array}$ & $22.8 \%$ & $16.8 \%$ & $60.3 \%$ & $100.0 \%$ \\
\hline & & $\begin{array}{l}\% \text { within Adoption - } \\
\text { Competition with other } \\
\text { organisational priorities }\end{array}$ & $100.0 \%$ & $100.0 \%$ & $100.0 \%$ & $100.0 \%$ \\
\hline & & $\%$ of Total & $22.8 \%$ & $16.8 \%$ & $60.3 \%$ & $100.0 \%$ \\
\hline
\end{tabular}

Table 8: Chi-Square test - adoption reform success and competition with other organisational priorities

\begin{tabular}{|c|c|c|c|}
\hline & Value & df & $\begin{array}{l}\text { Asymp. Sig. } \\
\text { (2-sided) }\end{array}$ \\
\hline Pearson Chi-Square & $10.615^{a}$ & 4 & .031 \\
\hline Likelihood Ratio & 11.349 & 4 & .023 \\
\hline $\begin{array}{l}\text { Linear-by-Linear } \\
\text { Association }\end{array}$ & 8.905 & 1 & .003 \\
\hline $\mathrm{N}$ of Valid Cases & 232 & & \\
\hline
\end{tabular}

a. 2 cells $(22.2 \%)$ have expected count less than 5 . The minimum expected count is 2.86 . 
Table 9: Cross tabulation of adoption reform success and senior manager leadership

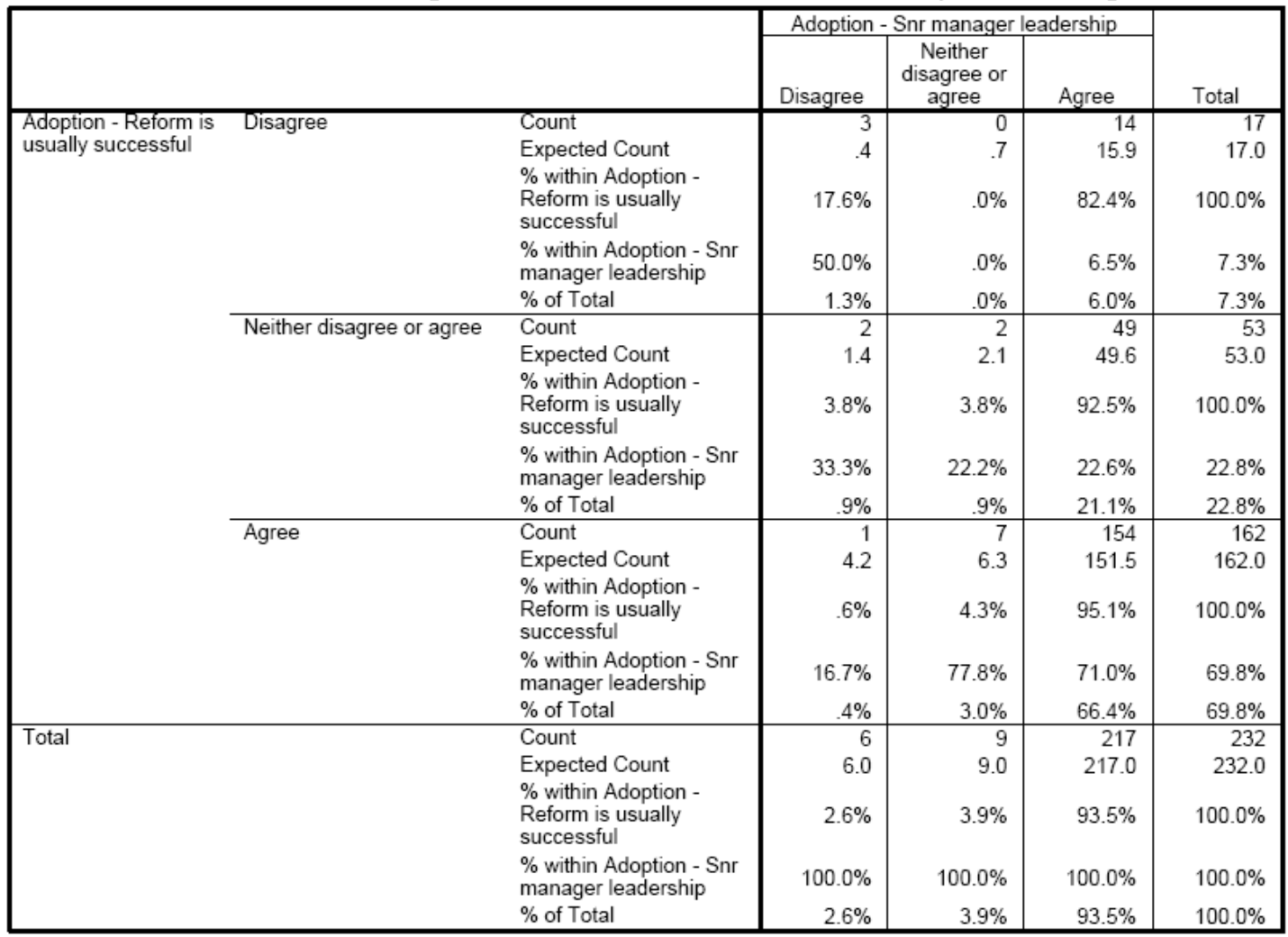

Table 10: Chi-Square test - reform adoption success and senior manager leadership

\begin{tabular}{|c|c|c|c|}
\hline & Value & df & $\begin{array}{l}\text { Asymp. Sig. } \\
\text { (2-sided) }\end{array}$ \\
\hline Pearson Chi-Square & $18.644^{a}$ & 4 & .001 \\
\hline Likelihood Ratio & 11.851 & 4 & .018 \\
\hline $\begin{array}{l}\text { Linear-by-Linear } \\
\text { Association }\end{array}$ & 8.616 & 1 & .003 \\
\hline $\mathrm{N}$ of Valid Cases & 232 & & \\
\hline
\end{tabular}

a. 5 cells $(55.6 \%)$ have expected count less than 5 . The minimum expected count is 44 . 
Table 11: Cross tabulation of adoption reform success and length of employment

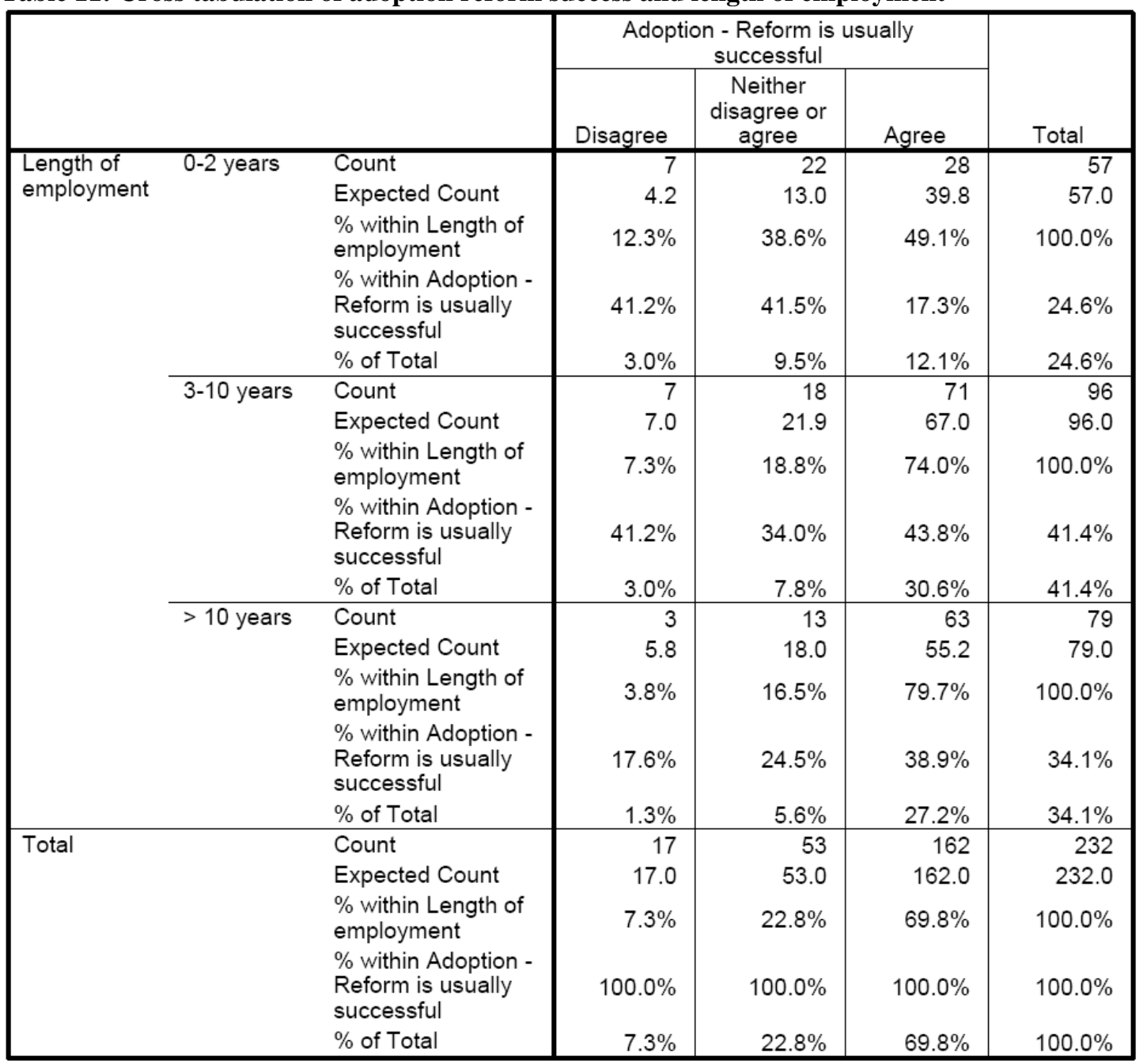

Table 12: Chi-Square test - Adoption reform success and length of employment

\begin{tabular}{|c|c|c|c|}
\hline & Value & df & $\begin{array}{l}\text { Asymp. Sig. } \\
\text { (2-sided) }\end{array}$ \\
\hline Pearson Chi-Square & $16.406^{\mathrm{a}}$ & 4 & .003 \\
\hline Likelihood Ratio & 15.853 & 4 & .003 \\
\hline $\begin{array}{l}\text { Linear-by-Linear } \\
\text { Association }\end{array}$ & 10.224 & 1 & .001 \\
\hline $\mathrm{N}$ of Valid Cases & 232 & & \\
\hline
\end{tabular}

a. 1 cells $(11.1 \%)$ have expected count less than 5 . The minimum expected count is 4.18 . 
Table 13: Cross tabulation of organisational budget and external drive to improve accountability

\begin{tabular}{|c|c|c|c|c|c|c|}
\hline & & & Adoption - & $\begin{array}{l}\text { External drive } \\
\text { accountability }\end{array}$ & mprove & \\
\hline & & & Disagree & $\begin{array}{c}\text { Neither } \\
\text { disagree or } \\
\text { agree }\end{array}$ & Agree & Total \\
\hline Org & $\$ 100-500 \mathrm{~m}$ & Count & 3 & 26 & 106 & 135 \\
\hline budget & & Expected Count & 6.4 & 19.8 & 108.8 & 135.0 \\
\hline & & $\%$ within Org budget & $2.2 \%$ & $19.3 \%$ & $78.5 \%$ & $100.0 \%$ \\
\hline & & $\begin{array}{l}\% \text { within Adoption - } \\
\text { External drive to } \\
\text { improve accountability }\end{array}$ & $27.3 \%$ & $76.5 \%$ & $56.7 \%$ & $58.2 \%$ \\
\hline & & $\%$ of Total & $1.3 \%$ & $11.2 \%$ & $45.7 \%$ & $58.2 \%$ \\
\hline & $\$ 501-1,000 \mathrm{~m}$ & Count & 4 & 4 & 25 & 33 \\
\hline & & Expected Count & 1.6 & 4.8 & 26.6 & 33.0 \\
\hline & & $\begin{array}{l}\% \text { within Org budget } \\
\% \text { within Adoption - }\end{array}$ & $12.1 \%$ & $12.1 \%$ & $75.8 \%$ & $100.0 \%$ \\
\hline & & $\begin{array}{l}\text { External drive to } \\
\text { improve accountability }\end{array}$ & $36.4 \%$ & $11.8 \%$ & $13.4 \%$ & $14.2 \%$ \\
\hline & & $\%$ of Total & $1.7 \%$ & $1.7 \%$ & $10.8 \%$ & $14.2 \%$ \\
\hline & $>\$ 1,001 \mathrm{~m}$ & Count & 4 & 4 & 56 & 64 \\
\hline & & Expected Count & 3.0 & 9.4 & 51.6 & 64.0 \\
\hline & & $\%$ within Org budget & $6.3 \%$ & $6.3 \%$ & $87.5 \%$ & $100.0 \%$ \\
\hline & & $\begin{array}{l}\text { \% within Adoption - } \\
\text { External drive to } \\
\text { improve accountability }\end{array}$ & $36.4 \%$ & $11.8 \%$ & $29.9 \%$ & $27.6 \%$ \\
\hline & & $\%$ of Total & $1.7 \%$ & $1.7 \%$ & $24.1 \%$ & $27.6 \%$ \\
\hline Total & & Count & 11 & 34 & 187 & 232 \\
\hline & & Expected Count & 11.0 & 34.0 & 187.0 & 232.0 \\
\hline & & $\%$ within Org budget & $4.7 \%$ & $14.7 \%$ & $80.6 \%$ & $100.0 \%$ \\
\hline & & $\begin{array}{l}\% \text { within Adoption - } \\
\text { External drive to } \\
\text { improve accountability }\end{array}$ & $100.0 \%$ & $100.0 \%$ & $100.0 \%$ & $100.0 \%$ \\
\hline & & $\%$ of Total & $4.7 \%$ & $14.7 \%$ & $80.6 \%$ & $100.0 \%$ \\
\hline
\end{tabular}

Table 14: Chi-Square test - organisational budget and external drive to improve accountability

\begin{tabular}{|l|r|r|r|}
\hline & Value & df & \multicolumn{1}{c|}{$\begin{array}{c}\text { Asymp. Sig. } \\
\text { (2-sided) }\end{array}$} \\
\hline Pearson Chi-Square & $11.634^{a}$ & 4 & .020 \\
Likelihood Ratio & 11.581 & 4 & .021 \\
Linear-by-Linear & .044 & 1 & .834 \\
Association & 232 & & \\
N of Valid Cases & & & \\
\hline
\end{tabular}

a. 3 cells $(33.3 \%)$ have expected count less than 5 . The minimum expected count is 1.56 . 
Table 15: Cross tabulation of organisational budget and internal drive to improve service coordination

\begin{tabular}{|c|c|c|c|c|c|c|}
\hline & & & Adoption & $\begin{array}{l}\text { Internal drive } \\
\text { vice coordina }\end{array}$ & mprove & \\
\hline & & & Disagree & $\begin{array}{c}\text { Neither } \\
\text { disagree or } \\
\text { agree }\end{array}$ & Agree & Total \\
\hline Org & $\$ 100-500 m$ & Count & 4 & 21 & 110 & 135 \\
\hline budget & & Expected Count & 8.1 & 15.1 & 111.7 & 135.0 \\
\hline & & $\%$ within Org budget & $3.0 \%$ & $15.6 \%$ & $81.5 \%$ & $100.0 \%$ \\
\hline & & $\begin{array}{l}\% \text { within Adoption - } \\
\text { Internal drive to improve } \\
\text { service coordination }\end{array}$ & $28.6 \%$ & $80.8 \%$ & $57.3 \%$ & $58.2 \%$ \\
\hline & & $\%$ of Total & $1.7 \%$ & $9.1 \%$ & $47.4 \%$ & $58.2 \%$ \\
\hline & $\$ 501-1,000 \mathrm{~m}$ & Count & 3 & 0 & 30 & 33 \\
\hline & & Expected Count & 2.0 & 3.7 & 27.3 & 33.0 \\
\hline & & $\%$ within Org budget & $9.1 \%$ & $.0 \%$ & $90.9 \%$ & $100.0 \%$ \\
\hline & & $\begin{array}{l}\% \text { within Adoption - } \\
\text { Internal drive to improve } \\
\text { service coordination }\end{array}$ & $21.4 \%$ & $.0 \%$ & $15.6 \%$ & $14.2 \%$ \\
\hline & & $\%$ of Total & $1.3 \%$ & $.0 \%$ & $12.9 \%$ & $14.2 \%$ \\
\hline & $>\$ 1,001 \mathrm{~m}$ & Count & 7 & 5 & 52 & 64 \\
\hline & & Expected Count & 3.9 & 7.2 & 53.0 & 64.0 \\
\hline & & $\%$ within Org budget & $10.9 \%$ & $7.8 \%$ & $81.3 \%$ & $100.0 \%$ \\
\hline & & $\begin{array}{l}\% \text { within Adoption - } \\
\text { Internal drive to improve } \\
\text { service coordination }\end{array}$ & $50.0 \%$ & $19.2 \%$ & $27.1 \%$ & $27.6 \%$ \\
\hline & & $\%$ of Total & $3.0 \%$ & $2.2 \%$ & $22.4 \%$ & $27.6 \%$ \\
\hline Total & & Count & 14 & 26 & 192 & 232 \\
\hline & & Expected Count & 14.0 & 26.0 & 192.0 & 232.0 \\
\hline & & $\%$ within Org budget & $6.0 \%$ & $11.2 \%$ & $82.8 \%$ & $100.0 \%$ \\
\hline & & $\begin{array}{l}\% \text { within Adoption - } \\
\text { Internal drive to improve } \\
\text { service coordination }\end{array}$ & $100.0 \%$ & $100.0 \%$ & $100.0 \%$ & $100.0 \%$ \\
\hline & & $\%$ of Total & $6.0 \%$ & $11.2 \%$ & $82.8 \%$ & $100.0 \%$ \\
\hline
\end{tabular}

Table 16: Chi-Square test - organisational budget and internal drive to improve service coordination

\begin{tabular}{|c|c|c|c|}
\hline & Value & df & $\begin{array}{l}\text { Asymp. Sig. } \\
\text { (2-sided) }\end{array}$ \\
\hline Pearson Chi-Square & $12.114^{\mathrm{a}}$ & 4 & .017 \\
\hline Likelihood Ratio & 15.559 & 4 & .004 \\
\hline $\begin{array}{l}\text { Linear-by-Linear } \\
\text { Association }\end{array}$ & .633 & 1 & .426 \\
\hline $\mathrm{N}$ of Valid Cases & 232 & & \\
\hline
\end{tabular}

a. 3 cells $(33.3 \%)$ have expected count less than 5 . The minimum expected count is 1.99 . 
Table 17: Cross tabulation of organisational budget and organisational decision making processes

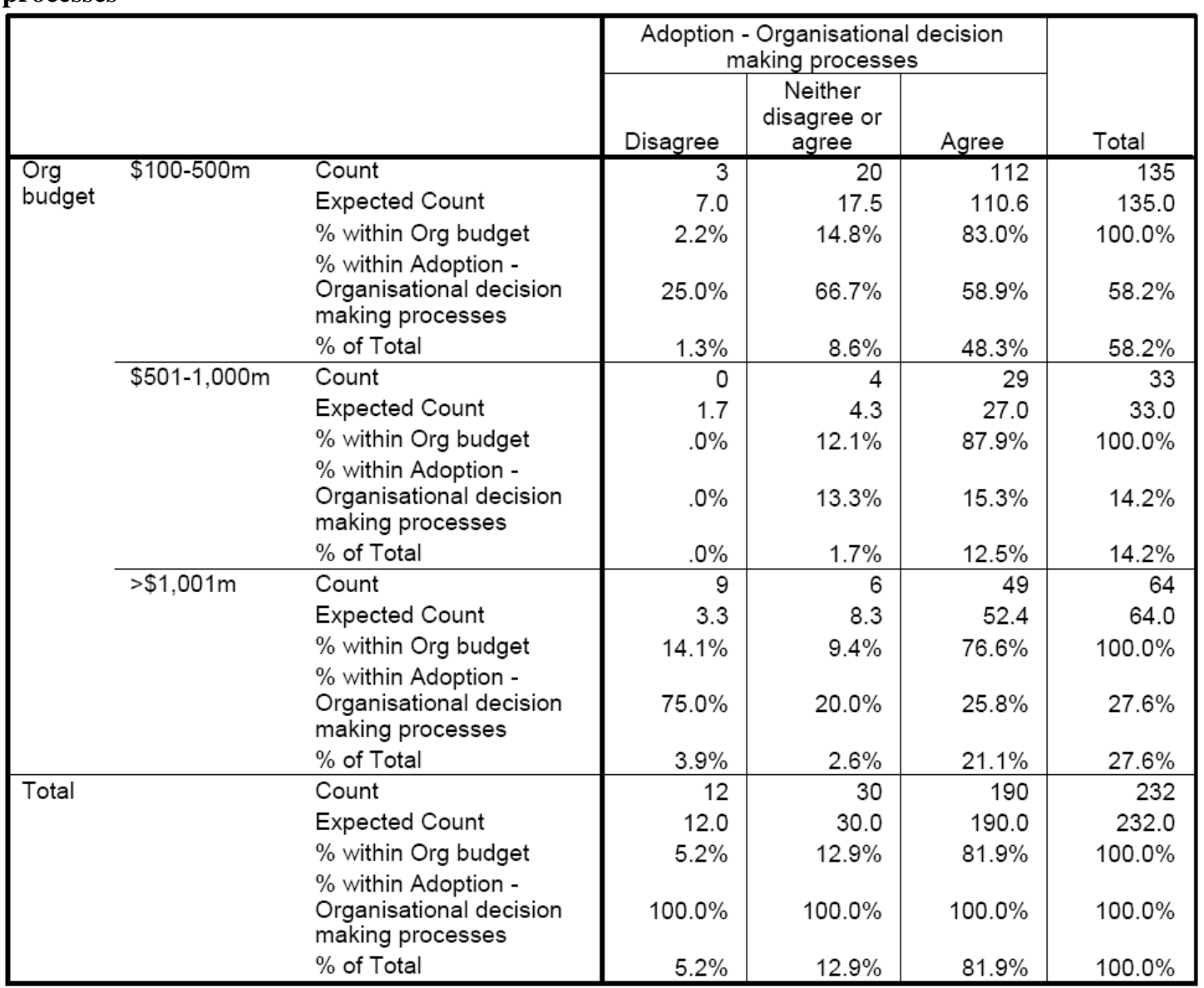

Table 18: Chi-Square test - organisational budget and organisational decision making processes

\begin{tabular}{|c|c|c|c|}
\hline & Value & df & $\begin{array}{l}\text { Asymp. Sig. } \\
\text { (2-sided) }\end{array}$ \\
\hline Pearson Chi-Square & $15.156^{\mathrm{a}}$ & 4 & .004 \\
\hline Likelihood Ratio & 14.384 & 4 & .006 \\
\hline $\begin{array}{l}\text { Linear-by-Linear } \\
\text { Association }\end{array}$ & 3.336 & 1 & .068 \\
\hline $\mathrm{N}$ of Valid Cases & 232 & & \\
\hline
\end{tabular}

a. 3 cells $(33.3 \%)$ have expected count less than 5 . The minimum expected count is 1.71 . 
Table 19: Cross tabulation of employment length and influence of internal groups

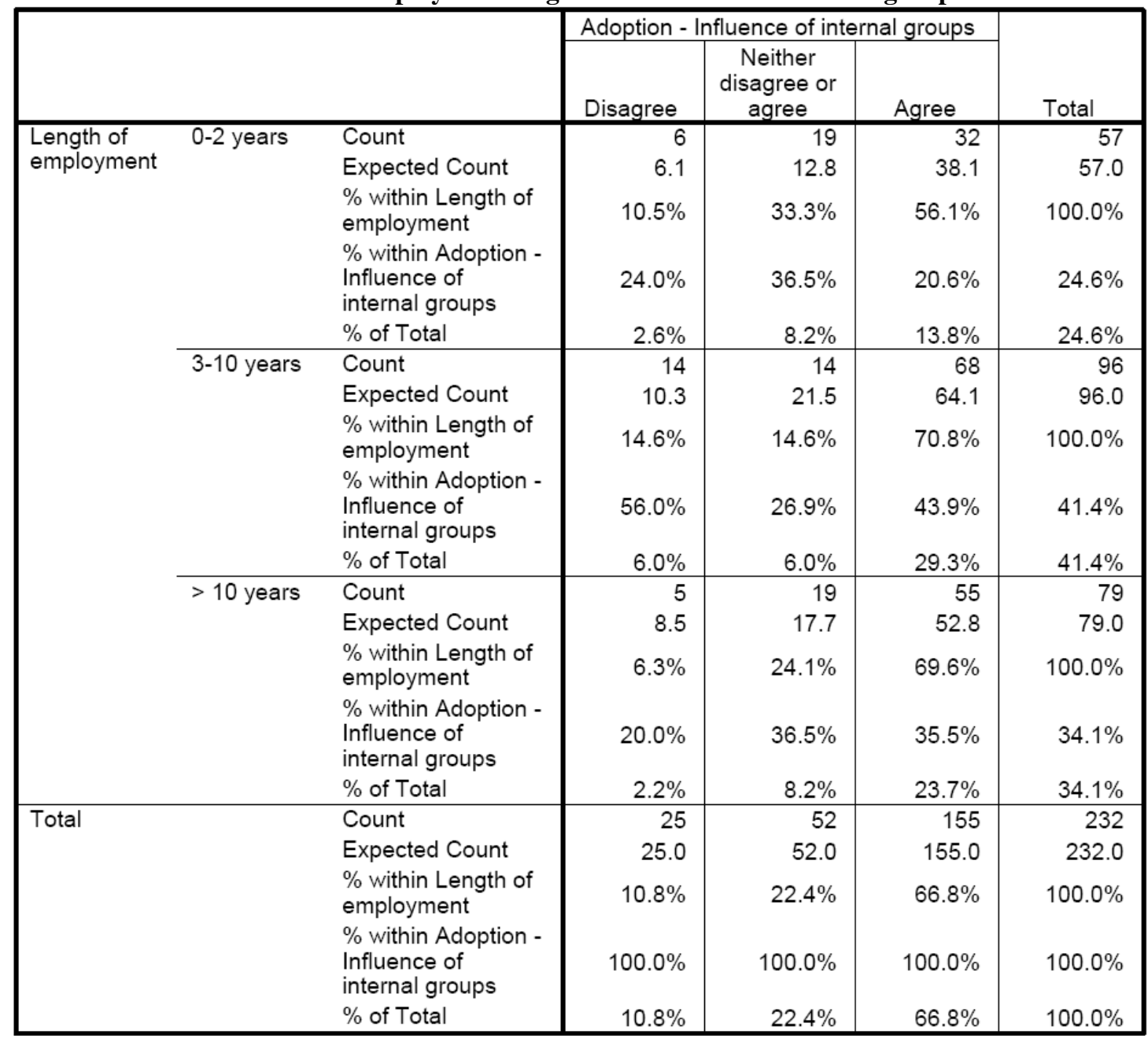

Table 20: Chi-Square test - employment length and influence of interest groups

\begin{tabular}{|l|r|r|r|}
\hline & Value & df & $\begin{array}{c}\text { Asymp. Sig. } \\
\text { (2-sided) }\end{array}$ \\
\hline Pearson Chi-Square & $9.795^{\mathrm{a}}$ & 4 & .044 \\
Likelihood Ratio & 9.943 & 4 & .041 \\
Linear-by-Linear & 1.985 & 1 & .159 \\
Association & 232 & & \\
N of Valid Cases & & & \\
\hline
\end{tabular}

a. 0 cells $(.0 \%)$ have expected count less than 5 . The minimum expected count is 6.14 . 
Table 21: Cross tabulation of employment length and costs associated with implementing change

\begin{tabular}{|c|c|c|c|c|c|c|}
\hline & & & \multicolumn{3}{|c|}{$\begin{array}{l}\text { Adoption - Costs associated with } \\
\text { implementing change }\end{array}$} & \multirow[b]{2}{*}{ Total } \\
\hline & & & Disagree & $\begin{array}{l}\text { Neither } \\
\text { disagree or } \\
\text { agree }\end{array}$ & Agree & \\
\hline \multirow{15}{*}{$\begin{array}{l}\text { Length of } \\
\text { employment }\end{array}$} & \multirow[t]{5}{*}{$0-2$ years } & Count & 1 & 10 & 46 & 57 \\
\hline & & Expected Count & 6.6 & 11.8 & 38.6 & 57.0 \\
\hline & & $\begin{array}{l}\% \text { within Length of } \\
\text { employment }\end{array}$ & $1.8 \%$ & $17.5 \%$ & $80.7 \%$ & $100.0 \%$ \\
\hline & & $\begin{array}{l}\% \text { within Adoption - } \\
\text { Costs associated with } \\
\text { implementing change }\end{array}$ & $3.7 \%$ & $20.8 \%$ & $29.3 \%$ & $24.6 \%$ \\
\hline & & $\%$ of Total & $.4 \%$ & $4.3 \%$ & $19.8 \%$ & $24.6 \%$ \\
\hline & \multirow[t]{5}{*}{$3-10$ years } & Count & 12 & 19 & 65 & 96 \\
\hline & & Expected Count & 11.2 & 19.9 & 65.0 & 96.0 \\
\hline & & $\begin{array}{l}\% \text { within Length of } \\
\text { employment }\end{array}$ & $12.5 \%$ & $19.8 \%$ & $67.7 \%$ & $100.0 \%$ \\
\hline & & $\begin{array}{l}\% \text { within Adoption - } \\
\text { Costs associated with } \\
\text { implementing change }\end{array}$ & $44.4 \%$ & $39.6 \%$ & $41.4 \%$ & $41.4 \%$ \\
\hline & & $\%$ of Total & $5.2 \%$ & $8.2 \%$ & $28.0 \%$ & $41.4 \%$ \\
\hline & \multirow[t]{5}{*}{$>10$ years } & Count & 14 & 19 & 46 & 79 \\
\hline & & Expected Count & 9.2 & 16.3 & 53.5 & 79.0 \\
\hline & & $\begin{array}{l}\% \text { within Length of } \\
\text { employment }\end{array}$ & $17.7 \%$ & $24.1 \%$ & $58.2 \%$ & $100.0 \%$ \\
\hline & & $\begin{array}{l}\% \text { within Adoption - } \\
\text { Costs associated with } \\
\text { implementing change }\end{array}$ & $51.9 \%$ & $39.6 \%$ & $29.3 \%$ & $34.1 \%$ \\
\hline & & $\%$ of Total & $6.0 \%$ & $8.2 \%$ & $19.8 \%$ & $34.1 \%$ \\
\hline \multirow{5}{*}{\multicolumn{2}{|c|}{ Total }} & \multirow{5}{*}{$\begin{array}{l}\text { Count } \\
\text { Expected Count } \\
\% \text { within Length of } \\
\text { employment } \\
\% \text { within Adoption - } \\
\text { Costs associated with } \\
\text { implementing change } \\
\% \text { of Total }\end{array}$} & 27 & 48 & 157 & 232 \\
\hline & & & 27.0 & 48.0 & 157.0 & 232.0 \\
\hline & & & $11.6 \%$ & $20.7 \%$ & $67.7 \%$ & $100.0 \%$ \\
\hline & & & $100.0 \%$ & $100.0 \%$ & $100.0 \%$ & $100.0 \%$ \\
\hline & & & $11.6 \%$ & $20.7 \%$ & $67.7 \%$ & $100.0 \%$ \\
\hline
\end{tabular}

Table 22: Chi-Square test - employment length and costs associated with implementing change

\begin{tabular}{|l|c|r|r|}
\hline & Value & df & $\begin{array}{c}\text { Asymp. Sig. } \\
\text { (2-sided) }\end{array}$ \\
\hline Pearson Chi-Square & $10.571^{\mathrm{a}}$ & 4 & .032 \\
Likelihood Ratio & 12.880 & 4 & .012 \\
Linear-by-Linear & 8.927 & 1 & .003 \\
Association & 232 & & \\
N of Valid Cases & & & \\
\hline
\end{tabular}

a. 0 cells $(.0 \%)$ have expected count less than 5 . The minimum expected count is 6.63 . 
Table 23: Cross tabulation of reform operation success and acceptance of innovation

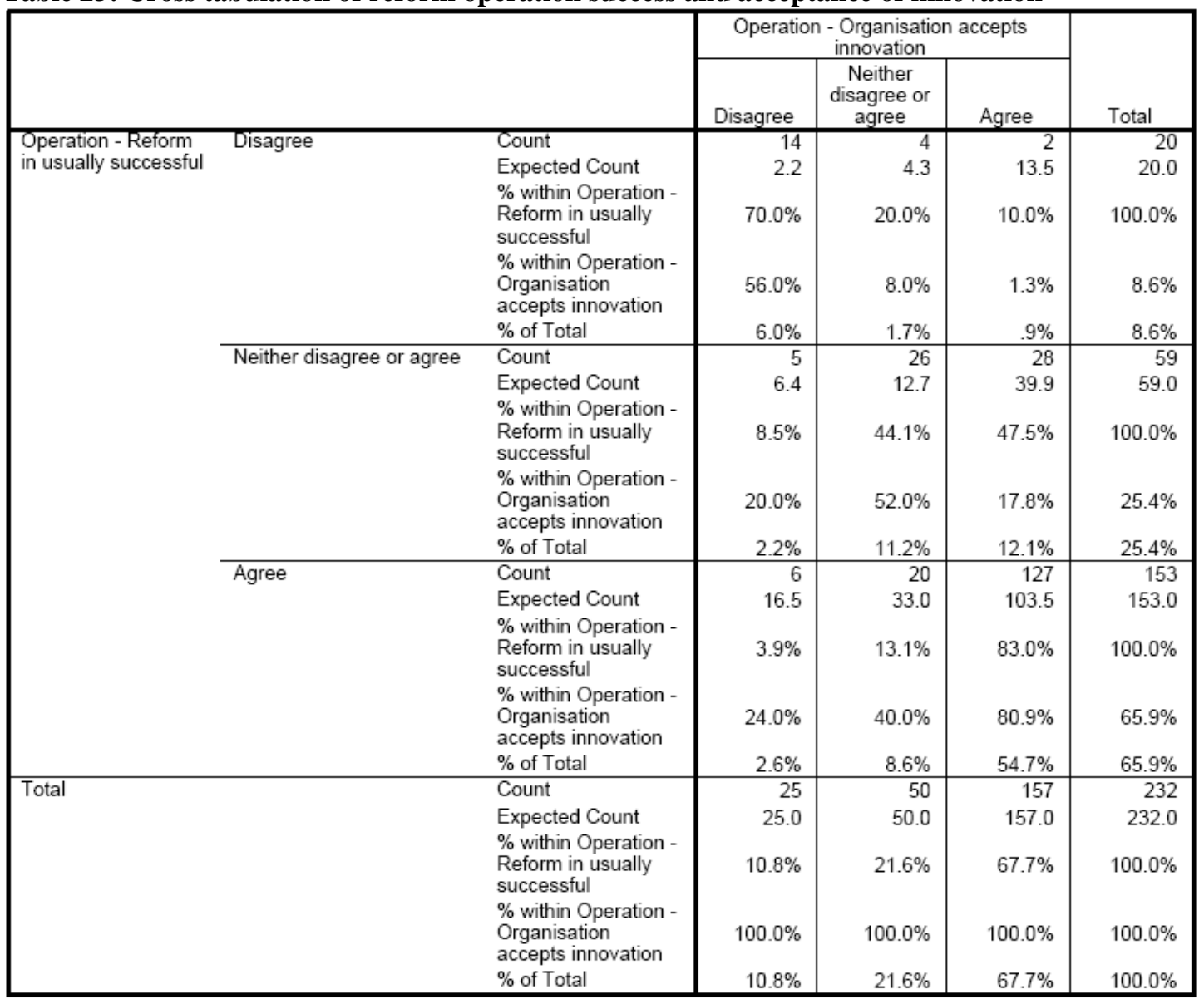

Table 24: Chi-Square test - reform operation success and acceptance of innovation

\begin{tabular}{|c|c|c|c|}
\hline & Value & $\mathrm{df}$ & $\begin{array}{l}\text { Asymp. Sig. } \\
\text { (2-sided) }\end{array}$ \\
\hline Pearson Chi-Square & $109.775^{\mathrm{a}}$ & 4 & .000 \\
\hline Likelihood Ratio & 78.815 & 4 & .000 \\
\hline $\begin{array}{l}\text { Linear-by-Linear } \\
\text { Association }\end{array}$ & 73.402 & 1 & .000 \\
\hline $\mathrm{N}$ of Valid Cases & 232 & & \\
\hline
\end{tabular}

a. 2 cells $(22.2 \%)$ have expected count less than 5 . The minimum expected count is 2.16 . 
Table 25: Cross tabulation of reform operation success and organisational acceptance of change

\begin{tabular}{|c|c|c|c|c|c|c|}
\hline & & & Operatic & $\begin{array}{l}\text { n- Organisati } \\
\text { ccepts chang }\end{array}$ & easily & \\
\hline & & & Disagree & $\begin{array}{l}\text { Neither } \\
\text { disagree or } \\
\text { agree }\end{array}$ & Agree & Total \\
\hline Operation - Reform & Disagree & Count & 18 & 2 & 0 & 20 \\
\hline in usually successful & & Expected Count & 6.4 & 6.6 & 7.0 & 20.0 \\
\hline & & $\begin{array}{l}\text { Reform in usually - } \\
\text { successful }\end{array}$ & $90.0 \%$ & $10.0 \%$ & $.0 \%$ & $100.0 \%$ \\
\hline & & $\begin{array}{l}\text { \% within Operation - } \\
\text { Organisation easily } \\
\text { accepts change }\end{array}$ & $24.3 \%$ & $2.6 \%$ & $.0 \%$ & $8.6 \%$ \\
\hline & & $\%$ of Total & $7.8 \%$ & $.9 \%$ & $.0 \%$ & $8.6 \%$ \\
\hline & Neither disagree or agree & Count & 28 & 25 & 6 & 59 \\
\hline & & $\begin{array}{l}\text { Expected Count } \\
\% \text { within Operation - }\end{array}$ & 18.8 & 19.6 & 20.6 & 59.0 \\
\hline & & $\begin{array}{l}\text { Reform in usually } \\
\text { successful }\end{array}$ & $47.5 \%$ & $42.4 \%$ & $10.2 \%$ & $100.0 \%$ \\
\hline & & $\begin{array}{l}\% \text { within Operation - } \\
\text { Organisation easily } \\
\text { accepts change }\end{array}$ & $37.8 \%$ & $32.5 \%$ & $7.4 \%$ & $25.4 \%$ \\
\hline & & $\%$ of Total & $12.1 \%$ & $10.8 \%$ & $2.6 \%$ & $25.4 \%$ \\
\hline & Agree & Count & 28 & 50 & 75 & 153 \\
\hline & & $\begin{array}{l}\text { Expected Count } \\
\% \text { within Operation - }\end{array}$ & 48.8 & 50.8 & 53.4 & 153.0 \\
\hline & & $\begin{array}{l}\text { Reform in usually } \\
\text { successful }\end{array}$ & $18.3 \%$ & $32.7 \%$ & $49.0 \%$ & $100.0 \%$ \\
\hline & & $\begin{array}{l}\% \text { within Operation - } \\
\text { Organisation easily } \\
\text { accepts change }\end{array}$ & $37.8 \%$ & $64.9 \%$ & $92.6 \%$ & $65.9 \%$ \\
\hline & & $\%$ of Total & $12.1 \%$ & $21.6 \%$ & $32.3 \%$ & $65.9 \%$ \\
\hline Total & & Count & 74 & 77 & 81 & 232 \\
\hline & & $\begin{array}{l}\text { Expected Count } \\
\% \text { within Oneration - }\end{array}$ & 74.0 & 77.0 & 81.0 & 232.0 \\
\hline & & $\begin{array}{l}\text { Reformin in usuatlon - } \\
\text { Refcessful }\end{array}$ & $31.9 \%$ & $33.2 \%$ & $34.9 \%$ & $100.0 \%$ \\
\hline & & $\begin{array}{l}\text { \% within Operation - } \\
\text { Organisation easily } \\
\text { accepts change }\end{array}$ & $100.0 \%$ & $100.0 \%$ & $100.0 \%$ & $100.0 \%$ \\
\hline & & $\%$ of Total & $31.9 \%$ & $33.2 \%$ & $34.9 \%$ & $100.0 \%$ \\
\hline
\end{tabular}

Table 26: Chi-Square test - reform operation success and organisational acceptance of change

\begin{tabular}{|c|c|c|c|}
\hline & Value & df & $\begin{array}{l}\text { Asymp. Sig. } \\
\text { (2-sided) }\end{array}$ \\
\hline $\begin{array}{l}\text { Pearson Chi-Square } \\
\text { Likelihood Ratio }\end{array}$ & $\begin{array}{l}65.315^{a} \\
70.448\end{array}$ & $\begin{array}{l}4 \\
4\end{array}$ & $\begin{array}{r}.000 \\
.000\end{array}$ \\
\hline $\begin{array}{l}\text { Linear-by-Linear } \\
\text { Association }\end{array}$ & 57.369 & 1 & .000 \\
\hline $\mathrm{N}$ of Valid Cases & 232 & & \\
\hline
\end{tabular}

a. 0 cells $(.0 \%)$ have expected count less than 5 . The minimum expected count is 6.38 . 
Table 27: Cross tabulation of reform operation success and number of actors in change process

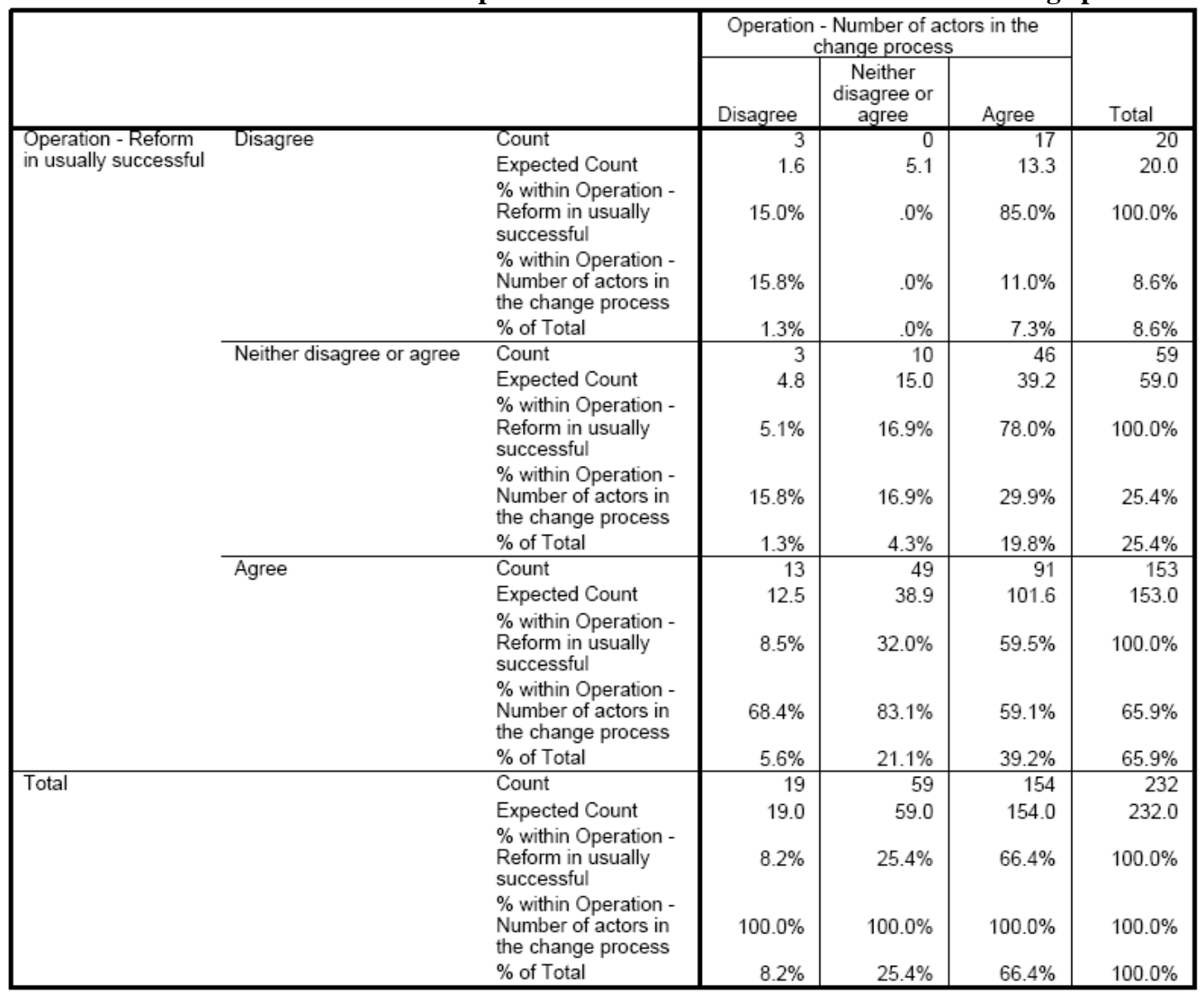

Table 28: Chi-Square test - reform operation success and number of actors in change process

\begin{tabular}{|c|c|c|c|}
\hline & Value & df & $\begin{array}{l}\text { Asymp. Sig. } \\
\text { (2-sided) }\end{array}$ \\
\hline Pearson Chi-Square & $14.553^{\mathrm{a}}$ & 4 & .006 \\
\hline Likelihood Ratio & 19.437 & 4 & .001 \\
\hline $\begin{array}{l}\text { Linear-by-Linear } \\
\text { Association }\end{array}$ & 4.534 & 1 & .033 \\
\hline $\mathrm{N}$ of Valid Cases & 232 & & \\
\hline
\end{tabular}

a. 2 cells $(22.2 \%)$ have expected count less than 5 . The minimum expected count is 1.64 . 
Table 29: Cross tabulation of reform operation success and length of employment

\begin{tabular}{|c|c|c|c|c|c|c|}
\hline & & & \multicolumn{3}{|c|}{$\begin{array}{c}\text { Operation - Reform in usually } \\
\text { successful }\end{array}$} & \multirow[b]{2}{*}{ Total } \\
\hline & & & Disagree & $\begin{array}{l}\text { Neither } \\
\text { disagree or } \\
\text { agree }\end{array}$ & Agree & \\
\hline \multirow{15}{*}{$\begin{array}{l}\text { Length of } \\
\text { employment }\end{array}$} & \multirow[t]{5}{*}{$0-2$ years } & Count & 11 & 19 & 27 & 57 \\
\hline & & Expected Count & 4.9 & 14.5 & 37.6 & 57.0 \\
\hline & & $\begin{array}{l}\% \text { within Length of } \\
\text { employment }\end{array}$ & $19.3 \%$ & $33.3 \%$ & $47.4 \%$ & $100.0 \%$ \\
\hline & & $\begin{array}{l}\% \text { within Operation - } \\
\text { Reform in usually } \\
\text { successful }\end{array}$ & $55.0 \%$ & $32.2 \%$ & $17.6 \%$ & $24.6 \%$ \\
\hline & & $\%$ of Total & $4.7 \%$ & $8.2 \%$ & $11.6 \%$ & $24.6 \%$ \\
\hline & \multirow[t]{5}{*}{$3-10$ years } & Count & 6 & 25 & 65 & 96 \\
\hline & & Expected Count & 8.3 & 24.4 & 63.3 & 96.0 \\
\hline & & $\begin{array}{l}\% \text { within Length of } \\
\text { employment }\end{array}$ & $6.3 \%$ & $26.0 \%$ & $67.7 \%$ & $100.0 \%$ \\
\hline & & $\begin{array}{l}\% \text { within Operation - } \\
\text { Reform in usually } \\
\text { successful }\end{array}$ & $30.0 \%$ & $42.4 \%$ & $42.5 \%$ & $41.4 \%$ \\
\hline & & $\%$ of Total & $2.6 \%$ & $10.8 \%$ & $28.0 \%$ & $41.4 \%$ \\
\hline & \multirow[t]{5}{*}{$>10$ years } & Count & 3 & 15 & 61 & 79 \\
\hline & & Expected Count & 6.8 & 20.1 & 52.1 & 79.0 \\
\hline & & $\begin{array}{l}\% \text { within Length of } \\
\text { employment }\end{array}$ & $3.8 \%$ & $19.0 \%$ & $77.2 \%$ & $100.0 \%$ \\
\hline & & $\begin{array}{l}\% \text { within Operation - } \\
\text { Reform in usually } \\
\text { successful }\end{array}$ & $15.0 \%$ & $25.4 \%$ & $39.9 \%$ & $34.1 \%$ \\
\hline & & $\%$ of Total & $1.3 \%$ & $6.5 \%$ & $26.3 \%$ & $34.1 \%$ \\
\hline \multirow{5}{*}{\multicolumn{2}{|c|}{ Total }} & Count & 20 & 59 & 153 & 232 \\
\hline & & Expected Count & 20.0 & 59.0 & 153.0 & 232.0 \\
\hline & & $\begin{array}{l}\% \text { within Length of } \\
\text { employment }\end{array}$ & $8.6 \%$ & $25.4 \%$ & $65.9 \%$ & $100.0 \%$ \\
\hline & & $\begin{array}{l}\% \text { within Operation - } \\
\text { Reform in usually } \\
\text { successful }\end{array}$ & $100.0 \%$ & $100.0 \%$ & $100.0 \%$ & $100.0 \%$ \\
\hline & & $\%$ of Total & $8.6 \%$ & $25.4 \%$ & $65.9 \%$ & $100.0 \%$ \\
\hline
\end{tabular}

Table 30: Chi-Square test - reform operation success and length of employment

\begin{tabular}{|c|c|c|c|}
\hline & Value & $\mathrm{df}$ & $\begin{array}{l}\text { Asymp. Sig. } \\
\text { (2-sided) }\end{array}$ \\
\hline Pearson Chi-Square & $17.549^{\mathrm{a}}$ & 4 & .002 \\
\hline Likelihood Ratio & 16.451 & 4 & .002 \\
\hline $\begin{array}{l}\text { Linear-by-Linear } \\
\text { Association }\end{array}$ & 12.860 & 1 & .000 \\
\hline $\mathrm{N}$ of Valid Cases & 232 & & \\
\hline
\end{tabular}

a. 1 cells $(11.1 \%)$ have expected count less than 5 . The minimum expected count is 4.91 . 
Table 31: Cross tabulation of state and reform operation success

\begin{tabular}{|c|c|c|c|c|c|c|}
\hline & & & \multicolumn{3}{|c|}{$\begin{array}{l}\text { Operation - Reform in usually } \\
\text { successful }\end{array}$} & \multirow[b]{2}{*}{ Total } \\
\hline & & & Disagree & $\begin{array}{c}\text { Neither } \\
\text { disagree or } \\
\text { agree }\end{array}$ & Agree & \\
\hline \multirow{30}{*}{$\begin{array}{l}\text { State } \\
\text { organisation } \\
\text { is located in }\end{array}$} & \multirow[t]{5}{*}{ Victoria } & Count & 2 & 3 & 27 & 32 \\
\hline & & Expected Count & 2.8 & 8.1 & 21.1 & 32.0 \\
\hline & & $\begin{array}{l}\% \text { within State } \\
\text { organisation is located in }\end{array}$ & $6.3 \%$ & $9.4 \%$ & $84.4 \%$ & $100.0 \%$ \\
\hline & & $\begin{array}{l}\% \text { within Operation - } \\
\text { Reform in usually } \\
\text { successful }\end{array}$ & $10.0 \%$ & $5.1 \%$ & $17.6 \%$ & $13.8 \%$ \\
\hline & & $\%$ of Total & $.9 \%$ & $1.3 \%$ & $11.6 \%$ & $13.8 \%$ \\
\hline & \multirow[t]{5}{*}{ New South Wales } & Count & 3 & 13 & 24 & 40 \\
\hline & & Expected Count & 3.4 & 10.2 & 26.4 & 40.0 \\
\hline & & $\begin{array}{l}\% \text { within State } \\
\text { organisation is located in }\end{array}$ & $7.5 \%$ & $32.5 \%$ & $60.0 \%$ & $100.0 \%$ \\
\hline & & $\begin{array}{l}\text { \% within Operation - } \\
\text { Reform in usually } \\
\text { successful }\end{array}$ & $15.0 \%$ & $22.0 \%$ & $15.7 \%$ & $17.2 \%$ \\
\hline & & $\%$ of Total & $1.3 \%$ & $5.6 \%$ & $10.3 \%$ & $17.2 \%$ \\
\hline & \multirow[t]{5}{*}{ Queensland } & Count & 4 & 7 & 38 & 49 \\
\hline & & Expected Count & 4.2 & 12.5 & 32.3 & 49.0 \\
\hline & & $\begin{array}{l}\% \text { within State } \\
\text { organisation is located in }\end{array}$ & $8.2 \%$ & $14.3 \%$ & $77.6 \%$ & $100.0 \%$ \\
\hline & & $\begin{array}{l}\text { \% within Operation - } \\
\text { Reform in usually } \\
\text { successful }\end{array}$ & $20.0 \%$ & $11.9 \%$ & $24.8 \%$ & $21.1 \%$ \\
\hline & & $\%$ of Total & $1.7 \%$ & $3.0 \%$ & $16.4 \%$ & $21.1 \%$ \\
\hline & \multirow[t]{5}{*}{ South Australia } & Count & 3 & 9 & 23 & 35 \\
\hline & & Expected Count & 3.0 & 8.9 & 23.1 & 35.0 \\
\hline & & $\begin{array}{l}\% \text { within State } \\
\text { organisation is located in }\end{array}$ & $8.6 \%$ & $25.7 \%$ & $65.7 \%$ & $100.0 \%$ \\
\hline & & $\begin{array}{l}\% \text { within Operation - } \\
\text { Reform in usually } \\
\text { successful }\end{array}$ & $15.0 \%$ & $15.3 \%$ & $15.0 \%$ & $15.1 \%$ \\
\hline & & $\%$ of Total & $1.3 \%$ & $3.9 \%$ & $9.9 \%$ & $15.1 \%$ \\
\hline & \multirow[t]{5}{*}{ Western Australia } & Count & 4 & 16 & 32 & 52 \\
\hline & & Expected Count & 4.5 & 13.2 & 34.3 & 52.0 \\
\hline & & $\begin{array}{l}\% \text { within State } \\
\text { organisation is located in }\end{array}$ & $7.7 \%$ & $30.8 \%$ & $61.5 \%$ & $100.0 \%$ \\
\hline & & $\begin{array}{l}\text { \% within Operation - } \\
\text { Reform in usually } \\
\text { successful }\end{array}$ & $20.0 \%$ & $27.1 \%$ & $20.9 \%$ & $22.4 \%$ \\
\hline & & $\%$ of Total & $1.7 \%$ & $6.9 \%$ & $13.8 \%$ & $22.4 \%$ \\
\hline & \multirow[t]{5}{*}{ Tasmania } & Count & 4 & 11 & 9 & 24 \\
\hline & & Expected Count & 2.1 & 6.1 & 15.8 & 24.0 \\
\hline & & $\begin{array}{l}\% \text { within State } \\
\text { organisation is located in }\end{array}$ & $16.7 \%$ & $45.8 \%$ & $37.5 \%$ & $100.0 \%$ \\
\hline & & $\begin{array}{l}\text { \% within Operation - } \\
\text { Reform in usually } \\
\text { successful }\end{array}$ & $20.0 \%$ & $18.6 \%$ & $5.9 \%$ & $10.3 \%$ \\
\hline & & $\%$ of Total & $1.7 \%$ & $4.7 \%$ & $3.9 \%$ & $10.3 \%$ \\
\hline \multirow[t]{5}{*}{ Total } & & Count & 20 & 59 & 153 & 232 \\
\hline & & Expected Count & 20.0 & 59.0 & 153.0 & 232.0 \\
\hline & & $\begin{array}{l}\% \text { within State } \\
\text { organisation is located in }\end{array}$ & $8.6 \%$ & $25.4 \%$ & $65.9 \%$ & $100.0 \%$ \\
\hline & & $\begin{array}{l}\% \text { within Operation - } \\
\text { Reform in usually } \\
\text { successful }\end{array}$ & $100.0 \%$ & $100.0 \%$ & $100.0 \%$ & $100.0 \%$ \\
\hline & & $\%$ of Total & $8.6 \%$ & $25.4 \%$ & $65.9 \%$ & $100.0 \%$ \\
\hline
\end{tabular}

Table 32: Chi-Square test - state and reform operation success

\begin{tabular}{|l|r|r|r|}
\hline & Value & df & \multicolumn{1}{c|}{$\begin{array}{c}\text { Asymp. Sig. } \\
\text { (2-sided) }\end{array}$} \\
\hline Pearson Chi-Square & $19.030^{\mathrm{a}}$ & 10 & .040 \\
Likelihood Ratio & 19.672 & 10 & .033 \\
Linear-by-Linear & 7.064 & 1 & .008 \\
Association & 232 & & \\
N of Valid Cases & & & \\
\hline
\end{tabular}

a. 6 cells $(33.3 \%)$ have expected count less than 5 . The minimum expected count is 2.07 . 
Table 33: Cross tabulation of organisational structure and reform operation success

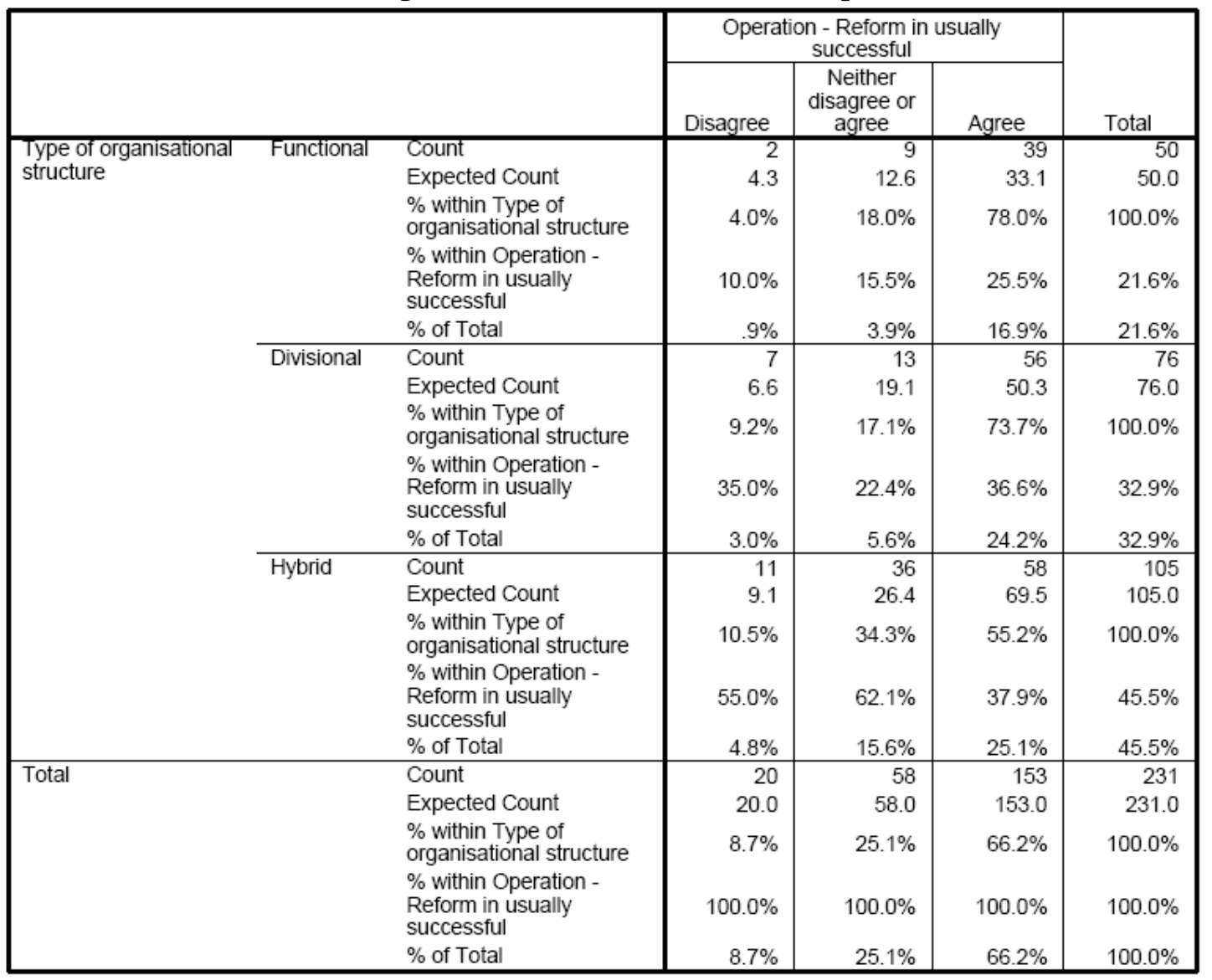

Table 34: Chi-Square test - organisational structure and reform operation success

\begin{tabular}{|l|r|r|r|}
\hline & Value & df & \multicolumn{1}{c|}{$\begin{array}{c}\text { Asymp. Sig. } \\
\text { (2-sided) }\end{array}$} \\
\hline Pearson Chi-Square & $11.747^{\mathrm{a}}$ & 4 & .019 \\
Likelihood Ratio & 12.067 & 4 & .017 \\
Linear-by-Linear & 7.891 & 1 & .005 \\
Association & 231 & & \\
N of Valid Cases & & \\
\hline
\end{tabular}

a. 1 cells $(11.1 \%)$ have expected count less than 5 . The minimum expected count is 4.33 . 
Table 35: Cross tabulation of organisational budget and organisational attributes

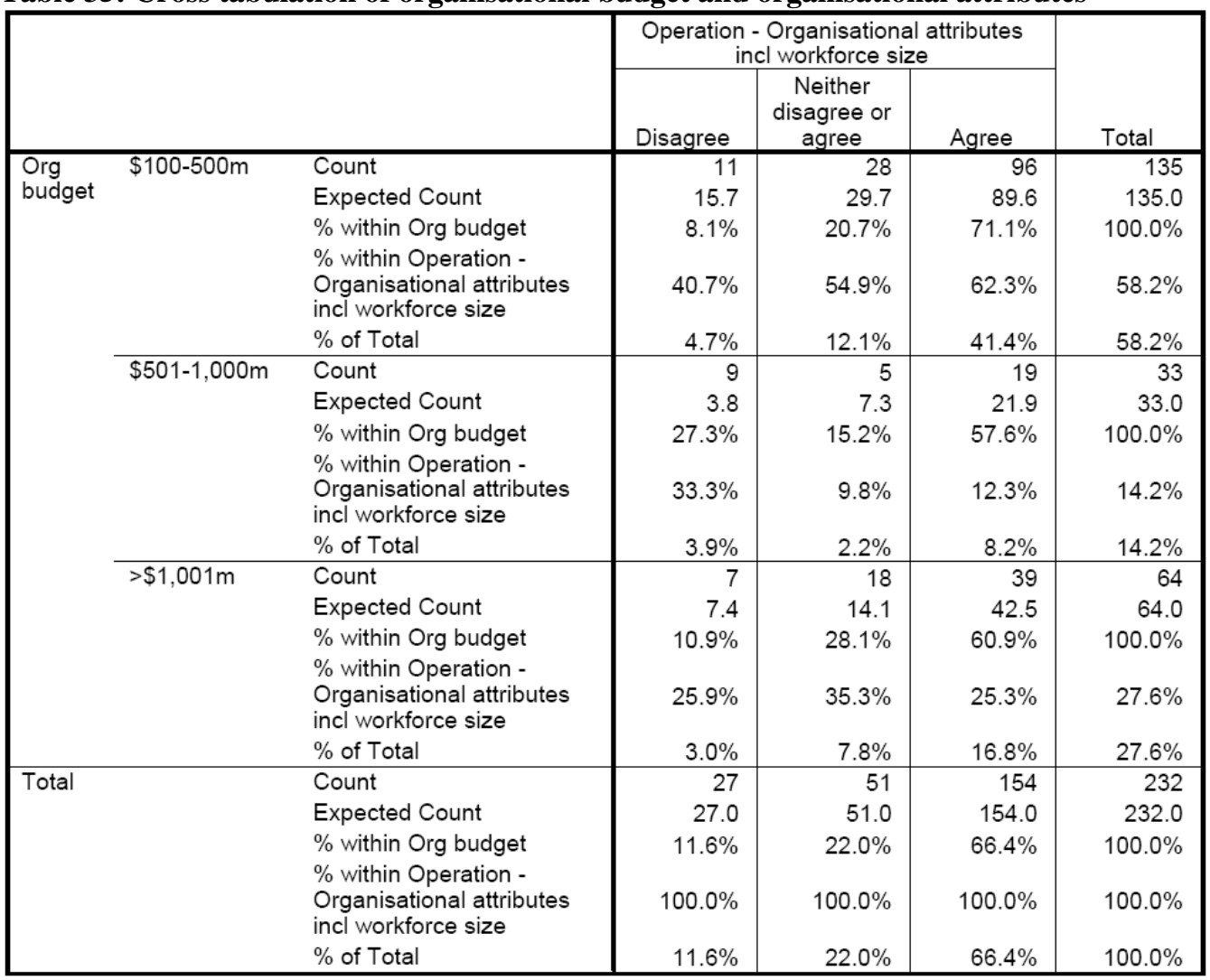

Table 36: Chi-Square test - organisational budget and organisational attributes

\begin{tabular}{|c|c|c|c|}
\hline & Value & df & $\begin{array}{l}\text { Asymp. Sig. } \\
\text { (2-sided) }\end{array}$ \\
\hline Pearson Chi-Square & $11.391^{\mathrm{a}}$ & 4 & .023 \\
\hline Likelihood Ratio & 9.652 & 4 & .047 \\
\hline $\begin{array}{l}\text { Linear-by-Linear } \\
\text { Association }\end{array}$ & 3.133 & 1 & .077 \\
\hline $\mathrm{N}$ of Valid Cases & 232 & & \\
\hline
\end{tabular}

a. 1 cells $(11.1 \%)$ have expected count less than 5 . The minimum expected count is 3.84 . 
Table 37: Cross tabulation of number of organisational sites and number of actors in change process

\begin{tabular}{|c|c|c|c|c|c|c|}
\hline & & & Operation & $\begin{array}{l}\text { Number of a } \\
\text { hange proces }\end{array}$ & $s$ in the & \\
\hline & & & Disagree & $\begin{array}{c}\text { Neither } \\
\text { disagree or } \\
\text { agree }\end{array}$ & Agree & Total \\
\hline Number of & $1-5$ & Count & 3 & 22 & 27 & 52 \\
\hline organisational & & Expected Count & 4.3 & 13.2 & 34.5 & 52.0 \\
\hline & & $\begin{array}{l}\% \text { within Number of } \\
\text { organisational sites }\end{array}$ & $5.8 \%$ & $42.3 \%$ & $51.9 \%$ & $100.0 \%$ \\
\hline & & $\begin{array}{l}\% \text { within Operation - } \\
\text { Number of actors in } \\
\text { the change process }\end{array}$ & $15.8 \%$ & $37.3 \%$ & $17.5 \%$ & $22.4 \%$ \\
\hline & & $\%$ of Total & $1.3 \%$ & $9.5 \%$ & $11.6 \%$ & $22.4 \%$ \\
\hline & $6-10$ & Count & 2 & 3 & 16 & 21 \\
\hline & & Expected Count & 1.7 & 5.3 & 13.9 & 21.0 \\
\hline & & $\begin{array}{l}\% \text { within Number of } \\
\text { organisational sites }\end{array}$ & $9.5 \%$ & $14.3 \%$ & $76.2 \%$ & $100.0 \%$ \\
\hline & & $\begin{array}{l}\% \text { within Operation - } \\
\text { Number of actors in } \\
\text { the change process }\end{array}$ & $10.5 \%$ & $5.1 \%$ & $10.4 \%$ & $9.1 \%$ \\
\hline & & $\%$ of Total & $.9 \%$ & $1.3 \%$ & $6.9 \%$ & $9.1 \%$ \\
\hline & $>10$ & Count & 14 & 34 & 111 & 159 \\
\hline & & Expected Count & 13.0 & 40.4 & 105.5 & 159.0 \\
\hline & & $\begin{array}{l}\% \text { within Number of } \\
\text { organisational sites }\end{array}$ & $8.8 \%$ & $21.4 \%$ & $69.8 \%$ & $100.0 \%$ \\
\hline & & $\begin{array}{l}\% \text { within Operation - } \\
\text { Number of actors in } \\
\text { the change process }\end{array}$ & $73.7 \%$ & $57.6 \%$ & $72.1 \%$ & $68.5 \%$ \\
\hline & & $\%$ of Total & $6.0 \%$ & $14.7 \%$ & $47.8 \%$ & $68.5 \%$ \\
\hline Total & & Count & 19 & 59 & 154 & 232 \\
\hline & & Expected Count & 19.0 & 59.0 & 154.0 & 232.0 \\
\hline & & $\begin{array}{l}\% \text { within Number of } \\
\text { organisational sites }\end{array}$ & $8.2 \%$ & $25.4 \%$ & $66.4 \%$ & $100.0 \%$ \\
\hline & & $\begin{array}{l}\% \text { within Operation - } \\
\text { Number of actors in } \\
\text { the change process }\end{array}$ & $100.0 \%$ & $100.0 \%$ & $100.0 \%$ & $100.0 \%$ \\
\hline & & $\%$ of Total & $8.2 \%$ & $25.4 \%$ & $66.4 \%$ & $100.0 \%$ \\
\hline
\end{tabular}

Table 38: Chi-Square test - number of organisational sites and number of actors in change process

\begin{tabular}{|c|c|c|c|}
\hline & Value & df & $\begin{array}{l}\text { Asymp. Sig. } \\
\text { (2-sided) }\end{array}$ \\
\hline Pearson Chi-Square & $10.589^{a}$ & 4 & .032 \\
\hline Likelihood Ratio & 10.017 & 4 & .040 \\
\hline $\begin{array}{l}\text { Linear-by-Linear } \\
\text { Association }\end{array}$ & 1.996 & 1 & .158 \\
\hline $\mathrm{N}$ of Valid Cases & 232 & & \\
\hline
\end{tabular}

a. 2 cells $(22.2 \%)$ have expected count less than 5 . The minimum expected count is 1.72 . 
Table 39: Cross tabulation of length of employment and organisational acceptance of innovation

\begin{tabular}{|c|c|c|c|c|c|c|}
\hline & & & \multicolumn{3}{|c|}{$\begin{array}{l}\text { Operation - Organisation accepts } \\
\text { innovation }\end{array}$} & \multirow[b]{2}{*}{ Total } \\
\hline & & & Disagree & $\begin{array}{l}\text { Neither } \\
\text { disagree or } \\
\text { agree }\end{array}$ & Agree & \\
\hline \multirow{15}{*}{$\begin{array}{l}\text { Length of } \\
\text { employment }\end{array}$} & \multirow[t]{5}{*}{$0-2$ years } & Count & 11 & 17 & 29 & 57 \\
\hline & & Expected Count & 6.1 & 12.3 & 38.6 & 57.0 \\
\hline & & $\begin{array}{l}\% \text { within Length of } \\
\text { employment }\end{array}$ & $19.3 \%$ & $29.8 \%$ & $50.9 \%$ & $100.0 \%$ \\
\hline & & $\begin{array}{l}\% \text { within Operation - } \\
\text { Organisation } \\
\text { accepts innovation }\end{array}$ & $44.0 \%$ & $34.0 \%$ & $18.5 \%$ & $24.6 \%$ \\
\hline & & $\%$ of Total & $4.7 \%$ & $7.3 \%$ & $12.5 \%$ & $24.6 \%$ \\
\hline & \multirow[t]{5}{*}{$3-10$ years } & Count & 10 & 14 & 72 & 96 \\
\hline & & Expected Count & 10.3 & 20.7 & 65.0 & 96.0 \\
\hline & & $\begin{array}{l}\% \text { within Length of } \\
\text { employment }\end{array}$ & $10.4 \%$ & $14.6 \%$ & $75.0 \%$ & $100.0 \%$ \\
\hline & & $\begin{array}{l}\% \text { within Operation - } \\
\text { Organisation } \\
\text { accepts innovation }\end{array}$ & $40.0 \%$ & $28.0 \%$ & $45.9 \%$ & $41.4 \%$ \\
\hline & & $\%$ of Total & $4.3 \%$ & $6.0 \%$ & $31.0 \%$ & $41.4 \%$ \\
\hline & \multirow[t]{5}{*}{$>10$ years } & Count & 4 & 19 & 56 & 79 \\
\hline & & Expected Count & 8.5 & 17.0 & 53.5 & 79.0 \\
\hline & & $\begin{array}{l}\% \text { within Length of } \\
\text { employment }\end{array}$ & $5.1 \%$ & $24.1 \%$ & $70.9 \%$ & $100.0 \%$ \\
\hline & & $\begin{array}{l}\% \text { within Operation - } \\
\text { Organisation } \\
\text { accepts innovation }\end{array}$ & $16.0 \%$ & $38.0 \%$ & $35.7 \%$ & $34.1 \%$ \\
\hline & & $\%$ of Total & $1.7 \%$ & $8.2 \%$ & $24.1 \%$ & $34.1 \%$ \\
\hline \multirow{5}{*}{\multicolumn{2}{|c|}{ Total }} & Count & 25 & 50 & 157 & 232 \\
\hline & & Expected Count & 25.0 & 50.0 & 157.0 & 232.0 \\
\hline & & $\begin{array}{l}\% \text { within Length of } \\
\text { employment }\end{array}$ & $10.8 \%$ & $21.6 \%$ & $67.7 \%$ & $100.0 \%$ \\
\hline & & $\begin{array}{l}\% \text { within Operation - } \\
\text { Organisation } \\
\text { accepts innovation }\end{array}$ & $100.0 \%$ & $100.0 \%$ & $100.0 \%$ & $100.0 \%$ \\
\hline & & $\%$ of Total & $10.8 \%$ & $21.6 \%$ & $67.7 \%$ & $100.0 \%$ \\
\hline
\end{tabular}

Table 40: Chi-Square test - length of employment and organisational acceptance of innovation

\begin{tabular}{|l|c|r|r|}
\hline & Value & df & \multicolumn{1}{|c|}{$\begin{array}{c}\text { Asymp. Sig. } \\
\text { (2-sided) }\end{array}$} \\
\hline Pearson Chi-Square & $13.706^{\mathrm{a}}$ & 4 & .008 \\
Likelihood Ratio & 13.833 & 4 & .008 \\
Linear-by-Linear & 5.348 & 1 & .021 \\
Association & 232 & & \\
N of Valid Cases & & & \\
\hline
\end{tabular}

a. 0 cells $(.0 \%)$ have expected count less than 5 . The minimum expected count is 6.14 . 
Table 41: Cross tabulation of employment length and organisational acceptance of change

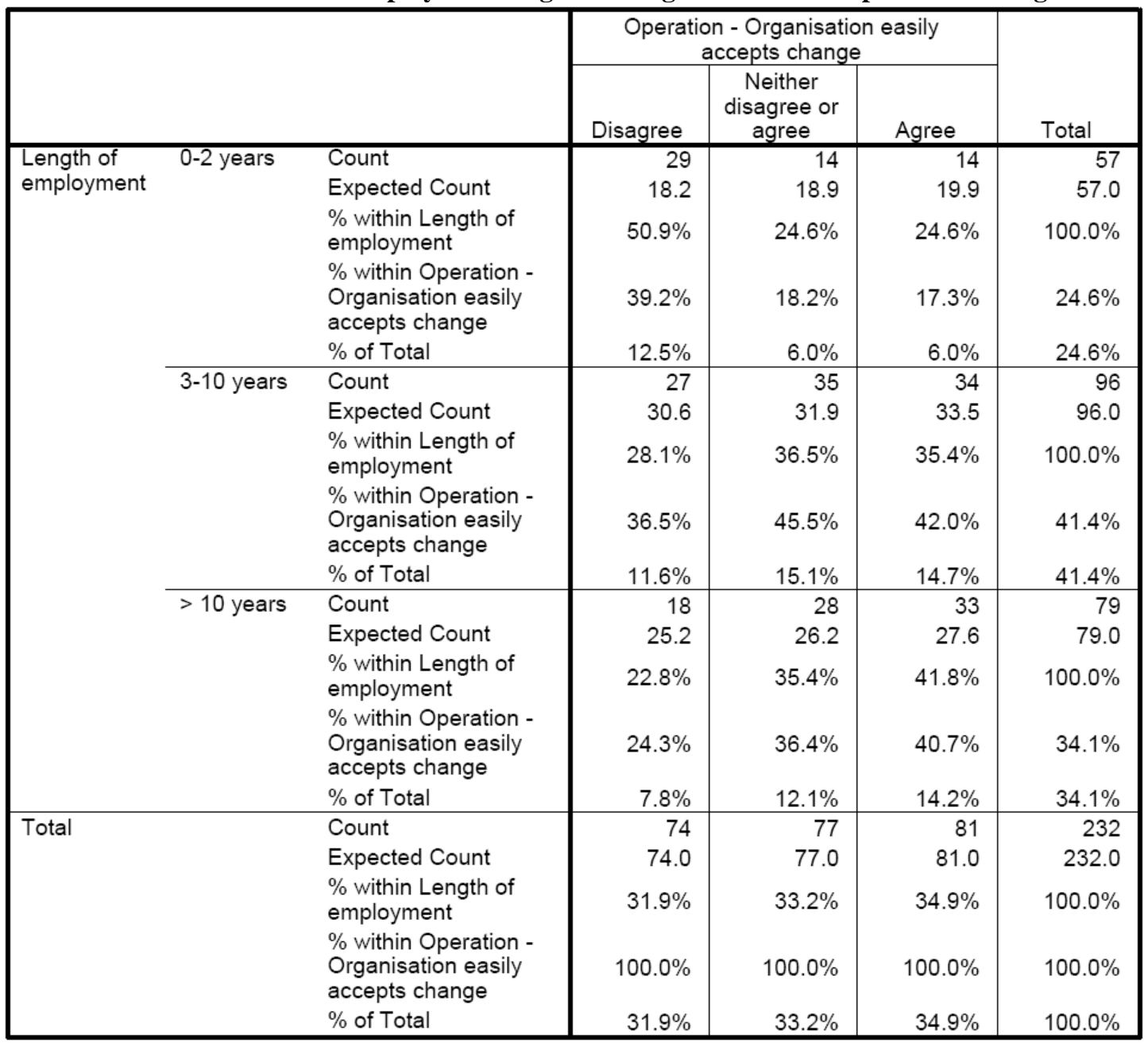

Table 42: Chi-Square test - employment length and organisational acceptance of change

\begin{tabular}{|l|r|r|r|}
\hline & Value & df & \multicolumn{1}{c|}{$\begin{array}{c}\text { Asymp. Sig. } \\
\text { (2-sided) }\end{array}$} \\
\hline Pearson Chi-Square & $13.452^{\mathrm{a}}$ & 4 & .009 \\
Likelihood Ratio & 12.961 & 4 & .011 \\
Linear-by-Linear & 7.983 & 1 & .005 \\
Association & 232 & & \\
N of Valid Cases & & & \\
\hline
\end{tabular}

a. 0 cells $(.0 \%)$ have expected count less than 5 . The minimum expected count is 18.18 . 
Table 43: Cross tabulation of organisation structure and impact of organisational attributes on reform operation

\begin{tabular}{|c|c|c|c|c|c|c|}
\hline & & & \multicolumn{3}{|c|}{$\begin{array}{l}\text { Operation - Organisational attributes } \\
\text { incl workforce size }\end{array}$} & \multirow[b]{2}{*}{ Total } \\
\hline & & & Disagree & $\begin{array}{c}\text { Neither } \\
\text { disagree or } \\
\text { agree }\end{array}$ & Agree & \\
\hline \multirow{14}{*}{$\begin{array}{l}\text { Type of organisational } \\
\text { structure }\end{array}$} & \multirow[t]{5}{*}{ Functional } & Count & 2 & 14 & 34 & 50 \\
\hline & & Expected Count & 5.8 & 10.8 & 33.3 & 50.0 \\
\hline & & $\begin{array}{l}\% \text { within Type of } \\
\text { organisational structure }\end{array}$ & $4.0 \%$ & $28.0 \%$ & $68.0 \%$ & $100.0 \%$ \\
\hline & & $\begin{array}{l}\% \text { within Operation - } \\
\text { Organisational attributes } \\
\text { incl workforce size }\end{array}$ & $7.4 \%$ & $28.0 \%$ & $22.1 \%$ & $21.6 \%$ \\
\hline & & $\%$ of Total & $.9 \%$ & $6.1 \%$ & $14.7 \%$ & $21.6 \%$ \\
\hline & \multirow[t]{4}{*}{ Divisional } & $\begin{array}{l}\text { Count } \\
\text { Expected Count }\end{array}$ & $\begin{array}{r}9 \\
8.9\end{array}$ & $\begin{array}{r}8 \\
16.5\end{array}$ & $\begin{array}{r}59 \\
50.7\end{array}$ & $\begin{array}{r}76 \\
76.0\end{array}$ \\
\hline & & $\begin{array}{l}\% \text { within Type of } \\
\text { organisational structure } \\
\% \text { within Oeration- }\end{array}$ & $11.8 \%$ & $10.5 \%$ & $77.6 \%$ & $100.0 \%$ \\
\hline & & $\begin{array}{l}\text { Organisational attributes } \\
\text { incl workforce size }\end{array}$ & $33.3 \%$ & $16.0 \%$ & $38.3 \%$ & $32.9 \%$ \\
\hline & & $\%$ of Total & $3.9 \%$ & $3.5 \%$ & $25.5 \%$ & $32.9 \%$ \\
\hline & \multirow[t]{5}{*}{ Hybrid } & Count & 16 & 28 & 61 & 105 \\
\hline & & Expected Count & 12.3 & 22.7 & 70.0 & 105.0 \\
\hline & & $\begin{array}{l}\% \text { within Type of } \\
\text { organisational structure }\end{array}$ & $15.2 \%$ & $26.7 \%$ & $58.1 \%$ & $100.0 \%$ \\
\hline & & $\begin{array}{l}\% \text { within Operation - } \\
\text { Organisational attributes } \\
\text { incl workforce size }\end{array}$ & $59.3 \%$ & $56.0 \%$ & $39.6 \%$ & $45.5 \%$ \\
\hline & & $\%$ of Total & $6.9 \%$ & $12.1 \%$ & $26.4 \%$ & $45.5 \%$ \\
\hline \multirow[t]{4}{*}{ Total } & & $\begin{array}{l}\text { Count } \\
\text { Expected Count }\end{array}$ & $\begin{array}{r}27 \\
27.0\end{array}$ & $\begin{array}{r}50 \\
50.0\end{array}$ & $\begin{array}{r}154 \\
154.0\end{array}$ & $\begin{array}{r}231 \\
231.0\end{array}$ \\
\hline & & $\begin{array}{l}\% \text { within Type of } \\
\text { organisational structure }\end{array}$ & $11.7 \%$ & $21.6 \%$ & $66.7 \%$ & $100.0 \%$ \\
\hline & & $\begin{array}{l}\% \text { within Operation - } \\
\text { Organisational attributes } \\
\text { incl workforce size }\end{array}$ & $100.0 \%$ & $100.0 \%$ & $100.0 \%$ & $100.0 \%$ \\
\hline & & $\%$ of Total & $11.7 \%$ & $21.6 \%$ & $66.7 \%$ & $100.0 \%$ \\
\hline
\end{tabular}

Table 44: Chi-Square Test - organisational structure and impact of organisational attributes on reform operation

\begin{tabular}{|l|r|r|r|}
\hline & Value & df & \multicolumn{1}{c|}{$\begin{array}{c}\text { Asymp. Sig. } \\
\text { (2-sided) }\end{array}$} \\
\hline Pearson Chi-square & $12.700^{\mathrm{a}}$ & 4 & .013 \\
Likelihood Ratio & 14.315 & 4 & .006 \\
Linear-by-Linear & 4.332 & 1 & .037 \\
Association & 231 & & \\
N of Valid Cases & & & \\
\hline
\end{tabular}

a. 0 cells $(.0 \%)$ have expected count less than 5 . The minimum expected count is 5.84 . 
Table 45: Cross tabulation of State and organisational acceptance of change

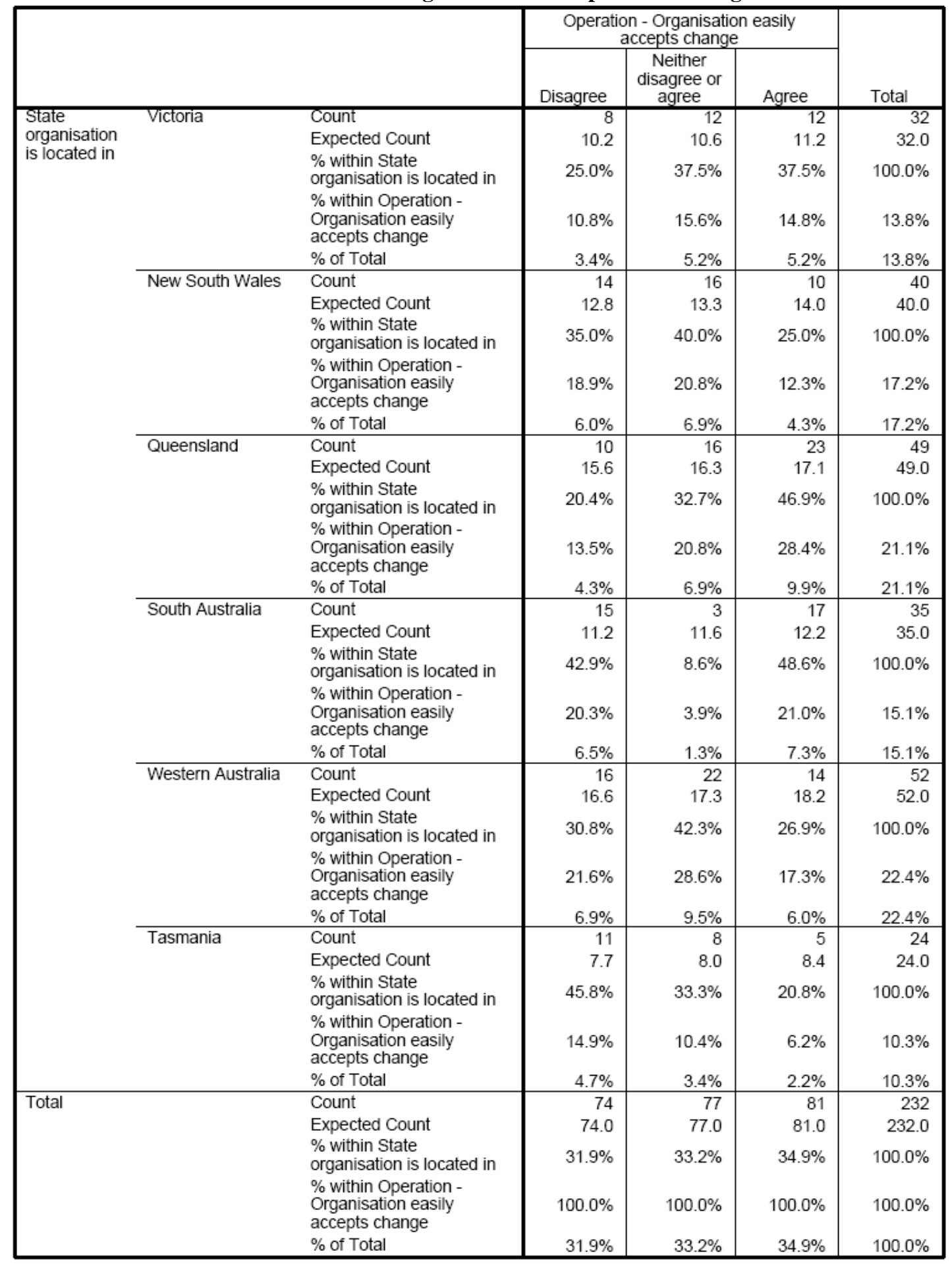

Table 46: Chi-Square test - State and organisational acceptance of change

\begin{tabular}{|l|r|r|r|}
\hline & \multicolumn{1}{|c|}{ Value } & \multicolumn{1}{c|}{ df } & \multicolumn{1}{c|}{$\begin{array}{c}\text { Asymp. Sig. } \\
\text { (2-sided) }\end{array}$} \\
\hline Pearson Chi-Square & $21.263^{\mathrm{a}}$ & 10 & .019 \\
Likelihood Ratio & 23.897 & 10 & .008 \\
Linear-by-Linear & 1.915 & 1 & .166 \\
Association & 232 & & \\
N of Valid Cases & & 16 & \\
\hline
\end{tabular}

a. 0 cells $(.0 \%)$ have expected count less than 5 . The minimum expected count is 7.66 . 
Table 47: Cross tabulation of employment length and governance reform training

\begin{tabular}{|c|c|c|c|c|c|}
\hline & & & $\begin{array}{l}\text { Have you } \\
\text { training rela }\end{array}$ & $\begin{array}{l}\text { ved any } \\
\text { o reform }\end{array}$ & \\
\hline & & & Yes & No & Total \\
\hline Length of & $0-2$ years & Count & 19 & 27 & 46 \\
\hline employment & & Expected Count & 26.1 & 19.9 & 46.0 \\
\hline & & $\begin{array}{l}\% \text { within Length of } \\
\text { employment }\end{array}$ & $41.3 \%$ & $58.7 \%$ & $100.0 \%$ \\
\hline & & $\begin{array}{l}\% \text { within Have you } \\
\text { received any training } \\
\text { related to reform }\end{array}$ & $17.1 \%$ & $31.8 \%$ & $23.5 \%$ \\
\hline & & $\%$ of Total & $9.7 \%$ & $13.8 \%$ & $23.5 \%$ \\
\hline & $3-10$ years & Count & 55 & 30 & 85 \\
\hline & & Expected Count & 48.1 & 36.9 & 85.0 \\
\hline & & $\begin{array}{l}\% \text { within Length of } \\
\text { employment }\end{array}$ & $64.7 \%$ & $35.3 \%$ & $100.0 \%$ \\
\hline & & $\begin{array}{l}\% \text { within Have you } \\
\text { received any training } \\
\text { related to reform }\end{array}$ & $49.5 \%$ & $35.3 \%$ & $43.4 \%$ \\
\hline & & $\%$ of Total & $28.1 \%$ & $15.3 \%$ & $43.4 \%$ \\
\hline & $>10$ years & Count & 37 & 28 & 65 \\
\hline & & Expected Count & 36.8 & 28.2 & 65.0 \\
\hline & & $\begin{array}{l}\% \text { within Length of } \\
\text { employment }\end{array}$ & $56.9 \%$ & $43.1 \%$ & $100.0 \%$ \\
\hline & & $\begin{array}{l}\% \text { within Have you } \\
\text { received any training } \\
\text { related to reform }\end{array}$ & $33.3 \%$ & $32.9 \%$ & $33.2 \%$ \\
\hline & & $\%$ of Total & $18.9 \%$ & $14.3 \%$ & $33.2 \%$ \\
\hline Total & & Count & 111 & 85 & 196 \\
\hline & & Expected Count & 111.0 & 85.0 & 196.0 \\
\hline & & $\begin{array}{l}\% \text { within Length of } \\
\text { employment }\end{array}$ & $56.6 \%$ & $43.4 \%$ & $100.0 \%$ \\
\hline & & $\begin{array}{l}\% \text { within Have you } \\
\text { received any training } \\
\text { related to reform }\end{array}$ & $100.0 \%$ & $100.0 \%$ & $100.0 \%$ \\
\hline & & $\%$ of Total & $56.6 \%$ & $43.4 \%$ & $100.0 \%$ \\
\hline
\end{tabular}

Table 48: Chi-Square test - employment length and governance reform training

\begin{tabular}{|l|c|r|r|}
\hline & Value & df & $\begin{array}{c}\text { Asymp. Sig. } \\
\text { (2-sided) }\end{array}$ \\
\hline Pearson Chi-Square & $6.659^{\mathrm{a}}$ & 2 & .036 \\
Likelihood Ratio & 6.652 & 2 & .036 \\
Linear-by-Linear & .828 & 1 & .363 \\
Association & 196 & & \\
N of Valid Cases & & & \\
\hline
\end{tabular}

a. 0 cells $(.0 \%)$ have expected count less than 5 . The minimum expected count is 19.95 . 
Table 49: Cross tabulation of organisational structure and governance reform training

\begin{tabular}{|c|c|c|c|c|c|}
\hline & & & $\begin{array}{l}\text { Have you I } \\
\text { training rela }\end{array}$ & $\begin{array}{l}\text { ved any } \\
\text { to reform }\end{array}$ & \\
\hline & & & Yes & No & Total \\
\hline Type of organisational & Functional & Count & 15 & 26 & 41 \\
\hline structure & & Expected Count & 23.2 & 17.8 & 41.0 \\
\hline & & $\begin{array}{l}\text { \% within Type of } \\
\text { organisational structure }\end{array}$ & $36.6 \%$ & $63.4 \%$ & $100.0 \%$ \\
\hline & & $\begin{array}{l}\% \text { within Have you } \\
\text { received any training } \\
\text { related to reform }\end{array}$ & $13.5 \%$ & $30.6 \%$ & $20.9 \%$ \\
\hline & & $\%$ of Total & $7.7 \%$ & $13.3 \%$ & $20.9 \%$ \\
\hline & Divisional & Count & 43 & 20 & 63 \\
\hline & & Expected Count & 35.7 & 27.3 & 63.0 \\
\hline & & $\begin{array}{l}\% \text { within Type of } \\
\text { organisational structure }\end{array}$ & $68.3 \%$ & $31.7 \%$ & $100.0 \%$ \\
\hline & & $\begin{array}{l}\text { \% within Have you } \\
\text { received any training } \\
\text { related to reform }\end{array}$ & $38.7 \%$ & $23.5 \%$ & $32.1 \%$ \\
\hline & & $\%$ of Total & $21.9 \%$ & $10.2 \%$ & $32.1 \%$ \\
\hline & Hybrid & Count & 53 & 39 & 92 \\
\hline & & Expected Count & 52.1 & 39.9 & 92.0 \\
\hline & & $\begin{array}{l}\% \text { within Type of } \\
\text { organisational structure }\end{array}$ & $57.6 \%$ & $42.4 \%$ & $100.0 \%$ \\
\hline & & $\begin{array}{l}\% \text { within Have you } \\
\text { received any training } \\
\text { related to reform }\end{array}$ & $47.7 \%$ & $45.9 \%$ & $46.9 \%$ \\
\hline & & $\%$ of Total & $27.0 \%$ & $19.9 \%$ & $46.9 \%$ \\
\hline Total & & Count & 111 & 85 & 196 \\
\hline & & Expected Count & 111.0 & 85.0 & 196.0 \\
\hline & & $\begin{array}{l}\text { \% within Type of } \\
\text { organisational structure }\end{array}$ & $56.6 \%$ & $43.4 \%$ & $100.0 \%$ \\
\hline & & $\begin{array}{l}\% \text { within Have you } \\
\text { received any training } \\
\text { related to reform }\end{array}$ & $100.0 \%$ & $100.0 \%$ & $100.0 \%$ \\
\hline & & $\%$ of Total & $56.6 \%$ & $43.4 \%$ & $100.0 \%$ \\
\hline
\end{tabular}

Table 50: Chi-Square test - organisational structure and governance reform training

\begin{tabular}{|l|c|r|r|}
\hline & Value & df & \multicolumn{1}{c|}{$\begin{array}{c}\text { Asymp. Sig. } \\
\text { (2-sided) }\end{array}$} \\
\hline Pearson Chi-Square & $10.209^{\mathrm{a}}$ & 2 & .006 \\
Likelihood Ratio & 10.261 & 2 & .006 \\
Linear-by-Linear & 2.812 & 1 & .094 \\
Association & 196 & & \\
N of Valid Cases & & & \\
\hline
\end{tabular}

a. 0 cells $(.0 \%)$ have expected count less than 5 . The minimum expected count is 17.78 . 
Table 51: Cross tabulation of state and length of employment

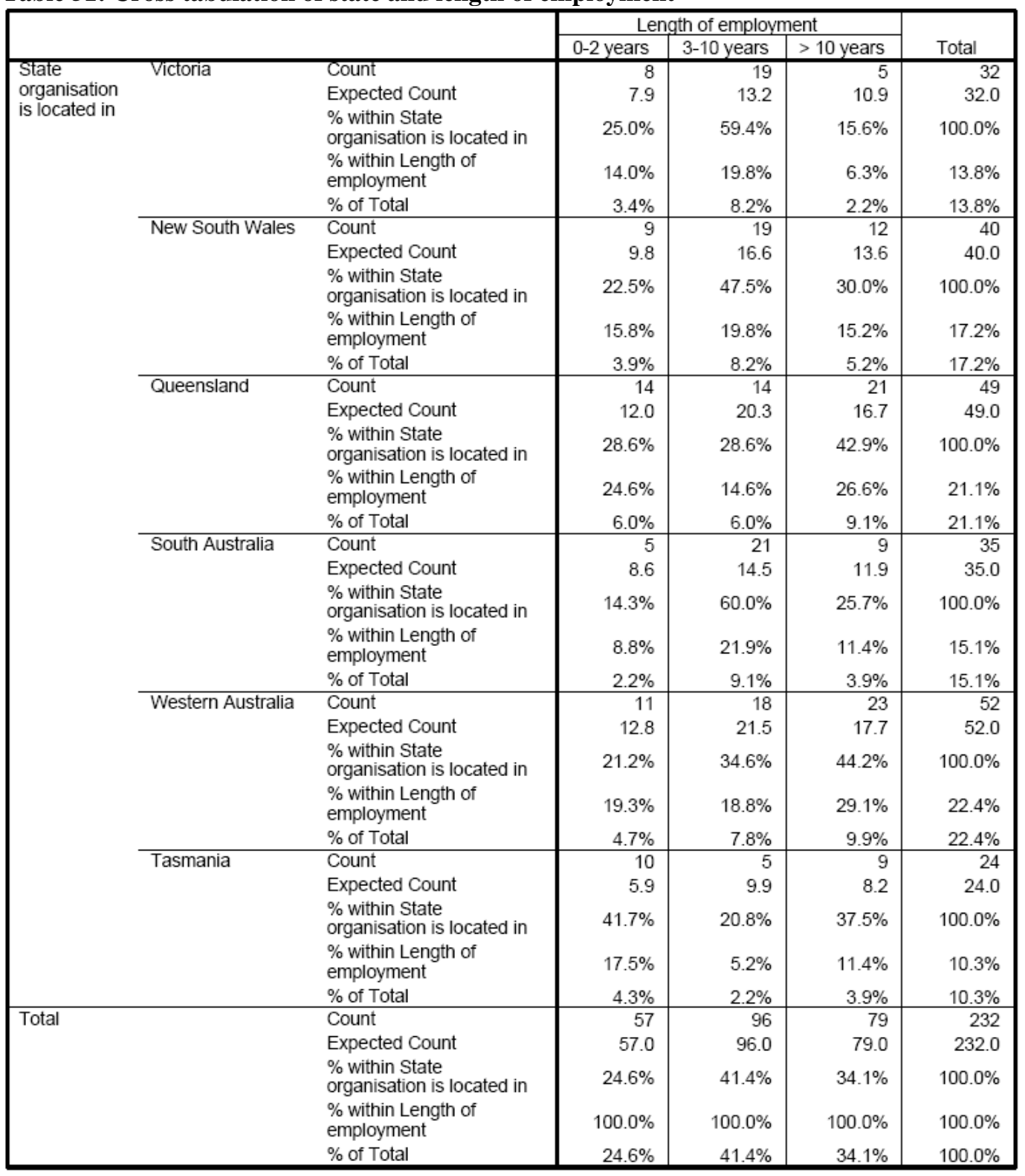

Table 52: Chi-Square test - state and length of employment

\begin{tabular}{|l|r|r|r|}
\hline & Value & df & \multicolumn{1}{|c|}{$\begin{array}{c}\text { Asymp. Sig. } \\
\text { (2-sided) }\end{array}$} \\
\hline Pearson Chi-Square & $22.646^{\mathrm{a}}$ & 10 & .012 \\
Likelihood Ratio & 23.223 & 10 & .010 \\
Linear-by-Linear & 2.085 & 1 & .149 \\
Association & 232 & & \\
N of Valid Cases & & & \\
\hline
\end{tabular}

a. 0 cells $(.0 \%)$ have expected count less than 5 . The minimum expected count is 5.90 . 
Table 53: Cross tabulation of State and organisational budget

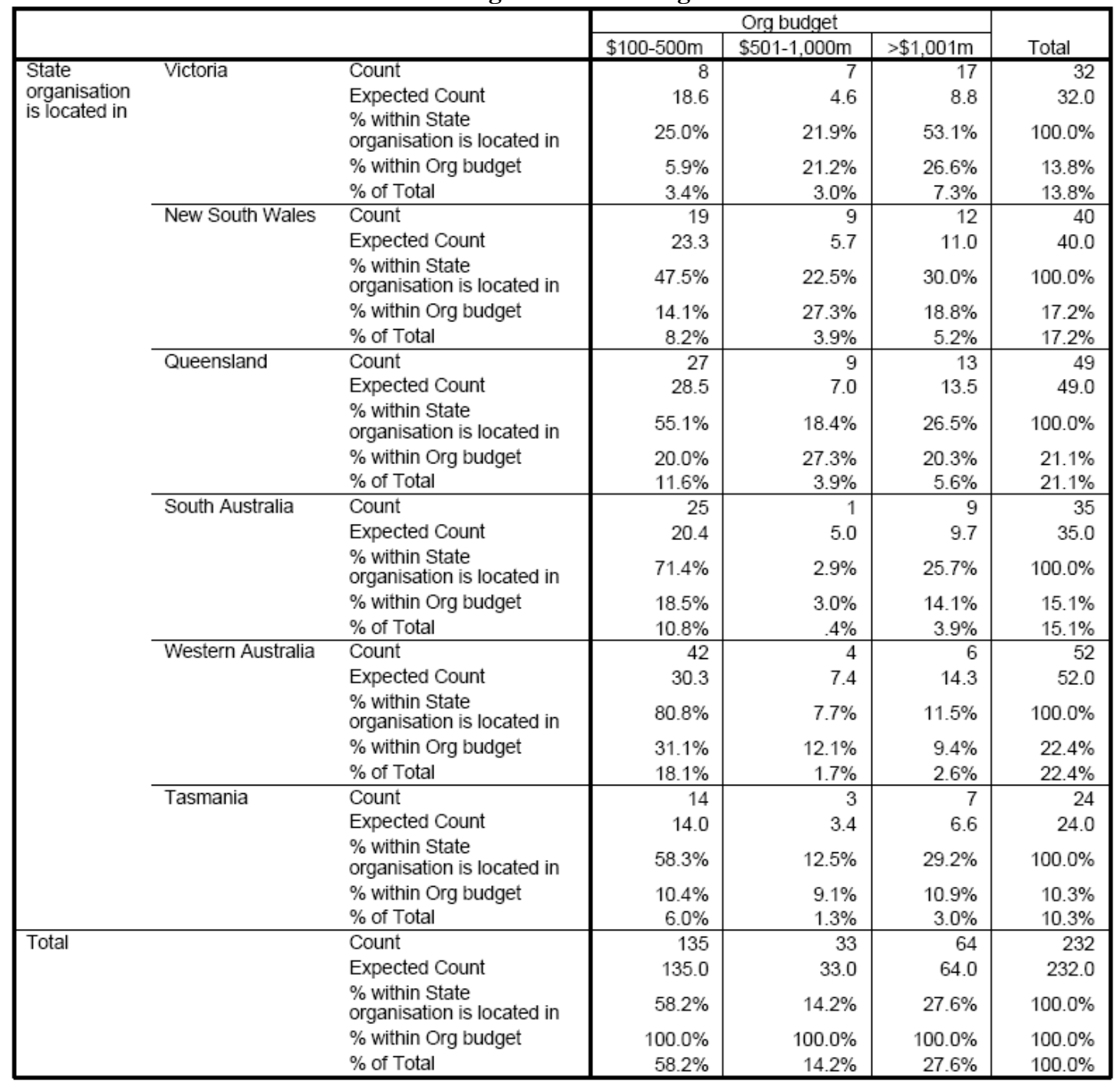

Table 54: Chi-Square test - State and organisational budget

\begin{tabular}{|l|r|r|r|}
\hline & Value & df & \multicolumn{1}{|c|}{$\begin{array}{c}\text { Asymp. Sig. } \\
\text { (2-sided) }\end{array}$} \\
\hline Pearson Chi-Square & $33.748^{a}$ & 10 & .000 \\
Likelihood Ratio & 36.000 & 10 & .000 \\
Linear-by-Linear & 18.878 & 1 & .000 \\
Association & 232 & & \\
N of Valid Cases & & & \\
\hline
\end{tabular}

a. 3 cells $(16.7 \%)$ have expected count less than 5 . The minimum expected count is 3.41 . 
Table 55: Cross tabulation of employment length and number of reforms undertaken

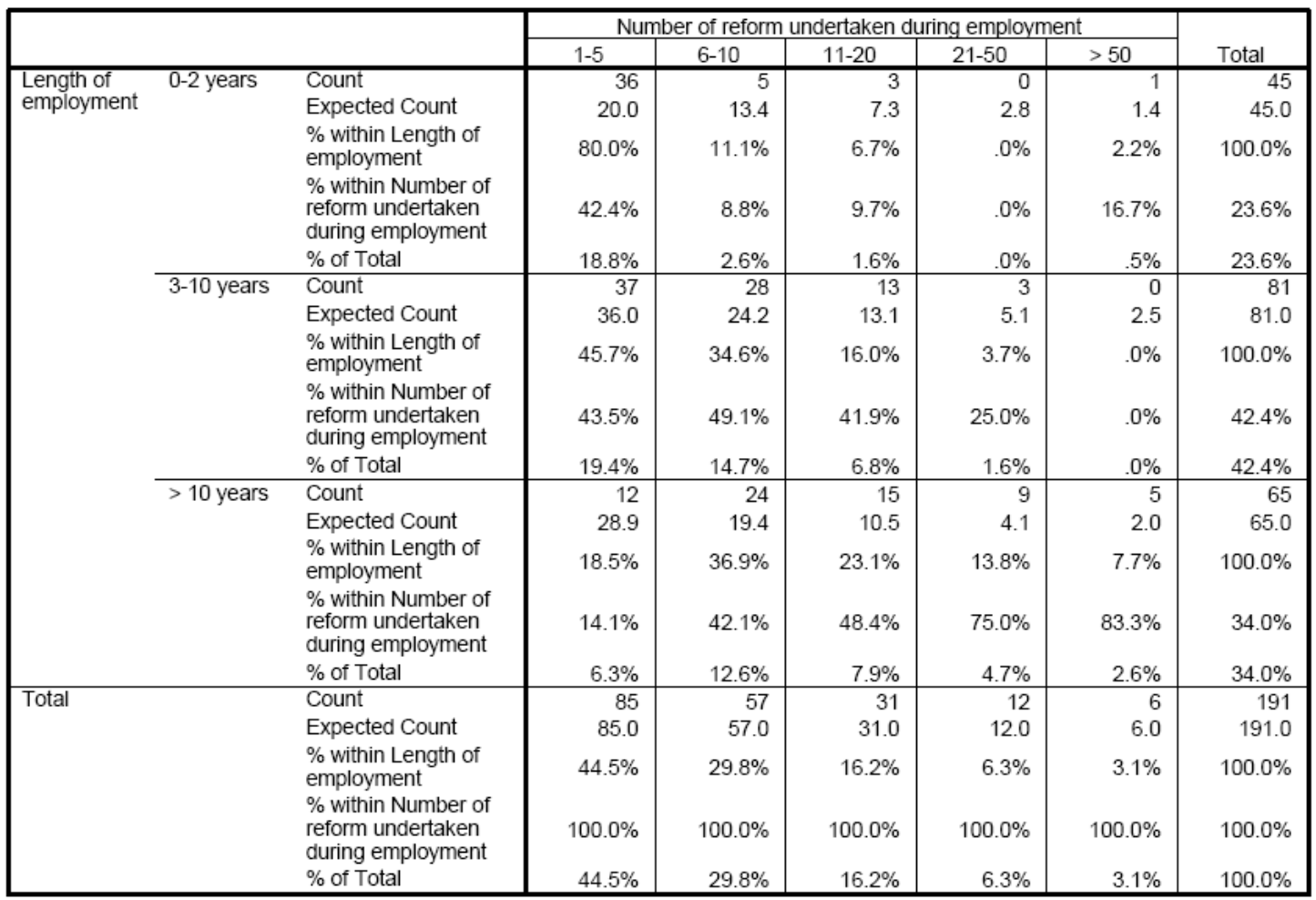

Table 56: Chi-Square test - employment length and reforms undertaken

\begin{tabular}{|l|c|r|r|}
\hline & Value & df & $\begin{array}{c}\text { Asymp. Sig. } \\
\text { (2-sided) }\end{array}$ \\
\hline Pearson Chi-Square & $50.629^{\mathrm{a}}$ & 8 & .000 \\
Likelihood Ratio & 55.855 & 8 & .000 \\
Linear-by-Linear & 37.717 & 1 & .000 \\
Association & 191 & & \\
N of Valid Cases & & & \\
\hline
\end{tabular}

a. 5 cells $(33.3 \%)$ have expected count less than 5 . The minimum expected count is 1.41 . 